\title{
Effects of dimethyl fumarate in two animal models of MS
}

\author{
Doctoral Thesis \\ In partial fulfillment of the requirements for the degree \\ "Doctor rerum naturalium (Dr. rer. nat.)" \\ in the Molecular Medicine Study Program \\ at the Georg-August University Göttingen
}

submitted by

Sarah Traffehn

born in Hennigsdorf

Göttingen, March 2017 
Members of the Thesis Committee:

First member of the thesis committee

Prof. Dr. Wolfgang Brück

Department of Neuropathology

University Medical Center, Georg-August-University Göttingen

Second member of the thesis committee

Prof. Dr. Eberhard Fuchs

German Primate Center

Leibniz Institute for Primate Research, Göttingen

Third member of the thesis committee

Prof. Dr. Fred Wouters-Bunt

Department of Neuropathology

University Medical Center, Georg-August-University Göttingen

\section{Supervisor}

PD. Dr. Imke Metz

Department of Neuropathology

University Medical Center, Georg-August-University Göttingen

\section{Supervisor}

Prof. Dr. Martin S. Weber

Department of Neuropathology and Department of Neurology University Medical Center, Georg-August-University Göttingen

Date of Disputation: 


\section{AFFIDAVIT}

Here I declare that my doctoral thesis entitled "Effects of dimethyl fumarate in two animal models of MS" has been written independently with no other sources and aids than quoted.

Göttingen, March 2017 
Für meine Eltern. 


\section{List of Publication}

\section{Original article}

Licht-Mayer S., Wimmer I., Traffehn S., Metz I., Brück W., Bauer J., Bradl M., Lassmann H. (2015) Cell type-specific Nrf2 expression in multiple sclerosis lesion. Acta Neuropathol. 130(2) 263-77

Metz I, Traffehn S, Straßburger-Krogias K., Keyvani K., Bergmann M., Nolte K, Weber MS., Bartsch T., Gold R., Brück W. (2015) Glial cells express nuclear nrf2 after fumarate treatment for multiple sclerosis and psoriasis. Neurol Neuroimmunol Neuroinflamm. 2(3)

Lehmann-Horn K., Kinzel S., Feldmann L., Radelfahr F., Hemmer B., Traffehn S., Bernard CC., Stadelmann C., Brück W., Weber MS. (2014) Intrathecal anti-CD20 efficiently depletes meningeal B cells in CNS autoimmunity.AnnClin Tranl Neurol. 1(7) 490-96

Schmoeckel K., Traffehn S., Eger C., Pötschke C., Bröker BM. (2015) Full activation of CD4 ${ }^{+} T$ cells early during sepsis requires specific antigen. Shock 43(2) 192-200

\section{Abstract}

Traffehn, S., Metz, I., Bernard CC., Brück, W., Weber MS.

In vivo dimethyl fumarate treatment enhances the ability of $B$ cells to present antigen

$13^{\text {th }}$ Congress of the International Society of Neuroimmunology, September $26^{\text {th }}-29^{\text {th }} 2016$, Jerusalem, Israel, Poster session

Traffehn, S., Metz, I., Brück, W., Weber MS.

Dimethyl fumarate treatment in a $B$ cell dependent EAE model

$12^{\text {th }}$ European Committee for Treatment and Research In Multiple Sclerosis, October $7^{\text {th }}-10^{\text {th }} 2015$, Barcelona, Spain, Poster session

Traffehn, S., Metz, I., Brück, W., Bernard CC. Weber MS.

DMF modulates pathogenic B cell function in chronic CNS autoimmune disease

$13^{\text {th }}$ Congress of the International Society of Neuroimmunology, September $26^{\text {th }}-29^{\text {th }} 2014$, Mainz, Germany, Oral presentation 


\section{Table of contents}





1.1.1. Symptoms, clinical course and diagnosis .................................................. 1











1.2.2. Experimental autoimmune encephalomyelitis............................................. 10







1.3.3. DMF effects on CNS resident cells in vitro ................................................. 14

1.3.4. DMF effects on immune cells in vitro and in vivo ........................................ 15





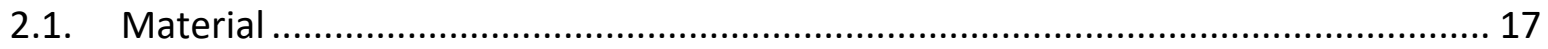

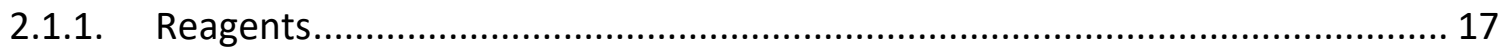

2.1.2. Solutions, buffers and cell culture media .................................................. 19












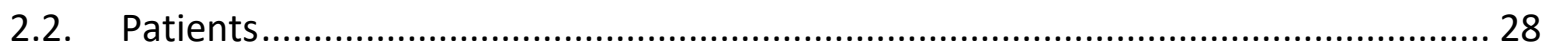

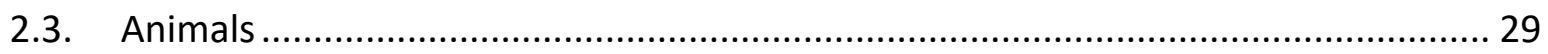



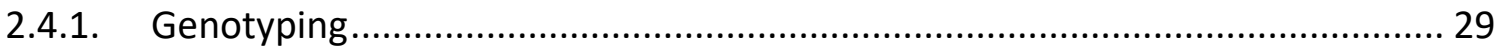

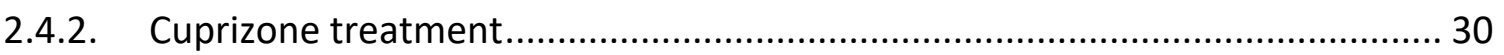





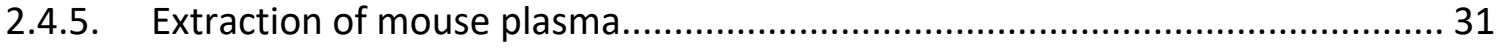

2.4.6. Analysis of monomethyl fumarate (MMF) in plasma and brain ....................... 32









2.4.11. In vitro stimulation of cytokine secretion .............................................. 37









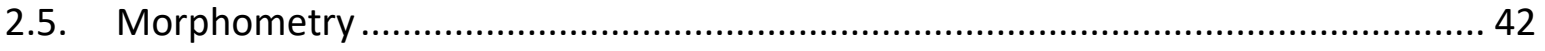

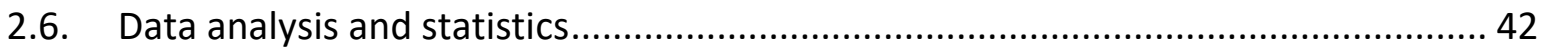

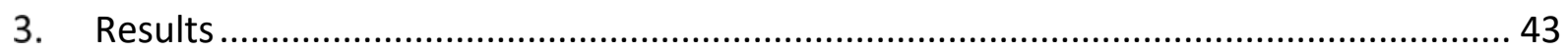

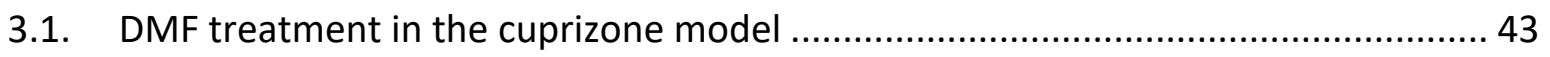

3.1.1. DMF effects after short-term cuprizone intoxication .................................... 43 
3.1.2. Long-term effects of DMF in the cuprizone mouse model............................ 49

3.1.3. DMF effects after cuprizone withdrawal .................................................. 53

3.1.4. MMF was detectable in the brain of DMF-treated mice ................................ 55

3.1.5. DMF did not reduce apoptosis of oligodendrocytes in Nrf2 k.o. mice............. 56

3.2. DMF effects in a B cell-mediated EAE model ........................................................ 58

3.2.1. DMF treatment decreased EAE severity and demyelination of the spinal cord 59

3.2.2. DMF had opposing effects on B cells and T cells during the early phase of EAE63

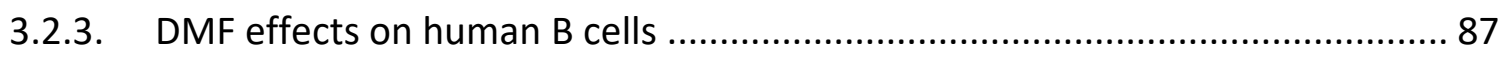



4.1. DMF shows neuroprotective and potentially regenerative effects in the cuprizone

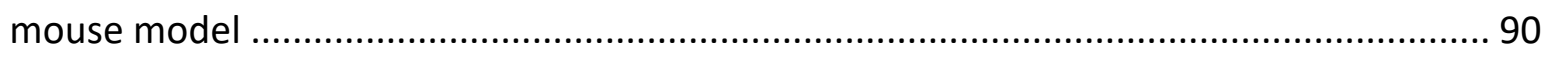

4.1.1. DMF exerts neuroprotective effects during short-term cuprizone treatment . 91

4.1.2. DMF treatment increases differentiation and regeneration of oligodendrocytes

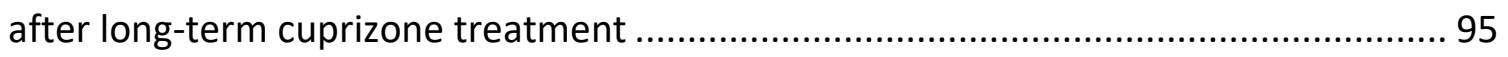

4.1.3. Therapeutic DMF treatment shows neuroprotective effects on axons ........... 96

4.2. DMF treatment shows opposing effects on lymphocytes in B cell-mediated EAE ... 98

4.2.1. DMF treatment improves clinic and pathology of EAE mice ......................... 99

4.2.2. DMF treatment has immunomodulatory effects on peripheral $B$ cells and T cells 101

4.2.3. DMF-treated B cells are more potent antigen-presenting cells 105

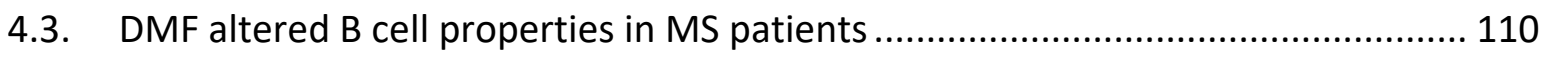

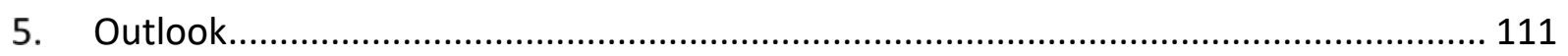

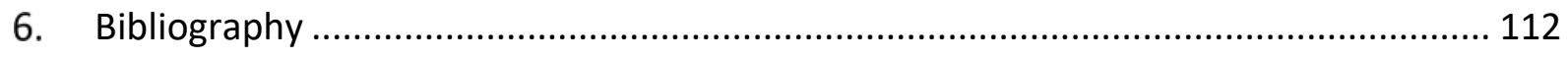




\section{Danksagung}

Ein besonderer Dank gilt PD Dr. Imke Metz, welcher ich als allererstes dafür danke dass sie mich mit diesem Projekt betraut hat. Die Arbeit mit dir hat mich sowohl in professioneller als auch in persönlicher Hinsicht sehr vorangebracht.

Ein großer Dank geht auch an Prof. Dr. Martin S. Weber, dem ich auch dafür danke dass er mich mit diesem Projekt betraut hat. Ich fand unsere Unterhaltungen stets sehr angenehm und aufschlussreich. Ich hatte eine sehr schöne Zeit in deiner Arbeitsgruppe.

Ich bedanke mich sehr bei Prof. Dr. Wolfgang Brück für die Gelegenheit meine Doktorarbeit in dem Institut für Neuropathologie anzufertigen sowie für die Betreuung meines Projektes als Thesis committee Mitglied.

Des Weiteren bedanke ich mich auch bei Prof. Dr. Eberhard Fuchs und Prof. Dr. Fred Wouters-Bunt für Ihr Interesse, Ihr kritisches Hinterfragen und Ihre Unterstützung während der jährlichen Thesis committee Treffen.

Ich bedanke mich auch sehr bei Cynthia und Heidi für ihre Hilfe sowie den Mitarbeitern des Promotionsprogrammes Molekulare Medizin, vor allem Dr. Erik Meskauskas.

Ich möchte mich auch sehr bei Mareike Gloth bedanken, die sämtliche Schnitte und histologischen Färbungen übernommen hat. Ich hatte sehr viel Spaß mit dir bei der Arbeit und auch bei unseren Treffen außerhalb des Klinikums.

Ein riesiger Dank geht an Caroline Jaß, Jan Einar Albin, Julian Koch und Katja Grondey, die mir bei allen Experimenten tatkräftig zu Seite standen. Ihr habt dafür gesorgt, dass jedes große Experiment nicht in den größten Stress ausgeartet ist, wir stets sehr viel Spaß und Grund zum Lachen hatten.

Ein großer Dank geht an Darius, an den ich mich mit jeder Frage oder Problemstellung wenden konnte. Vielen Dank für die viele Hilfe und auch für die angenehme und oft lustige Stimmung im Labor.

Ich bedanke mich sehr bei meinen Kolleginnen Verena, Insa, Ulla, Christin und Nasrin die von Anfang an dafür sorgten, dass ich mich herzlich aufgenommen gefühlt habe. Vielen Dank für die schöne und lustige Zeit die wir miteinander verbracht haben. 
Außerdem möchte ich mich wirklich sehr bei Kim und Linda bedanken.

Kim, deine stets positive und liebevolle Art haben immer dafür gesorgt, dass ich mich in deiner Gegenwart sehr wohl fühle und ich bin sehr froh dass du ein Teil unserer lustigen Büroclique geworden bist. Ich bin dir sehr dankbar für deine Freundschaft und deine Unterstützung während der letzten 1,5 Jahre.

Linda, du hast es immer geschafft mir auch an stressigen und tristen Tagen ein Lächeln zu entlocken und hast mich aufgebaut wenn mich mein Projekt mal wieder absolut in den Wahnsinn getrieben hat. Du bist meine Nummer 1 !

Ich möchte mich auch sehr bei meiner Mitbewohnerin Lisa bedanken, die dafür sorgte dass ich mich in Göttingen sofort wohl gefühlt habe. Ich finde es toll mir dir zusammen zu wohnen und habe unsere gemeinsamen Abende immer genossen.

Ich bedanke mich bei meinen Freunden Carmen, Tom, Jule, Steffi und Tony für eure Besuche in Göttingen und die tolle Zeit die wir immer wieder miteinander verbracht haben.

Der allergrößte Dank geht an meine Familie.

Ich bedanke mich bei meinen Großeltern, die immer für mich da sind, mir Trost spenden, sich mit mir freuen und immer an mich glauben. Ich bin sehr stolz darauf eure Enkelin zu sein.

Der mit Abstand größte Dank geht an meine Eltern. Ohne euch hätte ich es nicht geschafft die gesamte Zeit hier in Göttingen durchzuhalten. Ich bin sehr glücklich eure Tochter zu sein und liebe euch aus tiefstem Herzen!

Am Schluss möchte ich mich bei Sebastian bedanken, der es jeden Tag aufs Neue schafft dass ich mich glücklich fühle. 


\begin{abstract}
MS is a heterogeneous disease characterized by transient and later permanent disability caused by inflammatory CNS lesions with profound axonal loss and demyelination. Although the exact pathogenesis of the disease is still unknown, it is assumed that MS is an autoimmune disease. While earlier concepts focused on the role of T cells, B cells are increasingly recognized to play an important role. The fumaric acid ester DMF is an immunomodulatory agent which is approved for the therapy of relapsing-remitting MS. In MS patients, DMF effectively reduces the relapse rate as well as the number and extent of MRI lesions. DMF shows anti-inflammatory properties by modulating immune cell functions leading to a decrease in pro-inflammatory cytokine production. Furthermore, DMF may exert neuroprotective effects in part mediated by the induction of Nrf2 resulting in the activation of antioxidant response pathways. In our study, we investigated whether DMF has neuroprotective and/or neuroregenerative function independent of its effect on the peripheral immune system. For this purpose, DMF effects were studied in a setting of toxic demyelination, namely the cuprizone model. In the second part of our study, it was also analyzed to what extent DMF influences pathogenic $B$ cell and T cell properties in in an EAE model, in which B cells are involved in a pathogenic manner.

Regarding the first part of the project, we found that DMF significantly diminished the cuprizone-induced apoptosis of oligodendrocytes and increased the number of oligodendrocytes over time during cuprizone intoxication. Upon short-term cuprizone exposure, DMF increased the number of oligodendrocyte progenitor cells (OPCs) whereas after long-term cuprizone diet higher numbers of mature oligodendrocytes could be observed. Although DMF treatment did not influence demyelination and remyelination of the corpus callosum, acute axonal damage was significantly decreased in DMF treated mice. In conclusion, DMF was found to exert moderate neuroprotective and neuroregenerative effects independent of the peripheral immune system. The observation of higher OPC numbers in conjunction with a higher number of mature oligodendrocytes after long-term cuprizone diet may suggest that DMF treatment potentially promotes the differentiation of oligodendrocytes.
\end{abstract}


In the second part, preventive as well as therapeutic DMF treatment was effective in a $B$ cell-mediated EAE model. Clinical benefit of DMF treatment in mice with established EAE was associated with decreased demyelination and inflammation of the spinal cord. The infiltration of macrophages/microglia and partially also of T cells was reduced by DMF treatment, whereas DMF had no detectable effect on the number of infiltrating B cells. In peripheral compartments, DMF led to a lower Tcell frequency in the blood, while a complementary accumulation of T cells could be observed in lymph node and spleen of DMF-treated mice with EAE. Besides its effect on $T$ cell frequencies, DMF treatment significantly reduced activation, differentiation and proliferation of peripheral T cells. In contrast, DMF-treatment exerted no inhibitory effect on peripheral B cells and caused an enhanced activation and differentiation of B cells. Most persistently, we observed an upregulation of MHC II on B cells. Functionally, these alterations were associated with an enhanced capacity of B cells to act as antigen presenting cells for activation of T cells. In conclusion, the observed clinical and pathological benefit in EAE with pathogenic B cell function thus appears to be mediated by an immunomodulatory effect of DMF directly on T cells. Contrary, we found that DMF treatment promoted antigen-presenting properties of B cells, while this study could not conclusively reveal which T cell phenotype is induced by these more potent B cells. Nevertheless, the primary observation of an enhanced B cell activation and antigen presenting function upon DMF treatment might be of significant relevance in specific therapeutic decisions, such as choosing the appropriate MS medication subsequent to therapeutic B cell depletion. 


\section{List of Figures}

Figure 1: Effect of DMF treatment on cuprizone induced weight loss.

Figure 2: DMF treatment reduces cuprizone-induced apoptosis of oligodendrocytes in the CC.

Figure 3: DMF treatment increases number of oligodendrocytes after 7 days of cuprizone exposure. 46

Figure 4: DMF treatment reduces the acute axonal damage induced by cuprizone diet. 47

Figure 5: DMF treatment does not prevent apoptosis of oligodendrocytes in the CC after 2 weeks of cuprizone diet. 48

Figure 6: DMF application does not reduce demyelination in the CC. 50

Figure 7: No significant effect of DMF on acute axonal damage, astrogliosis and macrophage/microglial numbers after long-term cuprizone treatment. 51

Figure 8: DMF treatment shows no significant effect the axonal density 52

Figure 9: Higher numbers of mature oligodendrocytes after 6 weeks of cuprizone exposure with DMF treatment. 53

Figure 10: DMF has no effect on the remyelination of the CC. 54

Figure 11: DMF treatment decreases acute axonal damage after cuprizone withdrawal...... 55

Figure 12: MMF, the active metabolite of DMF, is present in the brain of DMF-treated mice.

Figure 13: DMF treatment does not decrease apoptosis of oligodendrocytes in the CC of Nrf2 k.o. mice. 57

Figure 14: Schematic representation of the experimental setup. 58

Figure 15: Clinical course of EAE is ameliorated by preventive and therapeutic DMF treatment. 59

Figure 16: Anti-MOG Ab serum levels remain constant under preventive and therapeutic DMF treatment. 60 
Figure 17: Spinal cord demyelination and infiltration is reduced after DMF treatment

Figure 18: T cell frequencies in blood, lymph node and spleen are altered under DMF treatment at day 12 p.i.

Figure 19: DMF decreases the expression of activation markers on T cells. 65

Figure 20: DMF decreases the frequency of $\mathrm{CD} 44^{\text {high }} \mathrm{CD} 4^{+} \mathrm{T}$ cells. 68

Figure 21: The frequency of $C D 44^{\text {high }} \mathrm{CD} 8^{+} T$ cells is reduced by DMF. 70

Figure 22: DMF treatment reduces the differentiation of IFN $\gamma^{+} \mathrm{T}$ cells and IL17 ${ }^{+} \mathrm{T}$ cells 72

Figure 23: DMF treatment does not alter regulatory $T$ cell frequencies. 74

Figure 24: Proliferation of in vivo DMF-treated T cells is decreased after antigen-independent stimulation. 77

Figure 25: MHC-II expression on B cells is increased after DMF treatment. 78

Figure 26: Expression levels of activation markers on B cells remain constant after DMF treatment. 80

Figure 27: DMF induces a shift in B cell subpopulations.

Figure 28: B cell phenotypes are not significantly affected by DMF treatment...... 83

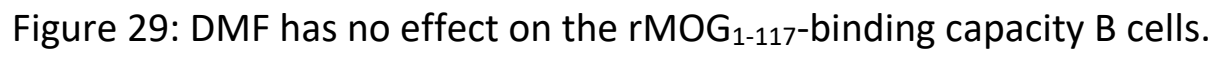
84

Figure 30: In vivo DMF treatment enhances the antigen-presenting function of B cells. 86

Figure 31: In vivo DMF-treated B cells do not alter T cell differentiation in vitro. 87

Figure 32: DMF effects on B cells of MS patients. 88 


\section{List of Tables}

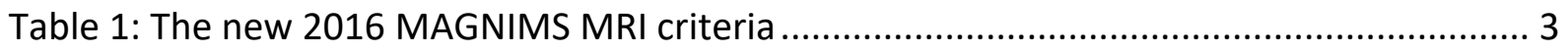

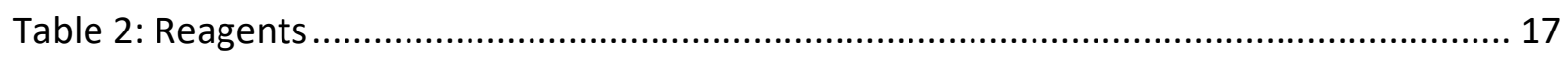

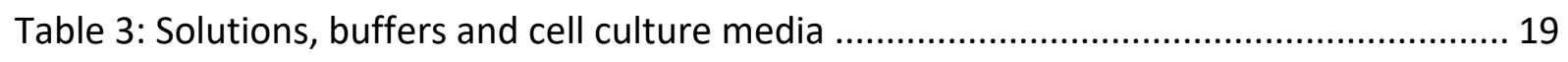

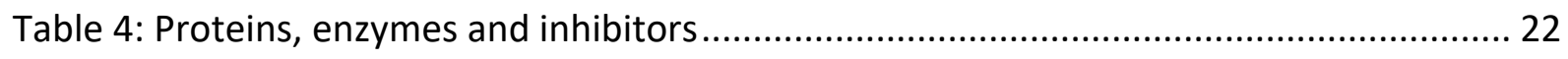

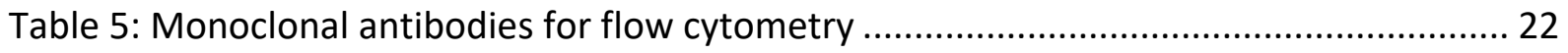

Table 6: Monoclonal antibodies for antigen-independent activation of T cells in vitro ......... 24

Table 7: Primary antibodies for immunhistochemical staining ......................................... 24

Table 8: Secondary antibodies for immunohistochemical staining ................................... 25

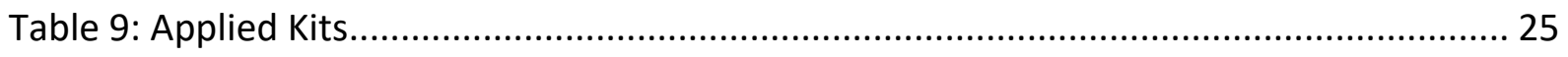

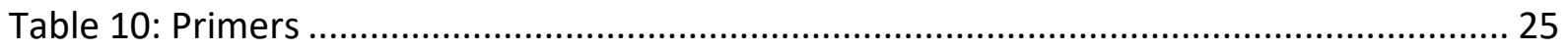





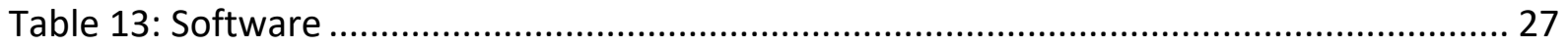






\section{Abbreviations}

APC

APC

APP

$\mathrm{Ag}$

BAFF

BBB

BCR

BDNF

BV

Casp3

CC

CD

CFSE

CIS

CNS

CSF

ctrl

DAPI

$\mathrm{dH}_{2} \mathrm{O}$

$\mathrm{ddH}_{2} \mathrm{O}$

DMD

DMF

DMSO

DNA

EAE
Allophycocyanin

Antigen-presenting cell

Amyloid precursor protein

Antigen

B cell activation factor

Blood brain barrier

B cell receptor

Brain-derived neurotrophic factor

Brilliant violet

Caspase 3

Corpus callosum

Cluster of differentiation

Carboxyfluorescein succinimidyl ester

Clinical isolated syndrome

Central nervous system

Cerebrospinal fluid

control

4',6-diamidino-2-phenylindole

Distilled water

Bidistilled water

Disease-modifying drug

Dimethyl fumarate

Dimethyl sulfoxide

Deoxyribonucleic acid

Experimental autoimmune encephalomyelitis 
FITC

Fluorescein isothiocyanate

GA

Glatiramer acetate

GFAP

Glial fibrillary acidic protein

h

Hour(s)

$H \& E$

Haematoxilin and eosin

$\mathrm{H}_{2} \mathrm{O}_{2}$

Hydrogen peroxide

$\mathrm{HCl}$

Hydrochloric acid

IFN

Interferon

$\lg$

Immunglobulin

i.p.

intrapertoneal

JCV

JC Virus

$\mathrm{mAb}$

Monoclonal antibody

MBP

Myelin basic protein

$\mathrm{mg}$

Milligram

MHC

Major histocompatibility complex

$\min$

Minute(s)

$\mu l$

Microliter

$\mathrm{ml}$

Milliliter

$\mu \mathrm{m}$

Micrometer

$\mu \mathrm{M}$

Micromolar

MOG

Myelin oligodendrocyte glycoprotein 


\begin{tabular}{|c|c|}
\hline MRI & Magnetic resonance imaging \\
\hline MS & Multiple Sclerosis \\
\hline OPC & Oligoclonal Band \\
\hline PBMC & Peripheral blood mononuclear cell \\
\hline PBS & Phosphate buffered saline \\
\hline PE & Phycoerithrin \\
\hline PFA & Paraformaldehyde \\
\hline p.i. & Post immunization \\
\hline PPMS & Primary progressive multiple sclerosis \\
\hline PML & Progressive multifocal leukoencephalopathy \\
\hline PLP & Proteolipid protein \\
\hline PTX & Pertussis Toxin \\
\hline RIS & Radiologically isolated syndrome \\
\hline rMOG & Recombinant Myelin oligodendrocyte glycoprotein \\
\hline RRMS & Relapsing-remitting multiple sclerosis \\
\hline $\mathrm{RT}$ & Room temperature \\
\hline s & Second(s) \\
\hline s.c. & Subcutaneous \\
\hline SPMS & Secondary progressive multiple sclerosis \\
\hline Th1 & T helper cells 1 \\
\hline Th17 & Thelper cells 17 \\
\hline TNF & Tumor necrosis factor \\
\hline
\end{tabular}




\section{Introduction}

\subsection{Multiple Sclerosis}

Multiple sclerosis (MS) is the most common autoimmune disease of the central nervous system (CNS) with approximately 2.5 million affected people worldwide (healthline.com/health/multiplesclerosis/facts-statistics-infographic). MS is most commonly diagnosed in adults in their late twenties or early thirties. The clinical characteristics and pathology of MS were first described by Robert Carswell in 1838, who described and illustrated lesions of the spinal cord. The pathological hallmarks of MS lesions are inflammation, demyelination, gliosis and axonal loss (Brück and Stadelmann, 2003). The inflammation is caused by microglia and infiltrating macrophages, T cells and B cells. Despite that MS was mainly described as a T cell-driven disease, growing evidence suggests that B cells play an important role in the pathogenesis of the disease (Weber et al., 2010; Franciotta et al., 2008).

\subsubsection{Symptoms, clinical course and diagnosis}

MS is associated with a large variety of symptoms, like vision loss (partly or complete), changed sensation in arms or legs as well as fatigue and impairment of balance (Smith and McDonald, 1999). The symptoms can be transient but may also persist.

In 1996 the US National Multiple Sclerosis Society (NMSS) Advisory Committee on Clinical Trials in Multiple Sclerosis described 4 phenotypes of MS: relapsing-remitting (RRMS), secondary progressive (SPMS), primary progressive (PPMS), and progressive relapsing (PRMS) (Lublin and Reingold, 1996). The definition of these subtypes was revised in 2013 and the clinical isolated syndrome (CIS) and the radiologically isolated syndrome (RIS) were added as new subtypes (Lublin et al., 2014). The progressive relapsing phenotype was removed since those patients would now be categorized as PPMS patients with superimposed relapses and/or MRI activity.

RRMS occurs in about $85 \%$ of patients and is therefore the most common subtype of MS (Weinshenker, 1998). The characteristics of RRMS are disease relapses with full recovery or remaining deficits after partial recovery. Relapses are defined by an acute worsening of disease over a short period of time, which is often followed by a varying degree of remission. The clinical course remains stable between relapses. Typical symptoms of RRMS are sensory dysfunctions, optic neuritis and bladder as well as bowel difficulties (Noseworthy et al., 2000). When the disease 
progresses continuously between relapses, the RRMS patient has converted to a secondary progressive phenotype. Approximately 70\% of RRMS patients develop a SPMS after about 20 years (Weinshenker, 1998).

SPMS is defined by a steady progression of disease after an initial relapsing-remitting disease course and rarely by additional occasional relapses with minor recovery (Lublin and Reingold, 1996).

The small proportion of MS patients who do not display the characteristics of RRMS or SPMS show the phenotype of PPMS. PPMS is characterized by a continuous disease progression from onset. Disease plateaus or minor improvements can occur over time. PPMS affects approximately 10-15\% of MS patients and the disease onset is about 10 years later compared to RRMS (Miller and Leary, 2007; Ontaneda and Fox, 2015; Thompson et al., 1997). The most important difference between RRMS and PPMS is how fast symptoms develop. In RRMS, new neurological deficits occur within days, but symptoms can resolve quickly. PPMS, in contrast, is characterized by accumulating disability over months and years and symptoms do not regress. Patients with PPMS often suffer from a progressive myelopathy which can emerge as a spastic, atactic paresis with dysfunction of the annular muscle (Ontaneda and Fox, 2015).

Nowadays, MS is diagnosed by application of the McDonald criteria (McDonald et al., 2001), which were first described in 2001 and revised in 2005 and 2010 (Polman et al., 2005, 2011). Following these criteria, MS is diagnosed after consideration of the clinical symptoms, MRI data and cerebrospinal fluid parameters (e.g. oligoclonal IgG bands). MRI criteria support an accurate diagnosis by depicting dissemination of lesions in time and space and thereby assist to exclude disorders which can mimic clinical and laboratory aspects of MS (Filippi et al., 2016). The European collaborative research network that studies MRI in MS (MAGNIMS) recommended in 2016 modifications to 2010 McDonald criteria which are depicted in Table 1 (Filippi et al., 2016). 
Table 1: The new 2016 MAGNIMS MRI criteria (modified from Radiopedia.org)

\begin{tabular}{|c|c|}
\hline $\begin{array}{c}\text { Dissemination in space } \\
\text { (established by two of five following areas) }\end{array}$ & $\begin{array}{l}\text { Dissemination in time } \\
\text { (established by one of two ways) }\end{array}$ \\
\hline $\begin{array}{l}\text { - } \\
\text { - } \text { infratentorial: } \geq 1 \text { lesions } \\
\text { - } \\
\text { - } \text { optic nerve: } \geq 1 \text { lesions } \\
\text { - } \\
\text { spiniventricular: } \geq 3 \text { lesions } \\
\text { spord: } \geq 1 \text { lesions }\end{array}$ & $\begin{array}{l}\text { - a new lesion when compared to a previous } \\
\text { scan (irrespective of timing) } \rightarrow \mathrm{T} 2 \text { bright lesion } \\
\text { and/or gadolinium-enhancing } \\
\text { - presence of enhancing lesion and a non- } \\
\text { enhancing T2 bright lesion on any one scan }\end{array}$ \\
\hline
\end{tabular}

\subsubsection{Pathogenesis and Pathology}

\subsubsection{MS Pathogenesis}

Based on results which were found in experimental autoimmune encephalomyelitis (EAE), an animal model of MS, it is assumed that peripheral immune cells cause an pro-inflammatory response in the CNS (Hemmer et al., 2015). T cells are assumed to be the cells activated first, which infiltrate the prior unaffected CNS tissue. The infiltrating auto-reactive T cells release proinflammatory cytokines like TNF- $\alpha$ and IFN $\gamma$ which trigger an increased release of other cytokines and chemokines (e.g..: CCL3, CCL5, CXCL8, CXC3L1) (Larochelle et al., 2011). As a result of this inflammatory condition, endothelial cells (ECS) of the blood brain barrier (BBB) become activated and their expression of cell adhesion molecules (CAMs) increases (Bartholomäus et al., 2009). This process leads to the attraction of additional immune cells, including monocytes, B and T cells, plasma cells and dendritic cells which numerously invade the CNS tissue. The resulting inflammation interferes with the astroglial and oligodendroglial homeostasis. The infiltrating plasma cells produce antibodies which might lead to the damage of glial cells and the myelin sheath (Hemmer et al., 2015). Microglia and macrophages can cause axonal damage and injure the myelin by release of reactive oxygen and nitrogen species (ROS) (Fischer et al., 2012). The interaction of those macrophages/microglial cells and lymphocytes leads to the formation of an inflammatory phagocytic lesion. The initiation of the disease by T cells, however, is just one of the hypothesized mechanisms. 
As newly forming MS lesions are associated with large numbers of activated microglia and only few infiltrating lymphocytes, an alternative hypothesis suggests that local CNS inflammation causes lesion formation (Barnett and Prineas, 2004; Henderson et al., 2009).

\subsubsection{Pathology}

Demyelination, inflammation, gliosis and axonal damage are the pathological hallmarks of MS (Kuhlmann et al., 2002). MS plaques (focal white matter lesions) can be present all over the CNS with predominant occurrence in the spinal cord, optic nerve, periventricular areas and brain stem (Stadelmann et al., 2011). Active plaques, defined by minor and major myelin protein degradation products within macrophages, most frequently arise in early disease stages, whereas smoldering (slowly expanding), inactive or shadow plaques are more prominent in chronic disease stages (Frischer et al., 2015). Inactive lesions show a sharp border and no or few macrophages and activated microglia. White matter lesions which are completely remyelinated are the so-called shadow plaques (Barkhof et al., 2003; Patrikios et al., 2006). Active lesions are more pronounced in RRMS patients but also occur in lower numbers in progressive MS. Smoldering plaques are characterized by an inactive center containing few macrophages but activated microglia are still present. These lesions seem to be characteristic of progressive MS, as they are exclusively found in progressive disease courses. Furthermore, patients with PPMS or SPMS show a higher frequency of cortical lesions and the injury of the normal-appearing white matter (NAWM) is more pronounced compared to RRMS patients (Kutzelnigg et al., 2005). It is characterized by a diffuse inflammation and axonal injury in non-demyelinated areas.

Early and chronic MS lesions differ in the extent of inflammatory cell infiltrates, demyelination and axonal damage (Brück et al., 1995; Kuhlmann et al., 2002, 2008a). Early lesions are characterized by a dominant accumulation of macrophages filled with myelin degradation products, a variable density of T cells in perivascular and parenchymal tissue, varying numbers of B cells and plasma cells, sometimes incomplete demyelination and a pronounced acute axonal damage. In chronic MS lesions only few lymphocytes and phagocytic cells are present, mature oligodendrocytes are often reduced, whereas oligodendrocyte precursor cells (OPC) may still be present. A pronounced reduction in the axonal density is especially found in lesions of MS patients, but also occurs in the NAWM (Evangelou et al., 2000; Tallantyre et al., 2009). The extent of remyelination is more pronounced in early than in chronic lesions (Goldschmidt et al., 2009). 
Early active MS lesions represent early stages of lesion formation. In those lesions, four different patterns of demyelination can be differentiated that are defined by the loss of myelin proteins, extent of oligodendrocyte destruction, extension and localization of plaques and evidence of immunoglobulin and complement deposition (Lucchinetti et al., 2000).

Pattern I lesions are characterized by active demyelination accompanied by a prominent T celland macrophage-associated inflammation. The myelin protein loss in pattern $\mathrm{I}$ is evenly distributed and the lesions show sharply demarcated edges.

MS pattern II is similar to pattern I, but additionally shows deposits of immunoglobulins (Ig) and complement C9neo antigens. As these hallmarks are most prominent at sites of active demyelination and within phagocytic cells, it has been suggested that the myelin injury in this pattern could be mediated by the humoral immune system.

MS pattern III and pattern IV lesions also show inflammatory infiltrates consisting of macrophages/microglia and T lymphocytes. Deposition of immunoglobulin and complement is not present in these lesions.

In contrast to pattern I and II lesions, pattern III lesions show a diffuse spread into the normalappearing white matter and the myelin around the vessels is mostly intact. The characteristic features of this pattern are a preferential loss of the myelin-associated glycoprotein (MAG) compared to other myelin proteins (e.g. myelin oligodendrocyte glycoprotein (MOG) and the apoptosis of oligodendrocytes.

The hallmark of pattern IV lesions is DNA fragmentation in oligodendrocytes in the absence of morphological features of apoptotic cell death. This pattern was only described in single autopsy cases and can thus be neglected.

\subsubsection{B cells in MS}

In the past years, the hypothesis of MS as a mainly T cell-mediated disease has been questioned and the role of B cells in the pathogenesis has been reevaluated (Franciotta et al., 2008). Activation of naïve $B$ cells is triggered by antigen which they present in the context of the major histocompatibility complex-II (MHC-II) to $\mathrm{CD}^{+}$T cells.

Full activation of $\mathrm{B}$ cells usually requires $\mathrm{T}$ cell help, namely the interaction of co-stimulatory molecules and the secretion of cytokines (Chen and Flies, 2013). Once B cells are activated, they 
can differentiate into antibody-secreting plasma cells and memory B cells. These responses are crucial for a proper humoral and cellular immune response to effectively eliminate pathogens. Furthermore, activated B cells produce various pro-inflammatory cytokines (e.g. IL-6, TNF $\alpha$, IFN ) that on one side are important for an inflammatory response against pathogens but on the other side could promote inflammation in autoimmune diseases leading to the exacerbation of the disease course (Krumbholz and Meinl, 2014). Besides pro-inflammatory cytokines, B cells also secrete regulatory cytokines (e.g. IL-10, IL-35) which can control the extent of inflammation and could therefore exert beneficial effects in autoimmune diseases like MS (Fillatreau et al., 2002). In conclusion, B cells can exert beneficial and detrimental effects by antigen presentation, (auto-) antibody production and cytokine secretion.

The presence of oligoclonal bands (OCBs) in the CSF of MS patients was a first indication that B cells could contribute to the pathogenesis of the disease (Karcher et al., 1959; Lowenthal et al., 1960). OCBs occur in more than $95 \%$ of patients with MS and originate from the intrathecal production of IgG by clonally expanded plasma cells which are observed in the CNS parenchyma (Obermeier et al., 2011; Owens et al., 2003). Plasma cells are found in the perivascular spaces within lesions of subacute and chronic MS patients and it is assumed that antibodies (e.g. $\operatorname{lgG}$ ) are synthesized at these sites (Henderson et al., 2009; Prineas, 1979). Additionally to the CNS parenchyma, B cell infiltrates are also found in the meninges of MS patients. Although only minor numbers of B cells and plasma cells are observed in MS lesions compared to T cells and myeloid cells, Type II lesions (that display deposits of Igs and complement and thus suggest a role of the humoral immune system in lesion development) are the most common lesion type in MS (Barnett et al., 2009; Lassmann et al., 2007; Lucchinetti et al., 2000).

While these first observations focused mainly on the pathogenic contribution of antibodies, emerging evidence suggests that the cellular function of $B$ cells as highly effective and selective antigen-presenting cells (APC) may be equally important. An evidence for a pathogenic cellular function of B cells was the observation that memory B cells of RRMS patients are capable of inducing $\mathrm{CD}^{+} \mathrm{T}$ cell proliferation and secretion of IFN $\gamma$ in the presence of myelin proteins (Harp et al., 2010). B cells bind antigen via their B cell receptor (BCR), afterwards the antigen is internalized, processed and finally presented on the surface in the context of the major histocompatibility complex-II (MHC-II). B cells simultaneously increase the expression of co-stimulatory molecules 
like CD80, CD86 and CD40 for an optimal capability to activate T cells. The co-stimulatory molecules CD80 and CD86 are upregulated on peripheral B cells from MS patients when compared to healthy controls (Fraussen et al., 2014). These B cells are capable of inducing a myelin-specific, pro-inflammatory $\mathrm{T}$ cell response, emphasizing the important role of $\mathrm{B}$ cell-dependent antigen presentation and co-stimulation in MS pathogenesis. Additionally, B cells can contribute to a proinflammatory response through the production of cytokines like Interleukin (IL)-6 and tumor necrosis factor alpha (TNF- $\alpha$ ) (Meinl et al., 2006). It was demonstrated that B cells isolated from MS patients and afterwards stimulated in vitro showed a significant higher production of IL-6 when compared to healthy controls (Barr et al., 2012). Furthermore, MS plaques show an upregulation of the $B$ cell activation factor (BAFF) with an expression level comparable to lymphoid tissue (Krumbholz et al., 2005). BAFF serves as a crucial survival factor for B cells, especially for autoantigen binding B cells (Lesley et al., 2004). Therefore, an increased BAFF expression could promote the long-term-survival of plasma cells in the CNS. In contrast to these findings, it was shown that the frequency of regulatory B cells is decreased in the peripheral blood of MS patients compared to healthy controls (Knippenberg et al., 2011). B cells themselves can regulate immune responses through the production of IL-10 and IL-35 (Fillatreau et al., 2002; Shen et al., 2014). Besides, human regulatory $B$ cells can control dendritic and macrophage cell functions, suppress proliferation of $\mathrm{T}$ cells and induce the generation of regulatory T cells (Krumbholz and Meinl, 2014). Balancing the pro-inflammatory and regulatory functions of B cells, for example through influencing the BAFF expression level, could be an important therapeutic target for MS.

The most conclusive evidence for a pathogenic contribution of B cells in MS pathogenesis were the beneficial effects of the B cell-depleting antibody rituximab and ocrelizumab (and other B celldepleting therapeutics in clinical development) in RRMS patients (Hauser et al., 2008a, 2017).

\subsubsection{Therapy of MS}

The treatment approaches in MS can be divided into disease-modifying therapies and the treatment of acute relapses. The choice for the initial disease-modifying MS medication depends on the disease activity and is also based on a benefit-risk evaluation. Today, more than ten different disease-modifying drugs (DMDs) are approved for the long term treatment of MS in Europe. 
The DMDs for patients with mild/moderate disease activity are the injectable drugs interferonbeta (IFNB) and glatiramer acetate (GA) as well as the recently developed orally active drugs dimethyl fumarate (DMF) and teriflunomide. These drugs are characterized by moderate immunomodulatory functions and a generally high safety profile. Teriflunomide should not be used for women who are pregnant or are planning a pregnancy within the next 2 years. Several clinical trials could show that IFN $\beta, G A$, teriflunomide and DMF efficiently reduce the relapse rate, decrease the development of new MRI lesions and counteract Expanded Disability Status Scale (EDSS) worsening (Claussen and Korn, 2012; Fox et al., 2012; Gold et al., 2012; Kappos et al., 2007; McCormack and Scott, 2004; Mikol et al., 2008; Paty and Li, 1993). The effects of DMF are described in detail in section 12.

For MS patients with a (highly) active disease course, monoclonal antibodies (mAbs) such as natalizumab and alemtuzumab or the oral agent fingolimod can be used as first choice of treatment. All three medications are characterized by a higher therapeutic efficacy than for example IFN $\beta$. These drugs are highly effective in reducing the relapse rate as well as decreasing the accumulation of disability and MRI activity (Cohen et al., 2010; Coles et al., 2012; Polman et al., 2006). Although natalizumab was proven to be very effective, the development of progressive multifocal leukoencephalopathy (PML) in natalizumab-treated patients became a major safety issue (Langer-Gould and Steinman, 2006). Since the risk to develop PML is associated with the presence of antibodies against the JCV, patients should be tested for those antibodies before starting natalizumab treatment and while on therapy (Plavina et al., 2014). If these first line drugs fail to effectively control disease activity, daclizumab, mitoxantrone and ocrelizumab (expected to be approved in 2017) are considered as alternative treatment option. Daclizumab and ocrelizumab are mAbs which significantly lower the relapse rate of MS patients (Gold et al., 2013; Kappos et al., 2011). Mitoxantrone is an immunosuppressive drug which was approved in 2000 for the therapy of worsening RRMS and is known to significantly reduce the relapse rate and worsening of symptoms (Vollmer et al., 2010).

The standard medication for an acute relapse is the daily intravenous administration of high dose corticosteroids (e.g. 1g/day methylprednisolone) for 3-5 days (Sellebjerg et al., 2005). Should the symptoms persist, a second application of $2 \mathrm{~g} /$ day is given after a timeframe of $10-14$ days. As a 
second therapy option, immunoadsorption or plasma exchange are utilized for patients with no or incomplete recovery after steroid treatment (Heigl et al., 2013; Trebst et al., 2009).

Besides the primary treatment objective to reduce relapse rate and to retard disease progression, the symptomatic MS therapy targets known signs and comorbidities of MS. Therapeutic approaches such as physical therapy, application of muscle relaxants and medications against fatigue, depression, bowel/bladder control problems or visual dysfunctions are important to improve the quality of life for patients (de Sa et al., 2011).

Most of the disease modifying drugs described above have also been tested for the therapy of progressive MS (PMS) with largely disappointing results (Ontaneda et al., 2016). It was shown that mitoxantrone was effective in patients with SPMS, but it rather reduced the relapse rate and did not affect the continuous disease progression (Ontaneda and Fox, 2015; Stüve et al., 2004). The limited success of these immunomodulatory and immunosuppressive drugs suggested that neuroprotective and repair-promoting approaches might be more effective for the therapy of PMS. However, the incomplete understanding of pathological processes contributing to the progression of disease complicates the development of such approaches. Hence, a broad range of treatments are currently under investigation. One example is the clinical trial MS-SMART, which currently investigates three neuroprotective agents (amiloride, riluzole, fluoxetine) for the therapy of SPMS patients.

\subsection{Animal models of MS}

Based on the restricted access to ex vivo specimens and the heterogeneity of MS, animal models are essential for a better understanding of the disease pathogenesis and for developing new therapeutic approaches. Several animal models of MS, like the cuprizone and EAE model, have been established, reproducing specific features of the disease.

\subsubsection{The cuprizone model}

The cuprizone model is a toxic demyelination model, which was developed to investigate demyelination and remyelination. The hallmark of this model is that the blood-brain-barrier (BBB) remains intact, which allows the analysis of de- and remyelination without major influences of the peripheral immune system (Bakker and Ludwin, 1987; McMahon et al., 2002). Cuprizone (biscyclohexanone-oxaldihydrazone) is a copper chelating agent and feeding cuprizone to young adult 
mice leads to apoptosis of oligodendrocytes and the spontaneous demyelination of the corpus callosum (CC) (Bénardais et al., 2013; Matsushima and Morell, 2001a). The most common mouse strain used for the cuprizone model is the C57BL/6 strain. C57BL/6 mice fed with $0.2-0.25 \%$ cuprizone for six weeks suffer from an almost complete demyelination of the CC (Hiremath et al., 1998). Besides weight loss and a slightly decreased activity, no major clinical signs (e.g. paralysis) can be observed under $0.2-0.25 \%$ cuprizone exposure (Praet et al., 2014). Several studies showed that cuprizone also leads to demyelination in several other brain regions such as the cerebellum, the hippocampus, the caudate-putamen and cortex (Groebe et al., 2009; Gudi et al., 2009; Hoffmann et al., 2008; Koutsoudaki et al., 2009; Norkute et al., 2009; Skripuletz et al., 2010). The exact mechanism of cuprizone-induced demyelination and apoptosis of oligodendrocytes is not completely understood. It is assumed that the cuprizone-mediated inhibition of mitochondrial enzymes leads to oligodendrocyte apoptosis and initiation of demyelination (Bénardais et al., 2013; Matsushima and Morell, 2001a; Ransohoff, 2012; Venturini, 1973). Oligodendroglial cell death starts early after initiation of cuprizone diet, weeks before demyelination is detectable (Hesse et al., 2010a). In the early phase, dying oligodendrocytes express activated caspase 3, which decreases in later stages suggesting a switch to a caspase 3-independent cell death mechanism. The early loss of oligodendrocytes leads to an enhanced recruitment of microglia/macrophages which is followed by an extensive astrogliosis (Hiremath et al., 1998). Microglia accumulation reaches its maximum with the peak of demyelination after 4-5 weeks of cuprizone exposure (Mason et al., 2001). Spontaneous remyelination occurs either upon cuprizone withdrawal or after 5-6 weeks of ongoing cuprizone diet. After cuprizone removal, the majority of axons is remyelinated within 2 weeks (Lindner et al., 2008a).

\subsubsection{Experimental autoimmune encephalomyelitis}

EAE is the most common model of MS and was first described in 1933 (Rivers et al., 1933). The model is mainly used to study the immune cell-mediated inflammation and demyelination of the CNS. EAE can be induced by active immunization with distinct myelin components emulsified in complete Freund's adjuvant (CFA) or by adoptive transfer of myelin-specific T cells (Stromnes and Goverman, 2006a, 2006b).

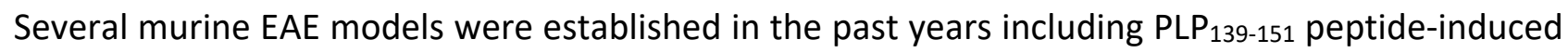
relapsing $\mathrm{EAE}$ in $\mathrm{SJL}$ mice, $\mathrm{MBP}$-induced $\mathrm{EAE}$ in $\mathrm{PL} / \mathrm{J}$ mice, $\mathrm{MOG}_{35-55}$ peptide-induced disease in 
C57/BL6 mice and active immunization with CNS tissue homogenates or MOG that induces a relapsing-remitting disease in Biozzi ABH mice (Amor et al., 1994; Ando et al., 1989; Mendel et al., 1995; Tuohy et al., 1992). First clinical signs of EAE can be observed 9-12 days after immunization, depending on the species and the specific disease-inducing agents (Gold et al., 2006). The main clinical characteristic of EAE is an ascending paralysis, gradually affecting the hind limbs, abdominal muscles and fore limbs.

EAE is mediated by complex interactions of the adaptive and the innate immune system. The most common active immunization model is the $\mathrm{MOG}_{35-55}$ peptide $\mathrm{EAE}$ model that leads to a relapsingremitting (SJL, Biozzi) or a chronic-progressive (C57BL/6) disease course. The immunization together with CFA leads to a primarily CD4 ${ }^{+}$T cell-mediated disease (Fletcher et al., 2010; Kurschus, 2015). The $\mathrm{MOG}_{35-55}$ peptide-containing CFA is recognized by antigen-presenting cells (APCs), such as dendritic cells, macrophages and B cells, which present the antigen in a complex with MHC-II molecules on their surface leading to an activation of peripheral encephalitogenic $T$ cells (Slavin et al., 2001). These autoreactive T cells migrate into the CNS mediating a subsequent breakdown of the BBB (Furtado et al., 2008; O'Connor et al., 2008). Inside the CNS, T cells become reactivated by local and infiltrating APCs which present myelin fragments in association with MHC-II leading to further inflammatory processes and subsequently to demyelination and axonal injury (Fletcher et al., 2010; Steinman and Zamvil, 2005). The disease worsening caused by depletion of $B$ cells led to the assumption that this model can be considered as a rather " $B$ cellindependent" EAE (Weber et al., 2010). An EAE model which generates antigen-activated B cells is achieved by immunization with recombinant MOG protein (recombinant ( $r$ ) MOG $_{1-117}$ ). After mice are immunized with $\mathrm{MOG}_{35-55}$ peptide, autoreactive $\mathrm{CD}^{+} \mathrm{T}$ cells become directly activated because the peptide is bound by MHC-II on APCs without processing (Constant et al., 1995; Slavin et al., 2001). In contrast, after immunization with $\mathrm{rMOG}_{1-117}$ the native $\mathrm{MOG}$ needs to be internalized and processed by APCs to present the encephalitogenic peptide to autoreactive $\mathrm{CD}^{+}{ }^{+} \mathrm{T}$ cells (Slavin et al., 2001). This leads to the generation of pathogenic B cells, which recognize the MOG-protein via their $B$ cell receptor (BCR). These B cells can, subsequently, efficiently activate $\mathrm{CD}^{+}{ }^{+} \mathrm{T}$ cells and develop into antibody-secreting plasma cells (Marta et al., 2005).

Although these EAE models represent several histopathological and immunological features of MS, their mode of induction does not model the triggers of CNS autoimmunity completely. Models 
more suitable to investigate the initiation of the disease are spontaneous EAE models. Opticospinal encephalomyelitis (OSE) mice spontaneously develop lesions restricted to the optic nerve and spinal cord (Krishnamoorthy et al., 2006). These mice are double-transgenic animals on a C57BL/6 background, which have transgenic Tcells specific for myelin oligodendrocyte glycoprotein peptide 35-55 (MOG 35-55) and transgenic B cells recognizing MOG antigen (Litzenburger et al., 1998). Approximately $50 \%$ of OSE mice develop spontaneous EAE. Another spontaneous EAE model is the RR mouse model (SJL/J background) which represents the first spontaneous animal model for the relapsing-remitting form of MS (Pöllinger et al., 2009). These single-transgenic mice carry $T$ cells with a $T$ cell receptor (TCR) specific for the MOG $_{91-106}$ peptide presented by MHC-II. Within one year $90 \%$ of the animals develop a relapsing-remitting course of EAE with lesions distributed throughout the CNS.

\subsection{The oral agent dimethyl fumarate (DMF)}

The fumaric acid ester DMF (Tecfider ${ }^{\circledR}$ ) is approved for the therapy of RRMS in Germany since February 2014. Previously DMF had been approved as a compound of the anti-psoriatic drug Fumaderm ${ }^{\circledR}$ since 1994, based on successful clinical studies (Altmeyer et al., 1994; Mrowietz et al., 1998; Nieboer et al., 1990). DMF has several immunomodulatory functions, but the mechanism of action is not completely understood. In the circulation, DMF is rapidly hydrolyzed to its metabolite monomethyl fumarate (MMF), which is supposed to be the active form in the body (Nibbering et al., 1993). However, in vitro and in vivo studies could show that both DMF and MMF have immunomodulatory effects (de Jong et al., 1996; Ockenfels et al., 1998; Treumer et al., 2003).

\subsubsection{Clinical MS trials of DMF}

Several clinical studies assessed the therapeutic effects, safety and tolerability of DMF in RRMS patients. The initial study was performed with Fumaderm ${ }^{\circledR}$ which is composed of ethylhydrogen fumarate-Ca salt, ethylhydrogen fumarate-Mg salt, ethylhydrogen fumarate-Zn salt and dimethyl fumarate. This pilot study showed that treatment of RRMS patients with fumaric acid esters (FAE) could significantly reduce the number and volume of gadolinium-enhanced $(\mathrm{Gd}+)$ lesions and modulate T cell-mediated cytokine production (Schimrigk et al., 2006). Based on these preliminary findings, an oral formulation of dimethyl fumarate, named BG-12, was tested in a phase II study in patients with RRMS (Kappos et al., 2008). Treatment with $240 \mathrm{mg}$ DMF three times daily decreased the number of new Gd+ lesions by $69 \%$ and the annualized relapse rate by $32 \%$ 
compared with placebo treated patients. Furthermore, the number of new or enlarging T2hyperintense and new T1-hypointense lesions was reduced by DMF. Two randomized, doubleblind phase III studies, the DEFINE (Gold et al., 2012) and the CONFIRM study (Fox et al., 2012), were performed.

The DEFINE study demonstrated that DMF significantly reduces the number of relapses in MS patients (relapse rate: $27 \%$ with DMF twice daily and 26\% with DMF thrice daily vs. $46 \%$ placebo) as well as the number of $\mathrm{Gd}+$ and new or enlarging T2-hyperintense lesions. The risk of disability progression was reduced by $38 \%$ and $34 \%$ with DMF treatment twice or thrice per day, respectively. In the CONFIRM study, the active agent GA was included as a reference comparator. The results regarding the efficacy and safety of DMF compared to placebo were fairly similar to the results of the DEFINE study. The comparison of DMF versus GA showed significant differences in favour of DMF in the annualized relapse rate (thrice-daily DMF), new or enlarging T2hyperintense lesions (both DMF doses), and new T1-hypointense lesions (thrice-daily DMF).

Adverse effects include gastrointestinal symptoms like abdominal pain and diarrhea, flushing and decreased lymphocyte counts. To minimize the risk of severe lymphopenia it is recommended to monitor complete blood count and absolute lymphocyte counts before the initiation and during DMF treatment. To date, 5 cases of PML have been reported with the use of fumaric acid esters in patients with psoriasis and 4 cases of PML in patients with MS treated with DMF (Rosenkranz et al., 2015; Williamson and Berger, 2015).

The FDA approved DMF (Tecfidera ${ }^{\circledR}$ ) in 2013 and the European Commission in 2014 as first-line oral treatment for patients with RRMS. The starting dose of Tecfidera ${ }^{\circledR}$ is $120 \mathrm{mg}$ twice a day orally, after seven days the dose should be increased to $240 \mathrm{mg}$ twice daily.

\subsubsection{Experimental DMF studies in vivo}

The effects of DMF were investigated in different animal models. In MOG $35-55$ peptide induced $E A E$, preventive DMF treatment of mice with $15 \mathrm{mg} / \mathrm{kg}$ twice daily could significantly ameliorate the clinical course compared to controls (Chen et al., 2014; Schilling et al., 2006; Schulze-Topphoff et al., 2016). The infiltration of macrophages into the spinal cord was significantly reduced in the early phase of EAE. Therapeutic application of DMF, started after EAE onset, could also attenuate EAE severity and first effects became apparent 10 days after treatment start (Linker et al., 2011). 
Histological analysis revealed that DMF leads to a significantly better preservation of myelin and axons in inflamed lesions as well as to a reduced astrogliosis.

A quantification of neuronal cells in spinal cord and cerebellum showed significantly higher numbers of neurons in DMF-treated mice compared to controls. It was shown that DMF can induce the nuclear factor erythroid 2-related factor (Nrf2) which leads to an increased activation of antioxidant response pathways (Thiessen et al., 2010). In vivo application of DMF led to an increased induction of Nrf2 target genes such as NADP(H) quinolone oxidoreductase-1 (NQO-1) in liver and cerebellum of MOG-peptide immunized rats (Linker et al., 2011). Furthermore, histological evaluation of DMF-treated EAE animals revealed an increased expression of Nrf2 in neurons and glial cells in the brain and spinal cord, suggesting that the observed neuroprotective effects of DMF are Nrf2-dependent. The study of Linker et al. demonstrated that DMF treatment could not ameliorate the EAE course of Nrf2 k.o. mice and thereby supported the hypothesis that DMF effects are mostly Nrf2-dependent. Nevertheless, a recent study showed that DMF treatment also ameliorated EAE of Nrf2 k.o. mice to the same extent as in WT mice, indicating that DMF may as well act via alternative pathways (Schulze-Topphoff et al., 2016). A further study suggested that the hydroxycarboxylic acid receptor $2\left(\mathrm{HCA}_{2}\right)$ could contribute to the protective effects of DMF in $E A E$, since DMF could not ameliorate the EAE course in $\mathrm{HCA}_{2}$ k.o. mice (Chen et al., 2014). MMF was shown to be a potent agonist of the $\mathrm{HCA}_{2}$ receptor, which is expressed on immune cells, especially neutrophils (Lukasova et al., 2011). Chen et al. assumed that DMF treatment could exert secondary immunomodulatory functions by impairing the recruitment of neutrophils.

DMF and MMF were also analyzed in the toxic cuprizone model, a model to investigate direct CNS effects of treatments independent of the peripheral immune system. MMF and DMF treatment revealed only minor effects on the demyelination of the CC (Moharregh-Khiabani et al., 2010). Furthermore, neither MMF nor DMF induced significant changes concerning the number of mature oligodendrocytes or OPCs. The cuprizone-induced microgliosis, astrogliosis and acute axonal damage were also not majorly changed by MMF or DMF treatment. MMF and DMF could slightly accelerate the remyelination in the CC.

\subsubsection{DMF effects on CNS resident cells in vitro}

DMF treatment in EAE showed that it exerts beneficial effects on different CNS cell populations. DMF increased the preservation of axons and neurons and reduced the number of activated 
astrocytes (Linker et al., 2011; Reick et al., 2014). The effects of DMF were also investigated on microglia, endothelial cells, astrocytes, neurons and oligodendrocytes in vitro. Both, MMF and DMF application leads to an increased activation of antioxidant response pathways via induction of Nrf2 (Linker et al., 2011; Thiessen et al., 2010). DMF treatment of neurons and astrocytes in vitro resulted in an upregulation of a Nrf2-dependent antioxidant response and could significantly increase the cell viability after toxic oxidative challenge (Scannevin et al., 2012a). Low concentrations of DMF $(10 \mu \mathrm{M})$ increase the synthesis and recycling of glutathione, an important intracellular antioxidant, in neuronal cells (Albrecht et al., 2012). Enhanced levels of antioxidant molecules (e.g. glutathione) are produced by oligodendrocytes when these were treated in vitro with DMF leading to an increased protection against oxidative stress (Albrecht et al., 2012). Furthermore, DMF decreases the synthesis of pro-inflammatory cytokines like TNF- $\alpha$, IL-1 $\beta$ and IL6 in activated astrocytes and microglia in vitro (Wilms et al., 2010). DMF also profoundly decreases the TNF $\alpha$-induced expression of adhesion molecules E-selectin, ICAM-1 and VCAM-1 on endothelial cells and reduces lymphocyte rolling, firm adhesion and diapedesis in vitro (Wallbrecht et al., 2011).

\subsubsection{DMF effects on immune cells in vitro and in vivo}

Besides the induction of the Nrf2-dependent antioxidant response element (ARE) pathway, DMF and MMF were able to inhibit the translocation and DNA-binding of nuclear factor $\mathrm{KB}$ (NF-KB), resulting downstream in altered cell maturation, reduced inflammatory cytokine production and function of antigen-presenting cells (Ghoreschi et al., 2011; Gillard et al., 2015; Litjens et al., 2006; Loewe et al., 2001). Several studies could reveal that ARE induction can inhibit the NF-kB signaling pathway and indirectly regulate inflammatory chemokine and cytokine production (Wakabayashi et al., 2010).

Application of DMF or MMF in vitro reduces the CCL-2 induced chemotaxis of human monocytes that is needed for CNS infiltration (Cross et al., 2011). In addition, in vitro experiments with cultured mononuclear blood cells revealed that DMF has anti-inflammatory functions by inducing T-helper cell type 2 (Th2) immune responses (de Jong et al., 1996). The DMF metabolite MMF increases the production of IL-5 and IL-4, which are driving Th2 cell development. It was later shown, that this effect could be linked to a direct effect of MMF on dendritic cells (DCs) (Litjens et al., 2004a). MMF treatment of monocyte-derived DCs leads to a down-regulation of Th1 cell 
responses, such as IFN secretion, by modulating the polarization of DCs. In humans and mice, DMF treatment stimulates the development of type II DCs that produce IL-10 and induce IL-4producing Th2 cells in vitro and in vivo (Ghoreschi et al., 2011). Furthermore, in vivo DMF treatment of MS patients leads to an alteration of circulating T helper cell subsets by decreasing the frequencies of Th1 cells and increasing the Th2 cell proportions (Gross et al., 2015). CD4 ${ }^{+}$and $\mathrm{CD}^{+}$memory $\mathrm{T}$ cells are also decreased with the use of DMF whereas the regulatory $\mathrm{T}$ cell population remains unaltered. Recent studies revealed that DMF influences B cell subsets of patients with RRMS, resulting in an increased number of B cells with regulatory functions (Lundy et al., 2016).

\subsection{Aim of the study}

The oral agent dimethyl fumarate (DMF) shows efficacy in the therapy of RRMS. It is assumed that DMF mainly acts via modulating the peripheral immune system and especially by reducing the proinflammatory properties of T cells (Gross et al., 2015; Mrowietz et al., 1998). Additionally, DMF treatment is suggested to exert neuroprotective effects through the activation of the transcription factor Nrf2 which in turn mediates the activation of ARE. Whether DMF can exert direct neuroprotective effects independent of the peripheral immune system is controversially discussed. Furthermore, it is still unknown if DMF has any direct immunomodulatory effects on B cells whose role in MS pathogenesis became increasingly important in the recent years.

In the first part of my thesis it was investigated if DMF exerts any CNS intrinsic effects independent of peripheral inflammation. DMF effects were analyzed on:

A1. Neurodegeneration including apoptosis of oligodendrocytes, demyelination and axonal damage as well as

A2. Neuroregeneration investigating remyelination, oligodendrocyte preservation and maturation.

In the second part of my thesis it was studied if DMF treatment is effective in a B cell-mediated EAE model. DMF effects were investigated on:

B1. Clinical course and histopathology of B cell-mediated EAE.

B2. Activation, functional properties and subtypes of B cells and T cells during the acute phase of EAE. 


\section{Material and Methods}

\subsection{Material}

\subsubsection{Reagents}

Table 2: Reagents

\begin{tabular}{|c|c|}
\hline REAGENT & SOURCE OF SUPPLY \\
\hline Acetic Acid & Merck Millipore, Germany \\
\hline Agarose & Starlab GmbH, Germany \\
\hline BD FACS Clean ${ }^{\mathrm{TM}}$ & BD Biosciences, USA \\
\hline BD FACS Flow ${ }^{\mathrm{TM}}$ & BD Biosciences, USA \\
\hline BD FACS Rinse ${ }^{\mathrm{TM}}$ & BD Biosciences, USA \\
\hline BD FACS ${ }^{\text {тм }}$ Lysing Solution, $10 x$ & BD Biosciences, USA \\
\hline BD Pharm Lyse $\mathrm{T}^{\mathrm{TM}}, 10 \mathrm{x}$ & BD Biosciences, , USA \\
\hline Boric Acid & Merck Millipore, Germany \\
\hline Crystal Violet & Sigma Aldrich, USA \\
\hline Cytofix/Cytoperm ${ }^{\mathrm{TM}}$ & BD Biosciences, , USA \\
\hline Cytofix ${ }^{\mathrm{TM}}$ & BD Biosciences, USA \\
\hline Chloral Hydrate & Merck Millipore, Germany \\
\hline Citric Acid & Merck Millipore, Germany \\
\hline DAB (3,3'-Diaminobenzidine) & Sigma-Aldrich Chemie GmbH, Germany \\
\hline DAPI (4',6-Diamidino-2-Phenylindole) & Sigma-Aldrich Chemie GmbH, Germany \\
\hline DDSA (2-Dodecenylsuccinic Acid Anhydride) & Serva Electrophoresis GmbH, Germany \\
\hline DEPEX & VWR International, Germany \\
\hline DMF (Dimethyl Fumarate) & Biogen Idec, USA \\
\hline DMSO (Dimethyl Sulfoxide) & Sigma Aldrich, USA \\
\hline EDTA (Ethylenediamine Tetraacetic Acid & Carl Roth, Germany \\
\hline Disodiumsalt Dihydrate) & \\
\hline
\end{tabular}




\begin{tabular}{|c|c|}
\hline Ethanol, $100 \%$ & Merck Millipore, Germany \\
\hline Ethidium Bromide & Sigma Aldrich, USA \\
\hline Eosin $\mathrm{G}$ & Merck Millipore, Germany \\
\hline FCS (Fetal Calf Serum) & Sigma Aldrich, USA \\
\hline $\begin{array}{l}\text { Foxp3 Fixation/Permeabilization } \\
\text { Concentrate }\end{array}$ & Ebioscience, USA \\
\hline Foxp3 Fixation/Permeabilization Diluent & Ebioscience, USA \\
\hline Foxp3 Permeabilization Buffer, 10x & Ebioscience, USA \\
\hline $\begin{array}{l}\text { Generuler }{ }^{\mathrm{TM}}, 100 \text { Base Pairs (bp) DNA } \\
\text { Ladder Plus }\end{array}$ & ThermoFisher Scientific, USA \\
\hline Go-Taq ${ }^{\circledR}$ DNA Polymerase Buffer, $5 x$ & Promega, USA \\
\hline $\mathrm{HCl}$ (Hydrochloric Acid) & Merck Millipore, Germany \\
\hline $\mathrm{H}_{2} \mathrm{O}_{2}$ (Hydroxic Peroxide), 30\% & Merck Millipore, Germany \\
\hline HPMC (Hydroxypropylmethylcellulose) & Biogen Idec, , USA \\
\hline Ionomycin & Sigma Aldrich, USA \\
\hline Isopropyl Alcohol & Merck Millipore, Germany \\
\hline L-Glutamine, $200 \mathrm{Mm}$ & Sigma Aldrich, USA \\
\hline LPS (Lipopolysaccharide) & Sigma Aldrich, USA \\
\hline Mayer's Hemalum & Merck Millipore, Germany \\
\hline $\begin{array}{l}\mathrm{NaCl} \text { (Sodium Chloride), } 0.9 \% \text { Solution, } \\
\text { Sterile }\end{array}$ & B. Braun Melsungen AG, Germany \\
\hline $\mathrm{NaCO}_{3}$ (sodium carbonate) & Merck Millipore, Germany \\
\hline $\mathrm{NaHCO}_{3}$ (sodium hydrogen carbonat) & Merck Millipore, Germany \\
\hline $\mathrm{NaF}$ (sodium fluoride) & Merck Millipore, Germany \\
\hline Paraffin Oil & Carl Roth, Germany \\
\hline PBS (Phosphate Buffered Saline), 10x & Biochrom AG, Germany \\
\hline $\begin{array}{l}\text { PBS (Phosphate Buffered Salt Solution), } \\
\text { Sterile }\end{array}$ & Sigma Aldrich, USA \\
\hline
\end{tabular}




\begin{tabular}{ll}
\hline Penicillin, 10,000 Units & Sigma Aldrich, USA \\
\hline Perm/Wash ${ }^{\text {TM }}$ Buffer, 10x & BD Biosciences, USA \\
\hline PFA (Paraformaldehyde), Powder & Merck Millipore, Germany \\
\hline PMA (Phorbol 12-Myristate 13-Acetate) & Sigma Aldrich, USA \\
\hline RPMI-1640 (Roswell Park Memorial & Sigma Aldrich, USA \\
Institute-1640) & \\
\hline Sodium Pyruvate, 100 mM & Sigma Aldrich, USA \\
\hline TMB (3,3',5,5'-Tetramethylbenzidine) & Ebioscience, USA \\
Substrate Solution & \\
\hline Tris (Tris(Hydroxymethyl)Aminomethane) & Carl Roth, Germany \\
\hline Trypan Blue & Sigma Aldrich, USA \\
\hline Tween & $\begin{array}{l}\text { Merck Millipore, Germany } \\
\text { B-Mercaptoethanol }\end{array}$ \\
\hline
\end{tabular}

2.1.2. Solutions, buffers and cell culture media

Table 3: Solutions, buffers and cell culture media

\begin{tabular}{ll} 
SOLUTION & COMPOSITION \\
\hline Blocking Buffer for Immunohistochemistry & PBS \\
& $10 \%$ FCS \\
CFA (Complete Freund's Adjuvant) & Paraffin oil \\
& $15 \%$ mannide monooleate \\
& $6.7 \mathrm{mg} / \mathrm{ml}$ Mycobacterium tuberculosis \\
& H37RA \\
& distilled water \\
Chloral Hydrate, 14\% & $14 \%$ chloral hydrate \\
\hline
\end{tabular}




\begin{tabular}{ll}
\hline Citric Acid Buffer, $10 \mathrm{Mm}$ & 2.1 g citric acid \\
& 1 I distilled water \\
& $\mathrm{NaOH}$, adjust to $\mathrm{pH} 6$ \\
\hline Coating buffer & 8.4 g NaHCO3 \\
& 3.5 g NaCO3 \\
& 1 I distilled water \\
& Stir filter, adjust to pH 9.5 \\
& $60 \%$ RPMI ${ }_{\text {complete }}$ \\
Cryo medium & $20 \%$ DMSO \\
& $20 \%$ FCS
\end{tabular}

\begin{tabular}{|c|c|c|}
\hline 3,3'-Diaminobenzidine & Tetrachloride (Dab) & PBS \\
\hline \multirow[t]{3}{*}{ Working Solution } & & $0.5 \mathrm{mg} / \mathrm{ml} \mathrm{DAB}$ \\
\hline & & add $20 \mu \mathrm{l} 30 \%$ hydrogen peroxidase per \\
\hline & & $50 \mathrm{ml}$ DAB solution before use \\
\hline \multirow[t]{2}{*}{ ELISA wash buffer } & & $200 \mathrm{ml} 10 x$ PBS \\
\hline & & $1 \mathrm{ml}$ Tween \\
\hline
\end{tabular}

\subsection{I distilled water}

ELISA stop solution

1\% Eosin
$1 \mathrm{~N} \mathrm{H}_{2} \mathrm{SO}_{4}$ solution

70\% isopropyl alcohol

$1 \% \operatorname{eosin} \mathrm{G}$

stir filter, before use add $0,5 \%$ acetic acid 


\begin{tabular}{ll}
\hline FACS (Fluorescence-Activated Cell Sorting) & PBS, sterile \\
Buffer & $2 \% \mathrm{FCS}$ \\
$1 \% \mathrm{HCl}$ & $1 \% \mathrm{HCl}$ absolute \\
& $70 \%$ ethanol
\end{tabular}

$\begin{array}{ll}\text { MACS (Magnetic-Activated Cell Sorting) Buffer } & \text { PBS, sterile } \\ & 0.5 \% \text { FCS } \\ & 2 \mathrm{mM} \text { EDTA } \\ & \mathrm{pH} 7.2 \\ & 40 \mathrm{mM} \text { Tris } \\ \text { Neutralization buffer } & 250 \mathrm{ml} \text { distilled water }\end{array}$

\begin{tabular}{|c|c|}
\hline \multirow[t]{2}{*}{ 10x PBS } & $95.5 \mathrm{~g}$ PBS \\
\hline & 1 I distilled water \\
\hline \multirow[t]{3}{*}{ RD1 buffer (ELISA block buffer) } & $200 \mathrm{ml} 10 x$ PBS \\
\hline & 20 g BSA \\
\hline & 1.8 I distilled water \\
\hline \multirow[t]{6}{*}{$\mathrm{RPMI}_{\text {complete }}$} & RPMI-1640 \\
\hline & $10 \%$ FCS \\
\hline & $1 \mathrm{mM}$ sodium pyruvate \\
\hline & $50 \mu \mathrm{M} \beta$-Mercaptoethanol \\
\hline & 100 units penicillin \\
\hline & 2 mM L-glutamine \\
\hline \multirow[t]{4}{*}{ TAE (Tris, acetic acid, EDTA) buffer } & $40 \mathrm{mM}$ Tris \\
\hline & $20 \mathrm{mM}$ acetic acid \\
\hline & $1 \mathrm{mM}$ EDTA \\
\hline & 1 I distilled water (adjusted to $\mathrm{pH} 8$ ) \\
\hline \multirow[t]{3}{*}{ Tail lysis buffer } & $25 \mathrm{mM} \mathrm{NaOH}$ \\
\hline & 2 mM EDTA \\
\hline & $250 \mathrm{ml}$ distilled water \\
\hline
\end{tabular}




\subsubsection{Antibodies, enzymes and proteins}

Table 4: Proteins, enzymes and inhibitors

\begin{tabular}{|c|c|}
\hline PROTEINS, ENZYMES, INHIBITORS & SOURCE OF SUPPLY \\
\hline BSA (bovine serum albumin) & SERVA Electrophoresis GmbH, Germany \\
\hline Recombinant mouse MOG-protein $_{1-117}$ & Monash University, Australia \\
\hline PTX (pertussis toxin) & List biological laboratories, USA \\
\hline DNase I & Roche, Basel, Switzerland \\
\hline Dreamtaq green PCR master mix $(2 x)$ & Thermo Fisher Scientific, USA \\
\hline Proteinase $\mathrm{K}$ & Sigma Aldrich, USA \\
\hline Trypsin, $0.05 \%$ & Gibco/Invitrogen, USA \\
\hline Golgistop $^{\mathrm{TM}}$ & BD Biosciences, USA \\
\hline
\end{tabular}

Table 5: Monoclonal antibodies for flow cytometry

\begin{tabular}{|c|c|c|c|c|}
\hline SPECIFICITY & FLUOROCHROME & CLONE & DILUTION & SOURCE OF SUPPLY \\
\hline B220 & FITC & RA3-6B2 & $1: 100$ & BioLegend \\
\hline B220 & PE-Cy7 & RA3-6B2 & $1: 100$ & BD Biosciences \\
\hline CD1D & Pacific Blue & 1B1 & $1: 100$ & BioLegend \\
\hline CD4 & BV510 & GK1.5 & $1: 100$ & BioLegend \\
\hline CD4 & PE & RM4-5 & $1: 100$ & BioLegend \\
\hline CD5 & PerCP-Сy5.5 & $53-7.3$ & $1: 100$ & BioLegend \\
\hline CD8a & FITC & $53-6.7$ & $1: 100$ & BioLegend \\
\hline CD19 & APC-Cy7 & $6 \mathrm{D} 5$ & $1: 100$ & BioLegend \\
\hline CD19 & FITC & HIB19 & $1: 100$ & BD \\
\hline CD23 & APC & B3B4 & $1: 100$ & BioLegend \\
\hline
\end{tabular}




\begin{tabular}{|c|c|c|c|c|}
\hline CD25 & APC & PC61 & $1: 100$ & BD Biosciences \\
\hline CD27 & FITC & LG.3A10 & $1: 100$ & BioLegend \\
\hline CD37 & $\mathrm{PE}$ & Duno85 & $1: 100$ & BioLegend \\
\hline CD40 & APC & $3 / 23$ & $1: 100$ & $\mathrm{BD}$ \\
\hline CD40 & $\mathrm{PE}$ & $5 C 3$ & $1: 100$ & BioLegend \\
\hline \multirow[t]{2}{*}{ CD38 } & Pacific & 90 & $1: 100$ & BioLegend \\
\hline & Blue & & & \\
\hline CD69 & PerCP-Сy5.5 & $\mathrm{H} 1.2 \mathrm{~F} 3$ & $1: 100$ & BD Biosciences \\
\hline CD80 & APC & $16-10 A 1$ & $1: 100$ & BD Biosciences \\
\hline CD80 & PerCP-Cy5.5 & 2D10 & $1: 100$ & BioLegend \\
\hline CD86 & $\mathrm{PE}$ & GL1 & $1: 100$ & BD Biosciences \\
\hline CD95 (FAs) & PE & Jo2 & $1: 100$ & BD Biosciences \\
\hline CD138 & BV-605 & $281-2$ & $1: 100$ & BioLegend \\
\hline Foxp3 & $\mathrm{PE}$ & FJK-16s & $1: 100$ & e-bioscience \\
\hline GL-7 & FITC & GL7 & $1: 100$ & BioLegend \\
\hline IFNГ & APC & XMG1.2 & $1: 100$ & BioLegend \\
\hline $\operatorname{lgM}$ & FITC & RMM-1 & $1: 100$ & BioLegend \\
\hline $\operatorname{lgD}$ & $\mathrm{PE}$ & $11-26 c .2 a$ & $1: 100$ & BD Biosciences \\
\hline IL-17 & $\mathrm{PE}$ & TC11-18H10 & $1: 100$ & BD Biosciences \\
\hline MHC-II & Pacific Blue & AF6-120.1 & $1: 100$ & BioLegend \\
\hline
\end{tabular}




\begin{tabular}{|c|c|c|c|c|}
\hline MHC-II & $\mathrm{PE}$ & AF6-120.1 & $1: 100$ & BD Biosciences \\
\hline
\end{tabular}

Table 6: Monoclonal antibodies for antigen-independent activation of $\mathrm{T}$ cells in vitro

\begin{tabular}{lll}
\hline SPECIFITY & CLONE & SOURCE OF SUPPLY \\
\hline LEAF $^{\mathrm{TM}}$ purified anti-mouse CD3 & $145-2$ C11 & BioLegend \\
LEAF $^{\mathrm{TM}}$ purified anti-mouse CD28 & 37.51 & BioLegend \\
\hline
\end{tabular}

Table 7: Primary antibodies for immunhistochemical staining

\begin{tabular}{|c|c|c|c|c|}
\hline SPECIFICITY & SPECIES/CLONE & $\begin{array}{l}\text { ANTIGEN } \\
\text { RETRIEVAL/FIXATION }\end{array}$ & DILUTION & $\begin{array}{l}\text { SOURCE } \\
\text { SUPPLY }\end{array}$ \\
\hline APP & mouse/MAB348 & $\begin{array}{l}\text { microwave, citric acid } \\
\text { buffer }\end{array}$ & $1: 2000$ & Merck Millipore \\
\hline B220 & rat & $\begin{array}{l}\text { microwave, citric acid } \\
\text { buffer }\end{array}$ & $1: 200$ & BD Pharmingen \\
\hline Casp3 & rabbit/C92-605 & Microwave, Tris-EDTA & $1: 150$ & BD Biosciences \\
\hline CD3 & rat/ CD3-12 & $\begin{array}{l}\text { microwave, citric acid } \\
\text { buffer }\end{array}$ & $1: 200$ & Biorad \\
\hline CNPase & Mouse/SMI-91R & $\begin{array}{l}\text { microwave, citric acid } \\
\text { buffer }\end{array}$ & $1: 200$ & Covance \\
\hline GFAP & mouse & $\begin{array}{l}\text { microwave, citric acid } \\
\text { buffer }\end{array}$ & $1: 300$ & Synaptic Systems \\
\hline GFAP & rabbit & none & $1: 1000$ & DAKO \\
\hline MAC3 & Rat/ M3/84 & $\begin{array}{l}\text { microwave, citric acid } \\
\text { buffer }\end{array}$ & $1: 200$ & BD Pharmingen \\
\hline MBP & rabbit/62301 & none & $1: 1000$ & DAKO \\
\hline NogoA & rabbit & microwave, Tris-EDTA & $1: 50$ & Santa Cruz \\
\hline
\end{tabular}




\begin{tabular}{lllll}
\hline Olig2 & rabbit & microwave, Tris-EDTA & $1: 300$ & IBL \\
PLP & mouse & microwave, citric acid & $1: 500$ & Biozol \\
& & & \\
& buffer & & \\
\hline
\end{tabular}

Table 8: Secondary antibodies for immunohistochemical staining

\begin{tabular}{lll}
\hline SECONDARY ANTIBODY & DILUTION & MANUFACTURER \\
\hline Anti-mouse IgG, biotinylated & $1: 200$ & GE Healthcare Europe GmbH, Germany \\
Anti-rabbit IgG, biotinylated & $1: 200$ & GE Healthcare Europe GmbH, Germany \\
Anti-rat IgG, biotinylated & $1: 200$ & GE Healthcare Europe GmbH, Germany \\
\hline
\end{tabular}

Table 9: Applied Kits

\begin{tabular}{ll}
\hline KIT & SOURCE OF SUPPLY \\
\hline CD4 ${ }^{+}$T cell isolation kit II, mouse & Miltenyi Biotec, Germany \\
Cell lineage panel kit, mouse & Miltenyi Biotec, Germany \\
Dylight 405 Antibody labeling Kit & Thermo Fisher Scientific, USA \\
\hline
\end{tabular}

\subsubsection{Oligonucleotide primers}

Table 10: Primers

\begin{tabular}{lll}
\hline NAME & SEQUENCE & SOURCE OF SUPPLY \\
\hline Ja18-2D2 & $\begin{array}{l}\text { 5'-CCC GGG CAA GGC TCA GCC } \\
\text { ATG CTC CTG-3' }\end{array}$ & $\begin{array}{l}\text { Eurofins Scientific, } \\
\text { Germany }\end{array}$ \\
Va3-2-2D2-M & 5'-GCG GCC GCA ATT CCC AGA & $\begin{array}{l}\text { Eurofins Scientific, } \\
\text { GAC ATC CCT CC-3' }\end{array}$ \\
\hline
\end{tabular}




\subsubsection{Consumables}

Table 11: Consumables

\begin{tabular}{|c|c|}
\hline REAGENT & SOURCE OF SUPPLY \\
\hline Bottle Top Filter, $0.2 \mu \mathrm{m}$ & Sarstedt, Germany \\
\hline Cell Culture Plates, Flat Bottom (6 Well, 24 & Greiner bio-one, Austria \\
\hline \multicolumn{2}{|l|}{ Well, 96 Well) } \\
\hline Cell Strainer $(70 \mu \mathrm{m})$ & Greiner bio-one, Austria \\
\hline FACS Tube, $5 \mathrm{ml}$ & Sarstedt, Germany \\
\hline LS Columns & Miltenyi Biotec, Germany \\
\hline Needles & BD Biosciences, USA \\
\hline Nunc $^{\mathrm{TM}}$ Maxisorp ${ }^{\circledR} 96$ Well ELISA Plate & Thermo Scientific, USA \\
\hline 96 Well Plate Round & Sarstedt, Germany \\
\hline Pre-Separation Filters, $30 \mu \mathrm{m}$ & Miltenyi Biotec, Germany \\
\hline Syringes & BD Biosciences, USA \\
\hline Serum Microtubes & Sarstedt, Germany \\
\hline Tubes $(50 \mathrm{ml}, 15 \mathrm{ml}, 10 \mathrm{ml}, 2 \mathrm{ml}, 1,5 \mathrm{ml}$, & Sarstedt, Germany \\
\hline $0.2 \mathrm{ml})$ & \\
\hline
\end{tabular}




\subsubsection{Technical devices}

Table 12: Technical devices

\begin{tabular}{|c|c|}
\hline DEVICE & SOURCE OF SUPPLY \\
\hline $\begin{array}{l}\text { Bx51 Olympus light microscope equipped } \\
\text { with DP71 digital and XM10 monochrome } \\
\text { camera }\end{array}$ & Olympus, Germany \\
\hline Centrifuge 5415 R & Eppendorf, Germany \\
\hline Centrifuge $5810 \mathrm{R}$ & Eppendorf, Germany \\
\hline FACS LSR II & BD Biosciences, USA \\
\hline GentleMACS ${ }^{\text {тм }}$ Dissociator & Miltenyi Biotec, Germany \\
\hline Cell Incubator BBD6220 & Thermo Scientific, USA \\
\hline IMARK ${ }^{\mathrm{TM}}$ Microplate Reader & Bio-Rad, Germany \\
\hline Microscope & Olympus \\
\hline Microtome & Leica, Germany \\
\hline Microwave & Bosch, Germany \\
\hline Neubauer Chamber & Superior Marienfeld, Germany \\
\hline QuadroMACS ${ }^{\mathrm{TM}}$ Separator & Miltenyi Biotec, Germany \\
\hline T3 Thermocycler & Biometra, Germany \\
\hline TP 1020 (Tissue Processor) & Leica, Germany \\
\hline
\end{tabular}

\subsubsection{Software}

Table 13: Software

\begin{tabular}{lll}
\hline SOFTWARE & APPLICATION & SOURCE OF SUPPLY \\
\hline BD biosciences FACSDiva software & Data acquisition flow & BD Biosciences, USA \\
6.1 .2 & cytometry & \\
FlowJo 10.1 & Data analysis flow & Tree Star Inc., USA \\
& cytometry & \\
\hline
\end{tabular}




\begin{tabular}{lll}
\hline GraphpadPrism 6 & Statistical analysis & GraphPad software Inc., USA \\
& Graphs & \\
ImageJ 1.47d & Data analysis histology & $\begin{array}{l}\text { National Institutes of Health, } \\
\text { USA }\end{array}$ \\
PSremote 1.6.5 & Gel documentation & Breeze systems limited, UK \\
\hline
\end{tabular}

\subsection{Patients}

Blood samples were obtained from non-treated and DMF-treated MS patients. MS patients receiving DMF were treated for at least six months.

Table 14: Clinical characteristics of MS patients

Non-treated DMF-treated

\begin{tabular}{lll}
\hline Age (years) & $36 \pm 10$ & $36 \pm 14$ \\
\hline Sex & 4 female, 2 male & 5 female, 1 male \\
\hline Disease duration (years) & $7 \pm 6$ & $5 \pm 5$ \\
\hline Therapy duration (month) & - & $6.5 \pm 1$ \\
\hline EDSS & $1.3 \pm 0.4$ & $0.8 \pm 1.0$ \\
\hline
\end{tabular}




\subsection{Animals}

\section{C57BI/6 mice}

8-12 week old female C57BL/6J mice were obtained from Charles River laboratories, Germany. Each experimental group contained 5-8 mice and each experiment was performed at least twice. All experiments were approved by the Lower Saxony authorities for animal experimentation.

\section{$\underline{2 D 2 \text { mice }}$}

2D2 animals were generated and characterized by Bettelli and colleagues in $2003.90-95 \%$ of the CD4+ T cells in 2D2 mice express the MOG35-55-specific T cell receptor V $\alpha 3.2$ / Vß11 (Bettelli et al., 2003). 2D2 CD4+ T cells were used as reporter cells in several proliferation assays.

\section{$\underline{\text { Nrf2 k.o. mice }}$}

A homozygous Nrf2 k.o. breeding pair was obtained from Jackson laboratory. Nrf2 k.o. animals were generated in 1996 by Chan and colleagues (Chan et al., 1996). In Nrf2 k.o. mice the genetic function of the transcription factor Nrf2 is abolished. 9-10 week old Nrf2 k.o. mice were cuprizone fed and used for further experiments.

\section{Breeding}

All transgenic mice were bred in the central animal facility of the University Medical Center Goettingen.

\section{Housing}

The mice were held under conventionally and specific pathogen free (SPF) conditions, they had access to food and water ad libitum and a 12h/12h light/dark cycle. Mice were allowed to adapt to the new environment for seven days before each experiment.

\subsection{Methods}

\subsubsection{Genotyping}

For the genotyping of 2D2 mice, tissue was obtained via a tail biopsy. After DNA extraction, transgenes were amplified with specific primers and separated by agarose gel electrophoresis as described below. All genotyping was performed by Ms. Katja Grondey, Mr. Jan Einar Albin and Mr. Julian Koch (Department of Neuropathology, University Medical Center Germany). 


\section{$\underline{\text { DNA extraction }}$}

DNA was isolated from tail biopsies of 2D2 mice. The tissue was digested in $100 \mu$ lysis buffer at $99^{\circ} \mathrm{C}$ for $30 \mathrm{~min}$. Afterwards $100 \mu \mathrm{l}$ neutralization buffer was added.

\section{$\underline{\mathrm{PCR} \text { reaction }}$}

Each reaction sample contained $1 \mu$ genomic DNA, $10 \mu$ l Dream Taq ${ }^{\circledR}$ PCR Mix $2 x, 1 \mu$ of each primer and $7 \mu$ l water (nuclease free).

Primer 1: 5'-CCC GGG CAA GGC TCA GCC ATG CTC CTG-3'

Primer 2: 5'-GCG GCC GCA ATT CCC AGA GAC ATC CCT CC-3'

\section{$\underline{\text { PCR conditions }}$}

- Initial denaturation: $94^{\circ} \mathrm{C}, 2 \mathrm{~min}$

- 35 cycles: $\quad$ Denaturation: $\quad 94^{\circ} \mathrm{C}, 1 \mathrm{~min}$

Annealing: $\quad 58^{\circ} \mathrm{C}, 1 \mathrm{~min}$

Extension: $\quad 72^{\circ} \mathrm{C}, 1 \mathrm{~min}$

- $\quad$ Final extension: $\quad 72^{\circ} \mathrm{C}, 10 \mathrm{~min}$

\section{Agarose gel electrophoresis}

For the analysis of PCR products, $5 \mu$ l of the sample were loaded on an agarose gel $(2 \%(w / v)$ in TAE buffer) containing $3 \mu$ lethidium bromide/GelRed. Electrophoresis was performed in a Sub-Cell GT Agarose Gel Electrophoresis System at $120 \mathrm{~V}$ for $45 \mathrm{~min}$. Evaluation of PCR products was done by visualization and documentation by UV-light in a gel-documentation device.

\subsubsection{Cuprizone treatment}

Mice received cuprizone at a $0.25 \%$ dosage ad libitum. Therefore $2.5 \mathrm{~g}$ cuprizone were mixed with $1000 \mathrm{~g}$ ground mouse chow. Mice were treated for one week or two weeks with cuprizone to analyze the apoptosis of oligodendrocytes and for six weeks to investigate the demyelination of the corpus callosum (CC). Body weights of the animals were measured weekly and transformed into percentage of initial weight. Therefore the mean of the initial body weights of each group was set to a hundred percent. 
To investigate the effects on remyelination, mice were fed with cuprizone for 5 weeks, then the cuprizone diet was stopped and mice were treated with either DMF or control for one week or three days.

\subsubsection{EAE induction}

Mice were subcutaneously injected with $100 \mu \mathrm{g}$ recombinant mouse MOG protein 1-117 $_{\text {emulsified }}$ in complete Freund's adjuvant. Directly and $48 \mathrm{~h}$ after immunization mice were intraperitoneally injected with 200 ng Pertussis toxin. Mice were scored daily according to a 0-5 scale score as described by (Weber et al., 2010). The rMOG ${ }_{1-117}$ was provided by the group of Claude C. Bernard (Monash University, Australia).

\subsubsection{DMF treatment}

Dimethyl fumarate (BG12) was synthesized at Biogen Idec. The compound was dissolved in a $0.8 \%$ hydroxypropyl methylcellulose solution (HPMC). The solution was stored at $8^{\circ} \mathrm{C}$ and used within a week. Cuprizone mice were treated twice daily with $15 \mathrm{mg} / \mathrm{kg}$ DMF or once daily with $100 \mathrm{mg} / \mathrm{kg}$ DMF. DMF was administered via oral gavage at a volume of $10 \mu \mathrm{l} / \mathrm{g}$ body weight. Control animals received $0.8 \% \mathrm{HPMC}$ solution (control) as sham treatment.

EAE mice were treated twice daily with $15 \mathrm{mg} / \mathrm{kg}$ DMF or control. Preventive treatment started two days prior to immunization. When mice were treated therapeutically, treatment started when mice showed an EAE score of two or higher. For clinical analysis mice were treated until day 50 or 60 post immunization, for immunological analysis animals were treated until day 12 p.i.

\subsubsection{Extraction of mouse plasma}

Mice received $0.25 \%$ cuprizone and DMF or control for one week or for six weeks. To measure MMF levels, mice were sacrificed at the end of the experiment and blood samples were collected in a tube containing $4 \mu \mathrm{l} \mathrm{NaF}$ solution $\left(250 \mathrm{mg} / \mathrm{ml}\right.$ in $\left.\mathrm{dH}_{2} \mathrm{O}\right)$. Samples were centrifuged latest $10 \mathrm{~min}$ after collection. The plasma was stored at $-80^{\circ} \mathrm{C}$ and later analyzed by mass spectrometry.

To measure the level of anti-MOG antibodies of mice during EAE, blood was collected from the facial vein into sera tubes and centrifuged at room temperature for $5 \mathrm{~min}$ at $10.0000 \mathrm{rpm}$. The plasma samples were stored at $-20^{\circ} \mathrm{C}$. 


\subsubsection{Analysis of monomethyl fumarate (MMF) in plasma and brain}

MMF measurements were performed by the lab of Rob Scannevin (Biogen, Cambridge, USA). Therefore, $25 \mu \mathrm{L}$ of either plasma or tissue homogenate samples were extracted by protein precipitation with acetonitrile containing 4C13-MMF as the internal standard. The aliquots of homogenization solution (plasma with $12.5 \mathrm{mg} / \mathrm{mL}$ of $\mathrm{NaF}$ ) were added to the tissue samples. The tissue samples were homogenized at $6.5 \mathrm{~m} / \mathrm{s}$ for $60 \mathrm{~s}$ on a Fast Prep Tissue Homogenizer prior to protein precipitation. The concentrations of MMF in plasma and brain samples were determined using qualified LC-MS/MS assays in the respective matrices. Data collections and integrations were accomplished using an API 5500 triple quadrupole mass spectrometer with a turbo ion spray interface ( $A B$ Sciex, Foster City, $C A$ ), and Analyst software (version 1.6.1). The peak area ratios of MMF relative to its internal standard were used to construct a standard curve using a quadratic regression with a $1 / x 2$ weighting.

\subsubsection{Detection of anti-MOG antibodies}

For the measurement of anti-MOG Ab levels, a 96 well plate was coated with $\mathrm{rMOG}_{1-117}$ diluted 1:200 (stock $2 \mathrm{mg} / \mathrm{ml}$ ) over night at $4^{\circ} \mathrm{C}$. The next day the plate was washed $3 x$ with wash buffer and blocked with $200 \mu \mathrm{l} /{ }^{\circ} \mathrm{RD} 1$ buffer for $1 \mathrm{~h}$ at RT shaking on a shaker plate (500 rpm). During this incubation time mouse plasma samples were diluted 1:40,500. Afterwards plates were washed $3 x$ with wash buffer and $100 \mu \mathrm{l}$ sample per well were added and incubated for $1.5 \mathrm{~h}$ at RT shaking on a shaker plate. Plates were washed $3 x$ with wash buffer and $100 \mu$ l of a mixture including detection Ab (IgG mouse $2 \mathrm{mg} / \mathrm{ml}$, diluted 1:6000 in RD1) und Streptavidin (diluted 1:40 in RD1) were added into each well and incubated for $1 \mathrm{~h}$ at RT in the dark. Plates were washed $4 \mathrm{x}$ with wash buffer and $100 \mu$ of TMB solution were added and incubated until wells turned blue (15-20 min). $4 x$ wachen. The reaction was stopped with ELISA stop buffer. The OD was determined at 450 $\mathrm{nm}$ with $540 \mathrm{~nm}$ wavelength correction using the iMark $^{\mathrm{TM}}$ microplate reader.

\subsubsection{Analysis of immune cells ex vivo}

For the immunological readout, spleen and inguinal lymph nodes were isolated from control- or DMF-treated animals. After preparing a single cell suspension, immune cells were investigated ex vivo via flow cytometry. 


\subsubsection{Preparation of single cell suspensions}

Single cell suspensions were prepared from spleen and lymph node for further investigation. Therefore, cells were disrupted by mechanical force through a sterile $70 \mu \mathrm{m}$ cell strainer. After two washing steps, splenocytes and lymphocytes were further processed dependent on the following experiment. Centrifugation steps with tubes were performed for $10 \mathrm{~min}$ at $300 \mathrm{xg}$ and $4^{\circ} \mathrm{C}$ and with plates for $8 \mathrm{~min}$ at $300 \times \mathrm{g}$ and $4^{\circ} \mathrm{C}$. Cells were washed with PBS, FACS or MACS buffer depending on the further analysis. For a direct flow cytometric analysis of B and T cells, splenocytes and lymphocytes were washed with FACS buffer and transferred to a 96 well plate. For further isolation of $B$ cells and $T$ cells by magnetic-activated cell sorting (MACS), splenocytes were washed twice with $20 \mathrm{ml}$ of MACS buffer. Cell numbers were determined prior to further analyses (see 2.4.7.4).

\subsubsection{Preparation of peripheral blood leukocytes from mice}

For analysis of the cell distribution in the blood under DMF treatment, blood samples were obtained by puncture of the facial vein. Several drops of blood were diluted in $300 \mu$ PBS containing $1 \mathrm{mM}$ EDTA and were transferred to a $5 \mathrm{ml} \mathrm{FACS} \mathrm{tube.} 1 \mathrm{ml}$ of FACS buffer was added and the tubes were centrifuged. Erythrocytes were lysed by resuspending the pellet in $1 \mathrm{ml}$ of BD Biosciences Pharm lyse ${ }^{\mathrm{TM}}$ solution (pre-diluted 1:10 in bidistilled water). Lysis was performed for $3 \mathrm{~min}$ at RT and stopped by adding $3 \mathrm{ml}$ of FACS buffer. FACS tubes with peripheral blood cells were centrifuged for $8 \mathrm{~min}$ at $300 \times \mathrm{g}$ at $4^{\circ} \mathrm{C}$ and the pellets were resuspended in $200 \mu \mathrm{FACS}$ buffer and transferred to a 96 well plate.

\subsubsection{Preparation of human peripheral blood mononuclear cells (PBMCs)}

To investigate the B cell frequency and activation under DMF treatment, blood samples were obtained from non-treated and DMF-treated MS patients. Afterwards, the collected blood was transferred into a $50 \mathrm{ml}$ tube and 1:1 diluted with PBS. The blood/PBS mixture was carefully layered over $15 \mathrm{ml}$ of Biocoll solution in a $50 \mathrm{ml}$ tube and samples were centrifuged at $400 \times \mathrm{g}$ and $20^{\circ} \mathrm{C}$ for $35 \mathrm{~min}$ without acceleration and brake. The mononuclear cell layer is gathered at the interphase and was carefully removed with a $10 \mathrm{ml}$ volumetric pipette in a new $50 \mathrm{ml}$ tube. Then $50 \mathrm{ml} \mathrm{RPMI} l_{\text {complete }}$ were added and samples were centrifuged for $10 \mathrm{~min}$ at $300 \times \mathrm{g}$ and $4^{\circ} \mathrm{C}$. 
Afterwards this washing step was repeated twice. Cell were counted in the Neubauer chamber and stored at $-80^{\circ} \mathrm{C}$ in cryo medium.

\subsubsection{Cell counting}

For the determination of cell numbers, a Neubauer chamber was used. The cell suspension was diluted 1:10 in trypan blue (pre-diluted 1:10 in PBS) prior to counting to exclude dead cells. Four squares with a surface of $1 \mathrm{~mm}^{2}$ and a volume $0.1 \mu \mathrm{l}$ each were counted for every sample. The concentration of cells in the original sample was calculated by the following formula:

Cells counted $/ 4 * 10 * 10^{4}=$ cells $/ \mathrm{ml}$

The total cell number was extrapolated to the sample volume.

\subsubsection{Flow cytometry}

The effects of DMF on different cell populations of the immune system were analyzed by flow cytometry. Single cell suspensions were stained with different combinations of fluorochromelabeled antibodies and cell populations were analyzed using a FACS LSR II and the BD FACSDiva Software 6.1.2. The staining procedure was always performed in 96 well round bottom plates, plates were centrifuged for $8 \mathrm{~min}$ at $300 \times \mathrm{g}$ and $4^{\circ} \mathrm{C}$ and cells were washed with $200 \mu \mathrm{FACS}$ buffer.

\subsubsection{FACS staining procedure of splenocytes, lymphocytes and peripheral blood leucocytes}

Isolated cells were centrifuged and washed with FACS buffer. Cells were resuspended in $30 \mu$ l blocking buffer, consisting of anti-CD16/CD32 antibody diluted 1:100 in FACS buffer, and incubated for $10 \mathrm{~min}$ at $4^{\circ} \mathrm{C}$. The fluorochrome-labeled antibodies per staining were diluted 1:50 in FACS buffer and $30 \mu \mathrm{l}$ of this master mix was added to each well (final dilution 1:100). The samples were incubated for $15 \mathrm{~min}$ at $4^{\circ} \mathrm{C}$ in the dark. Following incubation, the wells were filled with $150 \mu \mathrm{I}$ FACS buffer and plates were centrifuged. Cells were washed and resuspended in a mixture of $100 \mu \mathrm{l}$ FACS buffer and $100 \mu \mathrm{l}$ 4\% PFA and incubated for $30 \mathrm{~min}$. The fixed cells were then washed, resuspended in $200 \mu \mathrm{I}$ FACS buffer and transferred to a $5 \mathrm{ml}$ FACS tube. Fixed cells were analyzed by flow cytometry.

Thawed human PBMCs were counted in a Neubauer chamber and $1 \times 10^{6}$ cells were transferred to a $5 \mathrm{ml}$ tube. The samples were washed twice with FACS buffer and afterwards stained with $50 \mu \mathrm{l}$ of 
a master mix containing fluorochrome-labeled antibodies (diluted 1:100 in FACS buffer). The samples were incubated for $15 \mathrm{~min}$ at $4^{\circ} \mathrm{C}$ in the dark and afterwards the samples were washed twice with $1 \mathrm{ml}$ of FACS buffer. Finally cells were resuspended in $200 \mu \mathrm{l}$ FACS buffer and analyzed by flow cytometry.

\subsubsection{Intracellular detection of Foxp3}

For the intracellular detection of Foxp3, splenocytes and lymphocytes were isolated as described above. Afterwards surface molecules were stained with the usual FACS staining procedure. But instead of the fixation step with PFA, cells were fixed in $100 \mu$ Foxp3 fixation concentrate diluted 1:3 in dilution buffer overnight at $4^{\circ} \mathrm{C}$. The next day, $100 \mu \mathrm{l} \mathrm{Perm} / \mathrm{Wash}^{\mathrm{Tm}}$ buffer were added to each sample and plates were centrifuged. Afterwards the samples were washed two times with $100 \mu \mathrm{l} \mathrm{Perm} /$ Wash $^{\text {TM }}$ buffer. The anti-Foxp3 antibody was diluted 1:100 in permeabilization buffer (prediluted 1:10 in bidistilled water) and $50 \mu$ of the staining solution was added to each sample. Cells were incubated for $1 \mathrm{~h}$ at $4^{\circ} \mathrm{C}$ in the dark. After incubation, samples were washed two times with $100 \mu \mathrm{l}$ of Perm/Wash ${ }^{\mathrm{TM}}$ buffer and once with FACS buffer. Finally, cells were resuspended in $150 \mu \mathrm{I}$ FACS buffer and transferred to FACS tubes. Samples were analyzed by flow cytometry.

\subsubsection{Intracellular detection of cytokines}

To investigate the effects of DMF on the frequency of IL-17- and IFNY-producing T cells, splenocytes and lymphocytes were isolated from immunized mice, treated with control or DMF in vivo. 500,000 cells were seeded per well of a 96 well round bottom plate and stimulated with $200 \mu \mathrm{l} \mathrm{RPMI}$ complete supplemented with ionomycin $(0.5 \mu \mathrm{g} / \mathrm{ml})$ and PMA $(0.05 \mu \mathrm{g} / \mathrm{ml})$ for $5 \mathrm{~h}$ at 37 ${ }^{\circ} \mathrm{C}$ and $5 \% \mathrm{CO} 2$. After 3 hours, $100 \mu \mathrm{l}$ supernatant was collected and $1 \mu \mathrm{l} \mathrm{GolgiStop}{ }^{\mathrm{TM}}$ was added to each sample. Afterwards, a surface staining was performed as described above. Cells were fixed in Cytofix/Cytoperm ${ }^{\mathrm{TM}}$ over night at $8^{\circ} \mathrm{C}$. The next day, cells were washed twice with $100 \mu \mathrm{l}$ Perm/Wash ${ }^{\mathrm{TM}}$ buffer (10x) diluted 1:10 in bidistilled water. Anti-IL-17 and anti-IFNy antibodies were diluted 1:50 in Perm/Wash ${ }^{\mathrm{TM}}$ buffer and $50 \mu \mathrm{l}$ of the staining solution was added to each well. Cells were incubated with the staining antibodies for $1 \mathrm{~h}$ at $4^{\circ} \mathrm{C}$ in the dark. Afterwards, the cells were washed twice with $150 \mu$ of Perm/Wash ${ }^{\text {TM }}$ buffer and plates were centrifuged. Cells were washed once with FACS buffer, resuspended in $150 \mu$ l of FACS buffer and analyzed by flow cytometry. 


\subsubsection{Co-culture experiments}

\subsubsection{Purification of $C D 4^{+} T$ cells and $B$ cells}

For co-culture and ex-vivo experiments, $\mathrm{CD}^{+} \mathrm{T}$ cells or $\mathrm{B}$ cells were isolated from spleens of naïve C57BL/6 and 2D2 mice using MACS. Therefore, splenocytes were isolated as described above, but were washed immediately two times with $20 \mathrm{ml}$ of MACS buffer and counted in a Neubauer Chamber. $C D 4^{+} \mathrm{T}$ cells were purified using the $\mathrm{CD} 4^{+} \mathrm{T}$ cell isolation kit II (mouse, BD), B cells were purified using the Lineage panel (mouse, BD). LS columns and the QuadroMACS ${ }^{\mathrm{TM}}$ separator were used for separation of cells following the manufacturer's instructions. After the purification, cells were washed in $\mathrm{RPMI}_{\text {complete }}$ and. The specific cell number was either directly put into culture, CFSE labeled for further experiments (see 2.4.9.3) or co-cultured with B cells.

\subsubsection{2. rMOG binding assay}

To analyze the antigen-binding capacity of control-or DMF-treated B cells, 500,000 purified B cells were transferred into each well and incubated with $20 \mu \mathrm{g} / \mathrm{ml} \mathrm{rMOG}_{1-117}$ labeled with DyLight ${ }^{\mathrm{TM}}$ 405 for $2 \mathrm{~h}$ at $37^{\circ} \mathrm{C}$ and $5 \% \mathrm{CO}_{2}$. The $\mathrm{rMOG}_{1-117}$ was previously labeled with the use of the DyLight ${ }^{\mathrm{TM}}$ 405 Antibody labeling kit following the manufacturer's instructions. The labeling was performed by Ms. Elke Pralle (Department of Neuropathology, Göttingen). After the incubation, B cells were washed with $200 \mu \mathrm{l}$ FACS buffer, afterwards resuspended in $200 \mu \mathrm{FACS}$ buffer and immediately analyzed by flow cytometry.

\subsubsection{Analysis of $\mathrm{T}$ cell proliferation by CFSE dilution}

The effect of DMF-treated B cells on T cell proliferation in vitro was assessed by CFSE-staining of $\mathrm{CD}^{+} \mathrm{T}$ cells and subsequent flow cytometric analysis of CFSE dilution. CFSE can penetrate the intact cell membrane and binds irreversibly to intracellular proteins. Upon proliferation, the cytoplasm is shared between the two daughter cells and therefore the fluorescence intensity of CFSE is halved at each cell division. The CFSE profile of dividing cells can be analyzed by flow cytometry (Parish, 1999). CD4 ${ }^{+} \mathrm{T}$ cells were isolated from the spleen of naïve C57BI/6J or 2D2 mice and purified by MACS separation (see 2.4.9.1). CD4 ${ }^{+} \mathrm{T}$ cells were counted in a Neubauer chamber (see 2.4.7.4) and cells were resuspended in $1 \mathrm{ml}$ PBS. The CFSE stock solution (5 mM) was diluted 1:1,000. Afterwards $200 \mu \mathrm{l}$ of the CFSE solution was mixed with $800 \mu \mathrm{l}$ of the cell suspension. Cells were then incubated for $15 \mathrm{~min}$ at $37^{\circ} \mathrm{C}$ in the dark. The staining reaction was stopped by addition of $20 \mathrm{ml}$ cold $\mathrm{RPMI}_{\text {complete }}$ and cells were centrifuged for $10 \mathrm{~min}$ at $1250 \mathrm{rpm}$ and $4^{\circ} \mathrm{C}$. 
The supernatant was discarded and cells were washed again in $20 \mathrm{ml}$ of RPMI complete. Finally, cells were resuspended in $\mathrm{RPMI}_{\text {complete }}$ and counted in a Neubauer chamber (see 2.4.7.4). The appropriate number of CFSE-labeled $\mathrm{CD}^{+} \mathrm{T}$ cells was then used in cultures for different proliferation experiments. T cell proliferation was analyzed by measuring the CFSE dilution using flow cytometry.

\subsubsection{Co-culture of $B$ cells with $C D 4^{+} T$ cells}

To investigate the effect of DMF on the antigen-presenting function of B cells, co-culture assays were performed. Therefore, mice were immunized with $\mathrm{rMOG}_{1-117}$, treated with $\mathrm{DMF}$ or control until d12 p.i. in vivo and B cells were purified as described above. Splenic T cells were purified (see 2.4.9.1) from 2D2 mice and labeled with CFSE (see 2.4.9.3). 500,000 B cells and 20,000 CFSElabeled T cells were seeded in $200 \mu \mathrm{RPMI}$ complete per well of a 96 well flat bottom plate. The coculture was then stimulated with 0,25 or $50 \mu \mathrm{g} / \mathrm{ml} \mathrm{rMOG}_{1-117}$. Cells were cultured for $72 \mathrm{~h}\left(37^{\circ} \mathrm{C}\right.$, $5 \% \mathrm{CO}_{2}$ ) and stained for $\mathrm{T}$ cell and $\mathrm{B}$ cell markers (see 2.4.8.1). Finally, $\mathrm{T}$ cell proliferation and expression of activation markers was measured by flow cytometry.

\subsubsection{In vitro stimulation of cytokine secretion}

To investigate effects of DMF on the proliferation of T cells ex-vivo, splenocytes were isolated from naïve animals treated with DMF or control for 19 days in vivo. T cells were purified by MACS separation and stained with CFSE as described above. Afterwards 20,000 T cells were transferred to each well of a 96 flat bottom well plate. This plate was previously coated with different concentrations of anti-CD3 and anti-CD28 antibodies over night at $8^{\circ} \mathrm{C}$. T cells were incubated for $72 \mathrm{~h}$ at $37^{\circ} \mathrm{C}$ and $5 \% \mathrm{CO}_{2}$. T cell proliferation was investigated by FACS.

\subsubsection{Detection of cytokines using ELISA}

T cells are potent producers of a variety of cytokines. To analyze the DMF effects on this effector function, cytokine concentrations in the supernatant of stimulated single- and co-cultures were measured by ELISA.

T cells were stimulated as described in 2.4.10 and IFN $Y$ and GM-CSF secretion was analyzed. ELISA was performed using the Mouse IFNY or GM-CSF ELISA MAX ${ }^{\mathrm{TM}}$ standard set. All standards and samples were run as duplicates. The capture antibody was diluted 1:200 in coating buffer and the 96 well plate was coated with $100 \mu \mathrm{l} /$ well over night at $4^{\circ} \mathrm{C}$. 
The next day the plate was washed 3x with wash buffer and blocked with $200 \mu l /$ well RD1 buffer for $1 \mathrm{~h}$ at room temperature shaking on a shaker plate $(500 \mathrm{rpm})$. While the plate was being blocked standard solutions were prepared as described in the manufacturer's instruction. Afterwards plates were washed $3 x$ with wash buffer and $30 \mu \mathrm{l} /$ well samples and standard dilutions were added and incubated over night at $4^{\circ} \mathrm{C}$. The next day plates were washed $3 \mathrm{x}$ with wash buffer and $100 \mu$ l detection antibody (diluted 1:100 in RD1 buffer) were added. The plates were incubated for $2 \mathrm{~h}$ at room temperature with shaking $(500 \mathrm{rpm})$. After incubation plates were washed 3x with wash buffer and $100 \mu$ Avidin-HRP solution was added to each well, plate incubated for $30 \mathrm{~min}$ shaking $(500 \mathrm{rpm})$ in the dark. Thereafter, plates were washed 4 times with wash buffer and $100 \mu \mathrm{IMB}$ substrate solution were added and incubated until wells turned blue in color (20-30 $\mathrm{min})$. The reaction was stopped with ELISA stop buffer. The OD was determined at $450 \mathrm{~nm}$ with $540 \mathrm{~nm}$ wavelength correction using the $\mathrm{iMark}^{\mathrm{TM}}$ microplate reader.

\subsubsection{Histology}

Sample preparation, histochemical and immunohistochemical stainings were performed by Ms. Katja Grondey, Mr. Jan Einar Albin and Ms. Mareike Gloth (Department of Neuropathology, University Medical Center Germany).

\subsubsection{Perfusion, tissue collection and sample preparation}

At the end of the in vivo experiments, mice were injected with a lethal dose of $14 \%$ chloral hydrate solution. After mice were checked for loss of consciousness and protective reflexes, the perfusion was performed by puncturing the left heart ventricle and rinsing the blood system first with PBS followed by a solution of $4 \%$ PFA. Brains, spleen and a part of the liver were collected and stored in $4 \%$ PFA at $8^{\circ} \mathrm{C}$ for 2 days post-fixation. Afterwards the samples were transferred to PBS and stored at $8^{\circ} \mathrm{C}$ for $24 \mathrm{~h}$.

For the cuprizone experiments, brains were sliced in 4 transverse sections. For EAE Experiments, the spinal cord was collected additionally and dissected into 10 to 12 sections.

Before the paraffin embedding, the tissue was washed in water and then gradually dehydrated overnight. This was done by an automated tissue processor which is performing a graded alcohol/xylene/paraffin series. Paraffin blocks were sliced in $1 \mu \mathrm{m}$ thick sections using a sliding microtome, and then mounted on glass slides. 
Prior to the start of the staining procedure, the sections had to be deparaffinized. Therefore the slices were incubated for at least $30 \mathrm{~min}$ at $54{ }^{\circ} \mathrm{C}$ and then rehydrated using the following steps.

$4 \times 10 \min x y l o l$

$1 \times 5$ min isoxylol

2x 5 min 100\% isopropyl alcohol (IPA)

$1 \times 5 \min 90 \%$ isopropyl alcohol (IPA)

$1 \times 5 \min 70 \%$ isopropyl alcohol (IPA)

$1 \times 5 \min 50 \%$ isopropyl alcohol (IPA)

Distilled water

After finishing the staining, the stained tissue sections were dehydrated by performing the described series above in reverse order. This time the incubation time was only 2-3 min to avoid a weakening of the staining. As a final step the stained sections were mounted in DePex medium.

\subsubsection{Histochemical staining}

Hematoxylin and eosin (HE) staining

To obtain a general overview of the tissue, a HE staining was performed. This staining was used to analyze inflammation and apoptosis. Hematoxylin stains basophilic nucleoproteins which results in blue colored cell nuclei. Eosin is binding acidophilic and basic extra- and intracellular proteins and marks thereby the parenchyma red. For the staining, sections were deparaffinized and rehydrated as described above. Slides then were incubated in Mayer's hemalaun for $5 \mathrm{~min}$. Afterwards tissue sections were rinsed with $\mathrm{dH}_{2} \mathrm{O}$. The sections were differentiated by shortly dipping them in $1 \%$ $\mathrm{HCL}$-alcohol (1\% HCl-alcohol in $90 \%$ isopropyl alcohol). The sections were then blued by rinsing them under tap water. For the staining of the parenchyma the slides were incubated in $1 \%$ eosin for $5 \mathrm{~min}$ (1\% eosin in $70 \%$ isopropyl alcohol +10 drops glacial acetic acid). Finally the sections were rinsed with $\mathrm{dH}_{2} \mathrm{O}$, dehydrated and mounted in DePex medium.

$\underline{\text { Luxol Fast Blue/Periodic Acid Schiff (LFB/PAS staining) }}$

LFB/PAS staining was performed to visualize myelin. Myelin is stained deep blue by LFB through the binding to lipoproteins. In contrast, PAS colors demyelinated parenchyma and also grey matter 
in pink. At first, the sections were deparaffinized and rehydrated till the $90 \%$ IPA. Following the $90 \%$ IPA, the slides were put directly into the LFB solution over night at $60^{\circ} \mathrm{C}$. The next day, the slides were washed in 90\% IPA and differentiated by shortly dipping them into $0.05 \%$ lithium carbonate solution followed by a short dip into 70\% IPA and a rinsing step with $\mathrm{dH}_{2} \mathrm{O}$. Then the sections were incubated in 1\% periodic acid for $5 \mathrm{~min}$ and rinsed for $5 \mathrm{~min}$ under flowing tap water. Slides were shortly washed with $\mathrm{dH}_{2} \mathrm{O}$ and afterwards incubated in Schiff's solution for 20 min. Slides were washed under tap water for $5 \mathrm{~min}$ and incubated in Mayer's hemalaun for $2 \mathrm{~min}$. Slides were shortly dipped in $\mathrm{dH}_{2} \mathrm{O}$ and afterwards differentiated in $1 \% \mathrm{HCl}$-alcohol $(1 \% \mathrm{HCl}$ alcohol in $90 \%$ isopropyl). Sections were blued by rinsing under tap water for $10 \mathrm{~min}$. Finally the tissue was dehydrated and mounted in DePex medium.

\section{Bielschowsky silver impregnation}

The Bielschowsky silver staining was used to analyze the axonal density. In this staining the axons appear black and the parenchyma yellow/ brownish. For this staining, the sections were deparaffinized and rehydrated. Slides were washed 3 times in $\mathrm{dH}_{2} \mathrm{O}$ and then incubated for 20 min in a $20 \%$ silver nitrate solution. The slides were washed with $\mathrm{ddH}_{2} \mathrm{O}$ and a $32 \%$ ammonium hydroxide solution was added dropwise to the used silver nitrate solution until the brownish solution becomes clear. The slides were incubated in the cleared silver nitrate/ammonium hydroxide solution for $15 \mathrm{~min}$ in the dark. After incubation, slides were transferred into $\mathrm{ddH}_{2} \mathrm{O}$ containing 3 drops of ammonium hydroxide. 10 drops of a developer solution were added to the silver nitrate/ammonium solution and slides were incubated until the sections showed a deep brown color and transferred into $\mathrm{dH}_{2} \mathrm{O}$. The sections were incubated with a thiosulfate solution for 2 min and subsequently rinsed with tap water. Slides were rehydrated and mounted in DePex.

\subsubsection{Immunohistochemical staining}

For the detection of specific cell markers, immunohistochemical stainings with antibodies were used. The signal visualization was performed with the avidin biotin method. Therefore, the tissue was incubated with specific primary antibodies specific for the antigen of interest. Afterwards a further incubation step followed with a biotin conjugated secondary antibody directed against the primary antibody.

For a detailed list of the antibodies used for mouse tissue see Table 7. 
The visualization of the signal is obtained by the binding of the avidin coupled peroxidase (POX) and the oxidation of DAB by POX in the presence of $\mathrm{H}_{2} \mathrm{O}_{2}$. The fixation of the tissue can influence the binding efficacy of several antibodies. For a better antigen retrieval heat, acid or protease treatments were used.

The immunohistological stainings were performed as follows: At first, the tissue was deparaffinized, rehydrated and rinsed $3 \mathrm{x}$ with $\mathrm{dH}_{2} \mathrm{O}$. For the antigen retrieval with citric acid- or Tris-EDTA buffer, the slides were placed in polystyrene cuvettes. Those cuvettes were filled with $1 \mathrm{mM}$ citric acid buffer $(\mathrm{pH} 6)$ or $1 \mathrm{mM}$ Tris-EDTA buffer $(\mathrm{pH} 9)$ and boiled 5 times in a microwave at $800 \mathrm{~W}$ for $3 \mathrm{~min}$.

The cuvettes were alternately filled with buffer or $\mathrm{dH}_{2} \mathrm{O}$ after each of the boiling steps.

For the antigen retrieval with the proteinase solution the slides were incubated in a $37^{\circ} \mathrm{C}$ warm proteinase solution for 10 min and rinsed two times with $\mathrm{dH}_{2} \mathrm{O}$.

The slides were washed with PBS and incubated with $3 \% \mathrm{H}_{2} \mathrm{O}_{2}$ for 20 min at $4^{\circ} \mathrm{C}$ to block endogenous peroxidase and reduce unspecific signals. Afterwards the slides were rinsed 3 times with PBS. The slides were pre-incubated with 10\% FCS (in PBS) for $20 \mathrm{~min}$ at RT in a humidified chamber to prevent unspecific antibody binding. The slides were then incubated with the primary antibody (diluted in $10 \% \mathrm{FCS} / \mathrm{PBS}$ ) over night at $4{ }^{\circ} \mathrm{C}$ in a humidified chamber. The slides were rinsed 3 times with PBS and incubated with biotin conjugated secondary antibody (diluted in 10\% FCS/PBS) for $1 \mathrm{~h}$ at RT in a humidified chamber. The slides were rinsed with PBS for 3 times and incubated with $0.1 \%$ POX (diluted in 10\% FCS/PBS) for $1 \mathrm{~h}$ at RT in a humidified chamber. Afterwards, the slides were again rinsed with PBS 3 times. For the signal development, the slides were put into $D A B$ solution for several minutes and then rinsed 3 times with PBS. For the detection of mouse CD3 positive cells, the DAB signal was amplified with $2 \%$ copper sulfate in 0.9 $\%$ sodium chloride for $10 \mathrm{~min}$. The slides were washed with $\mathrm{dH}_{2} \mathrm{O}$. The nuclei were counterstained with Meyer's hemalaun solution for $30 \mathrm{sec}$ followed by a short dip (1 s) in $\mathrm{dH}_{2} \mathrm{O}$ and a short wash step in $\mathrm{dH}_{2} \mathrm{O}$. The differentiation was performed by a short dip into $1 \% \mathrm{HCl}$-alcohol $(1 \% \mathrm{HCl}$ alcohol in $90 \%$ isopropyl alcohol). The blueing of the tissue was done by rinsing the slides under tap water for $10 \mathrm{~min}$. The slides were dehydrated and mounted in DePex medium. 


\subsection{Morphometry}

Cuprizone: The number of cells stained with the corresponding antibodies was determined over the whole corpus callosum defined by an ocular morphometric grid at a $400 x$ magnification and shown as cells $/ \mathrm{mm}^{2}$. For the determination of demyelinated areas of the corpus callosum, myelinated as well as demyelinated area of the corpus callosum was measured after LFB/PAS, PLP or MBP staining using ImageJ software. The percentage of demyelinated area was calculated relative to the whole area of the corpus callosum.

EAE: The number of cells stained with the corresponding antibodies was determined in at least 6 spinal cord sections defined by an ocular morphometric grid at a 400x magnification and shown as cells $/ \mathrm{mm}^{2}$. Inflammatory infiltrates were analyzed via a semi quantitative score $(0=$ no inflammation, 1 = slight inflammation, 2 = moderate inflammation, 3 = strong inflammation) after H\&E staining in at least 6 spinal cord sections. To determine the white matter demyelination, myelinated and demyelinated areas were measured in at least 6 spinal cord cross sections after LFB-PAS staining using ImageJ software. The percentage of demyelinated area was calculated relative to the whole white matter area.

\subsection{Data analysis and statistics}

The software BDDiva and FlowJo 10.1 were used to analyze all flow cytometric data.

Statistics were calculated using the software GraphPad Prism 6. Data were tested for normal distribution with the help of the D'Agostino \& Pearson omnibus normality test. To compare two experimental groups, unpaired t-tests were used for parametric data and Mann-Whitney $U$ tests for non-parametric data. For comparison of more than two experimental groups one way ANOVA with Sidak post test was used. Statistical significance was defined as $p<0.05$. Data in text and figures are presented as mean \pm SD and EAE Scores and antibody titer as mean \pm SEM. 


\section{Results}

\subsection{DMF treatment in the cuprizone model}

The oral agent DMF has beneficial effects on the relapse rate and different MRI parameters in RRMS patients (Fox et al., 2012; Gold et al., 2012). Several in vitro studies demonstrated the immunomodulatory effects of DMF and its metabolite MMF on peripheral immune cells like T cells, B cells and dendritic cells (Litjens et al., 2004a; Mrowietz and Asadullah, 2005; Treumer et al., 2003; Zhu and Mrowietz, 2001). Besides its immunomodulatory effects, the question if DMF exerts direct neuroprotective functions is unclear and the mode of action is still not fully understood (Moharregh-Khiabani et al., 2010; Scannevin et al., 2012b). To address the question if DMF has CNS intrinsic neuroprotective effects, independent of the peripheral immune system, the cuprizone model was used.

\subsubsection{DMF effects after short-term cuprizone intoxication}

Initial experiments were performed using two different dosages of DMF, $15 \mathrm{mg} / \mathrm{kg}$ twice daily and $100 \mathrm{mg} / \mathrm{kg}$ once a day (data not shown), to determine the most appropriate treatment dosage in regard to efficacy. Data evaluation revealed that treatment with $15 \mathrm{mg} / \mathrm{kg}$ DMF twice a day was more effective and therefore only this dosage was used in subsequent experiments. The DMF short-term treatment was studied using 9 to 10 week old C57BL/6 mice which were fed with $0.25 \%$ cuprizone and simultaneously treated with control (HPMC) or $15 \mathrm{mg} / \mathrm{kg}$ DMF twice a day for 7 days or 2 weeks. Clinical and histological analyses were performed to assess control- and DMFtreated mice.

\subsubsection{DMF treatment decreased the cuprizone-induced weight loss of C57BL/6 mice}

Mice which are fed with cuprizone show a profound body weight loss during the first two weeks of cuprizone exposure. Furthermore, DMF is known to exert gastrointestinal side effects, like abdominal pain, which may lead to a decreased feed uptake by mice. For these reasons, body weight of control- and DMF-treated mice was evaluated every day of cuprizone treatment. After 4 days of $0.25 \%$ cuprizone treatment, control-treated mice lost significantly more weight compared to DMF-treated mice which persisted till 6 days after cuprizone treatment (Figure 1). The body weight of DMF-treated mice (day 4: $92.7 \% \pm 1.46 \%$, day 5: $92.7 \% \pm 1.2 \%$, day 6: $93.1 \% \pm 1.6 \%$ ) remained significantly higher than the body weight of control-treated animals (day 
4: $87.4 \% \pm 1.2 \%, p<0.05$; day 5: $86.5 \% \pm 1.8 \%, p<0.01$; day $6: 86.4 \% \pm 2.6 \%, p<0.05)$. No further weight loss was detectable at later time points (data not shown).
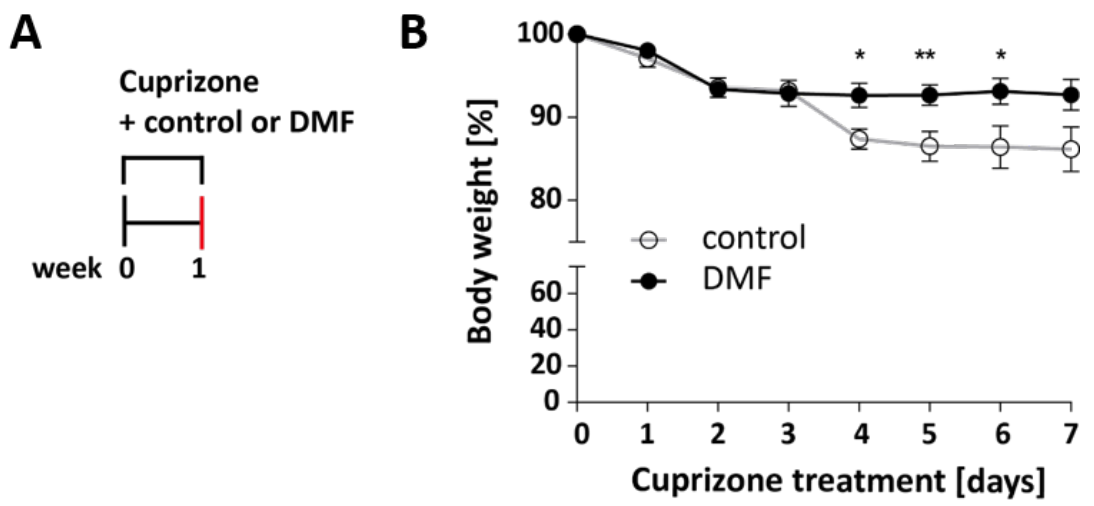

Figure 1: Effect of DMF treatment on cuprizone induced weight loss. (A) Schematic representation of cuprizone and control or DMF treatment. C57BL/6 mice were fed with $0.25 \%$ cuprizone for 1 week and simultaneously treated with control or $15 \mathrm{mg} / \mathrm{kg}$ DMF twice a day. (B) Mice were daily monitored for body weight. DMF treatment significantly reduced the cuprizone-induced weight loss compared to controls. Data are represented as mean \pm SEM $\left(n=12,{ }^{*} p<0.05,{ }^{* *} p<0.01\right.$, unpaired t-test).

\subsubsection{Apoptotic cell death of oligodendrocytes is decreased by DMF treatment}

The apoptosis of oligodendrocytes begins shortly after the initiation of the cuprizone diet. Therefore, histological evaluations were performed after 7 days of cuprizone exposure (Hesse et al., 2010a). The number of apoptotic oligodendrocytes was analyzed after staining for caspase-3 (Casp3), a marker for apoptotic cell death, and by morphological analysis (condensed and/or fragmented nuclei) of H\&E (haematoxilin and eosin) stained sections (Figure 2). DMF treatment significantly decreased the number of apoptotic oligodendrocytes after 7 days of cuprizone exposure compared to control treated animals. The mean number of caspase-3 positive cells in the CC decreased from $106 \pm 31$ cells $/ \mathrm{mm}^{2}$ in controls to $38 \pm 13$ cells $/ \mathrm{mm}^{2}$ in DMF-treated animals $(p<0.0001)$. Furthermore, the number of cells showing morphological signs of apoptosis was also significantly reduced from $87 \pm 25$ cells $/ \mathrm{mm}^{2}$ in control- to $38 \pm 14$ cells $/ \mathrm{mm}^{2}$ in DMF-treated animals $(p<0.0001)$. 


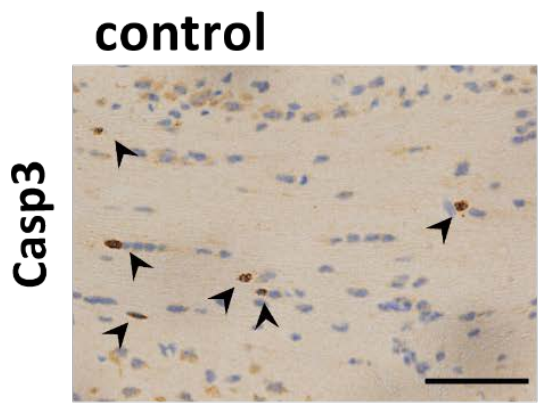

\section{DMF}
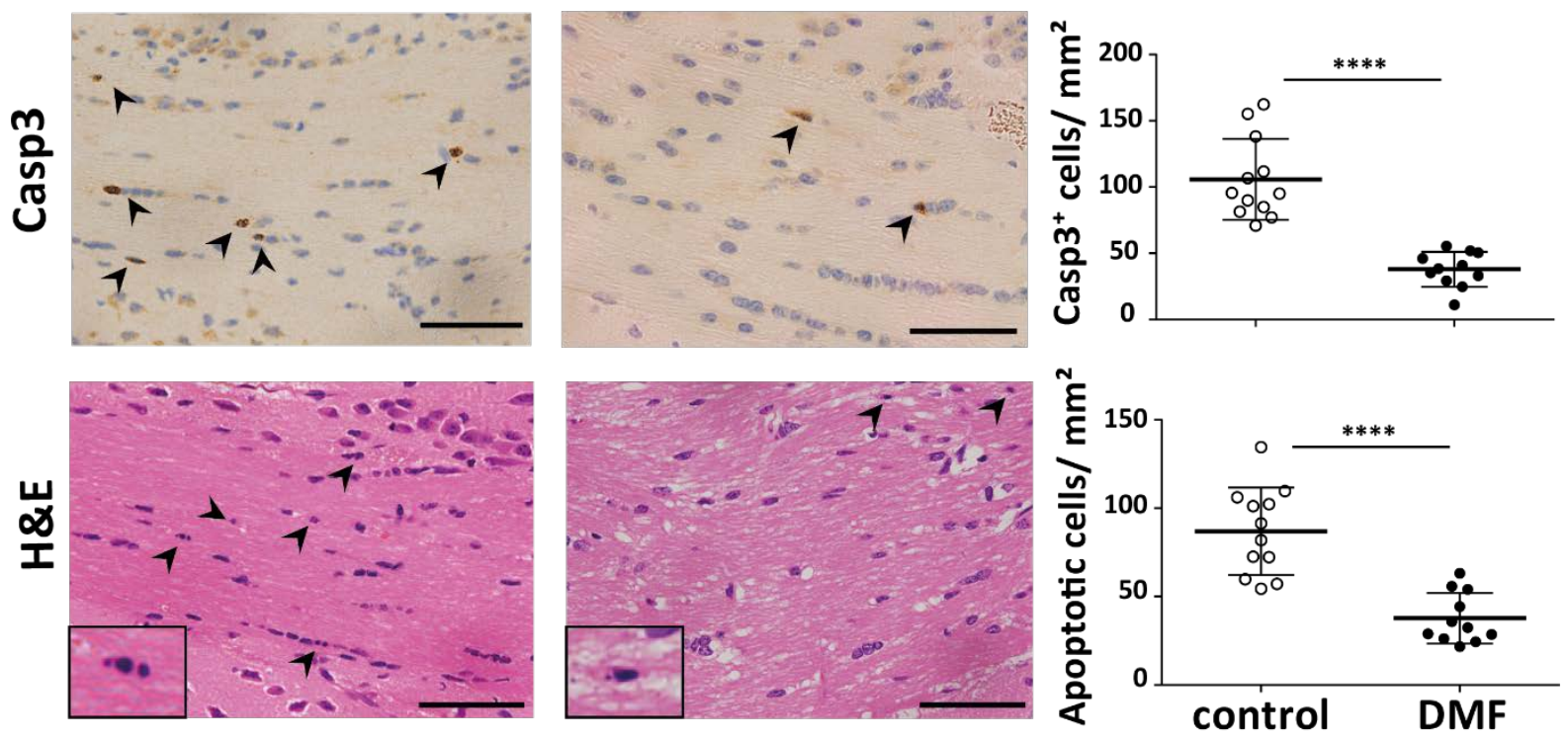

Figure 2: DMF treatment reduces cuprizone-induced apoptosis of oligodendrocytes in the CC. For the analysis of DMF effects on the apoptosis of oligodendrocytes C57BL/6 mice were fed with $0.25 \%$ cuprizone for 1 week and simultaneously treated with control or $15 \mathrm{mg} / \mathrm{kg}$ DMF twice a day. Apoptotic cells in the CC were identified after caspase-3 staining and by morphological criteria in H\&E staining. Representative sections of the CC are shown on the left and quantifications of cells on the right. Histological evaluation revealed that DMF treatment significantly decreases the apoptosis of oligodendrocytes under cuprizone diet. Data are represented as mean $\pm S D$ ( ${ }^{* * *} p<0.0001$, unpaired t-test). Inserts show an apoptotic cell in higher magnification. Scale bar $=50 \mu \mathrm{m}$

\subsubsection{Higher numbers of oligodendrocytes were present with DMF treatment}

Since DMF treatment significantly reduced the apoptosis of oligodendrocytes after 7 days of cuprizone treatment, it was investigated if DMF also influences the oligodendrocyte populations. The total number of oligodendrocytes including progenitor cells was analyzed after IHC staining for Olig2 and the number of mature oligodendrocytes after IHC staining for NogoA (Figure 3). DMFtreated mice showed a significantly higher number of Olig2 ${ }^{+}$cells $\left(235 \pm 35\right.$ cells $\left./ \mathrm{mm}^{2}\right)$ in the CC compared to controls $\left(156 \pm 43\right.$ cells $\left./ \mathrm{mm}^{2}\right) \quad(p<0.001)$. The number of NogoA cells was not significantly altered by application of DMF. 


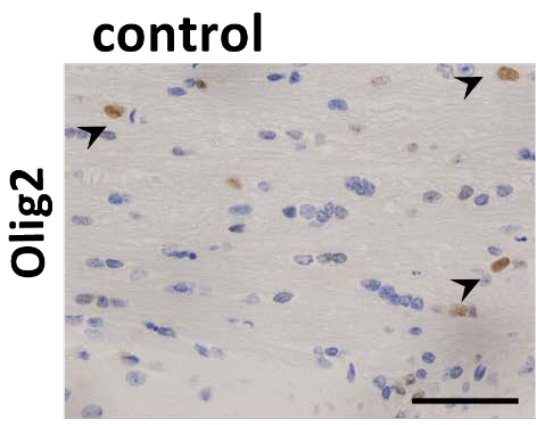

\section{DMF}
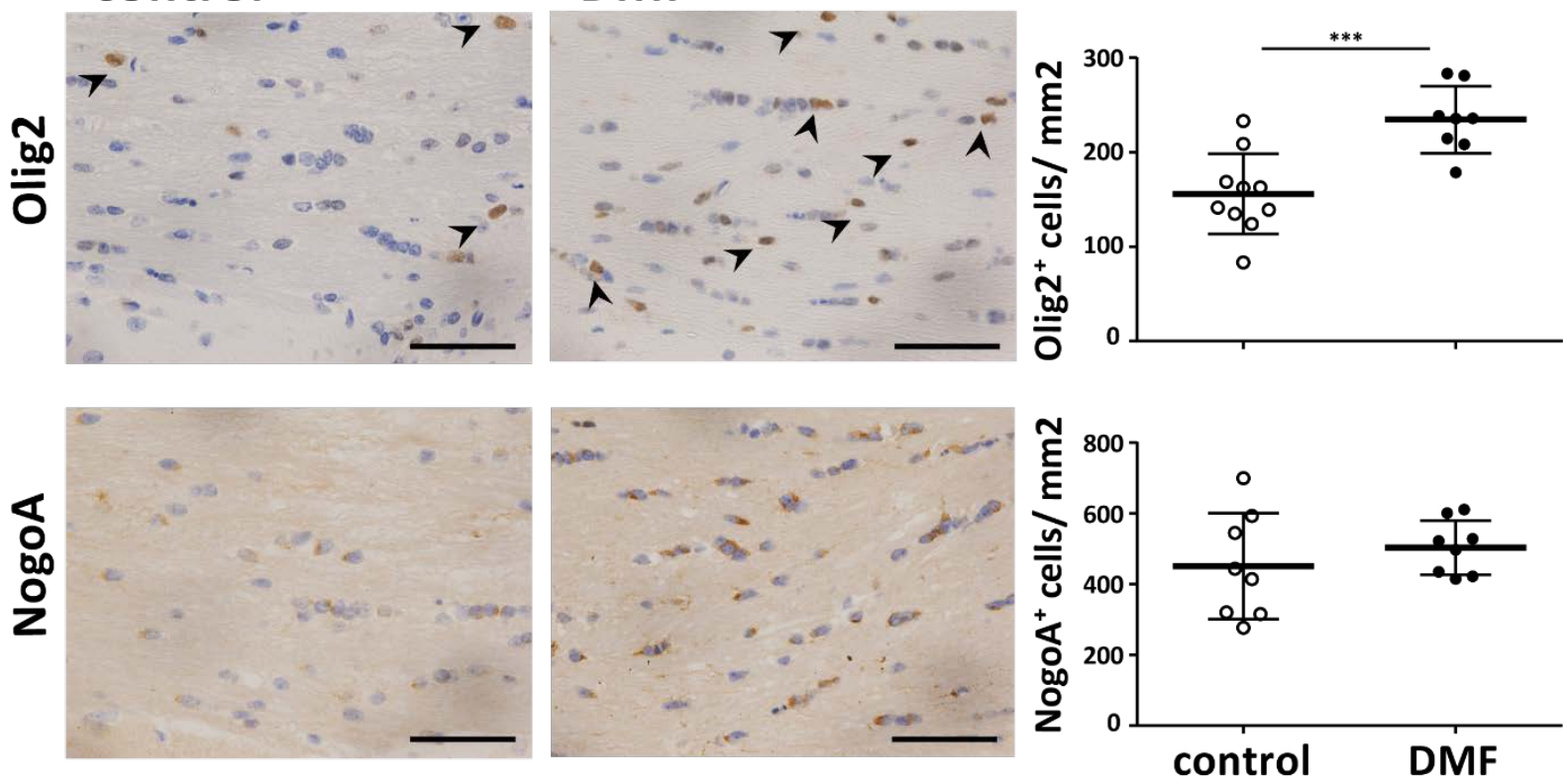

Figure 3: DMF treatment increases number of oligodendrocytes after 7 days of cuprizone exposure. C57BL/6 mice were fed with $0.25 \%$ cuprizone and simultaneously treated with control or $15 \mathrm{mg} / \mathrm{kg} \mathrm{DMF}$ twice a day for 7 days. The number of oligodendrocytes including progenitor cells $\left(\mathrm{Olig}^{+}\right)$and mature oligodendrocytes (NogoA ${ }^{+}$) in the $\mathrm{CC}$ was analyzed after $\mathrm{IHC}$ staining. Representative sections of the $\mathrm{CC}$ are shown on the left and quantifications of cells on the right. The number of Olig2 ${ }^{+}$oligodendrocytes is significantly higher after DMF treatment whereas the number of mature oligodendrocytes is not altered. Data are represented as mean \pm SD ( ${ }^{* *} p<0.01$, unpaired t-test). Scale bar $=50 \mu \mathrm{m}$

\subsubsection{DMF application reduced the acute axonal damage after 7 days of cuprizone exposure}

Brain sections from control- or DMF-treated mice were stained for amyloid precursor protein (APP, a marker for acute axonal damage), reactive astrocytes (GFAP) and microglia/macrophages (Mac3) (Figure 4). After 7 days of cuprizone diet, almost no acute axonal damage, represented by the number of $\mathrm{APP}^{+}$spheroids, was detectable in the CC of DMF-treated mice $\left(0 \pm 0.6 \mathrm{cells} / \mathrm{mm}^{2}\right)$ compared to controls $\left(6 \pm 6\right.$ cells $\left./ \mathrm{mm}^{2}\right)(\mathrm{p}<0.05)$. The number of $\mathrm{GFAP}^{+}$cells and $\mathrm{Mac}^{+}$cells was slightly reduced by DMF treatment, but this effect was not statistically significant when compared to controls. 


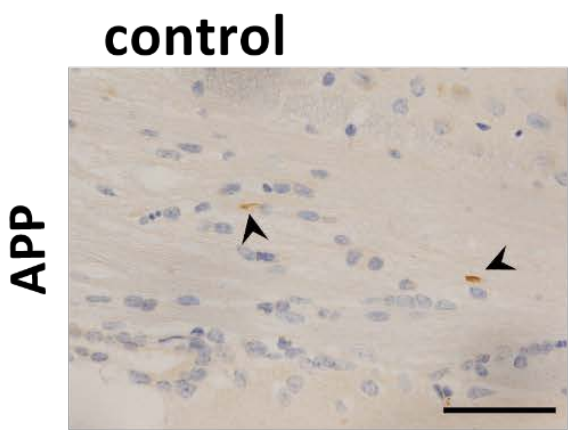

\section{DMF}
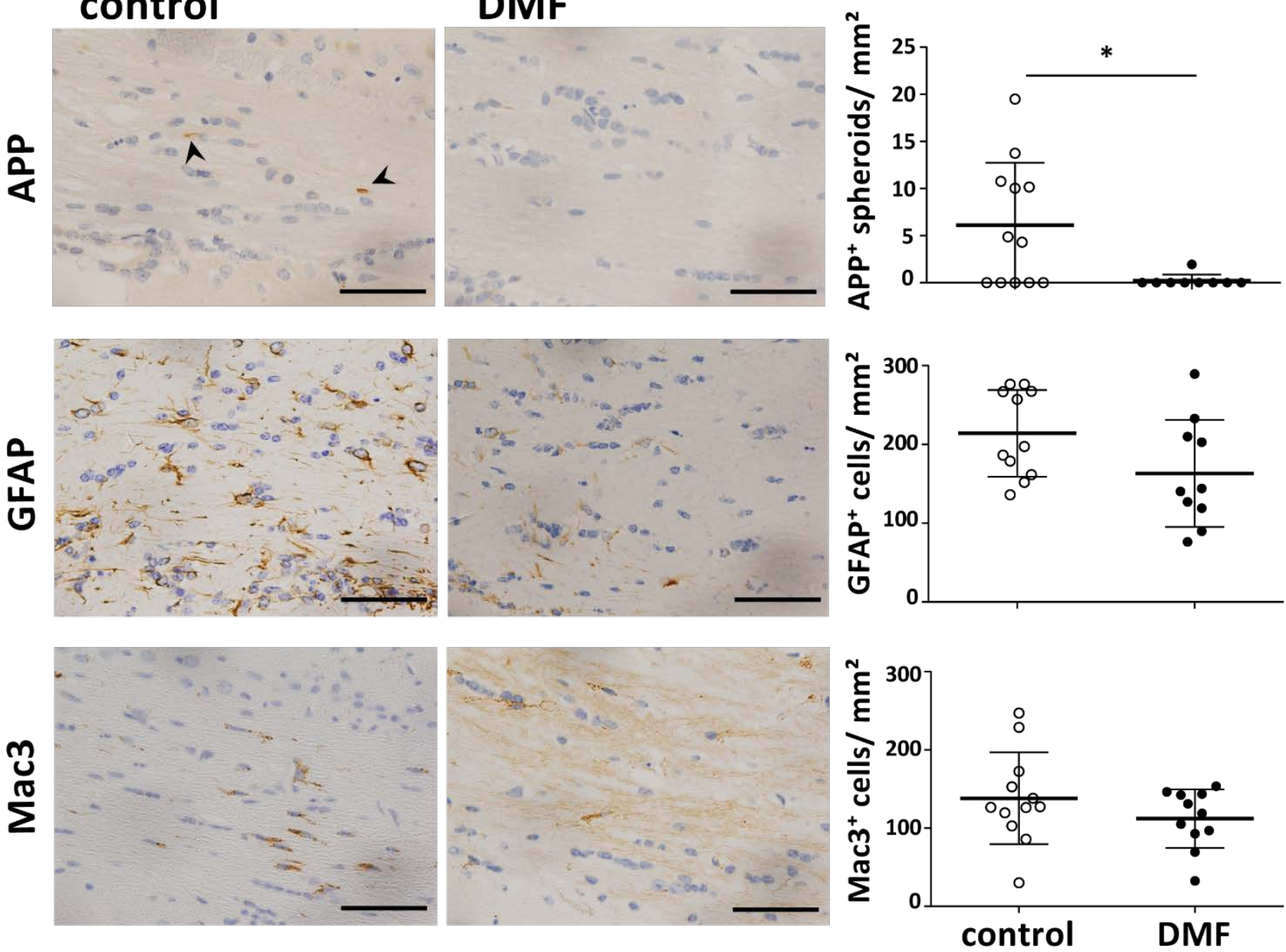

Figure 4: DMF treatment reduces the acute axonal damage induced by cuprizone diet. C57BL/ 6 mice were fed with $0.25 \%$ cuprizone for 7 days and simultaneously treated with control or $15 \mathrm{mg} / \mathrm{kg}$ DMF twice a day. IHC of brain sections was performed to investigate the acute axonal damage (APP), number of reactive astrocytes (GFAP) and number of microglia/macrophages (Mac3) in the CC. Representative sections of the $\mathrm{CC}$ are shown on the left and quantifications of axonal spheroids and cells on the right. DMF treatment significantly reduces cuprizone-induced acute axonal damage compared to controls. The number of reactive astrocytes and microglia/macrophages were not significantly altered by DMF application. Data are represented as mean \pm SD $\left({ }^{*} p<0.05\right.$, Mann-Whitney $U$ test $)$. Scale bar $=50 \mu \mathrm{m}$

\subsubsection{Anti-apoptotic effect of DMF was not detectable after 2 weeks of cuprizone exposure}

The number of apoptotic oligodendrocytes was significantly reduced by DMF application after 7 days of cuprizone diet. To investigate if this effect persists over a longer period of time, C57BL/ 6 mice were fed with $0.25 \%$ cuprizone and simultaneously treated with control or $15 \mathrm{mg} / \mathrm{kg}$ DMF twice a day for 2 weeks. Apoptosis of oligodendrocytes was morphologically analyzed in H\&E staining and the number of mature oligodendrocytes was evaluated after NogoA staining 
(Figure 5). DMF treatment slightly diminished the number of apoptotic cells after 2 weeks of cuprizone diet, but this effect was not statistically significant. The number of mature oligodendrocytes was comparable between control- and DMF-treated mice. In addition, DMFtreated mice showed a higher number of Olig2 ${ }^{+}$cells, but in contrast to the results received after 7 days of cuprizone exposure this effect was not statistically significant (data not shown).
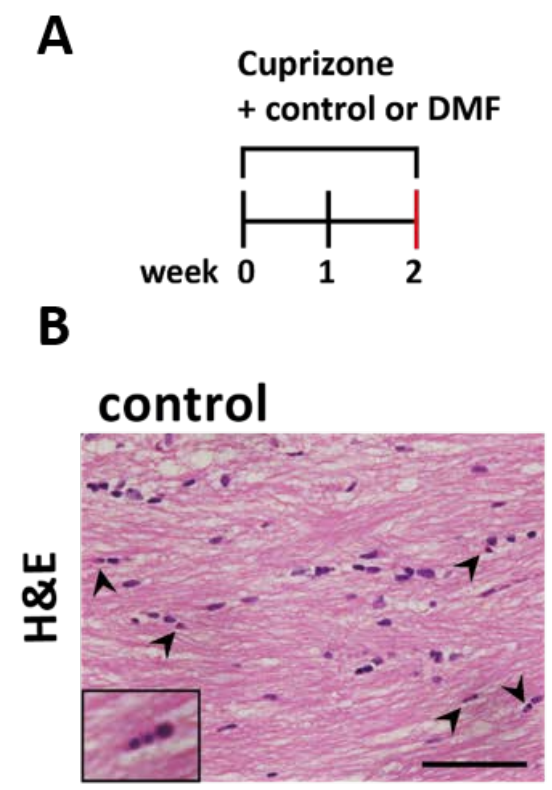

\section{DMF}
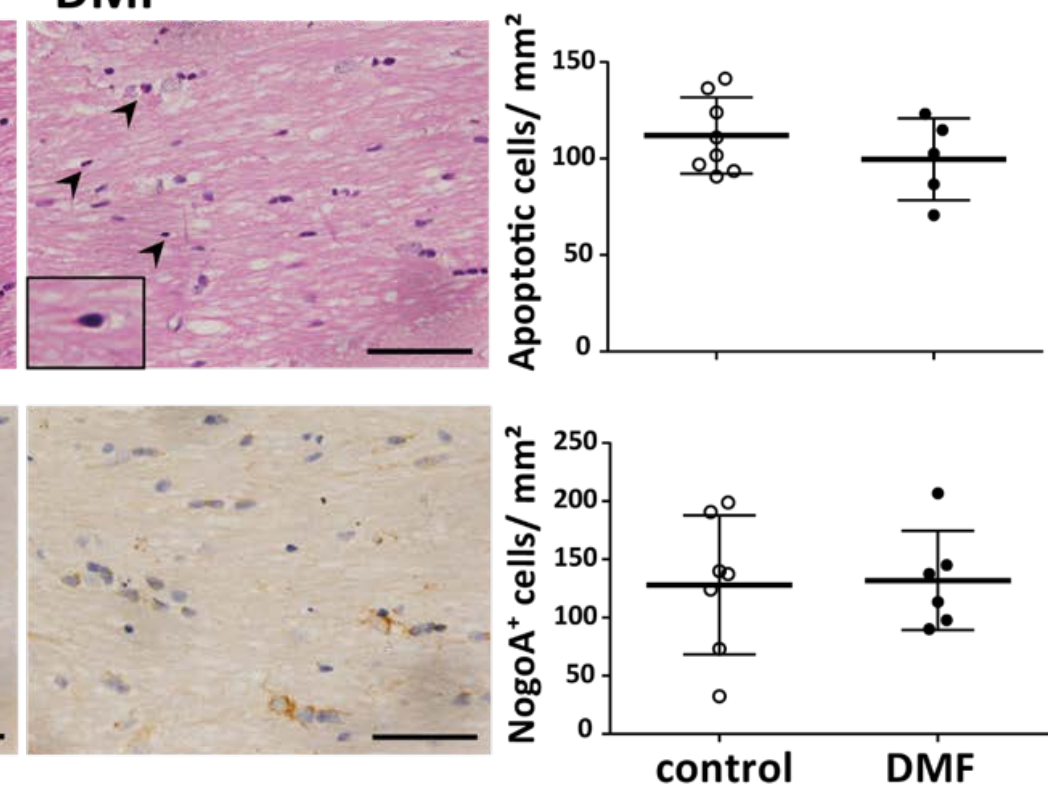

Figure 5: DMF treatment does not prevent apoptosis of oligodendrocytes in the CC after 2 weeks of cuprizone diet. The DMF effect on the apoptosis of oligodendrocytes was additionally analyzed after 2 weeks of cuprizone treatment. (A) Schematic representation of cuprizone and control or DMF treatment. C57BL/ 6 mice were fed with $0.25 \%$ cuprizone for 2 weeks and simultaneously treated with control or $15 \mathrm{mg} / \mathrm{kg}$ DMF twice a day. (B) Histological staining was performed to analyze the number apoptotic cells (H\&E) and number of mature oligodendrocytes (NogoA) in the CC. Representative sections of the CC are shown on the left and quantification of cells on the right. Histological evaluation revealed that DMF treatment does not significantly alter the apoptosis of oligodendrocytes and the number of mature oligodendrocytes after 2 weeks of cuprizone feeding. Data are represented as mean \pm SD. Inserts show an apoptotic cell in higher magnification. Scale bar $=50 \mu \mathrm{m}$ 


\subsubsection{Long-term effects of DMF in the cuprizone mouse model}

DMF-treated mice showed reduced numbers of apoptotic oligodendrocytes and higher numbers of Olig2 ${ }^{+}$oligodendrocytes after 7 days of cuprizone exposure leading to the suggestion that DMF might also reduce cuprizone-induced demyelination of the CC. As the acute axonal damage was reduced by DMF after short term treatment, we were also interested in the axonal damage after long-term DMF treatment in the cuprizone model. To address this question, 9 to 10 week old C57BL/6 mice were fed with $0.25 \%$ cuprizone and simultaneously treated with control or $15 \mathrm{mg} / \mathrm{kg}$ DMF twice a day for 6 weeks to study DMF effects on the demyelination of the CC as well as to analyze the axonal damage. Body weight of control- and DMF-treated mice was evaluated every week of cuprizone treatment (data not shown). However, the DMF effects seen on the body weight after one week of cuprizone treatment did not last in the long term therapy.

\subsubsection{Cuprizone-induced demyelination was not affected by DMF treatment}

Brain sections of control- and DMF-treated mice were examined and analyzed for demyelination of the CC after LFB-PAS and PLP (proteolipid protein) staining (Figure 6). The myelin in the LFB-PAS staining appears in blue and in PLP staining in brown. First, the area of the whole CC was measured and afterwards only the demyelinated regions. The demyelinated area is then indicated as percentage of the total CC. The LFB-PAS staining showed that the myelin appeared to be better preserved in the medial part of the CC of DMF-treated mice, but this effect did not reach statistical significance when compared to controls. The extent of demyelination in the PLP staining was similar between both groups. DMF effects on the cortical demyelination were also examined in DMF- and control-treated mice. However, the extent of demyelination was comparable between both groups (data not shown). 
A

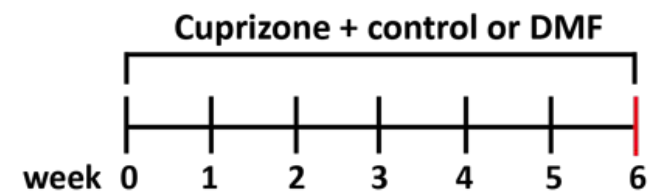

B
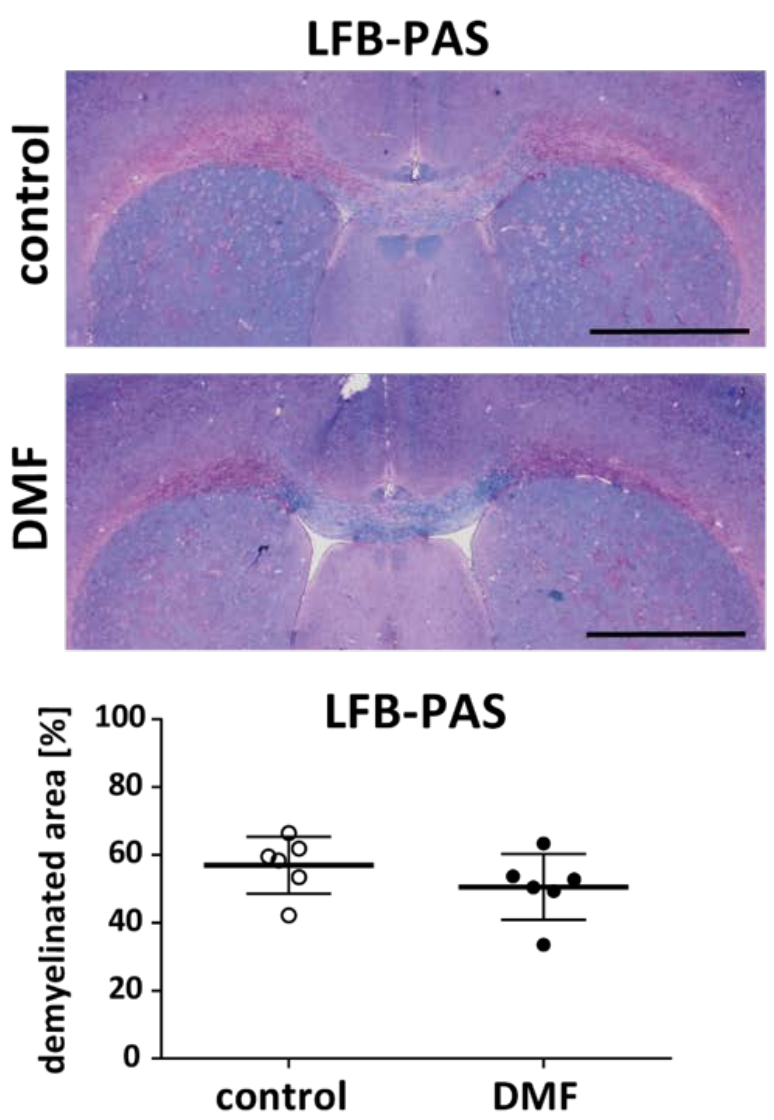

PLP
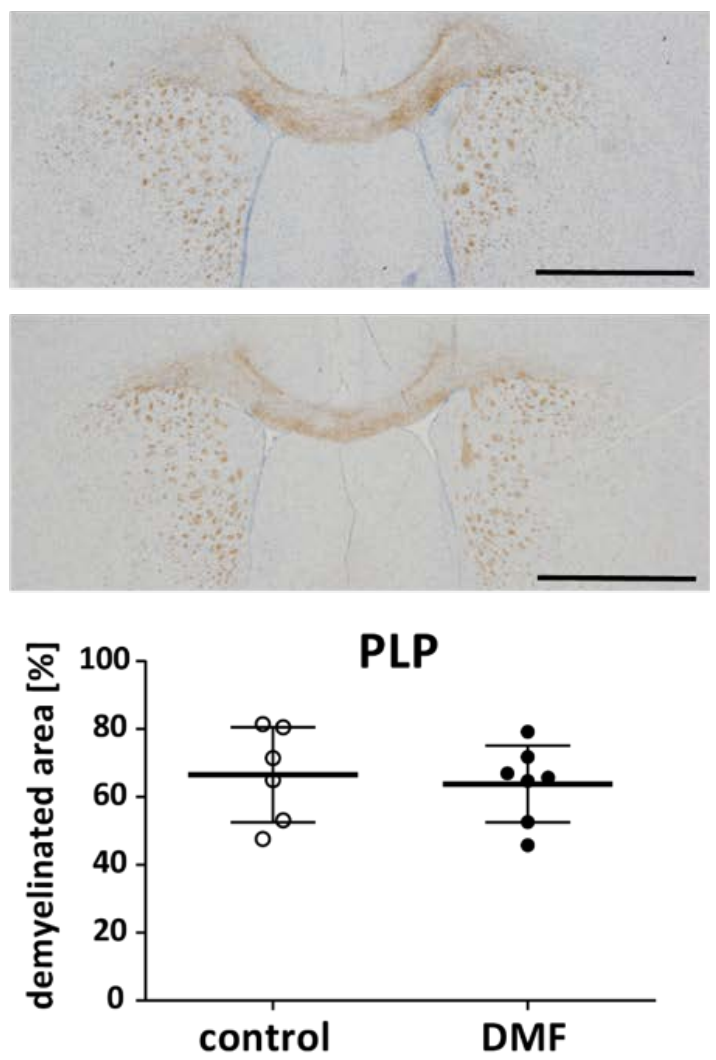

Figure 6: DMF application does not reduce demyelination in the CC. The demyelination of the CC was investigated after long-term cuprizone diet. (A) Schematic representation of cuprizone and control or DMF treatment. C57BL/ 6 mice were fed with $0.25 \%$ cuprizone and simultaneously treated with control or $15 \mathrm{mg} / \mathrm{kg}$ DMF twice a day for 6 weeks. (B) LFB/PAS and PLP stainings were performed to measure the demyelinated area of the CC. Representative sections of the $\mathrm{CC}$ are shown above and the corresponding quantifications below. Demyelination is not significantly decreased by DMF treatment after 6 weeks of cuprizone exposure. Data are represented as mean \pm SD. Scale bar $=1000 \mu \mathrm{m}$

\subsubsection{DMF treatment did not significantly reduce the acute axonal damage, astrogliosis and microglia/macrophages after 6 weeks of cuprizone intoxication}

Cuprizone-mediated demyelination leads to an increased accumulation of microglia/macrophages, acute axonal damage and higher numbers of astroglia. Mac3, APP and GFAP immunohistochemistry was used to assess the number of microglia/macrophages, acute axonal 
damage and the number of activated astrocytes (Figure 7). DMF treatment did not significantly alter the number of $\mathrm{Mac}^{+}$cells compared to controls. Additionally, the number of $\mathrm{APP}^{+} \mathrm{spheroids}$ and $\mathrm{GFAP}^{+}$cells was not significantly reduced by $\mathrm{DMF}$ treatment compared to controls. Nevertheless, a trend for less acute axonal damage and lower numbers of reactive astrocytes and macrophages/microglial cells was observed in DMF-treated animals after 6 weeks of cuprizone diet.

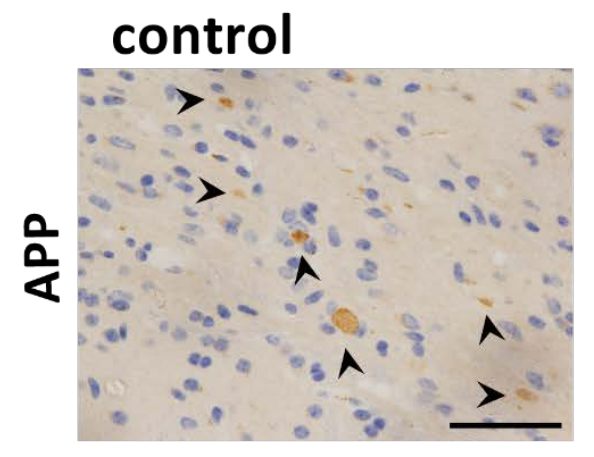

\section{DMF}
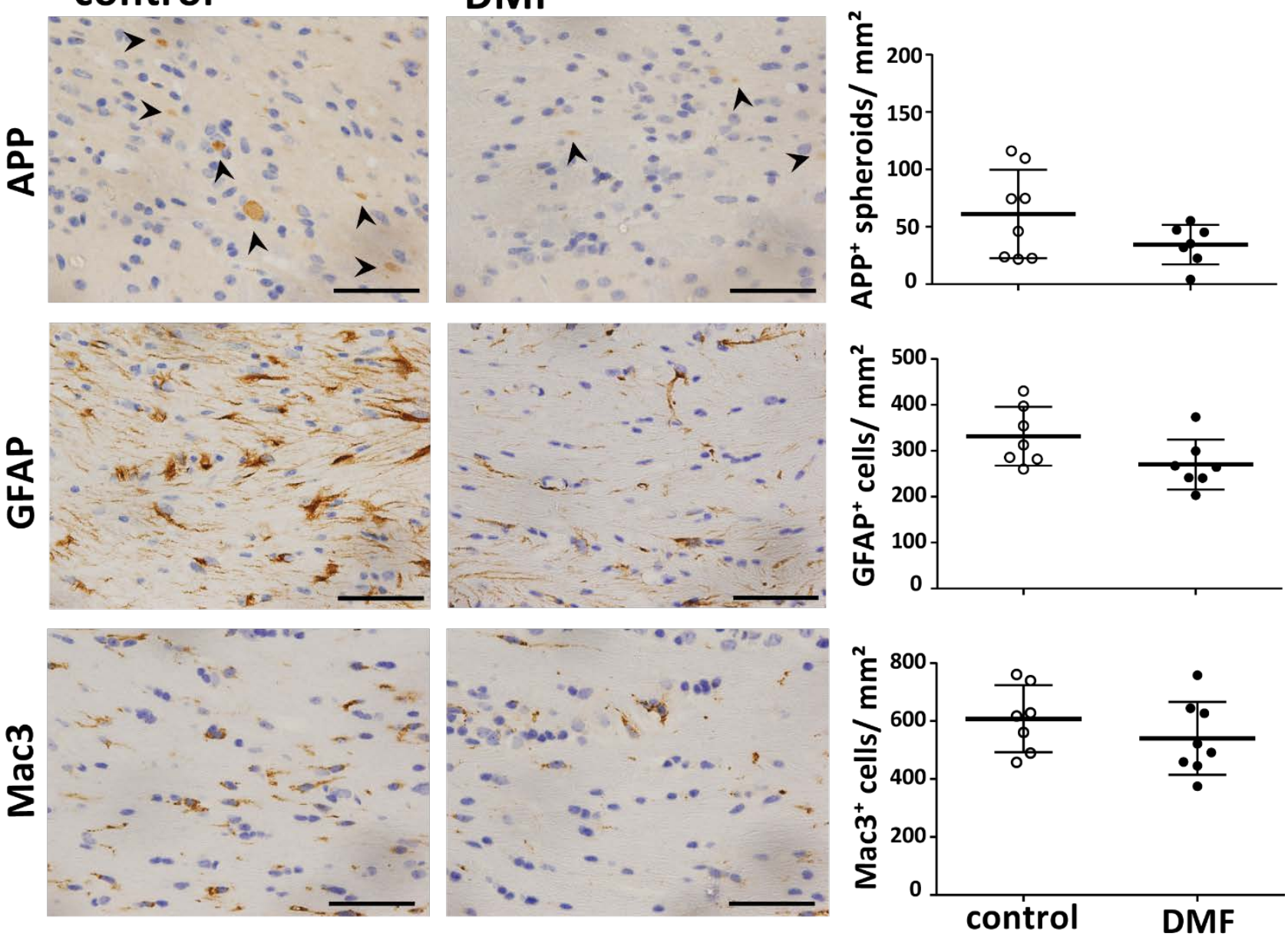

Figure 7: No significant effect of DMF on acute axonal damage, astrogliosis and macrophage/microglial numbers after long-term cuprizone treatment. IHC staining for microglia/macrophages (Mac3), acute axonal damage (APP) and reactive astrocytes (GFAP) was performed of brain sections from C57BL/ 6 mice fed with $0.25 \%$ cuprizone and simultaneously treated with control or $15 \mathrm{mg} / \mathrm{kg}$ DMF twice a day for 6 weeks. Representative sections of the CC are shown on the left and quantifications of cells on the right. The number of microglia/macrophages (Mac3), acute axonal damage and the number of reactive astrocytes are not significantly reduced by DMF application after 6 weeks of cuprizone diet. Data are represented as mean \pm SD. Scale bar $=50 \mu \mathrm{m}$ 


\subsubsection{Axonal density was not significantly higher after DMF treatment}

In addition to the evaluation of the acute axonal damage, DMF effects were analyzed on the axonal density during cuprizone intoxication. Therefore a Bielschowsky staining was performed and axons were counted across the width of the CC under the cingulum bundle as depicted in Figure 8. The axonal density in the CC was tended to be higher in DMF-treated mice, but this effect did not reach statistical significance.
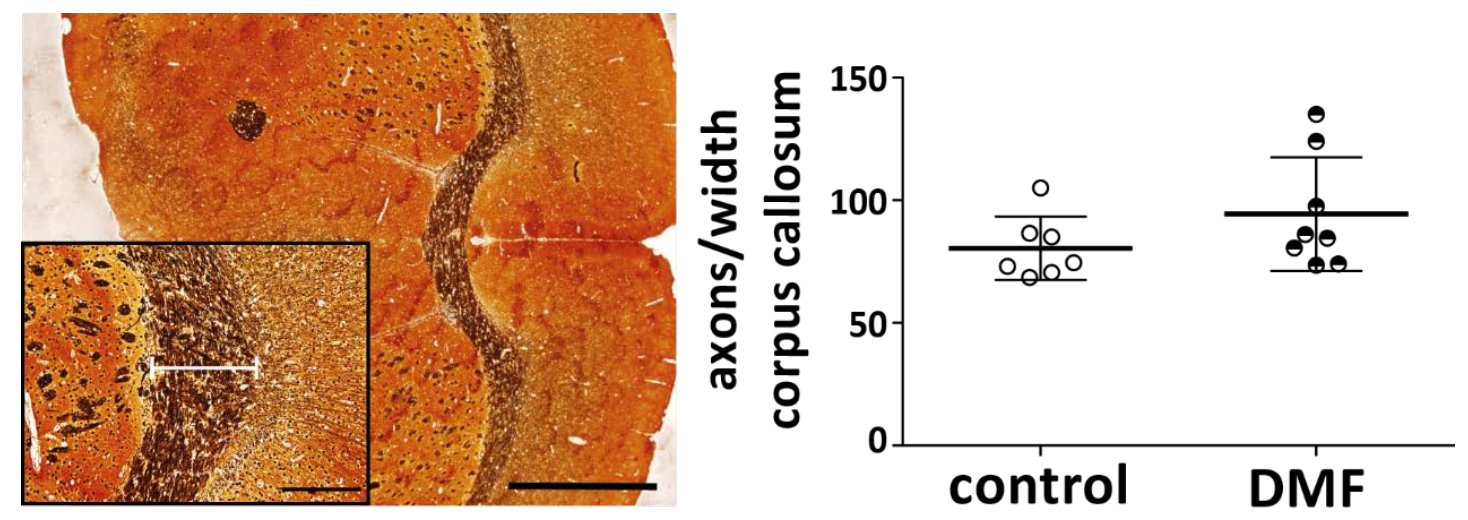

Figure 8: DMF treatment shows no significant effect the axonal density. C57BL/6 mice were fed with $0.25 \%$ cuprizone and simultaneously treated with control or $15 \mathrm{mg} / \mathrm{kg}$ DMF twice a day for 6 weeks. The number of axons in the CC was analyzed by Bielschowsky staining. Axons were counted over the width of the CC (white bar) under the cingulum bundle. Representative sections of the CC are shown on the left and quantification of axons on the right. The number of axons is not altered by DMF treatment. Data are represented as mean \pm SEM. Scale bar $=1000 \mu \mathrm{m}$, scale bar insert $=200 \mu \mathrm{m}$

\subsubsection{DMF treatment enhanced the number of mature oligodendrocytes after 6 weeks of cuprizone}

Olig2 ${ }^{+}$oligodendrocytes (including progenitor cells) were preserved by DMF treatment after 7 days of cuprizone diet whereas no difference in the number of Olig2 ${ }^{+}$oligodendrocytes and mature oligodendrocytes was observed after 2 weeks. To examine the number of mature oligodendrocytes after 6 weeks of cuprizone exposure, an IHC staining for NogoA was performed (Figure 9). Histological evaluation showed that the number of $\mathrm{NogoA}^{+}$cells was significantly lower in controls $\left(110 \pm 38\right.$ cells $\left./ \mathrm{mm}^{2}\right)$ compared to DMF-treated animals $\left(146 \pm 21\right.$ cells $\left./ \mathrm{mm}^{2}\right)(p<0.05)$. The total number of oligodendrocytes (Olig2 ${ }^{+}$cells) was not altered by DMF treatment after 6 weeks of cuprizone (data not shown). 

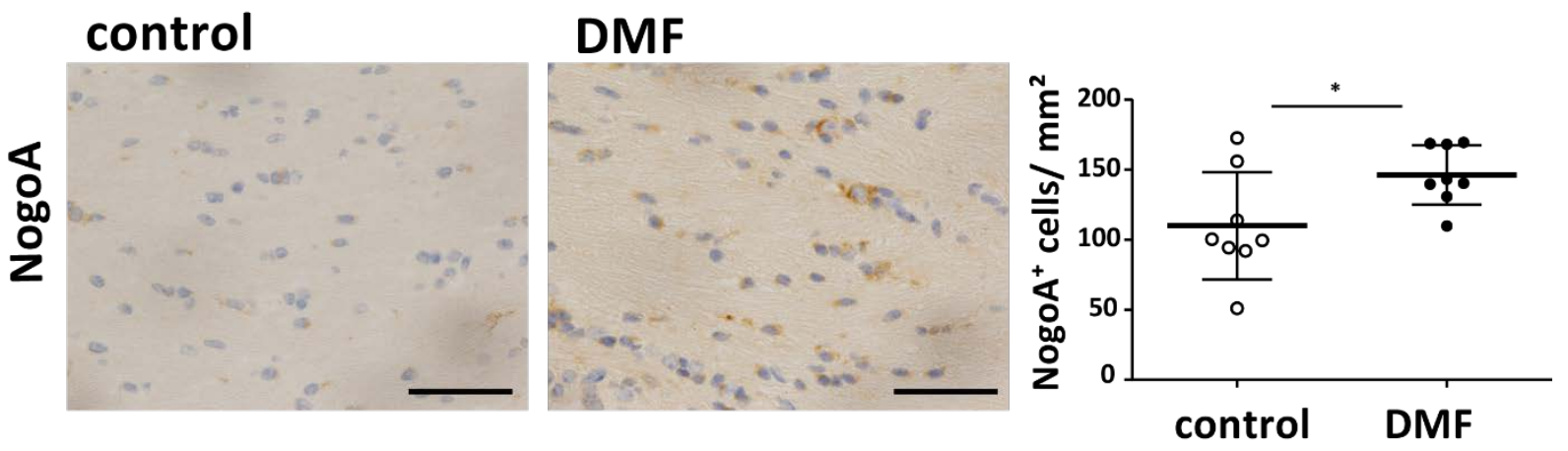

Figure 9: Higher numbers of mature oligodendrocytes after 6 weeks of cuprizone exposure with DMF treatment. C57BL/ 6 mice were fed with $0.25 \%$ cuprizone and simultaneously treated with control or $15 \mathrm{mg} / \mathrm{kg}$ DMF twice a day for 6 weeks. The number of mature oligodendrocytes (NogoA) in the CC was analyzed after IHC staining. Representative sections of the CC are shown on the left and quantification of cells on the right. The number of mature oligodendrocytes is significantly higher after DMF treatment. Data are represented as mean $\pm S D\left({ }^{*} p<0.05\right.$, unpaired t-test $)$. Scale bar $=50 \mu \mathrm{m}$

\subsubsection{DMF effects after cuprizone withdrawal}

For the analysis of remyelination, C57BL/ 6 mice were fed with $0.25 \%$ cuprizone for 5 weeks to induce demyelination of the CC. This time point was chosen because endogenous remyelination already starts after 5 weeks of cuprizone exposure. After 5 weeks, cuprizone diet was stopped and mice were fed with normal chow and treated therapeutically with control or $15 \mathrm{mg} / \mathrm{kg}$ DMF twice a day for 3 days. Next to remyelination, analyses focused on the axonal damage and accumulation of microglia/macrophages.

\subsubsection{Remyelination was not enhanced by DMF treatment}

Naturally, the removal of cuprizone leads to rapid remyelination of the CC of mice. In the first experiment, remyelination was analyzed after 7 days of cuprizone withdrawal and control or DMF treatment (data not shown). Since remyelination was already far advanced at this time point, a shorter treatment period was chosen for further analyses. To investigate the potential of DMF to increase remyelination, C57BL/ 6 mice were fed with $0.25 \%$ cuprizone for 5 weeks to induce demyelination. Afterwards cuprizone diet was stopped and mice were treated with control or $15 \mathrm{mg} / \mathrm{kg}$ DMF twice a day for 3 days. Remyelination was investigated after LFB-PAS staining (Figure 10). Both groups still showed the same extent of demyelination in the lateral region of the CC illustrating that DMF treatment could not increase the remyelination of the CC compared to controls. Additionally, the extent of remyelination in the CC was analyzed in sections stained for 
PLP, MBP and CNPase. No significant difference between control- and DMF-treated animals was observed for these three myelin proteins (data not shown). The number of mature oligodendrocytes ( $\mathrm{NogoA}^{+}$cells) and the total number of oligodendrocytes (Olig2 ${ }^{+}$cells) was not altered by 3 days of DMF treatment after cuprizone withdrawal (data not shown).

A

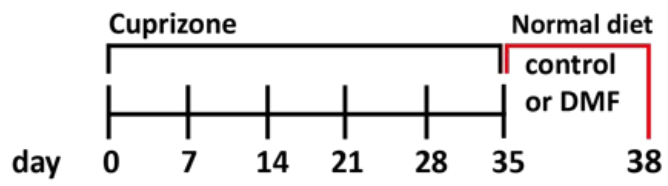

B

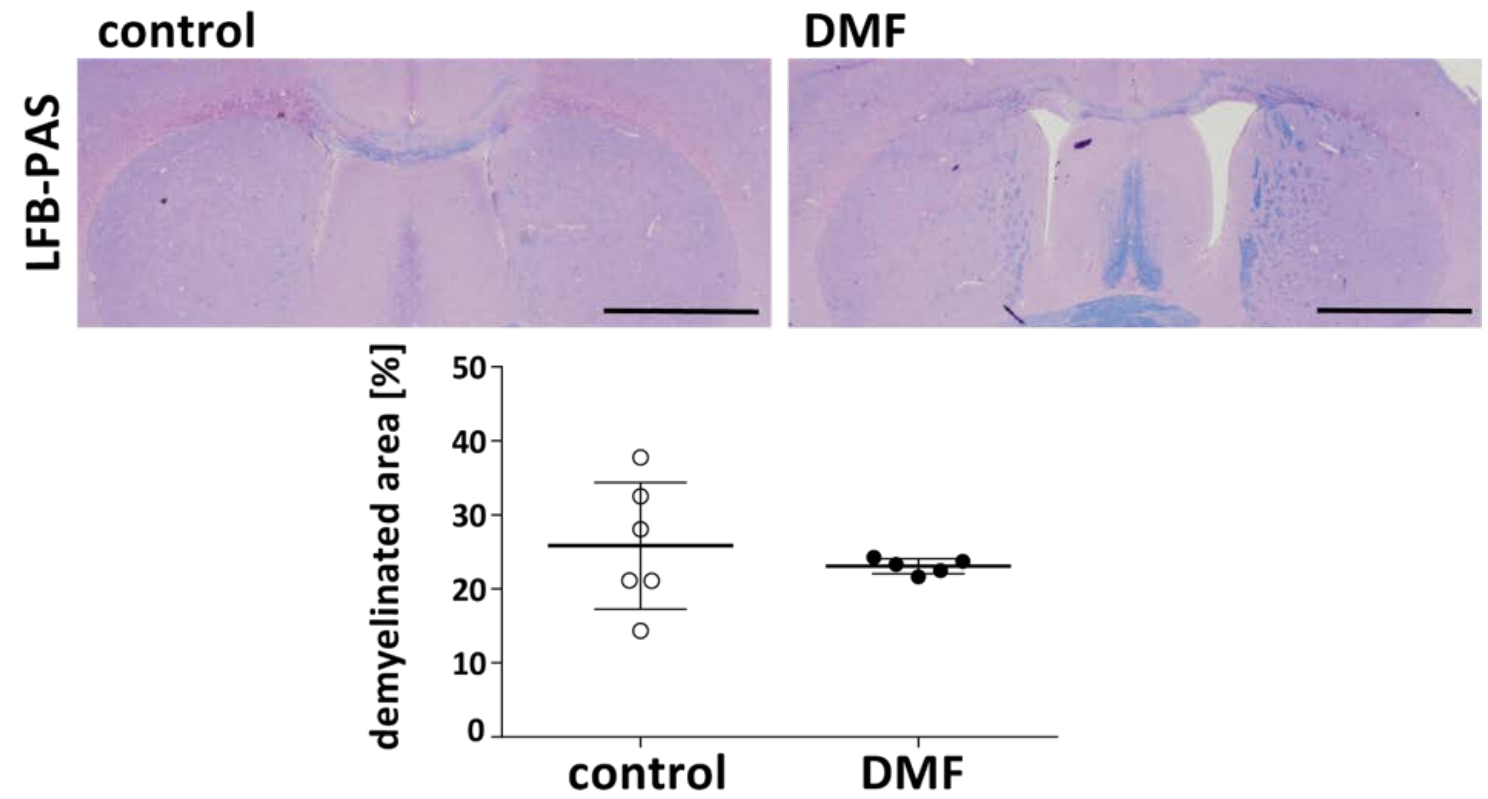

Figure 10: DMF has no effect on the remyelination of the CC. (A) Schematic representation of cuprizone and control or DMF treatment. C57BL/ 6 mice were fed with $0.25 \%$ cuprizone for 5 weeks. Afterwards cuprizone diet was stopped and mice were treated with control or $15 \mathrm{mg} / \mathrm{kg}$ DMF twice a day for 3 days. (B) LFB/PAS staining was performed to measure the demyelinated area of the CC. Representative sections of the $\mathrm{CC}$ are shown above and the corresponding quantification below. Remyelination is not significantly increased by 3 days of DMF treatment after cuprizone withdrawal. Data are represented as mean \pm SD. Scale bar $=1000 \mu \mathrm{m}$

\subsubsection{Acute axonal damage was diminished by DMF after 3 days of cuprizone withdrawal}

The effects of DMF on acute axonal damage and numbers of microglia/macrophages after cuprizone removal were investigated after IHC staining of brain sections from control- or DMFtreated mice. Acute axonal damage was investigated by counting $\mathrm{APP}^{+}$spheroids and phagocyte accumulation by counting $\mathrm{Mac3}^{+}$cells (Figure 11). The number of $\mathrm{APP}^{+}$spheroids was significantly 
decreased by DMF $\left(84 \pm 53\right.$ cells $\left./ \mathrm{mm}^{2}\right)$ when compared to controls $\left(190 \pm 78\right.$ cells $\left./ \mathrm{mm}^{2}\right)(p<0.05)$. The accumulation of microglia/macrophages was comparable between both groups.

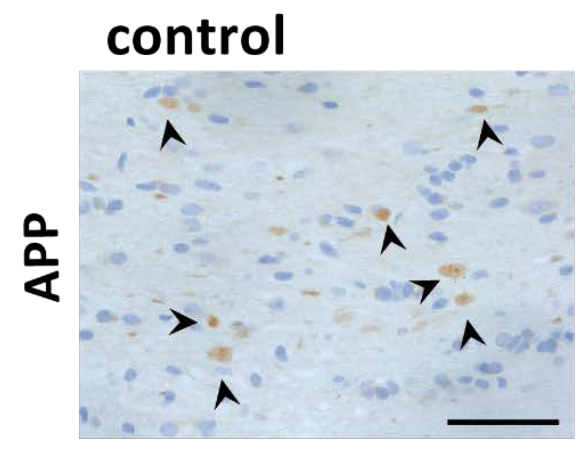

\section{DMF}
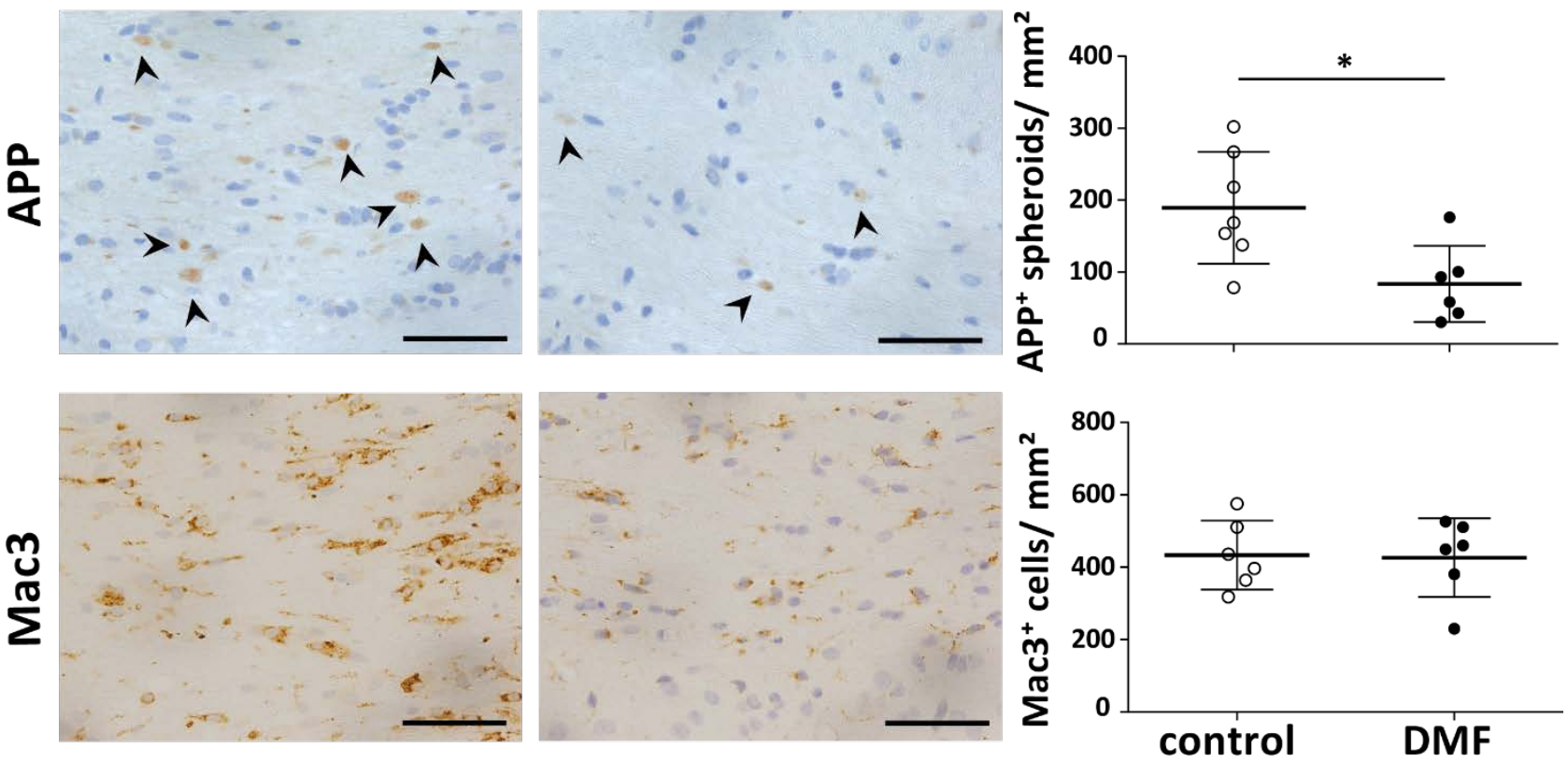

Figure 11: DMF treatment decreases acute axonal damage after cuprizone withdrawal. C57BL/6 mice were fed with $0.25 \%$ cuprizone for 5 weeks. Afterwards cuprizone diet was stopped and mice were treated with control or $15 \mathrm{mg} / \mathrm{kg}$ DMF twice a day for 3 days. IHC staining for acute axonal damage (APP) and the number of microglia/macrophages was performed. Representative sections of the CC are shown on the left and quantification of cells on the right. Acute axonal damage is significantly reduced by 3 days of DMF treatment after cuprizone withdrawal. Data are represented as mean \pm SD ( ${ }^{*} p<0.05$, unpaired t-test). Scale bar $=50 \mu \mathrm{m}$

\subsubsection{MMF was detectable in the brain of DMF-treated mice}

An important feature of the cuprizone mouse model is the intact blood brain barrier (BBB) which allows the investigation of CNS intrinsic effects without the influence of the peripheral immune system. To analyze if DMF can pass the BBB and reaches the CNS, its metabolite MMF was measured in plasma and brain samples of control- and DMF-treated mice by mass spectrometry. MMF could be detected in the plasma and brain samples of DMF-treated mice after 7 days and was even slightly increased after six weeks of therapy (Figure 12). No MMF was found in the plasma and brain of controls. Mass spectrometry analysis was kindly performed by the lab of Rob Scannevin (Biogen Idec, Cambridge). 



Figure 12: MMF, the active metabolite of DMF, is present in the brain of DMF-treated mice. C57BL/6 mice were fed with $0.25 \%$ cuprizone and simultaneously treated with control or $15 \mathrm{mg} / \mathrm{kg} \mathrm{DMF}$ twice a day for 7 days or 6 weeks. The amount of the DMF metabolite MMF was analyzed by mass spectrometry in plasma and brain. MMF can be detected in the plasma and brain of DMF-treated mice after 7 days and 6 weeks whereas in control-treated mice MMF is not detectable. Data are represented as mean \pm SD ( 7 days $n=6,6$ weeks $n=4)$.

\subsubsection{DMF did not reduce apoptosis of oligodendrocytes in Nrf2 k.o. mice}

It is assumed that DMF exerts protective functions via the activation and stabilization of the transcription factor Nrf2, which activates antioxidant response pathways and thereby leads to a better protection of cells against oxidative stress (Linker et al., 2011; Scannevin et al., 2012c; Thiessen et al., 2010). To investigate if the DMF-mediated reduction of apoptotic oligodendrocytes after 7 days of cuprizone is dependent on Nrf2, apoptosis of oligodendrocytes was examined in Nrf2 k.o. mice. Similar to the first experiments, Nrf2 k.o. mice were fed with $0.25 \%$ cuprizone for 7 days and simultaneously treated with control or $15 \mathrm{mg} / \mathrm{kg}$ DMF twice a day. Apoptosis of oligodendrocytes was analyzed in H\&E stained tissue (Figure 13). Histological evaluation revealed that control-treated Nrf2 k.o. mice already showed reduced numbers of apoptotic cells when compared to C57BL/6 mice (Figure 2). The number of apoptotic cells was similar in control- and DMF-treated Nrf2 k.o. mice. 
A

Cuprizone

+ control or DMF

week 1

B
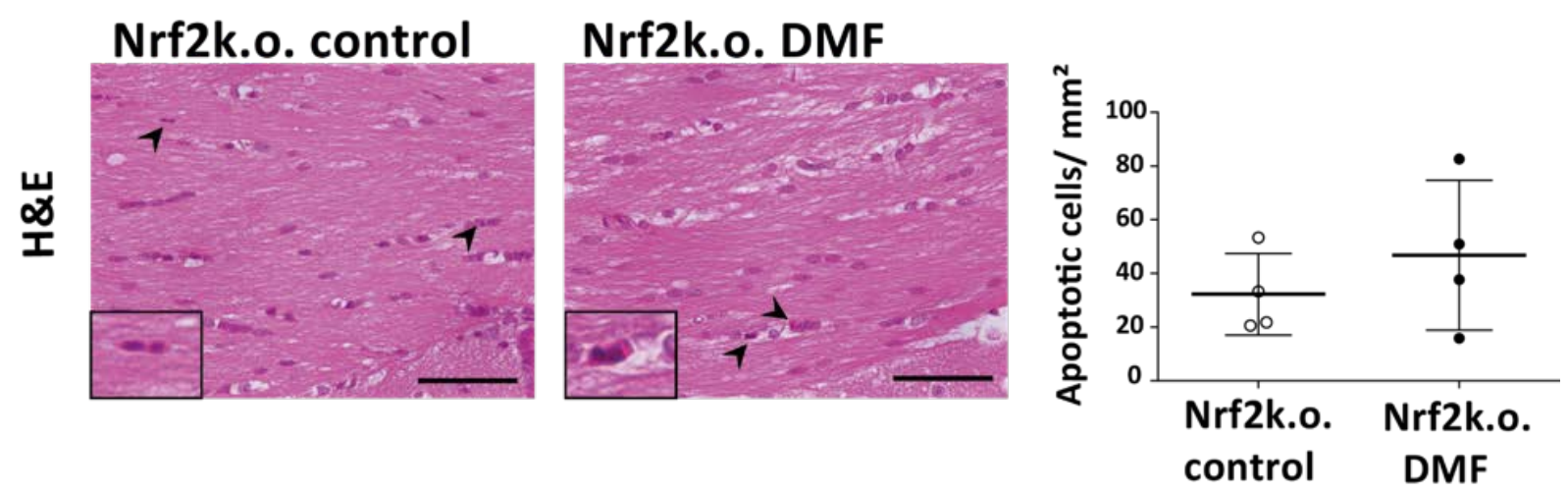

Figure 13: DMF treatment does not decrease apoptosis of oligodendrocytes in the CC of Nrf2 k.o. mice. (A) Schematic representation of cuprizone and control or DMF treatment. Nrf2 k.o. mice were fed with $0.25 \%$ cuprizone for 7 days and simultaneously treated with control or $15 \mathrm{mg} / \mathrm{kg}$ DMF twice a day. (B) Apoptotic cells in the CC were identified by morphology in H\&E staining. Representative sections of the CC are shown on the left and quantification of cells on the right. Histological evaluation revealed that the number of apoptotic oligodendrocytes is not reduced in Nrf2 k.o. mice by DMF treatment. Data are represented as mean \pm SD. Inserts show an apoptotic cell in higher magnification. Scale bar $=50 \mu \mathrm{m}$

In summary, although DMF did not profoundly alter the extent of demyelination and remyelination, the number of oligodendrocytes was increased in DMF-treated animals over time. Whereas after short-term cuprizone exposure the overall number of oligodendrocytes including OPCs was increased with DMF treatment, after 6 weeks of cuprizone diet the number of mature oligodendrocytes was higher in DMF-treated animals compared to controls.

DMF treatment reduced the acute axonal damage after 7 days of cuprizone treatment. Although this effect was not significant after 6 weeks of cuprizone diet, a trend towards less acute axonal damage in DMF-treated animals was observed. Nevertheless, therapeutic DMF treatment significantly decreased the number of damaged axons after 3 days of treatment following cuprizone withdrawal. 


\subsection{DMF effects in a B cell-mediated EAE model}

Besides the analysis of CNS intrinsic effects, further studies focused on peripheral effects mediated by DMF treatment. Therefore, DMF was analyzed in a B cell-mediated EAE model.

The beneficial effects of the B cell-depleting agent rituximab in the therapy of RRMS emphasized the pathological role of B cells in the disease pathogenesis (Hauser et al., 2008b). Previous studies investigated the effects of DMF in more T cell-dependent EAE models, induced by immunization with MOG peptide. In this model, B cells do not extensively contribute to the disease pathogenesis demonstrated by the detrimental effects of rituximab in this EAE (Weber et al., 2010). Therefore, the present study aimed to examine the effects of DMF on adaptive immune cells in an EAE model, induced by immunization with MOG protein, in which B cells contribute in a pathogenic manner.

For the investigation of DMF-mediated effects, mice were treated once in a preventive setting, starting 2 or 7 days before immunization, or in a therapeutic regimen starting when mice showed an EAE score of 2 (hind limb weakness) or higher (Figure 14).

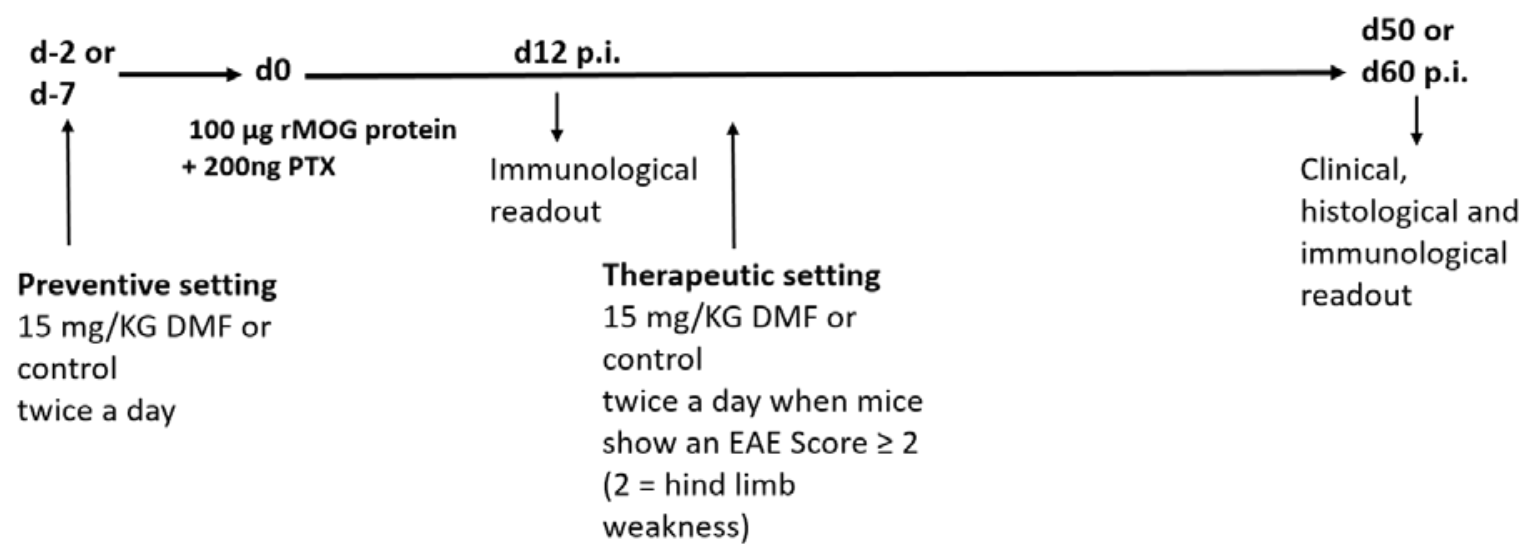

Figure 14: Schematic representation of the experimental setup. C57BL/6 mice were immunized with $100 \mu \mathrm{rMOG}_{1-117}$ and treated with $15 \mathrm{mg} / \mathrm{kg}$ DMF or control twice a day. Preventive treatment started 2 or 7 days prior to immunization, therapeutic treatment when mice showed an EAE Score of 2 (hind limb weakness) or higher. For immunological evaluations mice were treated until day 12 and for clinical and histological evaluations until day 60. 


\subsubsection{DMF treatment decreased EAE severity and demyelination of the spinal cord}

To investigate the efficiency of DMF to improve B cell-mediated chronic EAE, C57BL/6 mice were immunized with $\mathrm{rMOG}_{1-117}$ and received oral treatment with either $15 \mathrm{mg} / \mathrm{kg}$ DMF or control twice a day. In the preventive setting, mice were treated until $\mathrm{d} 60$, in the therapeutic regimen until d50 p.i. (Figure 14). Clinical, histological and immunological analyses were performed to examine DMF-mediated alterations of adaptive and innate immunity.

\subsubsection{Preventive and therapeutic DMF treatment ameliorated the clinical course of EAE}

The initial experiments focused on the clinical effects mediated by DMF application. Hence, EAE score and body weight (data not shown) of immunized mice were monitored daily (Figure 15). Animals of the preventively treated groups showed an overall lower EAE severity compared to therapeutically treated animals. Data evaluations revealed that both preventive and therapeutic DMF treatment significantly ameliorated the disease course of mice $\left(* p<0.05,{ }^{*} p<0.01\right)$.
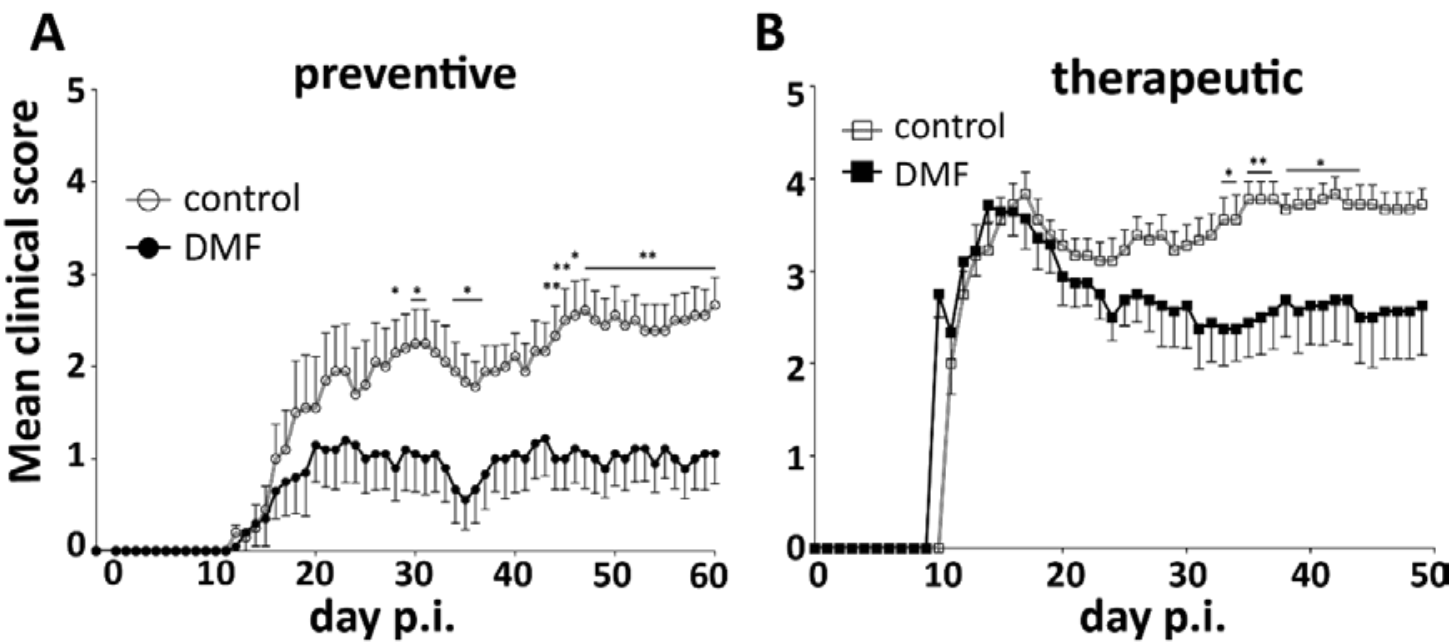

Figure 15: Clinical course of EAE is ameliorated by preventive and therapeutic DMF treatment. Clinical disease scores of chronic EAE in C57BL/6 mice, immunized with $\mathrm{rMOG}_{1-117}$ and treated with $15 \mathrm{mg} / \mathrm{kg}$ DMF (black) or control (grey) twice a day. (A) Preventive DMF treatment significantly ameliorates the disease course as compared to control. Mice were treated from d-2 until d60. Data are represented as mean \pm SEM ( $n=10$ per group, ${ }^{*} p<0.05, * * p<0.01$, Mann-Whitney $U$ test). (B) Therapeutic DMF treatment started when mice showed an EAE Score of 2 (hind limb weakness) or higher. Therapeutic application of DMF significantly ameliorates the course of disease compared to control. Data are represented as mean \pm SEM (control $n=9$ per group, DMF $n=8$ per group, ${ }^{*} p<0.05,{ }^{* *} p<0.01$, Mann-Whitney $U$ test). 


\subsubsection{Anti-MOG Ab titers were not altered by DMF application}

To evaluate the effects of DMF treatment on the humoral immune response, production of antiMOG Ab levels in the serum of $\mathrm{rMOG}_{1-117}$ immunized mice treated with $15 \mathrm{mg} / \mathrm{kg}$ DMF or control was determined weekly until day 42 p.i. (Figure 16). Animals which were treated with DMF preventively showed slightly increased $A b$ levels whereas the Ab level was slightly reduced in animals after the start of therapeutic DMF therapy compared to controls. Neither preventive nor therapeutic DMF application could significantly change the amount of anti-MOG Abs at any time point.
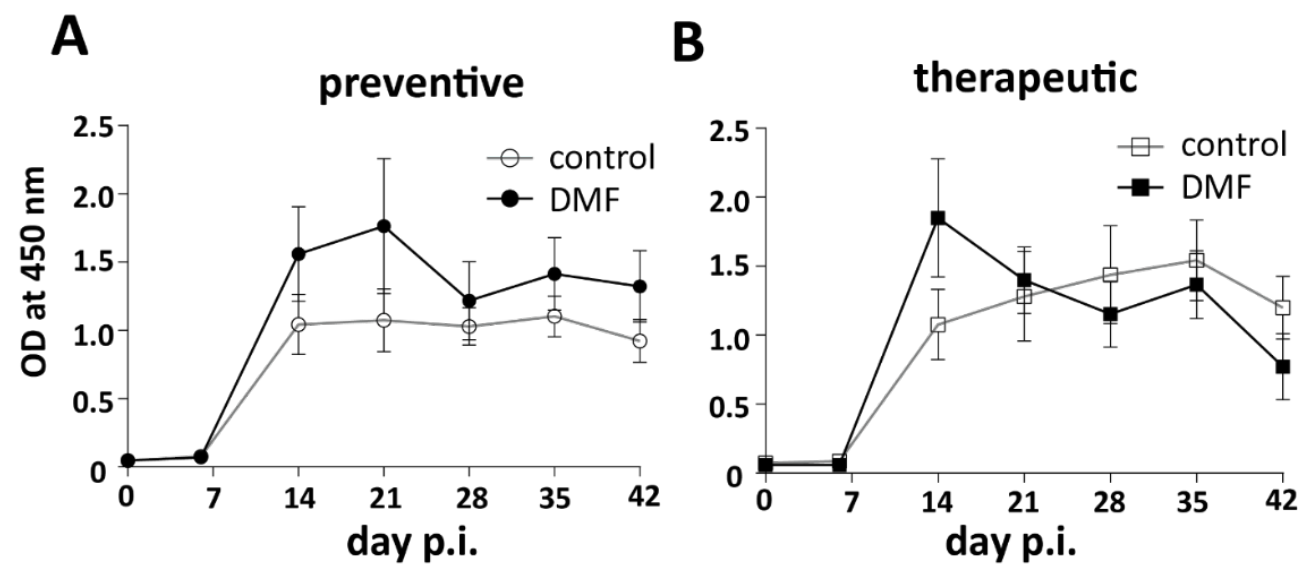

Figure 16: Anti-MOG Ab serum levels remain constant under preventive and therapeutic DMF treatment. C57BL/6 mice were immunized with $\mathrm{rMOG}_{1-117}$ and treated with $15 \mathrm{mg} / \mathrm{kg}$ DMF (black) or control (grey) twice a day. Anti-MOG Ab serum levels were weekly determined by ELISA until day 42 p.i. Before analysis serum samples were diluted 1:40,500. (A) Preventive and (B) therapeutic DMF treatment do not alter anti-MOG Ab levels compared to controls. Preventive DMF treatment started 2 days before immunization and therapeutic DMF treatment started when mice showed an EAE Score of 2 (hind limb weakness) or higher. Data are represented as mean \pm SEM (preventive control and DMF $n=10$, therapeutic control $n=9$, therapeutic DMF $n=8$ ).

\subsubsection{Demyelination and inflammation of the spinal cord was decreased by DMF}

DMF could significantly reduce the EAE severity in the preventive setting as well as in the therapeutic regimen. To study if DMF could also diminish the damage of the CNS, spinal cord sections of control-or DMF-treated mice were analyzed for demyelination, inflammation and the number of infiltrated cells. LFB-PAS staining was performed to measure the demyelinated area and inflammation was analyzed in H\&E staining (Figure 17). 
Additionally, spinal cord sections were examined for infiltrating B cells (B220), T cells (CD3) and macrophages (Mac3). Mice which were preventively treated with DMF showed no significantly reduced demyelination, inflammation or number of infiltrating cells compared to their controls. In contrast, demyelination was reduced in therapeutically DMF-treated mice $(4.7 \% \pm 0.9 \%)$ compared to controls $(14.0 \% \pm 2.4 \%)(p<0.05)$. Furthermore, therapeutic application of DMF significantly decreased inflammation from a mean inflammation score of $1.6 \pm 0.2$ in controls to a mean score of $0.7 \pm 0.2(p<0.01)$. The number of infiltrating $\mathrm{Mac}^{+}$cells was significantly diminished by therapeutic DMF treatment $\left(217 \pm 59\right.$ cells $\left./ \mathrm{mm}^{2}\right)$ compared to controls $\left(444 \pm 102\right.$ cells $\left./ \mathrm{mm}^{2}\right)(p<0.05)$. Infiltrating B cell and T cell numbers were not significantly altered by therapeutic DMF treatment. 


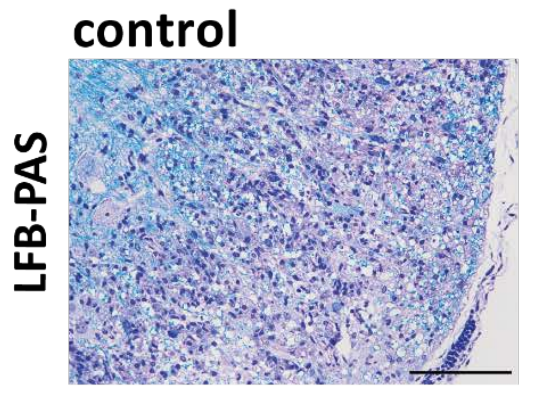

\section{DMF}
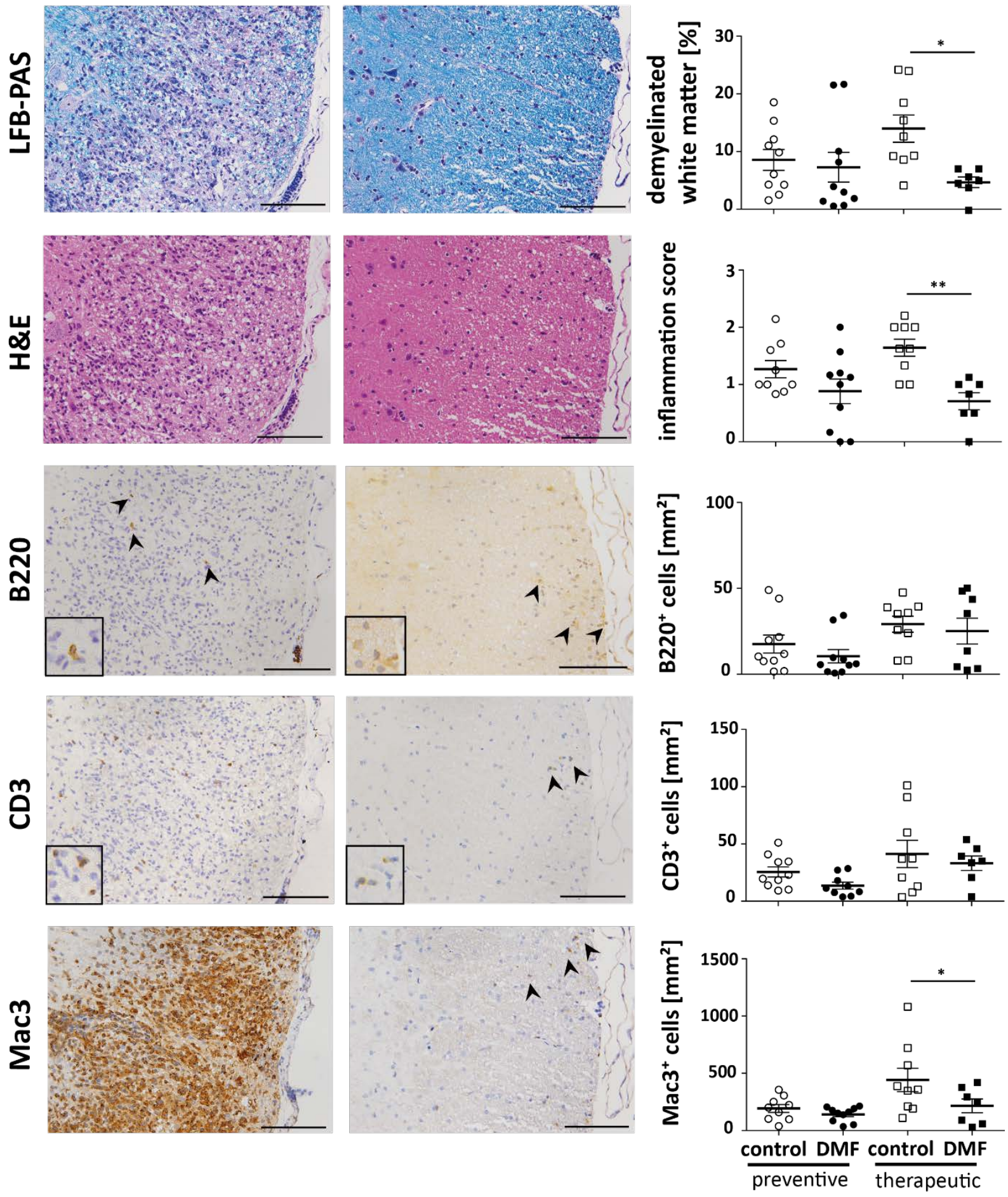

Figure 17: Spinal cord demyelination and infiltration is reduced after DMF treatment. Histological evaluation of $\mathrm{C} 57 \mathrm{BL} / 6$ mice, immunized with $\mathrm{rMOG}_{1-117}$ and preventive or therapeutically treated with $15 \mathrm{mg} / \mathrm{kg}$ DMF or control twice a day. Demyelination (LFB/PAS), inflammation (H\&E) and immune cell infiltration of the spinal cord evaluated by B220-, CD3- and Mac3-immunohistochemistry 50 days (therapeutic) and 60 days (preventive) after immunization. Representative sections of therapeutic treated mice (left) and percentage of demyelinated white matter area, score of spinal cord inflammation $(0=$ no inflammation, 1 = slight inflammation, 2 = moderate inflammation, 3 = strong inflammation) and number of infiltrating immune cells $/ \mathrm{mm}^{2}$ spinal cord (right). Therapeutic DMF treatment significantly reduces spinal cord demyelination and infiltration of cells. Data are represented as mean $\pm \operatorname{SEM}\left({ }^{*} p<0.05, * * p<0.01\right.$, one

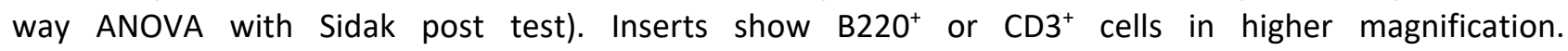
Scale bar $=100 \mu \mathrm{m}$ 


\subsubsection{DMF had opposing effects on B cells and T cells during the early phase of EAE}

DMF treatment ameliorated the clinical course of B cell-mediated chronic EAE and could also reduce the demyelination and inflammation of the spinal cord. To investigate if DMF-mediated effects already occur at the beginning of the disease, an earlier time point of EAE was chosen for immunological evaluations. Therefore, $\mathrm{C} 57 \mathrm{BL} / 6$ mice were immunized with $\mathrm{rMOG}_{1-117}$ and preventively treated with $15 \mathrm{mg} / \mathrm{kg}$ DMF or control 2 or 7 days prior to immunization until day 12, a day of the disease onset (Figure 14).

\subsubsection{DMF treatment altered the activation and differentiation of T cells}

Effects of DMF on the activation and differentiation of T cells were evaluated by analyzing T cell molecules which reflect their activation state and subpopulations.

\subsection{DMF induced a shift in the local distribution of $T$ cells}

Lymphopenia is an abnormally low level of lymphocytes and a common side effect of DMF therapy in MS patients (Longbrake et al., 2015). Therefore DMF effects on the cell frequency of immunized mice were analyzed in blood, lymph node and spleen 12 days after immunization. The frequencies of $\mathrm{CD}^{+} \mathrm{T}$ cells, CD8 ${ }^{+} \mathrm{T}$ cells, $\mathrm{CD} 19^{+}$cells (B cells) and $\mathrm{CD} 11 \mathrm{~b}^{+}$cells (including monocytes/macrophages, granulocytes, dendritic cells) were analyzed by flow cytometry (Figure 18). Data evaluation revealed a significant decrease in the frequency of $\mathrm{CD} 4^{+} \mathrm{T}$ cells in DMF-treated animals $(12.6 \% \pm 1.5 \%)$ compared to control-treated animals $(14.7 \% \pm 1.8 \%)$. In contrast, the $\mathrm{CD}^{+} \mathrm{T}$ cell frequency was significantly increased in lymph node and spleen by DMF treatment from a mean of $20.0 \% \pm 2.7 \%$ and $12.8 \% \pm 2.4 \%$ respectively in controls to a mean of $23.2 \% \pm 3.0 \%$ and $15.4 \% \pm 1.9 \%$ respectively in DMF-treated mice $(p<0.05)$. The frequency of $\mathrm{CD}^{+} \mathrm{T}$ cells was also increased in the spleen of DMF-treated mice $(8.9 \% \pm 1.3 \%)$ compared to controls $(7.1 \% \pm 1.8 \%)(p<0.05)$. In the blood the frequency of $\mathrm{CD} 8^{+} \mathrm{T}$ cells was slightly decreased and in the lymph node slightly increased. The frequencies of $C_{1} 19^{+}$cells and CD11 $b^{+}$cells were comparable between both groups in all analyzed compartments. 
A

blood

lymph node

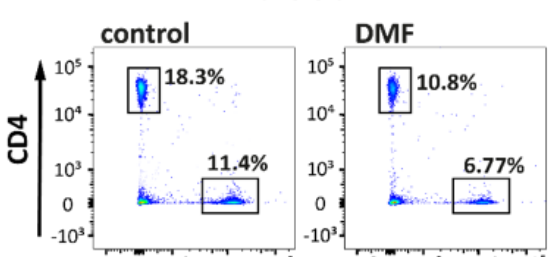
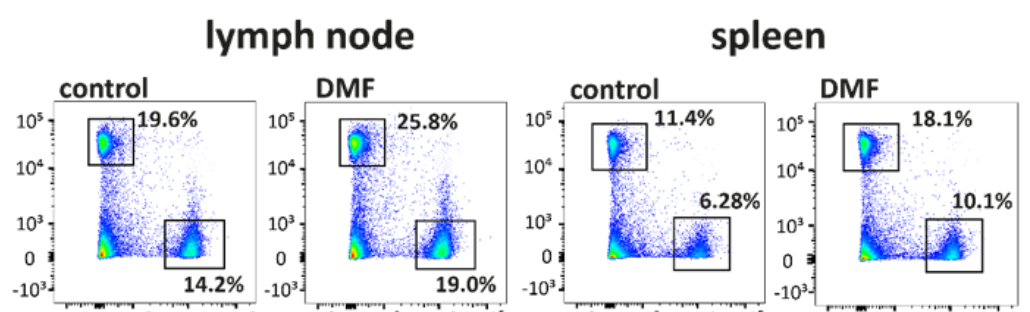

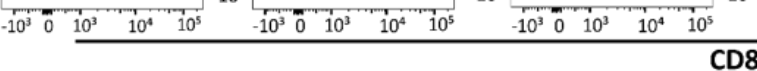
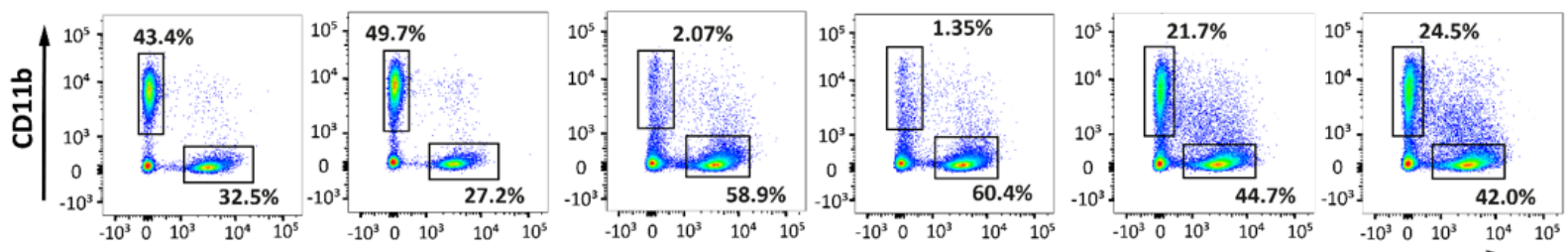

CD19

B
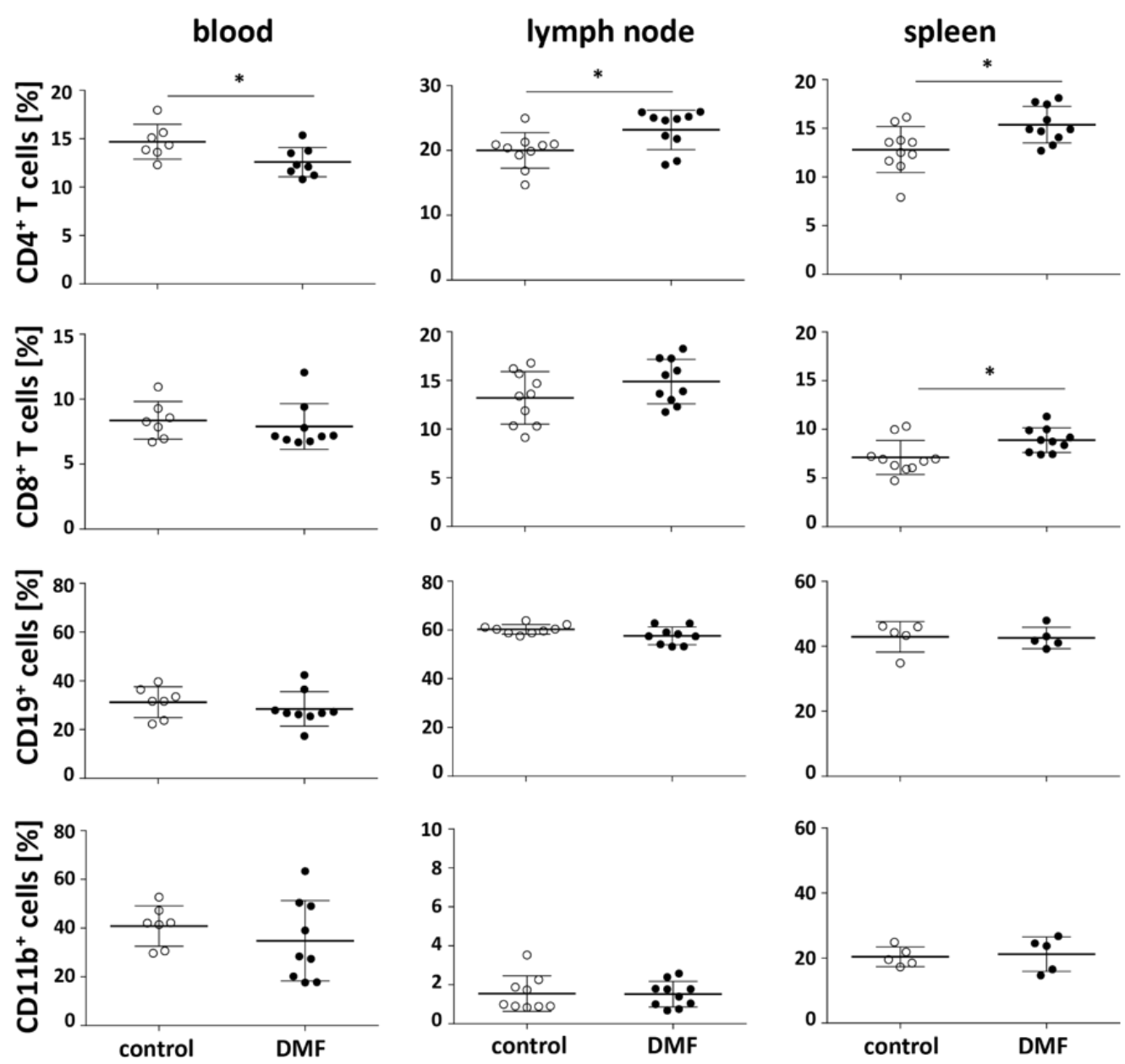

Figure 18: $T$ cell frequencies in blood, lymph node and spleen are altered under DMF treatment at day 12 p.i. Cell frequencies of $C D 4^{+} \mathrm{T}$ cells, $\mathrm{CD} 8^{+} \mathrm{T}$ cells, $\mathrm{CD} 19^{+}$cells and $\mathrm{CD} 11 \mathrm{~b}^{+}$cells were analyzed by flow cytometry (A). C57BL/6 mice were immunized with $\mathrm{rMOG}_{1-117}$ and treated with $15 \mathrm{mg} / \mathrm{kg}$ DMF or control twice a day from d-7 until d12 p.i. (B) In vivo DMF treatment significantly reduces the frequency of $\mathrm{CD}^{+} \mathrm{T}$ cells in blood and increases the frequency of $\mathrm{CD}^{+} \mathrm{T}$ cells in lymph node and the frequencies of $\mathrm{CD} 4^{+} \mathrm{T}$ cells and $\mathrm{CD} 8^{+} \mathrm{T}$ cells in spleen compared to controls. Data are represented as mean $\pm \mathrm{SD}\left({ }^{*} \mathrm{p}<0.05\right.$, unpaired t-test). 


\subsection{Reduced T cell activation upon DMF treatment}

Since DMF treatment significantly increased the T cell frequency in lymph node and spleen, the next experiment focused on the activation status of these T cells. DMF-induced changes in the activation of $\mathrm{CD}^{+} \mathrm{T}$ cells and $\mathrm{CD}^{+} \mathrm{T}$ cells were analyzed in lymph node and spleen from immunized mice treated with DMF or control until day 12 p.i. T cell activation was characterized by the expression of activation markers CD69 and CD25, samples were gated on CD4 ${ }^{+} \mathrm{T}$ cells and $\mathrm{CD}^{+} \mathrm{T}$ cells. The geometric mean fluorescence intensity (gMFI) of CD69 and CD25 was examined by flow cytometry (Figure 19). Data values were normalized to control (set 100\%). The expression of $\mathrm{CD} 69$ on $\mathrm{CD}^{+} \mathrm{T}$ cells was significantly downregulated in lymph node and spleen by DMF treatment from a mean of $100.0 \% \pm 8.9 \%$ and $100.0 \% \pm 5.0 \%$ in controls to a mean of $91.1 \% \pm 4.5 \%$ and $92.2 \% \pm 4.2 \%$ in DMF-treated mice $(p<0.05, p<0.01)$. CD4 ${ }^{+} T$ cells of the lymph node from DMF-treated mice also showed a reduced expression of CD25 compared to controls $(92.2 \% \pm 7.5 \%$ vs. $100.0 \% \pm 6.3 \%) \quad(p<0.05)$. CD25 expression on splenic $\mathrm{CD}^{+} \mathrm{T}$ cells remained unaltered by DMF. Furthermore, DMF treatment decreased the expression of CD69 on CD8 ${ }^{+} \mathrm{T}$ cells in lymph node and spleen from a mean of $100.0 \% \pm 11.3 \%$ and $100.0 \% \pm 3.9 \%$ in controls to a mean of $89.1 \% \pm 7.0 \%$ and $91.7 \% \pm 6.0 \%$ in DMF-treated mice $(p<0.05, p<0.01)$.

\section{Next page $\rightarrow$}

Figure 19: DMF decreases the expression of activation markers on T cells. (A) The effects of DMF on the expression of $\mathrm{CD} 69$ on $\mathrm{CD} 4^{+} \mathrm{T}$ cells and $\mathrm{CD} 8^{+} \mathrm{T}$ cells and $\mathrm{CD} 25$ on $\mathrm{CD} 4^{+} \mathrm{T}$ cells in lymph node and spleen were analyzed ex vivo by flow cytometry. $\mathrm{C} 57 \mathrm{BL} / 6$ mice were immunized with $\mathrm{rMOG}_{1-117}$ and treated with $15 \mathrm{mg} / \mathrm{kg}$ DMF or control twice a da y from d-7 until d12 p.i. (B) Application of DMF significantly reduces the expression of $\mathrm{CD} 69$ on $\mathrm{CD} 4^{+} \mathrm{T}$ cells and $\mathrm{CD} 8^{+} \mathrm{T}$ cells in lymph node and spleen and the expression $\mathrm{CD} 25$ on $\mathrm{CD}^{+} \mathrm{T}$ cells in the lymph node. Data are normalized to control and represented as mean $\pm \mathrm{SD}\left({ }^{*} p<0.05\right.$, $* * p<0.01$, unpaired t-test). 
A

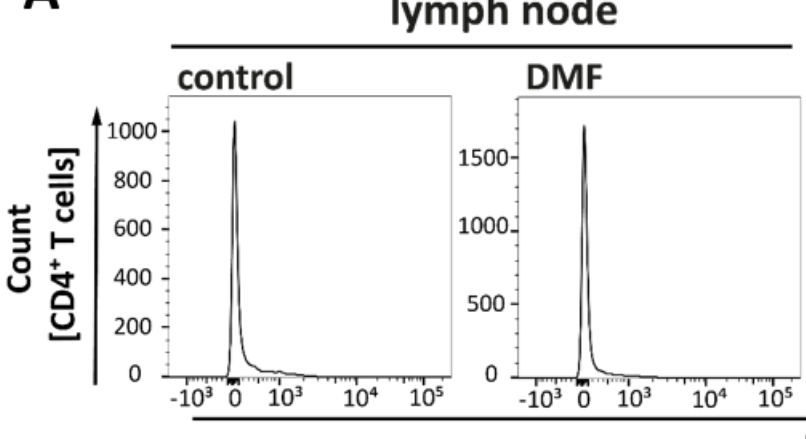

spleen
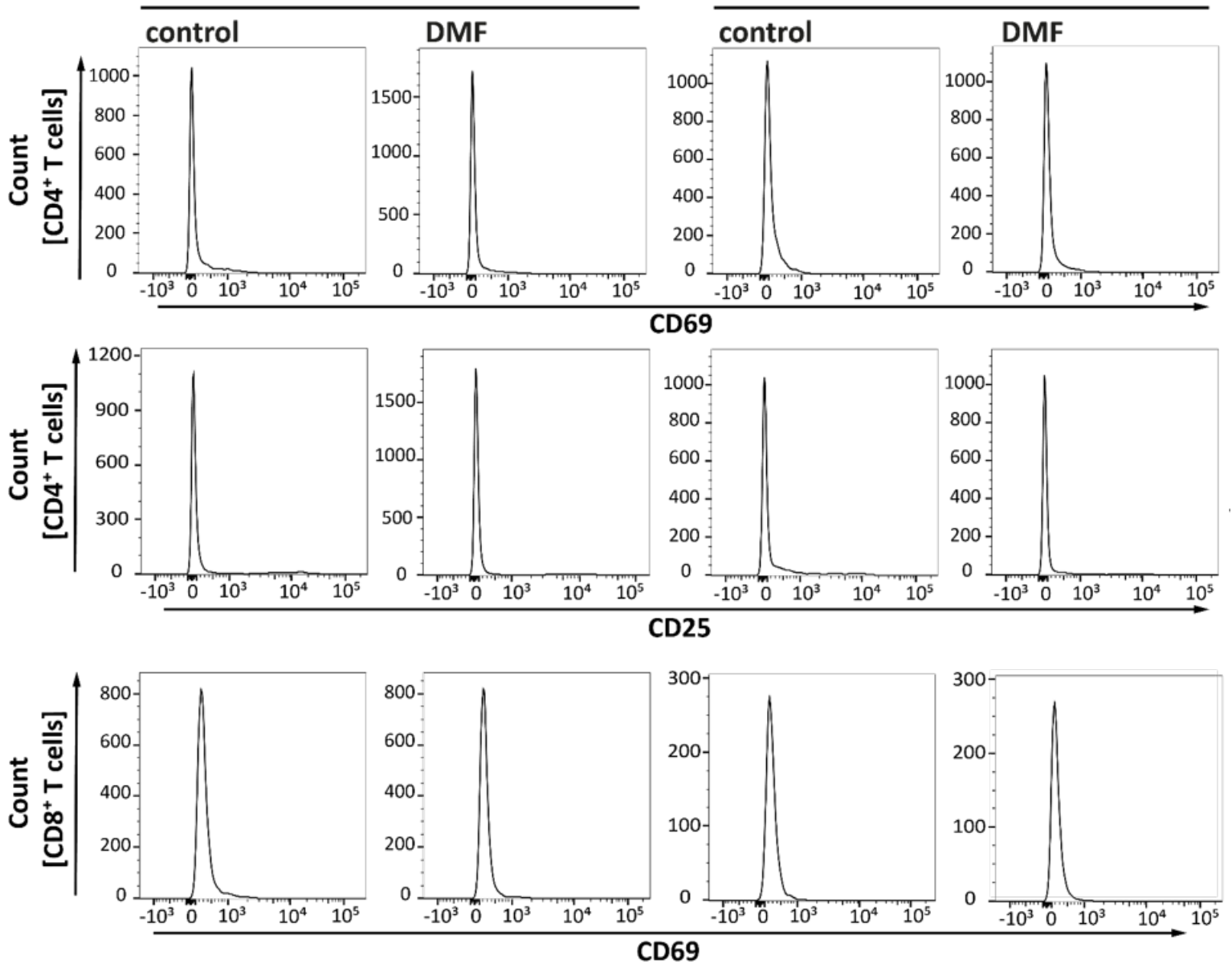

B

lymph node

spleen
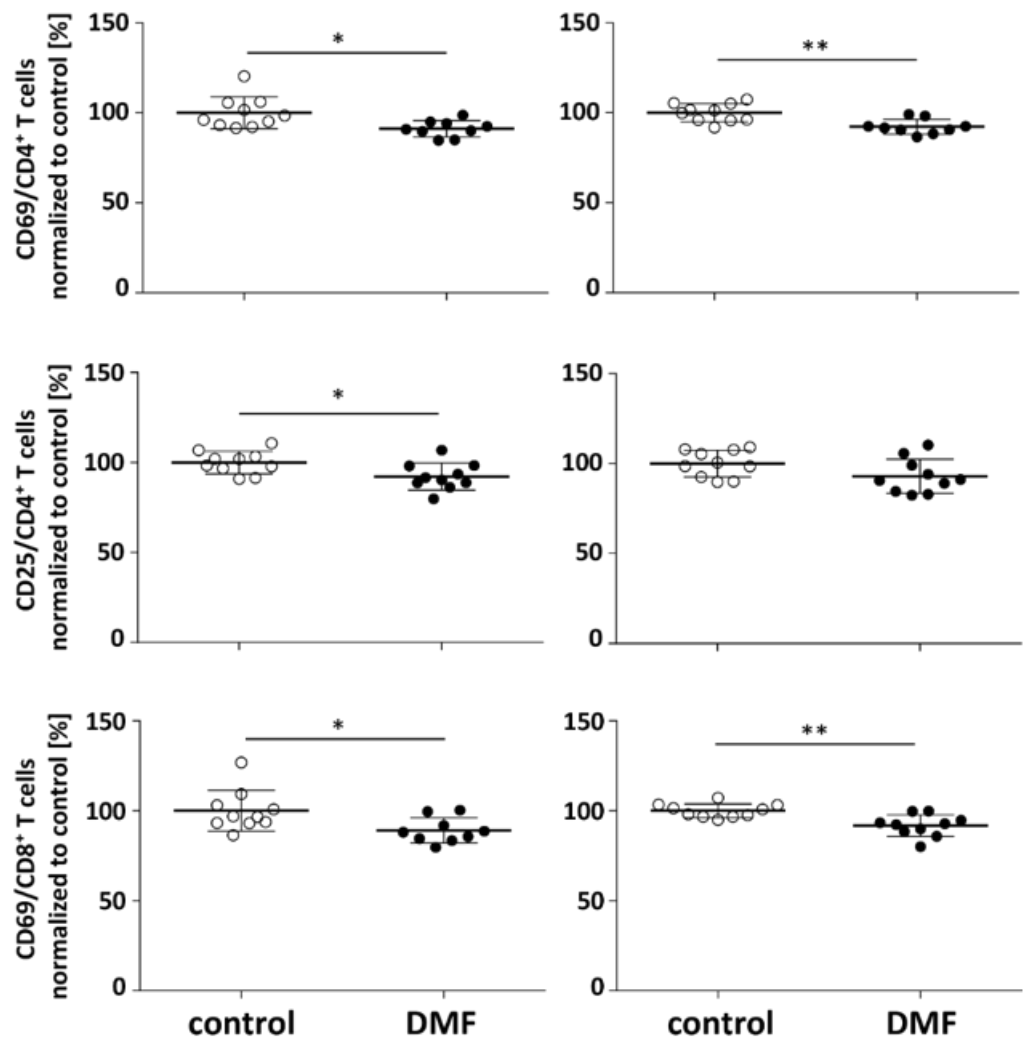


\subsection{DMF affected the $T$ cell activation marker CD44 on $\mathrm{CD}^{+}$ $T$ cells and $C D 8^{+} T$ cells}

CD44 is an adhesion receptor and usually expressed on activated T cells and long-lived memory cells (Baaten et al., 2010a). It is involved in several biological processes like migration of cells and inflammation. To investigate the effects of DMF on the expression of CD44 on CD4 ${ }^{+} \mathrm{T}$ cells and $\mathrm{CD}^{+} \mathrm{T}$ cells, lymphocytes and splenocytes were isolated from immunized mice treated with DMF or control and were stained for CD4, CD8 and CD44. CD4 ${ }^{+} \mathrm{T}$ cells and $\mathrm{CD} 8^{+} \mathrm{T}$ cells were divided into CD44 high (CD44 $\left.{ }^{\text {hi }}\right)$, CD44 intermediate (CD44 $\left.{ }^{\text {int }}\right)$ and CD44 low (CD44 ${ }^{\text {low }}$ ) T cells (Figure 20, Figure 21).

The frequency of $\mathrm{CD} 44^{\mathrm{hi}} \mathrm{CD} 4^{+} \mathrm{T}$ cells was significantly decreased in the spleen of DMF-treated mice $(22.1 \% \pm 1.8 \%)$ compared to controls $(25.5 \% \pm 4.1 \%) \quad(p<0.05)$ whereas the frequencies of CD44 ${ }^{\text {int }} \mathrm{CD} 4^{+} \mathrm{T}$ cells and $\mathrm{CD} 44^{\text {low }} \mathrm{CD} 4^{+} \mathrm{T}$ cells remained unaltered by DMF application (Figure 20). DMF treatment did not significantly modify the frequencies of $\mathrm{CD} 44^{\text {hi }} \mathrm{CD} 4^{+} \mathrm{T}$ cells, CD44 ${ }^{\text {int }} \mathrm{CD} 4^{+} \mathrm{T}$ cells and $\mathrm{CD} 44^{\text {low }} \mathrm{CD} 4^{+} \mathrm{T}$ cells in the lymph node. 
A

lymph node

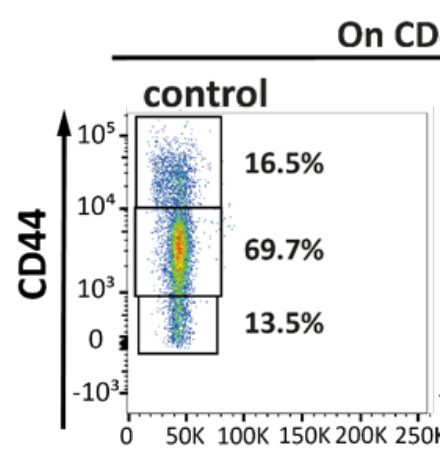

$4^{+} \mathrm{T}$ cells

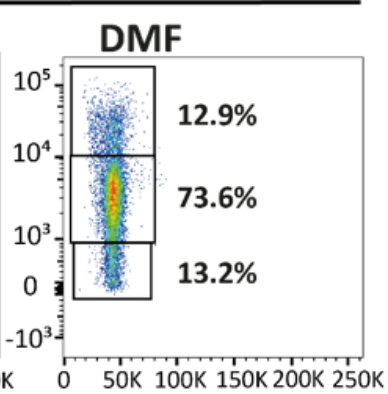

spleen

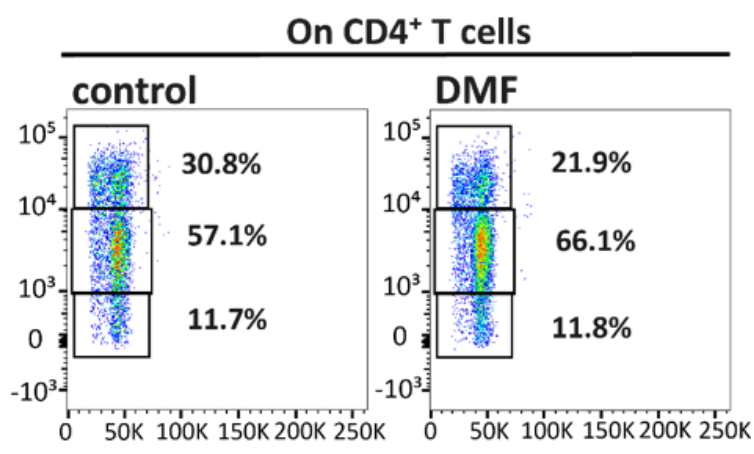

FSC-H

B

lymph node
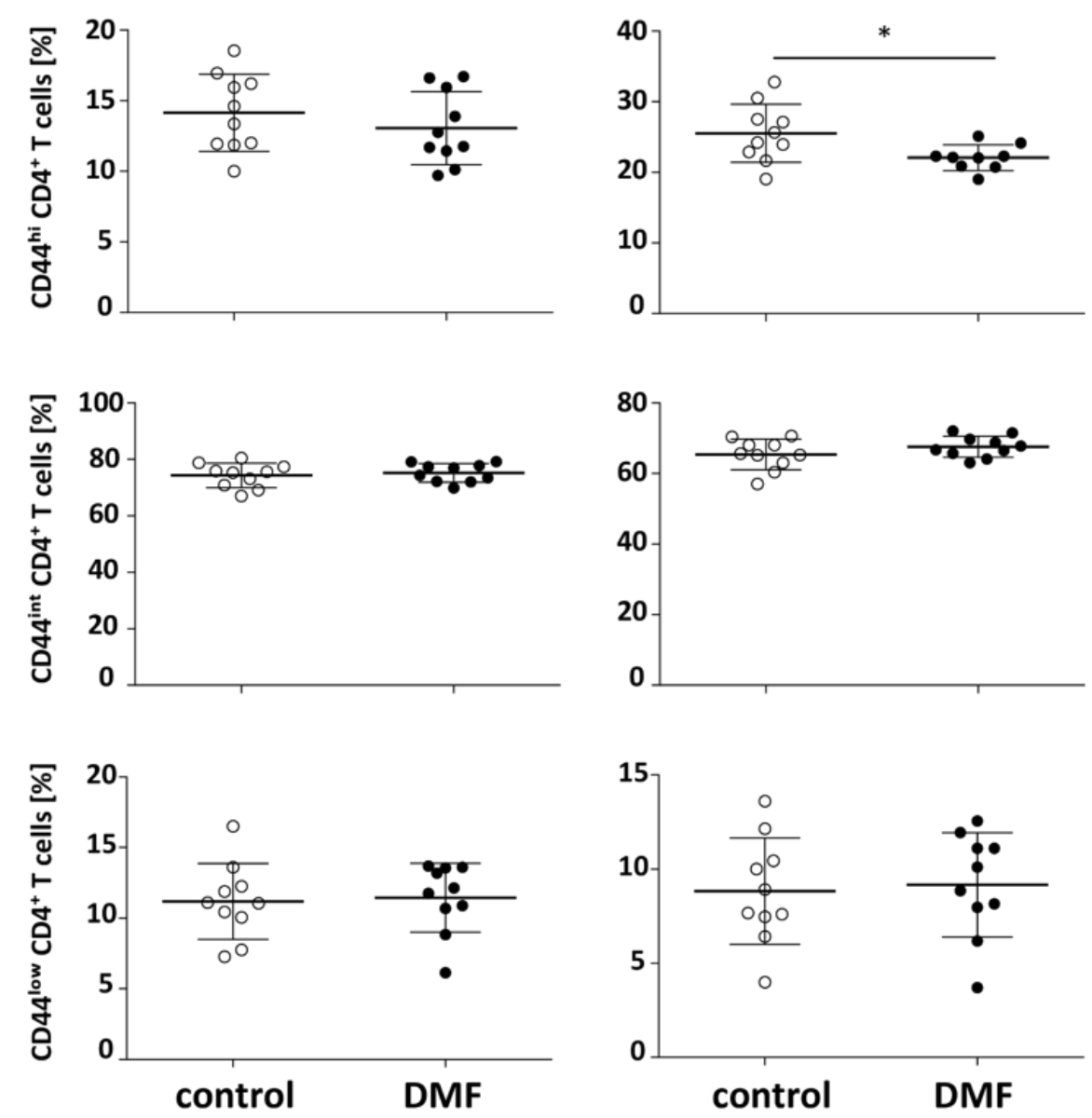

Figure 20: DMF decreases the frequency of $\mathrm{CD}_{4} 4^{\text {high }} \mathrm{CD}^{+} \mathbf{T}$ cells. The effects of $\mathrm{DMF}$ on CD44 expression were investigated in lymph node and spleen from $\mathrm{rMOG}_{1-117}$-immunized $\mathrm{C} 57 \mathrm{BL} / 6$ mice treated with $15 \mathrm{mg} / \mathrm{kg}$ DMF or control twice a day from d-7 until d12 p.i. (A) The expression of CD44 on the surface of $C D 4^{+} T$ cells was analyzed by flow cytometry. Subsets of $C D 4^{+} T$ cells were classified as follows: $C D 44$ high $\left(\mathrm{CD} 44^{\text {hi }}\right)$, CD44 intermediate $\left(\mathrm{CD} 44^{\text {int }}\right)$ and $\mathrm{CD} 44$ low $\left(\mathrm{CD} 44^{\text {low }}\right)$. (B) DMF treatment induces a shift in $\mathrm{CD}^{+} \mathrm{T}$ cell subpopulations towards fewer $\mathrm{CD} 44$ high cells in spleen. The frequencies of $\mathrm{CD} 4^{+} \mathrm{T}$ cell subpopulations in the lymph node remain unaltered under DMF treatment. Data are represented as mean $\pm \mathrm{SD}\left({ }^{*} p<0.05\right.$, unpaired t-test). 
Besides the analysis of $\mathrm{CD}^{+} \mathrm{T}$ cell subpopulations, DMF effects were also examined on subpopulations of $\mathrm{CD} 8^{+} \mathrm{T}$ cells. The frequency of splenic $\mathrm{CD} 44^{\mathrm{hi}} \mathrm{CD} 8^{+} \mathrm{T}$ cells was considerably reduced by DMF treatment $(14.4 \% \pm 2.0 \%)$ compared to controls $(16.8 \% \pm 1.8 \%)(p<0.05)$ whereas the frequencies of $\mathrm{CD} 44^{\text {int }} \mathrm{CD} 8^{+} \mathrm{T}$ cells and $\mathrm{CD} 44^{\text {low }} \mathrm{CD} 8^{+} \mathrm{T}$ cells were not altered by $\mathrm{DMF}$ application (Figure 21). DMF treatment did not significantly influence the frequencies of CD44 ${ }^{\text {hi }} \mathrm{CD} 4^{+} \mathrm{T}$ cells, $\mathrm{CD} 44^{\text {int }} \mathrm{CD} 4^{+} \mathrm{T}$ cells and $\mathrm{CD} 44^{\text {low }} \mathrm{CD} 4^{+} \mathrm{T}$ cells in the lymph node. 
A

lymph node

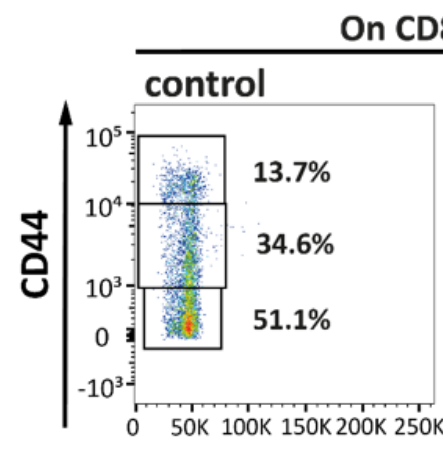

spleen

On $\mathrm{CD}^{+} \mathrm{T}$ cells

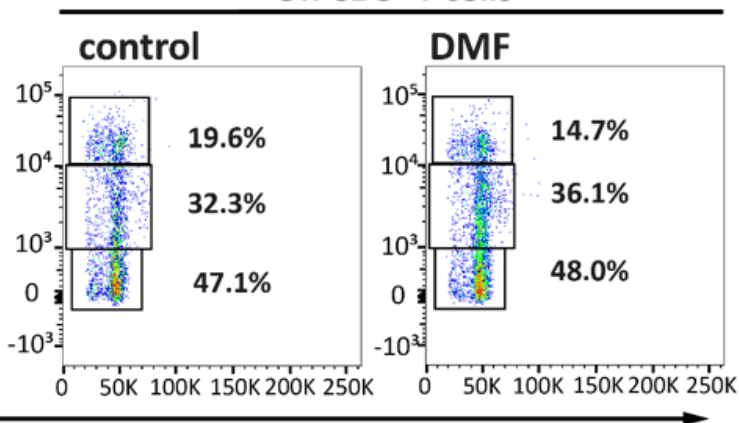

FSC-H
B
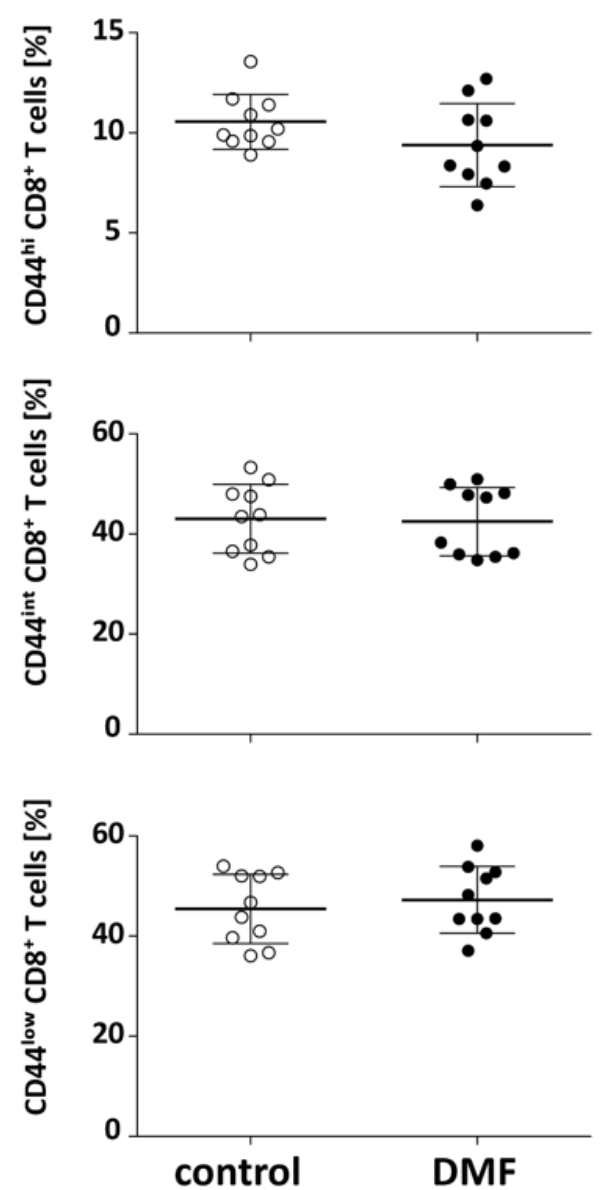

spleen
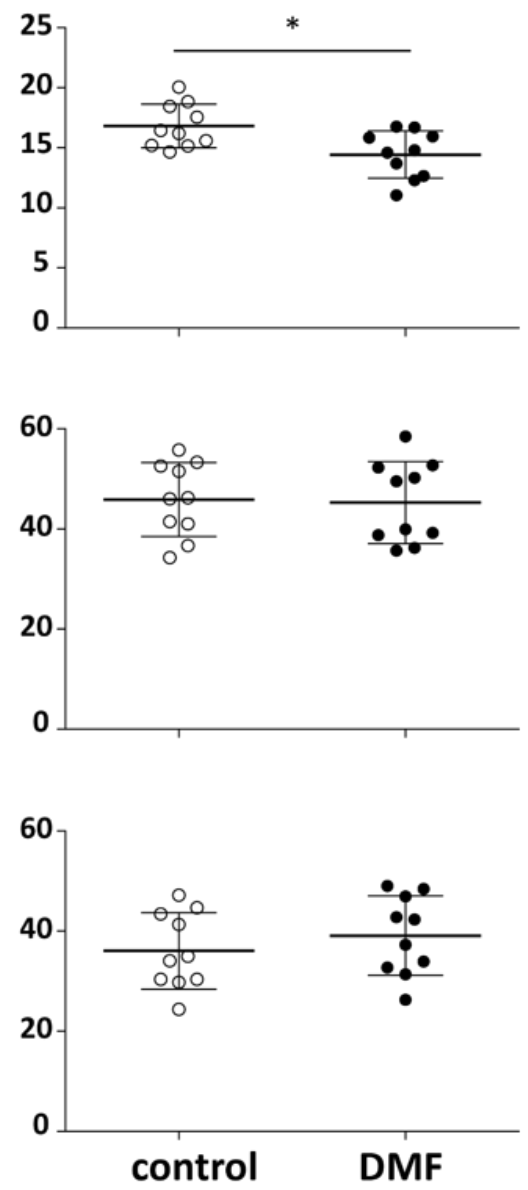

Figure 21: The frequency of $C D 44^{\text {high }} \mathrm{CD}^{+} \mathrm{T}$ cells is reduced by DMF. The effects of DMF on CD44 expression were investigated in lymph node and spleen from $\mathrm{rMOG}_{1-117}$-immunized $\mathrm{C} 57 \mathrm{BL} / 6$ mice treated with $15 \mathrm{mg} / \mathrm{kg}$ DMF or control twice a day from d-7 until d12 p.i. (A) The expression of CD44 on the surface of $\mathrm{CD}^{+} \mathrm{T}$ cells was analyzed by flow cytometry. Subsets of $\mathrm{CD} 8^{+} \mathrm{T}$ cells were classified as follows: $\mathrm{CD} 44$ high

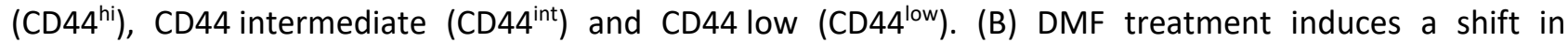
$\mathrm{CD}^{+} \mathrm{T}$ cell subpopulations towards fewer $\mathrm{CD} 44$ high cells in spleen. The frequencies of $\mathrm{CD} 8^{+} \mathrm{T}$ cell subpopulations in the lymph node remain unaltered under DMF treatment. Data are represented as mean $\pm \mathrm{SD}\left({ }^{*} \mathrm{p}<0.05\right.$, unpaired t-test). 


\subsection{DMF decreased IFN $\quad$-producing $\mathrm{CD}^{+} \mathrm{T}$ cells numbers}

After the characterization of DMF effects on the T cell activation, it was further analyzed if DMF treatment could directly affect the differentiation of pro-inflammatory T cells. Effects of DMF on the frequency of IFN $y$-producing $C D 4^{+} T$ cells and IL-17-producing $C D 4^{+} T$ cells were investigated by ex vivo stimulation of lymphocytes and splenocytes, isolated from control- or DMF-treated mice, with ionomycin and PMA respectively. Cytokine secretion was blocked and intracellular IFNY and IL-17 staining was analyzed by flow cytometry (Figure 22). CD4 ${ }^{+} \mathrm{T}$ cells were investigated for IFN $\gamma$ and IL-17 production. DMF significantly reduced the frequency of IFNY-producing CD4+ $4^{+}$cells in lymph node and spleen from a mean of $2.1 \% \pm 0.9 \%$ and $6.8 \% \pm 2.2 \%$ in controls to a mean of $1.0 \% \pm 0.4 \%$ and $4.4 \% \pm 0.9 \%$ in DMF-treated mice $(p<0.01)$. DMF treatment slightly reduced IL-17producing $\mathrm{CD}^{+} \mathrm{T}$ cells compared to controls, but this effect was not statistically significant. 
A lymph node

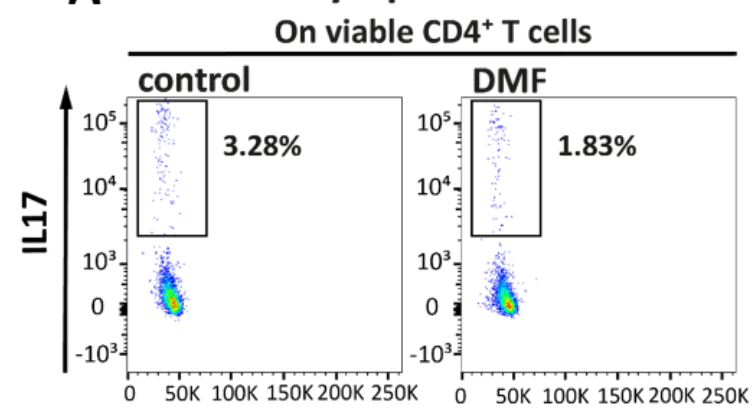

spleen

On viable $\mathrm{CD}^{+} \mathrm{T}$ cells
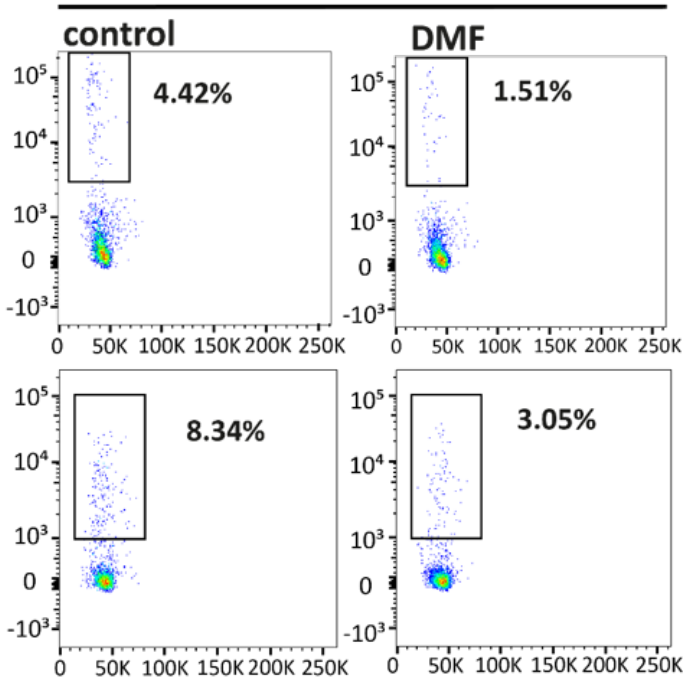

\section{FSC-H}

B
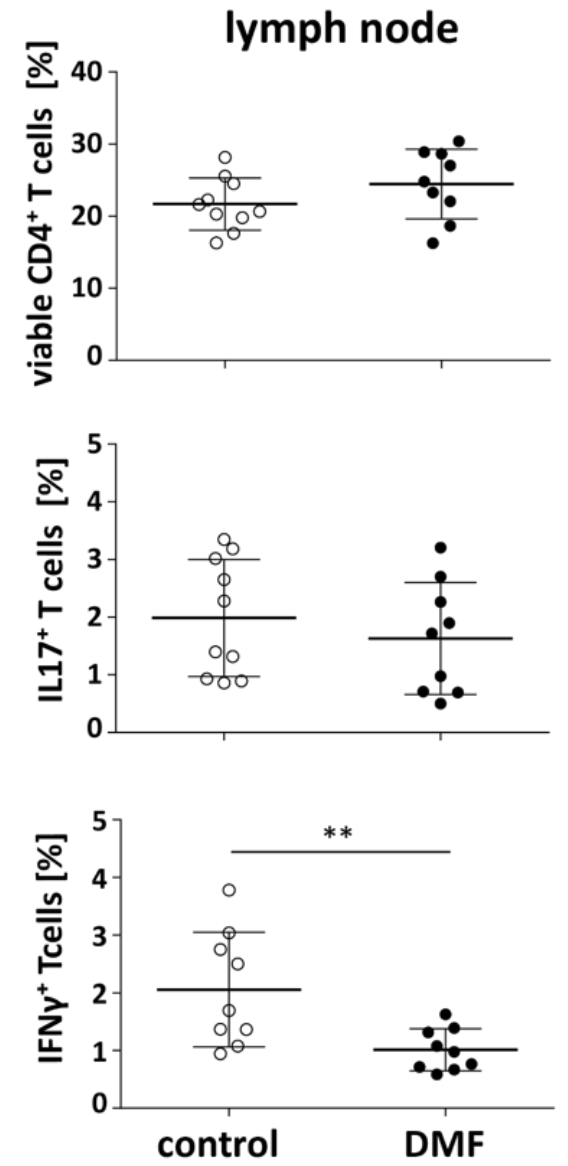

spleen
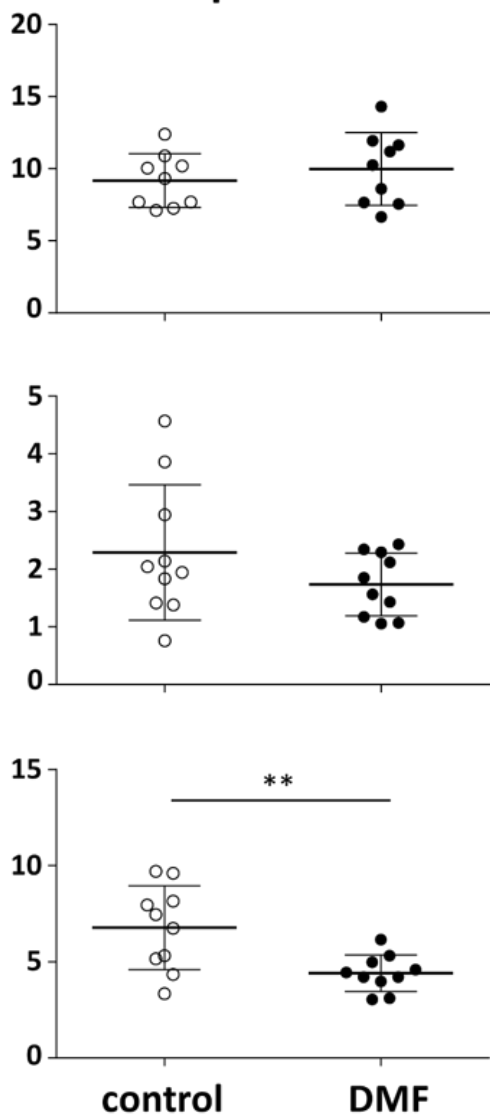

Figure 22: DMF treatment reduces the differentiation of IFN ${ }^{+} T$ cells and IL17 ${ }^{+} \mathrm{T}$ cells Splenocytes and lymphocytes were isolated from C57BL/6 mice immunized with $\mathrm{rMOG}_{1-117}$ and treated with $15 \mathrm{mg} / \mathrm{kg}$ DMF or control twice a day from d-7 until d12 p.i. (A) After ex vivo stimulation with lonomycin and PMA the

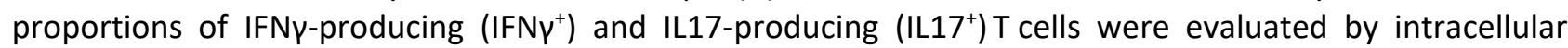
cytokine staining and flow cytometry. (B) In vivo treatment with DMF significantly decreases the frequency of IFN $\gamma^{+} T$ cells in lymph node and spleen while the frequencies of viable CD4 $4^{+} \mathrm{T}$ cells and $I \mathrm{~L} 17^{+} \mathrm{T}$ cells remain unaltered. Data are represented as mean $\pm S D(* * p<0.01$, unpaired t-test) 


\subsection{The frequency of regulatory $T$ cells was not influenced by DMF treatment}

For the investigation of DMF effects on anti-inflammatory T cells, the frequency of regulatory T cells among lymphatic and splenic $\mathrm{CD}^{+}{ }^{+} \mathrm{T}$ cells was determined in immunized mice treated with either DMF or control. Regulatory T cells are characterized by the expression of the transcription factor Foxp3 and additionally by the surface marker CD25 (Hori et al., 2003). Thus, surface staining for CD4, CD25 and intracellular staining of Foxp3 was performed and the frequencies of Foxp3 ${ }^{+}$ and Foxp $3^{+} \mathrm{CD} 25^{+}$cells within the population of $\mathrm{CD} 4^{+} \mathrm{T}$ cells were analyzed via flow cytometry. As seen in Figure 23, data analysis revealed that DMF treatment did not majorly affect the frequency of regulatory T cells. 


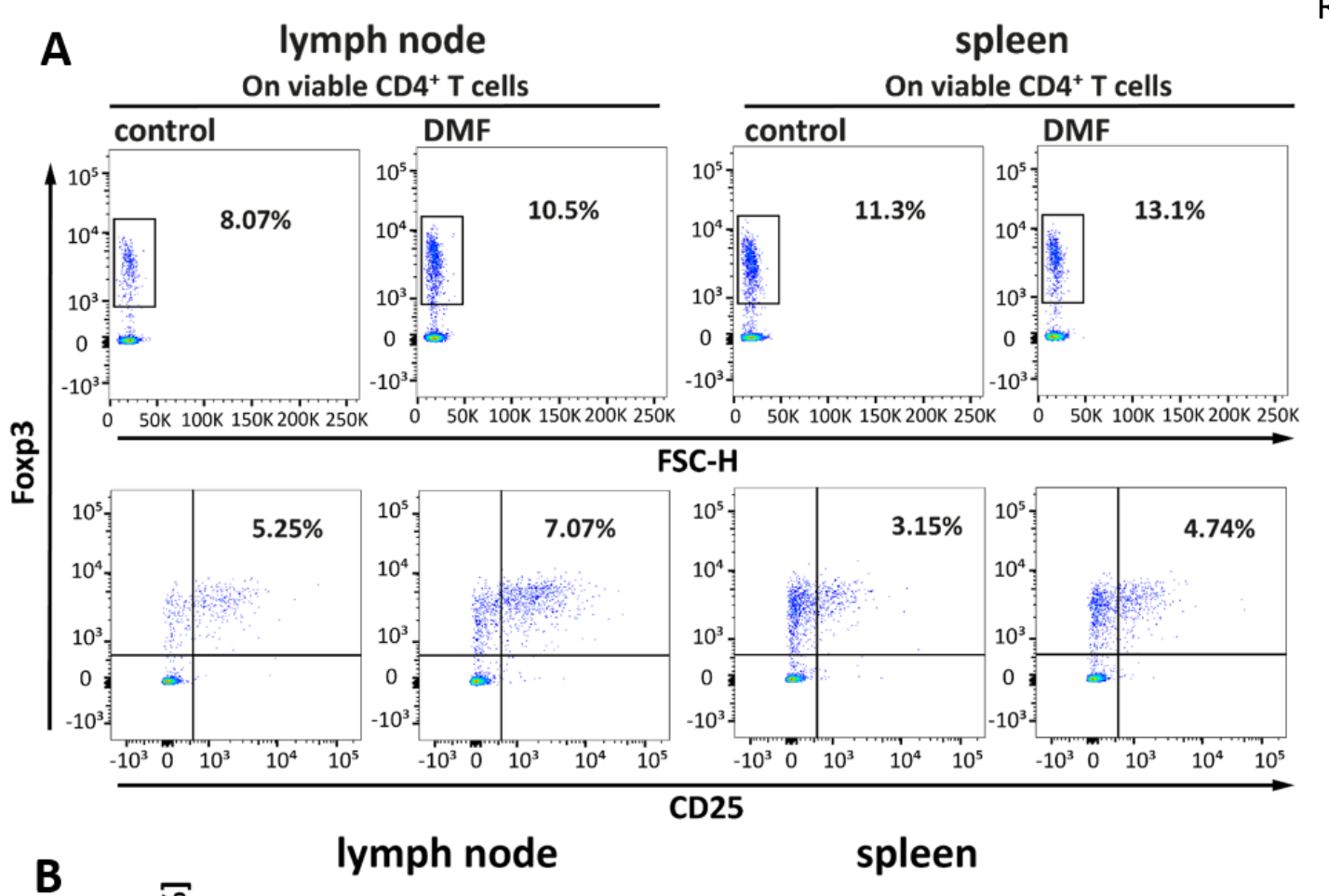

Results
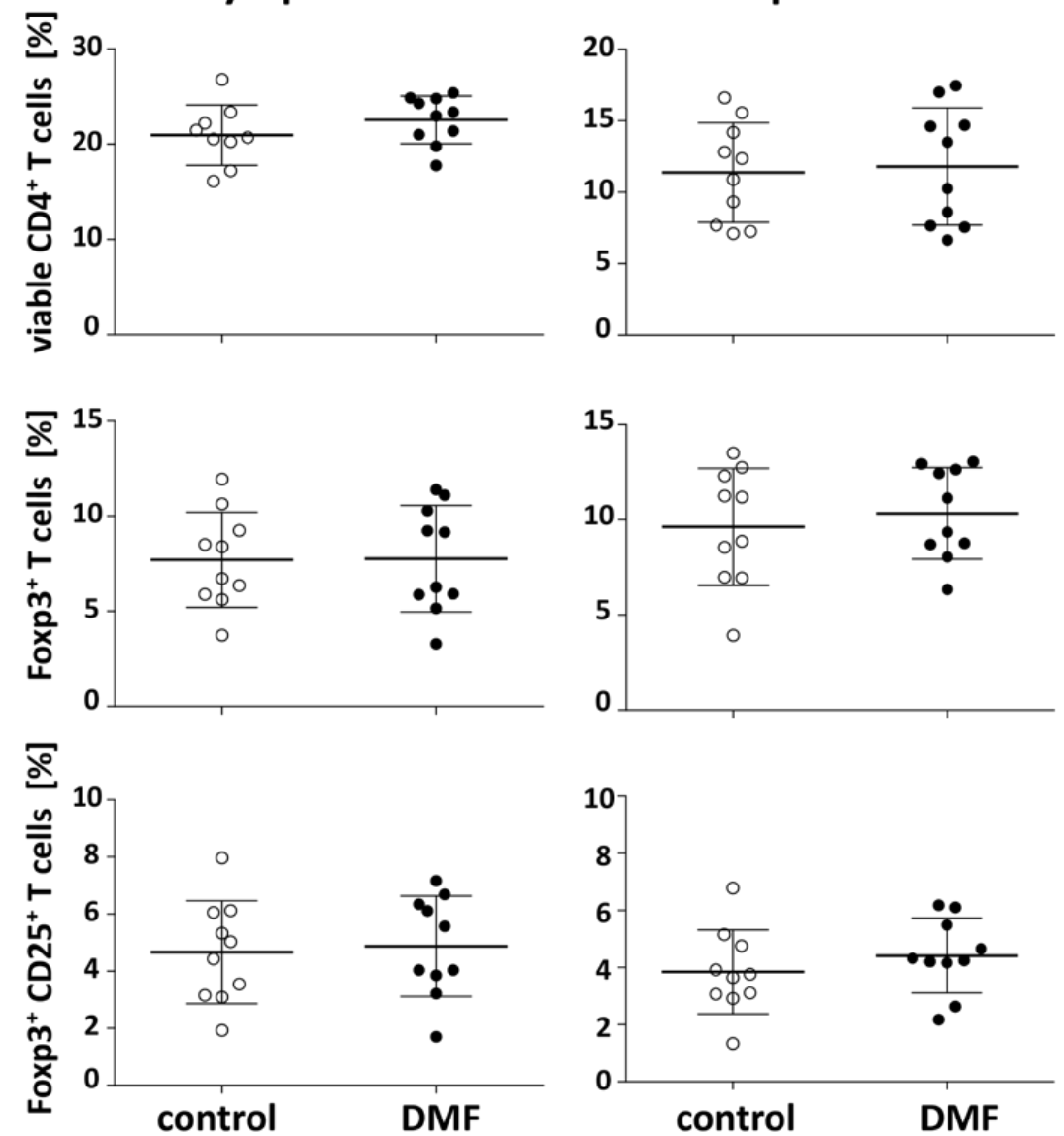

Figure 23: DMF treatment does not alter regulatory $T$ cell frequencies. Splenocytes and lymphocytes were isolated from $\mathrm{C} 57 \mathrm{BL} / 6$ mice immunized with $\mathrm{rMOG}_{1-117}$ and treated with $15 \mathrm{mg} / \mathrm{kg}$ DMF or control twice a day from d-7 until d12 p.i. The frequencies of Foxp $3^{+} \mathrm{T}$ cells and Foxp $3^{+} \mathrm{CD} 25^{+} \mathrm{T}$ cells were assessed by intracellular and surface staining and flow cytometry. In vivo treatment with DMF does not alter the frequencies of Foxp3 $3^{+} \mathrm{T}$ cells and Foxp $3^{+} \mathrm{CD} 25^{+} \mathrm{T}$ cells in lymph node and spleen. Data are represented as mean \pm SD. 


\subsection{In vivo DMF-treated T cells showed reduced proliferation upon antigen-independent activation in vitro}

To investigate whether DMF treatment in vivo could alter the functional properties of T cell activation and proliferation in vitro, T cells were isolated from naïve C57BL/6 mice treated with $15 \mathrm{mg} / \mathrm{kg}$ DMF or control for 19 days. The purified T cells were labeled with the fluorescent dye CFSE and stimulated with anti-CD3/CD28 in an antigen-independent manner. CFSE fluorescence intensity is halved with each cell division and by analyzing the CFSE profile of T cells by flow cytometry, the number of cell divisions can be measured (Parish, 1999).

Proliferation of $\mathrm{CD}^{+} \mathrm{T}$ cells and $\mathrm{CD}^{+} \mathrm{T}$ cells was divided in following proliferation rates: low proliferation, intermediate proliferation and high proliferation (Figure 24B). The total proliferation of in vivo DMF-treated $\mathrm{CD}^{+} \mathrm{T}$ cells, stimulated with $0.125 \mu \mathrm{g} / \mathrm{ml}$ anti-CD3, was significantly reduced compared to controls $(76.4 \% \pm 3.8 \%$ vs. $89.2 \% \pm 2.7 \%) \quad(p<0.001)$. This reduced proliferation was also demonstrated by the number of cell divisions. DMF-treated $C D 4^{+} T$ cells showed an increased frequency of cells with low proliferation rate compared to controls (DMF: $38.3 \% \pm 3.5 \%$ vs. control: $22.7 \% \pm 7.0 \%)(p<0.01)$ and reduced frequency of cells with high proliferation rate (DMF: $13.9 \% \pm 3.7 \%$ vs. control: $36.9 \% \pm 12.3 \%)(p<0.001)$. DMF-treated $\mathrm{CD}^{+} \mathrm{T}$ cells, stimulated with $0.25 \mu \mathrm{g} / \mathrm{ml}$ anti-CD3, showed only a significant reduction in the frequency of cells with high proliferation rate (DMF: $30.6 \% \pm 12.9 \%$ vs. control: $46.4 \% \pm 10.7 \%$ ) $(p<0.01)$. The frequency of $\mathrm{CD}^{+} \mathrm{T}$ cells with low proliferation rate, stimulated with $0.25 \mu \mathrm{g} / \mathrm{ml}$ anti-CD3, and the frequencies $\mathrm{CD}^{+} \mathrm{T}$ cells with intermediate proliferation rate, stimulated with $0.125 \mu \mathrm{g} / \mathrm{ml}$ anti-CD3 or $0.25 \mu \mathrm{g} / \mathrm{ml}$ anti-CD3, were not significantly altered by DMF treatment.

In vivo DMF treatment also reduced the total proliferation of $\mathrm{CD}^{+} \mathrm{T}$ cells, stimulated with $0.125 \mu \mathrm{g} / \mathrm{ml}$ anti-CD3, when compared to control-treated $\mathrm{CD} 8^{+}$T cells $(86.9 \% \pm 3.4 \%$ vs. $94.6 \% \pm 0.9 \%)(p<0.0001$ ) (Figure 24B). This decreased proliferation was also demonstrated by the number of cell divisions. DMF-treated $C D 8^{+} \mathrm{T}$ cells showed an increased frequency of cells with low proliferation rate compared to controls (DMF: $27.5 \% \pm 5.6 \%$ vs. control: $9.6 \% \pm 4.6 \%)(p<0.05)$ and reduced frequency of cells with high proliferation rate (DMF: $28.1 \% \pm 8.4 \%$ vs. control: $61.3 \% \pm 12.4 \%)(p<0.0001)$. The frequency of $\mathrm{CD} 8^{+} \mathrm{T}$ cells with intermediate proliferation rate, stimulated with $0.125 \mu \mathrm{g} / \mathrm{ml}$ anti-CD3, was not significantly altered by DMF treatment. 
Proliferation of $\mathrm{CD}^{+} \mathrm{T}$ cells, stimulated with $0.25 \mu \mathrm{g} / \mathrm{ml}$ anti-CD3, was neither changed totally nor in single proliferation rates by DMF treatment.

Besides the analysis of proliferation, T cell differentiation of proliferating $T$ cells was analyzed by the production of IFN $\gamma$ and GM-CSF measured by ELISA (Figure 24C). DMF-treated T cells, stimulated with $0.125 \mu \mathrm{g} / \mathrm{ml}$ anti-CD3, secreted significantly less IFN $\gamma$ when compared to controls (DMF: $2844 \pm 578 \mathrm{pg} / \mathrm{ml}$ vs. control: $3851 \pm 845 \mathrm{pg} / \mathrm{ml}$ ) (p<0.05). In vivo DMF treatment of T cells also significantly reduced the production of GM-CSF in vitro from mean secretion of $3553 \pm$ $796 \mathrm{pg} / \mathrm{ml}$ by control-treated T cells to a mean secretion of $2404 \pm 1194 \mathrm{pg} / \mathrm{ml}$ by DMF-treated T cells $(\mathrm{p}<0.05)$. In vitro IFNy production of T cells stimulated with $0.25 \mu \mathrm{g} / \mathrm{ml}$ anti-CD3 and GM-CSF production of T cells stimulated with $0.125 \mu \mathrm{g} / \mathrm{ml}$ anti-CD3 was not altered by DMF application in vivo. 
A

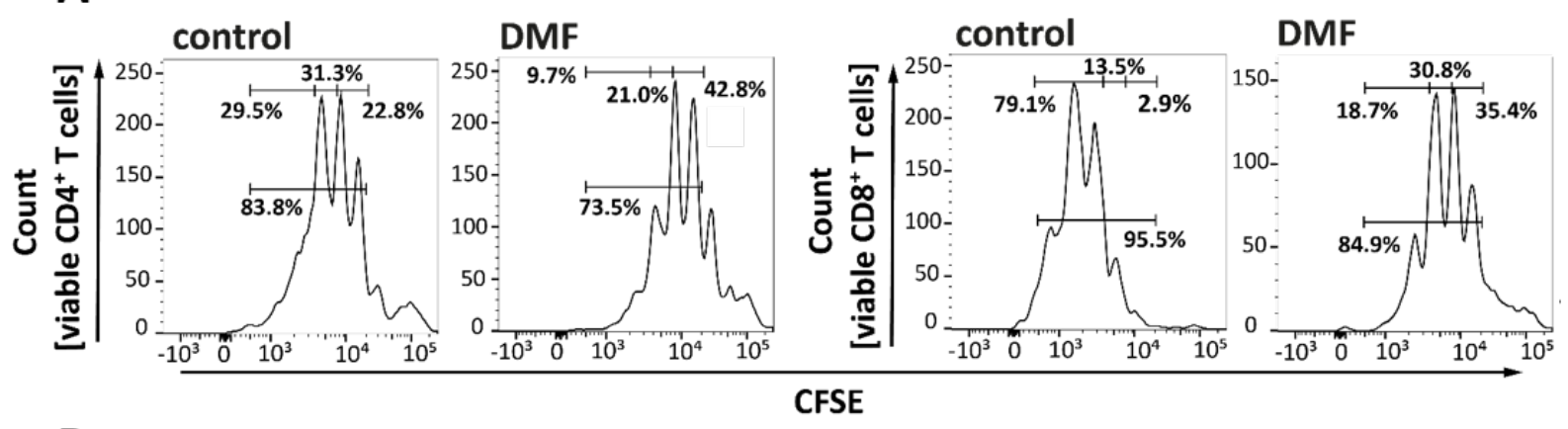

B
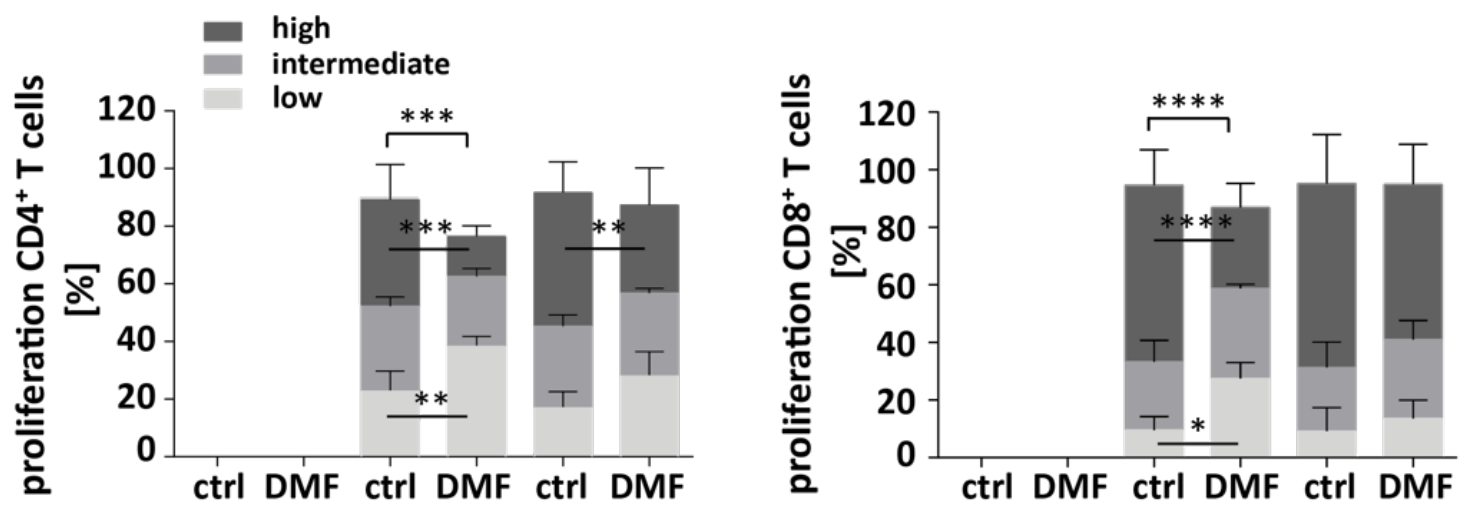

$\begin{array}{llll}\mu \mathrm{g} / \mathrm{ml} \text { anti-CD3 } & 0 & 0.125 & 0.25 \\ / \mathrm{ml} \text { anti-CD28 } & & 5 & \end{array}$

$\mu \mathrm{g} / \mathrm{ml}$ anti-CD3 $\quad 0 \quad \underline{0.125} \quad \underline{0.25}$

$\mu \mathrm{g} / \mathrm{ml}$ anti-CD28

5
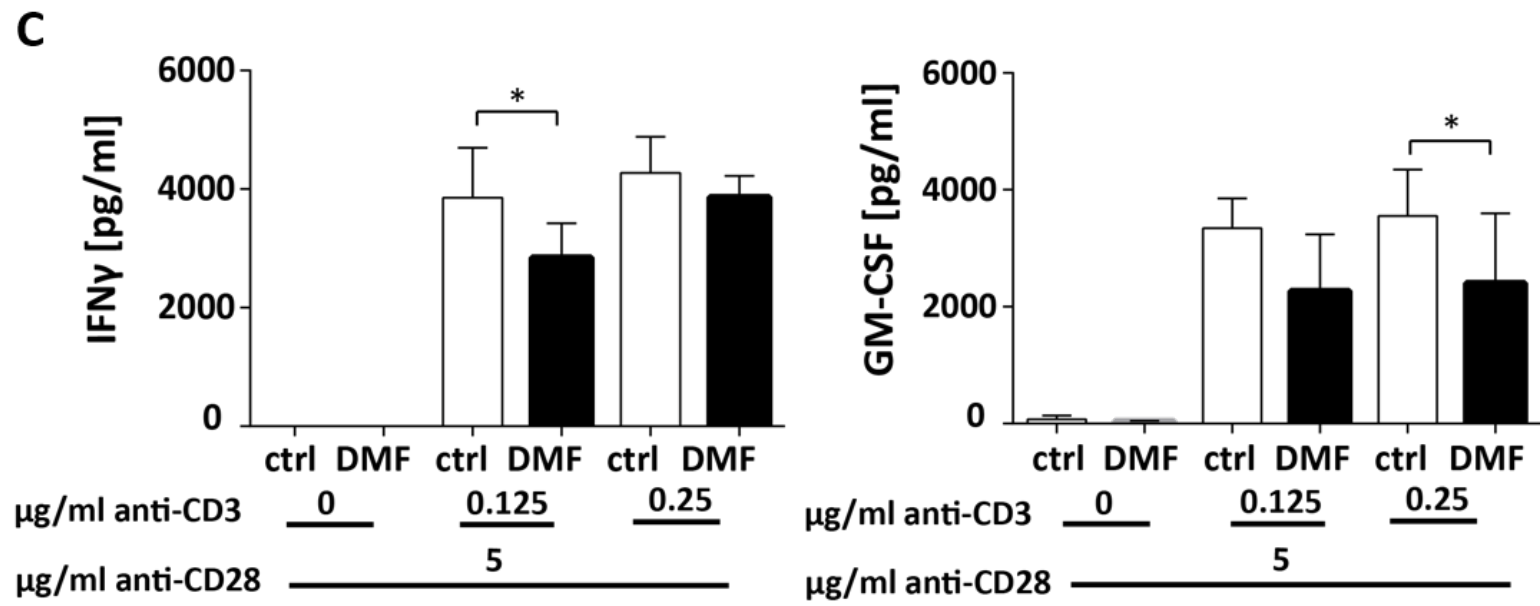

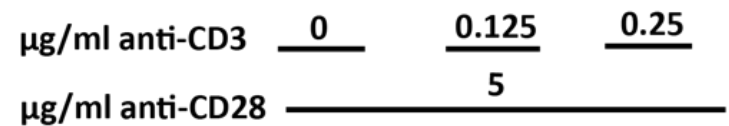

Figure 24: Proliferation of in vivo DMF-treated T cells is decreased after antigen-independent stimulation. T cells were purified from the spleens of naïve C57BL/6 mice treated with $15 \mathrm{mg} / \mathrm{kg}$ DMF or control twice a day for 19 days. In vitro, these T cells were stimulated with $0,0.125$ or $0.25 \mu \mathrm{g} / \mathrm{ml}$ anti-CD3 and $5 \mu \mathrm{g} / \mathrm{ml}$ anti-CD28 to induce $\mathrm{T}$ cell proliferation. (A) Proliferation of $\mathrm{CD} 4^{+} \mathrm{T}$ cells and $\mathrm{CD} 8^{+} \mathrm{T}$ cells was analyzed by flow cytometry. Representative FACS plots for $C D 4^{+} T$ cells and $C D 8^{+} T$ cells stimulated with $0.125 \mu \mathrm{g} / \mathrm{ml}$ anti-CD3 and $5 \mu \mathrm{g} / \mathrm{ml}$ anti-CD28 are shown. (B) In vivo DMF-treated T cells proliferate significantly less after antigen-independent stimulation compared to controls. Data are represented as mean \pm SD $\left(n=4,{ }^{*} p<0.05,{ }^{* *} p<0.01,{ }^{* * *} p<0.001,{ }^{* * * *} \mathrm{p}<0.0001\right.$, one-way ANOVA with Sidak post test, twoway ANOVA with Turkey multiple comparison test) (C) IFNY and GM-CSF production by control- or DMF treated T cells stimulated with $0,0.125$ or $0.25 \mu \mathrm{g} / \mathrm{ml}$ anti-CD3 and $5 \mu \mathrm{g} / \mathrm{ml}$ anti-CD28 was determined by ELISA. T cells treated with DMF produce significantly less IFN $\gamma$ and GM-CSF compared to control-treated T cells. Data are represented as mean \pm SD ( $n=5,{ }^{*} p<0.05$, one-way ANOVA with Sidak post test). 


\subsubsection{DMF treatment increased the antigen-presenting function of B cells}

After the investigation of DMF effects on T cells, it was analyzed how DMF influences pathogenic $B$ cells which contribute to the disease pathogenesis in this EAE model. The activation, function and phenotype of B cells were investigated via flow cytometry and co-culture experiments.

\subsection{DMF application increased MHC-II expression on B cells}

The next set of experiments investigated DMF-induced alterations in B cell subpopulations, activation state and effector functions. Therefore, $\mathrm{rMOG}_{1-117}$ immunized mice received daily oral treatment with either $15 \mathrm{mg} / \mathrm{kg}$ DMF or control from d-7 until d12 p.i. The activation state of B cells was analyzed ex vivo via the expression of MHC-II and the co-stimulatory molecules CD80, CD86 and CD40 in lymph node and spleen by flow cytometry (Figure 25). MHC-II expression was significantly enhanced on B cells in lymph nodes of DMF-treated mice from a mean of $3653 \pm$ $714 \mathrm{gMFI}$ in controls to a mean of $4538 \pm 620 \mathrm{gMFI}$ in DMF-treated animals. The expression of CD80, CD86 and CD40 on lymphatic and splenic B cells as well as MHC-II expression on splenic $B$ cells was not significantly changed by DMF application.

\section{Next page $\rightarrow$}

Figure 25: MHC-II expression on B cells is increased after DMF treatment. For the analysis of DMF effects on B cell activation, splenocytes and lymphocytes were isolated from C57BL/6 mice immunized with $\mathrm{rMOG}_{1-117}$ and treated with $15 \mathrm{mg} / \mathrm{kg}$ DMF or control twice a day from d-7 until d12 p.i. (A) The expression of MHC-II and co-stimulatory molecules CD80, CD86 and CD40 on B cells (B220 $0^{+} \mathrm{CD}^{+} 9^{+}$) was analyzed by flow cytometry. (B) Data evaluation revealed that DMF significantly increases the expression of MHC-II on $B$ cells of the lymph node whereas the co-stimulatory molecules remain mostly unaltered. Data are represented as mean $\pm S D\left({ }^{* *} p<0.01\right.$, unpaired t-test). 


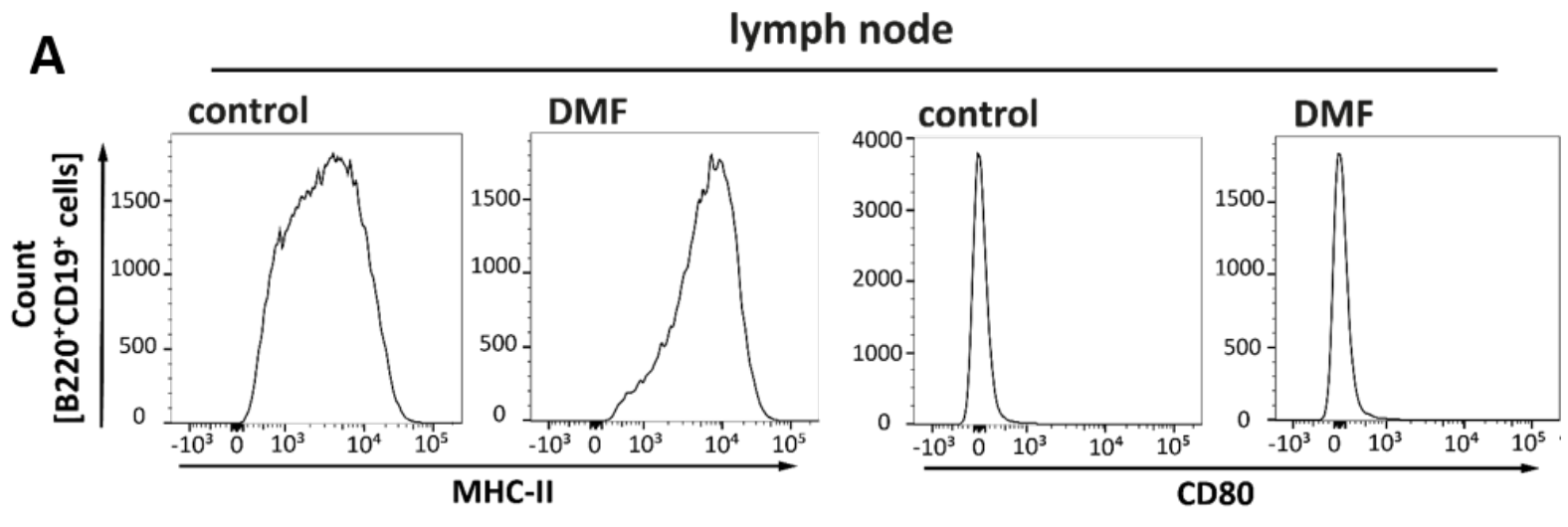

lymph node
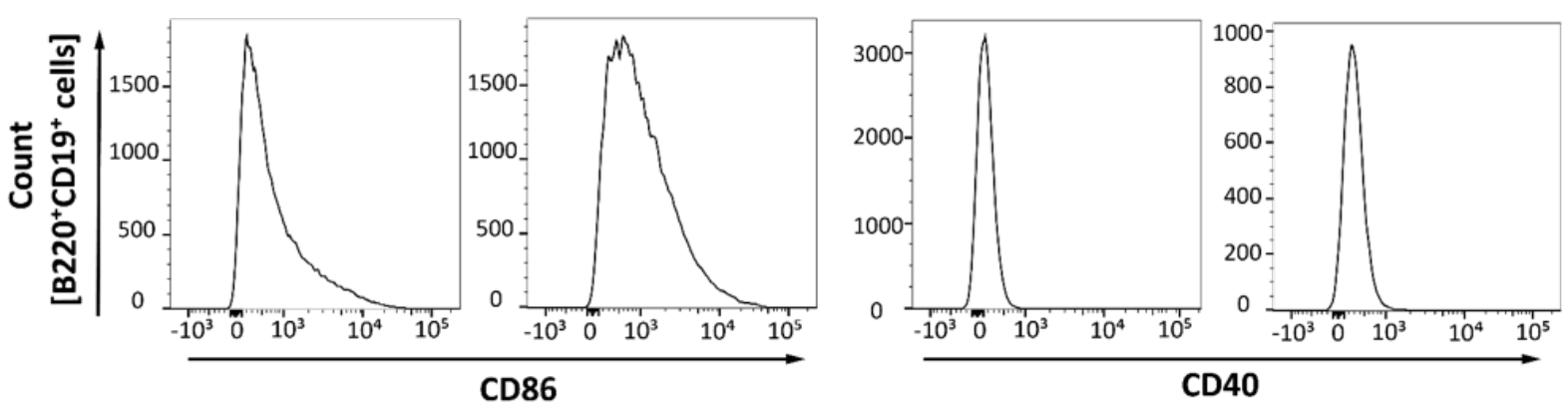

B
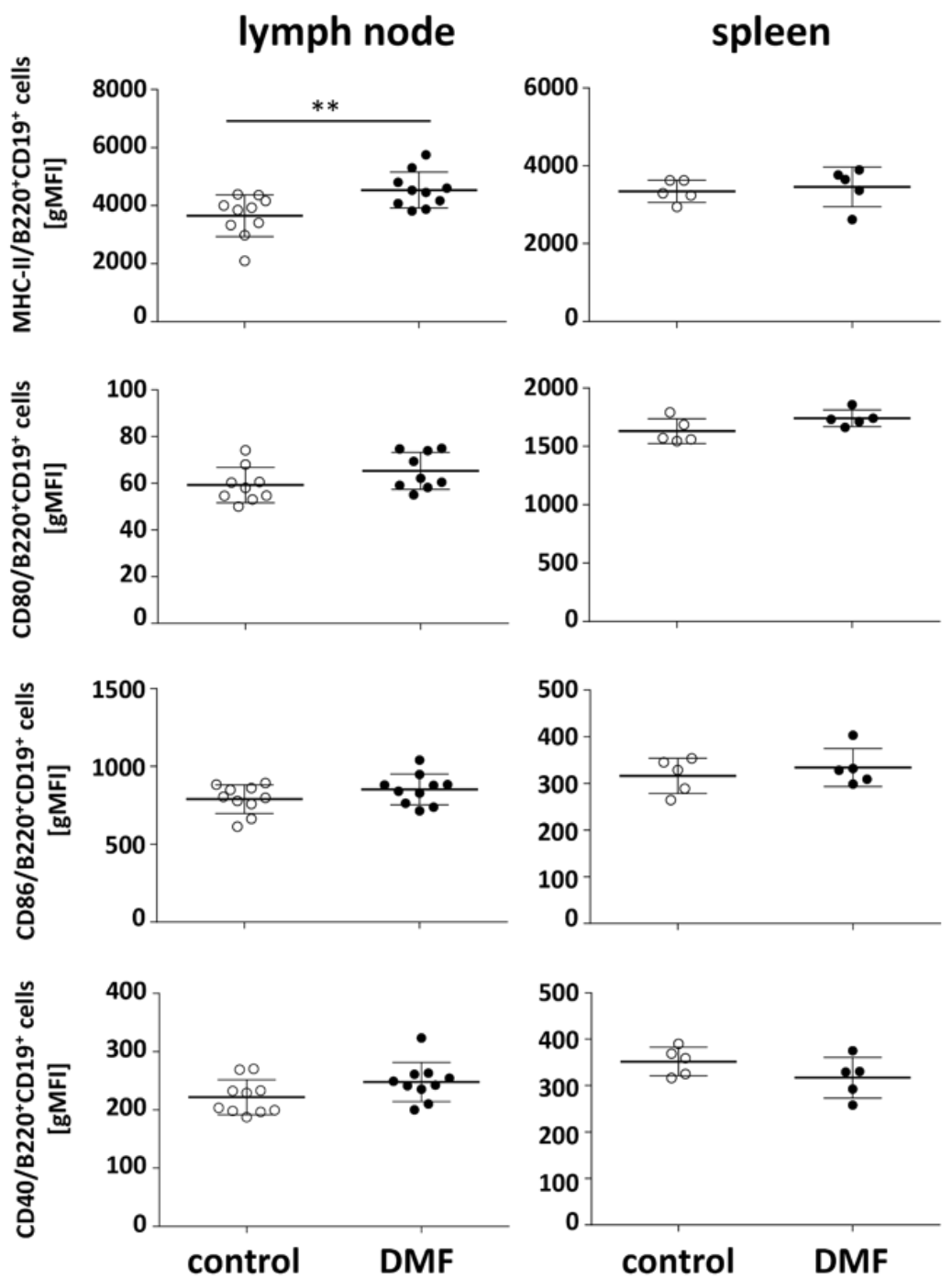


\subsection{The expression of activation markers was not influenced by DMF treatment}

To further investigate the DMF effect on B cell activation, the expression of the activation markers CD69 and CD25 as well as the expression of the antigen-specific activation marker Fas (CD95) were measured on B cells from DMF- or control-treated mice. Therefore lymph nodes and spleen were isolated from immunized mice treated with either $15 \mathrm{mg} / \mathrm{kg}$ DMF of control and B cell activation markers were analyzed by flow cytometry (Figure 26). The expression of CD69, CD25 and Fas on $B$ cells isolated from lymph node and spleen was comparable between DMF-treated and controltreated mice.
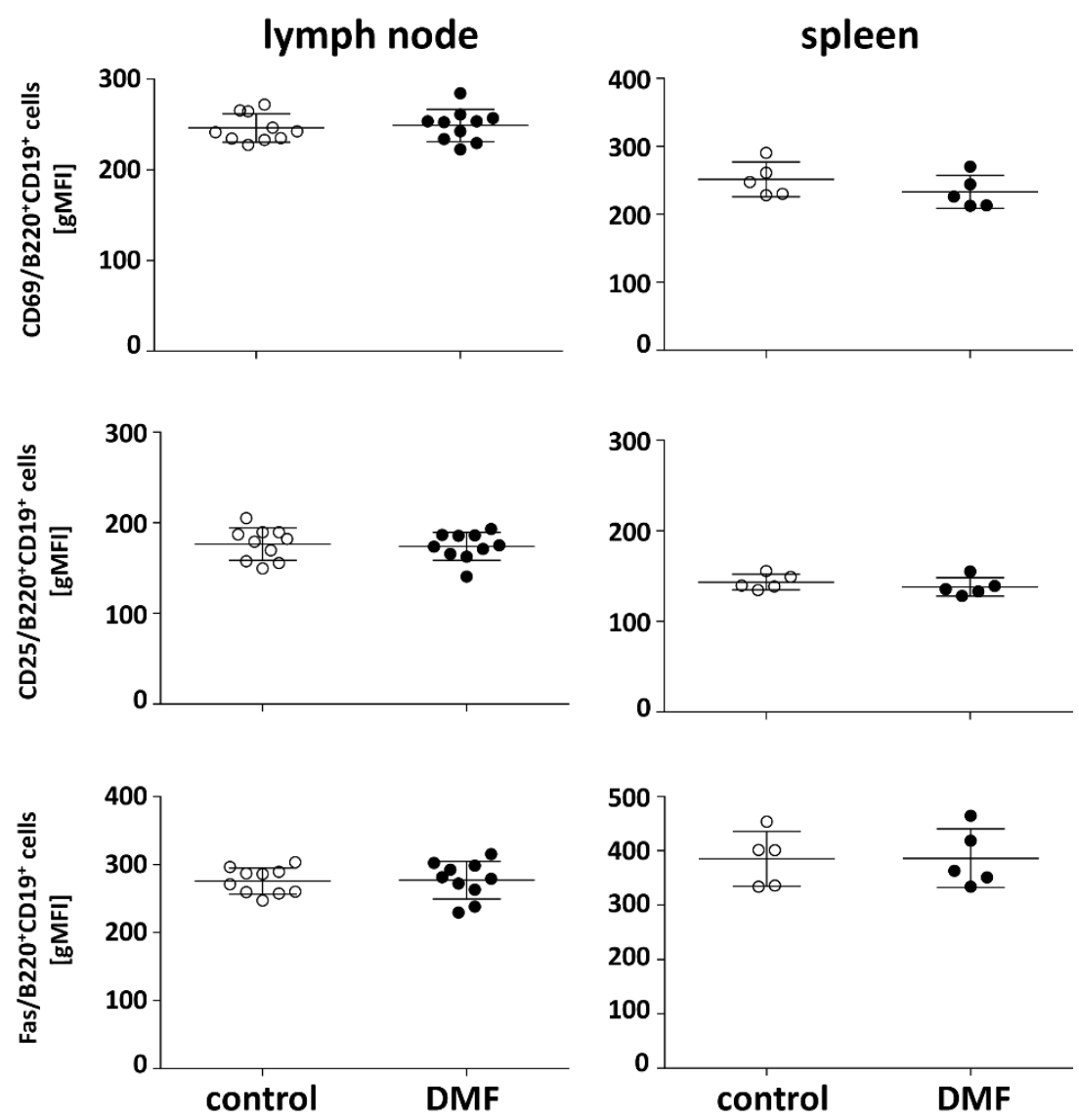

Figure 26: Expression levels of activation markers on B cells remain constant after DMF treatment. For the analysis of DMF effects on B cell activation, splenocytes and lymphocytes were isolated from $\mathrm{C} 57 \mathrm{BL} / 6$ mice immunized with $\mathrm{rMOG}_{1-117}$ and treated with $15 \mathrm{mg} / \mathrm{kg}$ DMF or control twice a day from d-7 until d12 p.i. The expression of activation marker CD69, CD25 and Fas (CD95) on B cells (B220 CD19+) was analyzed by flow cytometry. DMF treatment does not significantly alter the expression of activation markers on $B$ cells. Data are represented as mean \pm SD. 


\subsection{DMF treatment shifted B cell subsets towards more CD21 ${ }^{\text {int }} B$ cells}

After DMF effects were investigated on B cell activation, it was further analyzed if DMF also affects specific subpopulations of $B$ cells. Murine $B$ cells can be divided by distinct expression pattern of the surface molecules $C D 21$ and $C D 23$. Using flow cytometry, $C D 21^{\text {hi }} C D 23^{+} B$ cells can be distinguished from $\mathrm{CD} 21^{\text {int }} \mathrm{CD} 23^{+} \mathrm{B}$ cells and $\mathrm{CD} 21^{-} \mathrm{CD} 23^{-} \mathrm{B}$ cells (Shen and Fillatreau, 2015). $\mathrm{CD} 21^{\text {hi }} \mathrm{CD} 23^{+} \mathrm{B}$ cells, $\mathrm{CD} 21^{\text {int }} \mathrm{CD} 23^{+} \mathrm{B}$ cells and $\mathrm{CD} 21^{-} \mathrm{CD} 23^{-} \mathrm{B}$ cells will be further referred to as transitional, follicular and immature B cells, respectively, in this work.

To examine the effects of DMF on B cell subpopulations in spleen and bone marrow, the proportion of transitional, follicular and immature B cells were analyzed within the proportion of $\mathrm{B} 220^{+} \mathrm{CD} 19^{+} \mathrm{B}$ cells by flow cytometry (Figure 27). DMF treatment profoundly altered B cell subpopulations in immunized mice. DMF mediated a shift towards more follicular B cells and fewer transitional B cells in spleen, whereas the immature B cells in the bone marrow remained constant. Transitional B cells were decreased in DMF-treated animals $(12.9 \% \pm 2.5 \%)$ when compared to controls $(14.9 \% \pm 0.9 \%)(p<0.05)$. Follicular B cells were increased in DMF-treated mice $(74.6 \% \pm 2.5 \%)$ compared to control-treated animals $(72.6 \% \pm 1.1 \%)(p<0.05)$. 
spleen

On $\mathrm{B}^{220}{ }^{+} \mathrm{CD} 19^{+}$cells

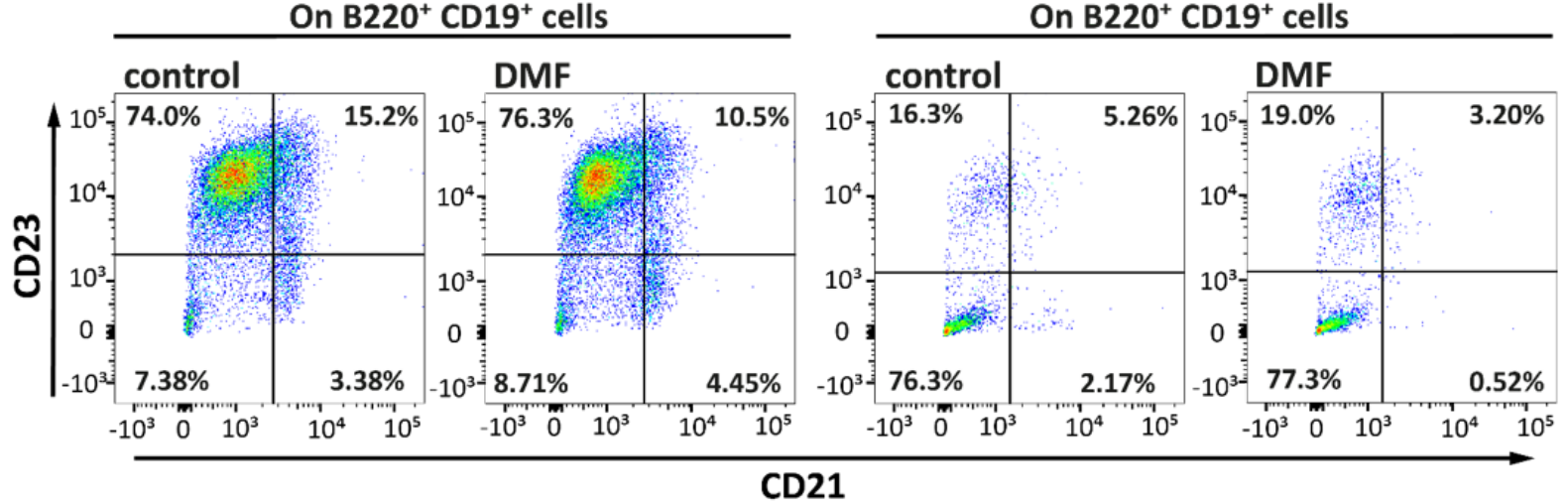

B
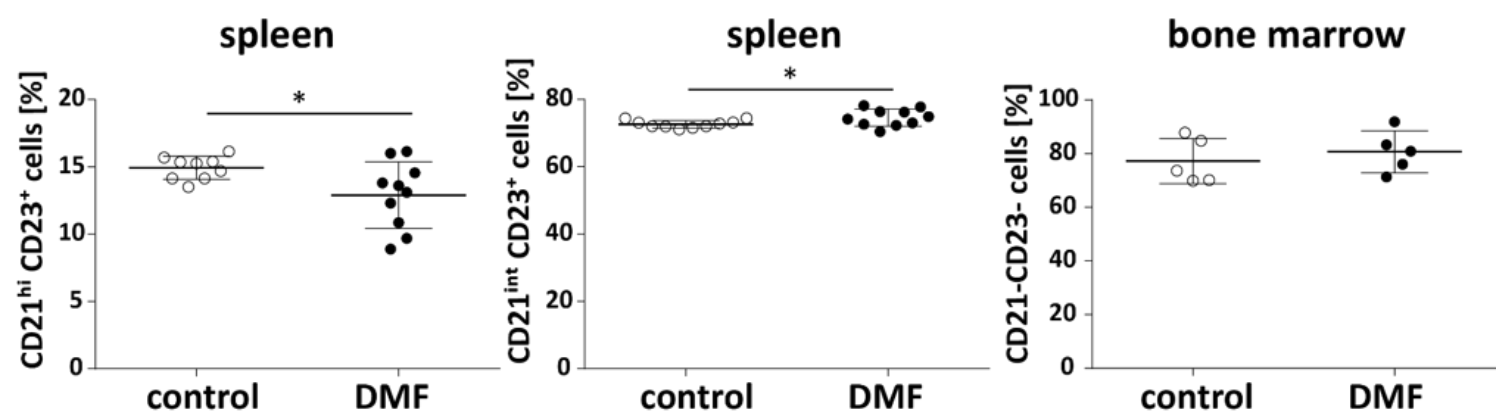

Figure 27: DMF induces a shift in B cell subpopulations. The effects of DMF B cell subpopulations were

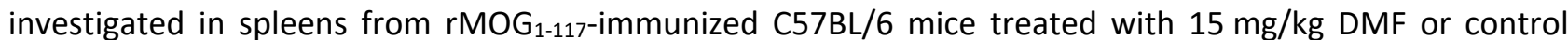
twice a day from d-7 until d12 p.i. The expression of CD21 and CD23 on the surface of $B$ cells $\left(B 220^{+} C D 19^{+}\right)$ was analyzed by flow cytometry. Subsets of $B$ cells were classified as follows: $C D 21^{\text {hi }} C D 23^{+} B$ cells (transitional B cells), CD21 $1^{\text {int }} \mathrm{CD} 23^{+} \mathrm{B}$ cells (follicular B cells) and CD21- $\mathrm{CD} 23^{-} \mathrm{B}$ cells (immature B cells). DMF treatment induces a shift in $B$ cell subpopulations towards fewer transitional and more follicular $B$ cells in spleen. Data are represented as mean \pm SD $\left({ }^{*} p<0.05\right.$, unpaired t-test).

\subsection{B cell phenotypes were not altered under DMF treatment}

Investigation of DMF effects on B cell subpopulations revealed that DMF treatment enhanced the frequency of follicular B cells, which reside in lymphoid follicles inside the spleen. Additionally, B cells can be divided in more specific phenotypes. Figure 28 shows the DMF effects on the following $B$ cell phenotypes: immature naïve $B$ cells $\left(C D 23^{-}, \lg M^{+}, \lg D^{-}\right)$, mature naïve $B$ cells $\left(\mathrm{CD}^{2} 3^{+}, \mathrm{CD} 38, \operatorname{IgM} \mathrm{I}^{-}, \operatorname{IgD}^{+}\right)$, memory $\mathrm{B}$ cells $\left(\mathrm{B} 220^{\text {high }}, \mathrm{CD} 38^{+}, \operatorname{IgD}\right)$, regulatory $\mathrm{B}$ cells $\left(\mathrm{CD} 1 \mathrm{~d}^{\text {high }}\right.$, $\left.\mathrm{CD}^{+}\right)$, germinal center $\mathrm{B}$ cells $\left(\mathrm{CD} 37^{+}, \mathrm{GL}^{+}\right)$and antigen-activated $\mathrm{B}$ cells $\left(\mathrm{CD} 27^{+}, \mathrm{CD} 69^{+}, \mathrm{CD} 80^{+}\right.$, MHC-II high).

To analyze whether DMF treatment in vivo could affect specific phenotypes of B cells, B cells were isolated from the spleen of immunized C57BL/6 mice treated with $15 \mathrm{mg} / \mathrm{kg}$ DMF or control from 
d-7 until d12 p.i. The purified B cells were analyzed and phenotypes distinguished by flow cytometry using the surface markers described above (Figure 28). DMF-treated animals displayed slightly lower frequencies of immature naïve and germinal center B cells. The frequencies of antigen-activated and regulatory B cells were slightly increased by DMF treatment. Nevertheless, these effects did not reach any statistically significance. The frequencies of mature naïve and memory B cells remained unaltered by DMF.
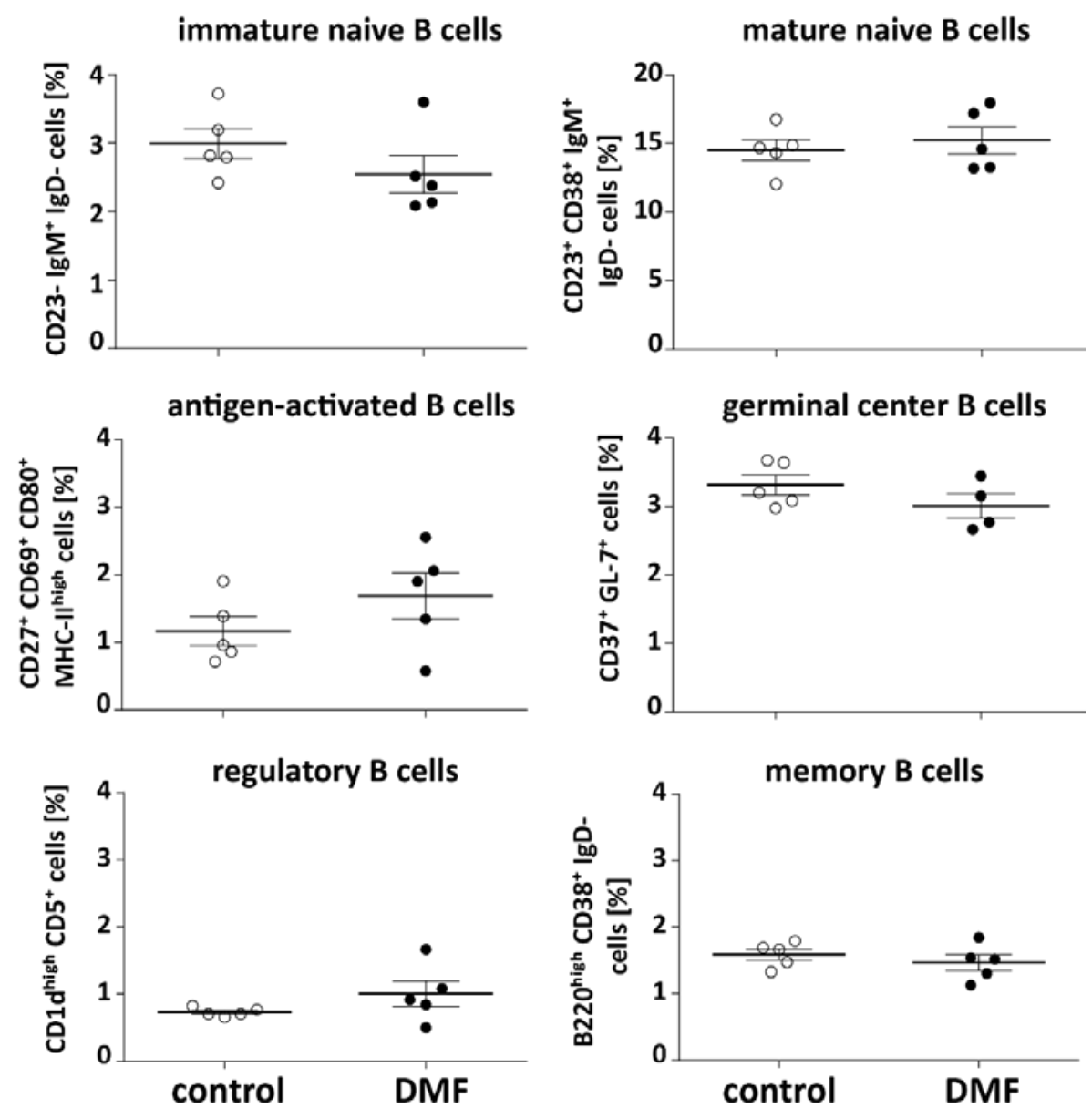

Figure 28: B cell phenotypes are not significantly affected by DMF treatment. B cells were purified from the spleens of $\mathrm{C} 57 \mathrm{BL} / 6$ mice immunized with $\mathrm{rMOG}_{1-117}$ and treated with $15 \mathrm{mg} / \mathrm{kg} \mathrm{DMF}$ or control twice a day from d-7 until d12 p.i. The expression of B220, CD1d, CD5, CD23, CD27, CD37, CD38, CD69, CD80, GL-7, IgD, IgM and MHC-II on the surface of B cells was analyzed by flow cytometry. Subsets of B cells were classified as follows: immature naïve $B$ cells $\left(C D 23^{-}, \operatorname{lgM}^{+} \text {, IgD }\right)^{-}$, mature naïve $B$ cells $\left(C D 23^{+}, C D 38\right.$, $\operatorname{lgM}$, $\left.\lg D^{+}\right)$, memory $B$ cells $\left.\left(B 220^{\text {high }}, C D 38^{+}, \operatorname{lgD}\right)^{-}\right)$, regulatory $B$ cells $\left(C D 1 d^{\text {high }}, C D 5^{+}\right)$, germinal center $B$ cells $\left(\mathrm{CD} 7^{+}, \mathrm{GL7}^{+}\right)$and antigen-activated $\mathrm{B}$ cells $\left(\mathrm{CD} 27^{+}, \mathrm{CD} 69^{+}, \mathrm{CD} 80^{+}, \mathrm{MHC}-\mathrm{II}^{\text {high }}\right)$. FACS evaluation revealed that these $B$ cell phenotypes are not significantly influenced by DMF application in vivo. Data are represented as mean \pm SD. 


\subsection{DMF did not alter the frequency of $\mathrm{rMOG}_{1-117}$-binding B cells}

As a first functional analysis of in vivo control- or DMF-treated B cells, an rMOG-binding assay was performed to examine the antigen-binding capacity of B cells. Purified B cells of control- or DMFtreated mice were then incubated with fluorescence-labeled rMOG for 2 hours and the frequency of B cells which had bound to rMOG was analyzed by flow cytometry (Figure 29). Data evaluation revealed that in vivo DMF treatment did not significantly alter the rMOG-binding capacity of B cells in vitro.

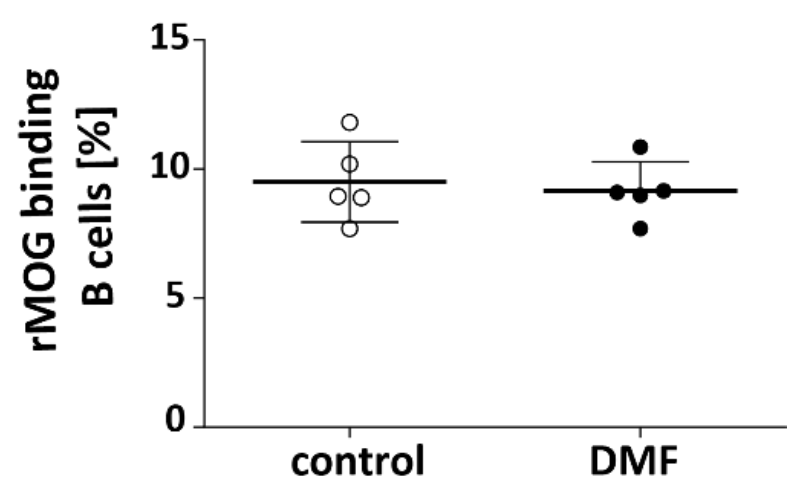

Figure 29: $D M F$ has no effect on the $\mathrm{rMOG}_{1-117}$-binding capacity $B$ cells. $B$ cells were purified from the spleens of C57BL/6 mice immunized with $\mathrm{rMOG}_{1-117}$ and treated with $15 \mathrm{mg} / \mathrm{kg}$ DMF or control twice a day from d-7 until d12 p.i. In vitro, these B cells were incubated with fluorescence-labeled $\mathrm{rMOG}_{1-117}$ and frequency of rMOG-binding B cells was evaluated by flow cytometry. In vivo treatment with DMF does not influence the antigen-binding capacity of $B$ cells. Data are represented as mean \pm SD.

\subsection{In vivo DMF-treated B cells promoted antigen-dependent T cell proliferation in vitro}

In a next experiment it was investigated how DMF affects the antigen-presenting functions of B cells. Therefore a co-culture experiment with control- or DMF-treated B cells and 2D2 T cells was performed to analyze B cell-mediated effects on T cell proliferation and T cell differentiation in vitro. Immunized C57BL/6 mice were treated with $15 \mathrm{mg} / \mathrm{kg}$ DMF or control from d-2 until day12 p.i. B cells were purified from the spleens of control- or DMF-treated C57BL/6 mice. Afterwards, these purified B cells were co-cultured with unlabeled or CFSE-labeled T cells isolated from naïve $2 \mathrm{D} 2$ mice and stimulated with $\mathrm{rMOG}_{1-117}$. T cell proliferation and differentiation were analyzed by flow cytometry. 
The first co-culture experiment investigated whether DMF treatment in vivo could alter the antigen-presenting functions of B cells. Therefore in vivo control- or DMF-treated B cells were cocultured with CFSE-labeled 2D2 T cells and stimulated with 0,25 or $50 \mu \mathrm{g} / \mathrm{ml} \mathrm{rMOG}_{1-117}$. B cells with a more potent antigen-presenting function induce a higher activation and proliferation of 2D2 T cells. Figure 30 illustrates the DMF-mediated effects on the antigen-presenting function of B cells measured indirectly by $T$ cell proliferation after $65 \mathrm{~h}$.

To acquire a more detailed analysis of DMF-induced effects, the proliferation of 2D2 T cells was divided in different proliferation rates. A low proliferation rate would therefore indicate a weak antigen-presenting function of B cells whereas high proliferation rate would indicate a more potent antigen-presenting function of $B$ cells. The impact of DMF treatment on the antigenpresenting function of B cells and thereby on 2D2 T cell proliferation is shown in Figure 30B. The total proliferation of 2D2 T cells co-cultured with in vivo DMF-treated B cells was significantly enhanced compared to controls $\left(25 \mu \mathrm{g} / \mathrm{ml} \mathrm{rMOG}_{1-117}\right.$ : ctrl $13.6 \% \pm 2.5 \%$ vs. DMF $18.7 \% \pm 4.4 \%$, $50 \mu \mathrm{g} / \mathrm{ml} \mathrm{rMOG}_{1-117}: \operatorname{ctrl} 16.8 \% \pm 3.6 \%$ vs. DMF $\left.24.2 \% \pm 4.2 \%\right)(\mathrm{p}<0.05, \mathrm{p}<0.01)$. When compared to control, DMF-treated B cells increased the frequency of 2D2 T cells with low proliferation rate $\left(50 \mu \mathrm{g} / \mathrm{ml} \mathrm{rMOG}_{1-117}: \operatorname{ctrl} 5.6 \% \pm 0.5 \%\right.$ vs. DMF $\left.6.2 \% \pm 0.7 \%, \mathrm{p}<0.05\right)$, the frequency of $2 \mathrm{D} 2 \mathrm{~T}$ cells with intermediate proliferation rate $\left(50 \mu \mathrm{g} / \mathrm{ml} \mathrm{rMOG}_{1-117}\right.$ : $\operatorname{ctrl} 5.8 \% \pm 1.6 \%$ vs. DMF $8.2 \% \pm 1.1 \%$, $\mathrm{p}<0.05)$ and the frequency of $2 \mathrm{D} 2 \mathrm{~T}$ cells with high proliferation rate $(25 \mu \mathrm{g} / \mathrm{ml} \mathrm{rMOG} 1-117$ : ctrl $4.4 \% \pm 0.7 \%$ vs. DMF $7.4 \% \pm 2.1 \%, p<0.001 ; 50 \mu \mathrm{g} / \mathrm{ml} \mathrm{rMOG}_{1-117}:$ ctrl $5.4 \% \pm 1.6 \%$ vs. DMF $8.2 \% \pm 2.3 \%, \mathrm{p}<0.01)$. The frequencies of $2 \mathrm{D} 2 \mathrm{~T}$ cells with low and intermediate proliferation rate stimulated with $25 \mathrm{\mu g} / \mathrm{ml} \mathrm{rMOG}_{1-117}$ were not significantly altered by DMF-treated B cells when compared to 2D2 T cells co-cultured with control-treated B cells.

Additionally to the analysis of 2D2 T cell proliferation, co-cultured B cells were analyzed for MHC-II expression by flow cytometry (Figure 30C). In accordance with the ex vivo staining of B cells (Figure 25), MHC-II expression was slightly increased on DMF-treated co-cultured B cells, stimulated with $25 \mu \mathrm{g} / \mathrm{ml} \mathrm{rMOG}_{1-117}$, when compared to control-treated B cells. Nevertheless, this effect did not reach statistically significance. 
A

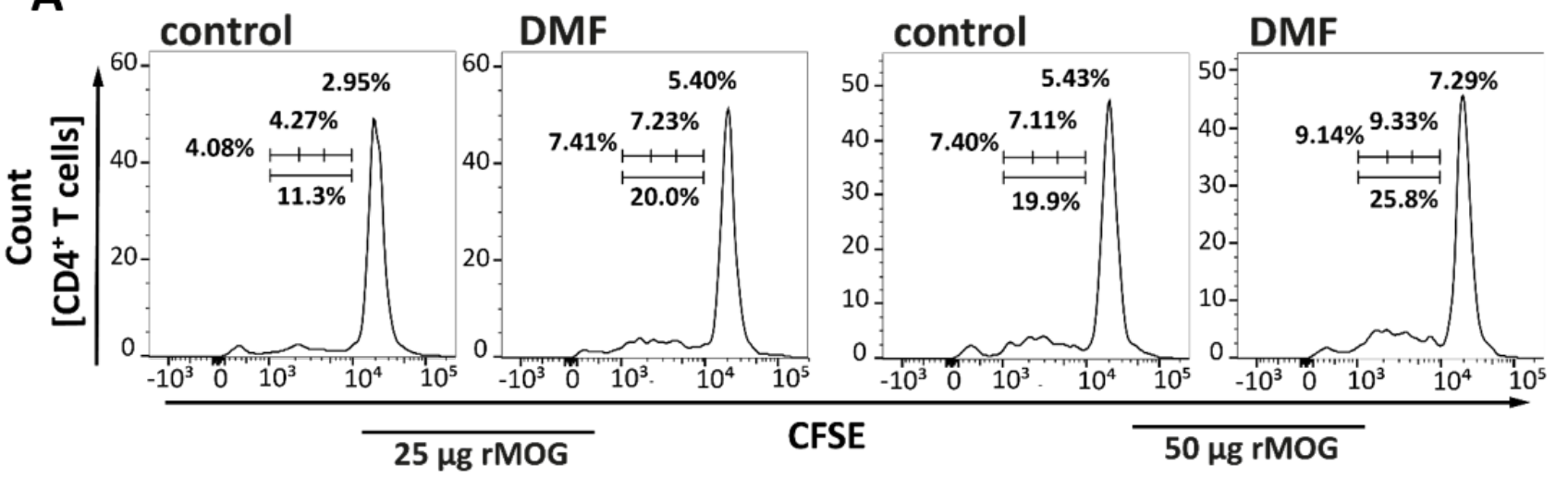

B

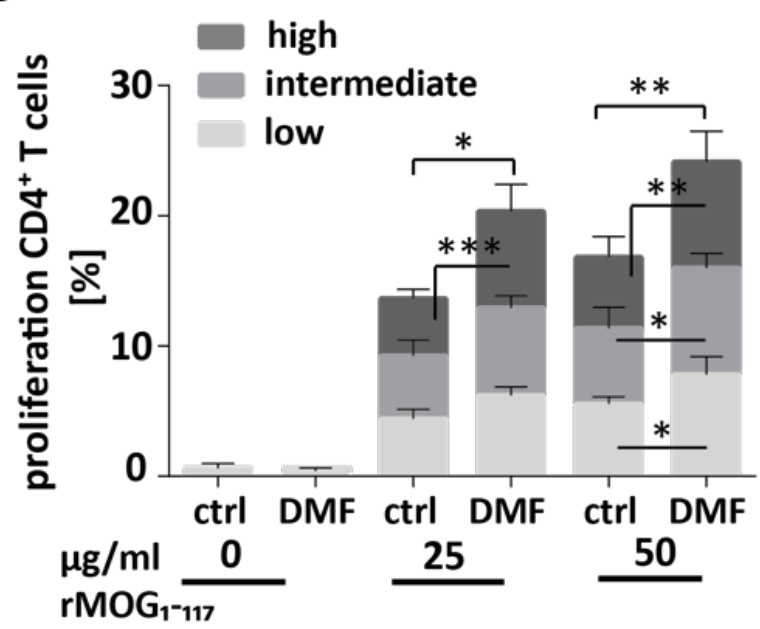

C

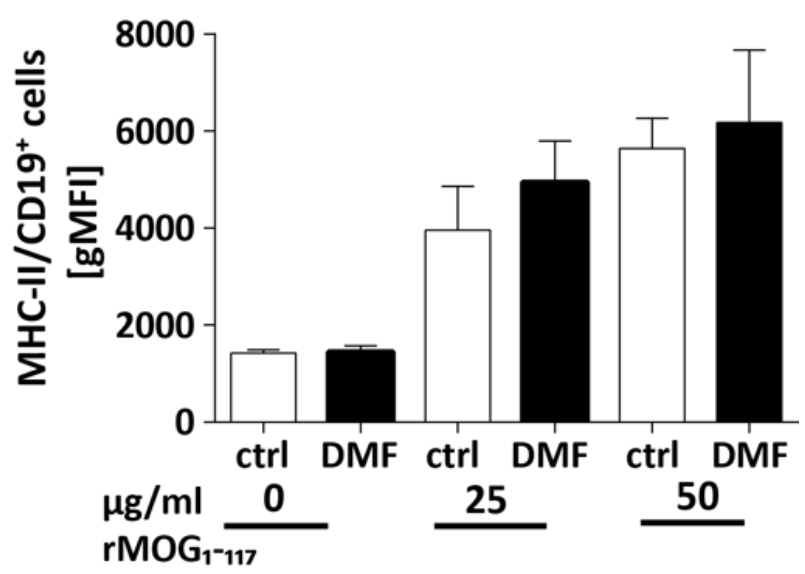

Figure 30: In vivo DMF treatment enhances the antigen-presenting function of $B$ cells. To investigate the effects of DMF on the antigen-presenting function, B cells were purified from C57BL/ 6 mice immunized with $\mathrm{rMOG}_{1-117}$ and treated with $15 \mathrm{mg} / \mathrm{kg}$ DMF or control twice a day from d-2 until d12 p.i. These isolated $B$ cells were then co-cultured with CFSE-labeled 2D2T cells and stimulated with 0,25 or $50 \mu \mathrm{g} / \mathrm{ml} \mathrm{rMOG}_{1-117}$. $(A, B)$ The proliferation was analyzed by flow cytometry in the presence of either control- or DMF-treated B cells. Proliferation of 2D2 T cells is significantly increased when these are cocultured with DMF-treated B cells. (C) Simultaneously, MHC-II expression was analyzed on co-cultured $B$ cells via flow cytometry. MHC-II is not significantly upregulated on B cells isolated from DMF-treated mice. Data are represented as mean \pm SD $\left(n=5, * p<0.05,{ }^{* *} p<0.01, * * * p<0.001\right.$, two-way ANOVA).

\subsection{In vivo DMF-treated B cells do not influence differentiation of IFN $\boldsymbol{Y}$-producing $\mathrm{T}$ cells}

The first co-culture experiment demonstrated that 2D2 T cell proliferation could be amplified by in vivo DMF treatment of B cells. Hence, it was interesting to further analyze the fate of these high proliferating 2D2 T cells. To address this question, the differentiation of 2D2 T cells in vitro was analyzed in another co-culture system. The co-culture assay was performed as described in sections 2.4.10.4 and 3.2.2.2.6, except for the CFSE labeling of 2D2 T cells. 
After 65 hours, 2D2 T cells were treated with ionomycin and PMA, cytokine secretion was blocked and intracellular IFNy staining was analyzed by flow cytometry. As depicted in Figure 31, there was no difference in the frequency of IFN ${ }^{+} \mathrm{T}$ cells between 2D2 T cells which were co-cultured with control- or DMF-treated B cells.

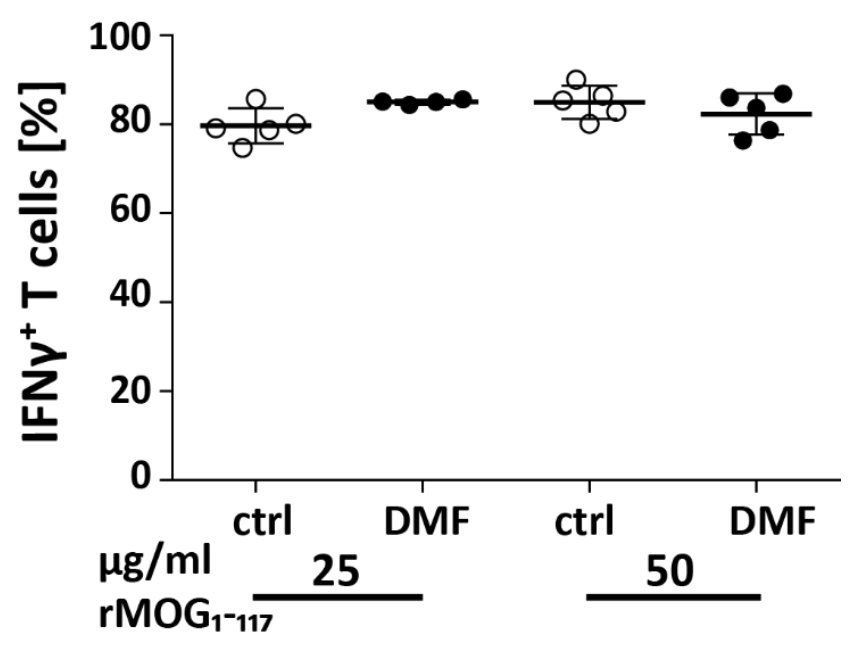

Figure 31: In vivo DMF-treated B cells do not alter T cell differentiation in vitro. B cells were purified from $\mathrm{C} 57 \mathrm{BL} / 6$ mice immunized with $\mathrm{rMOG}_{1-117}$ and treated with $15 \mathrm{mg} / \mathrm{kg}$ DMF or control twice a day from $\mathrm{d}-2$ until d12 p.i. These isolated B cells were then co-cultured with CFSE-labeled 2D2 T cells and stimulated with 25 or $50 \mu \mathrm{g} / \mathrm{ml} \mathrm{rMOG}_{1-117}$. The differentiation of IFNY-producing (IFNY $\gamma^{+}$) T cells was analyzed by intracellular staining and flow cytometry in the presence of either control- or DMF-treated B cells. The frequency of IFN $\gamma^{+}$T cells is not altered in the presence of DMF-treated B cells. Data are represented as mean $\pm S D$.

\subsubsection{DMF effects on human $B$ cells}

We could observe that DMF treatment induced profound alterations of B cell functions in mice. To study if these DMF effects could also partly be seen on human B cells, a FACS analysis of B cells from non-treated MS patients (MS control) and DMF-treated MS patients (MS DMF) was performed.

\subsubsection{DMF treatment enhanced MHC-Il expression on human B cells}

For the analysis of B cells, PBMCs isolated from MS patients were stained for CD19, MHC-II, CD80 and CD40 analyzed via flow cytometry (Figure 32). MHC-II expression was significantly increased on B cells from DMF-treated MS patients when compared to non-treated MS patients (MS DMF 
$13078 \pm 2199$ gMFI vs. MS control $10592 \pm 1428$ gMFI) $(p<0.05)$. The frequency of B cells and expression of CD80 and CD40 was comparable between DMF- and non-treated MS patients.

A
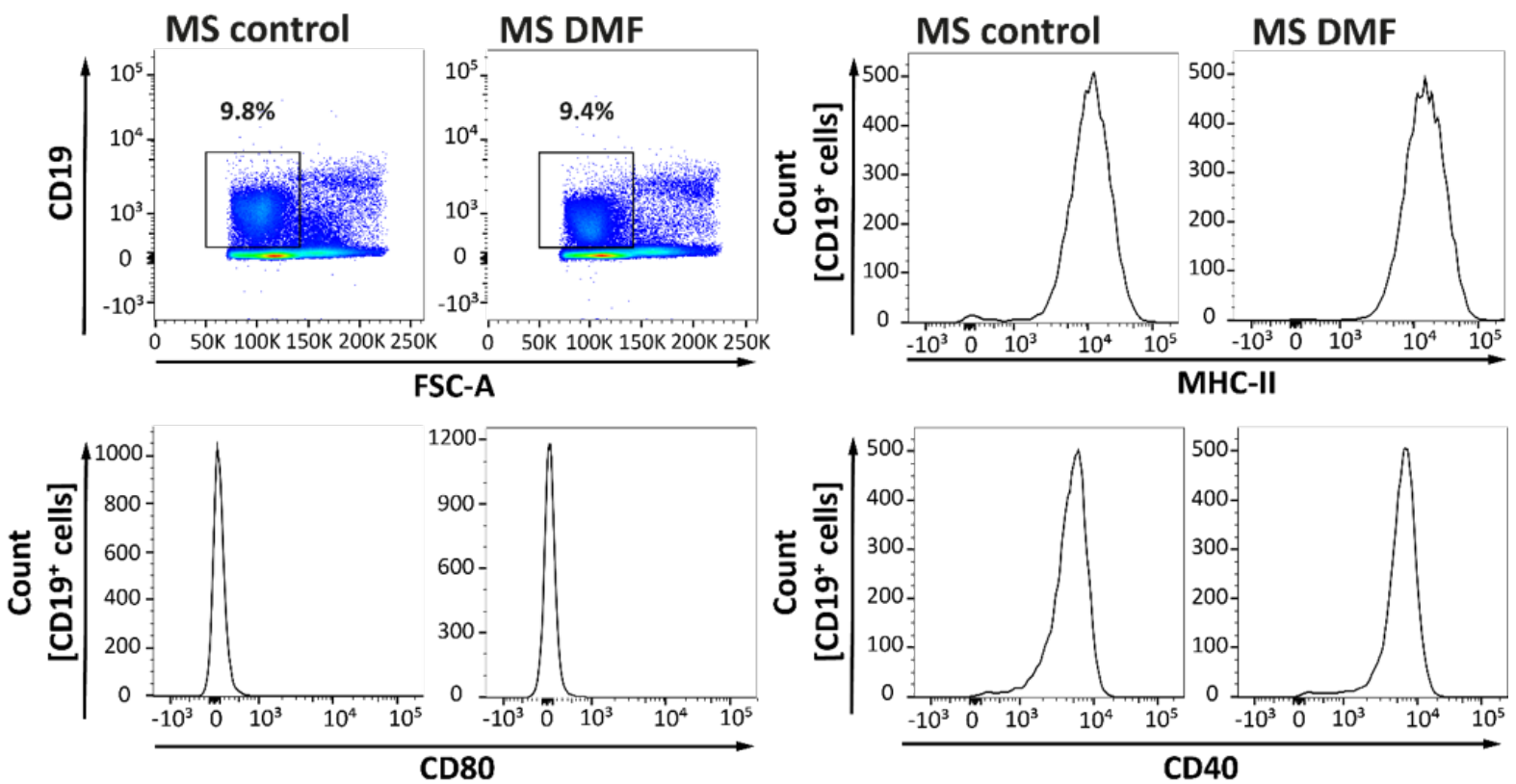

B

\section{human PBMCs}
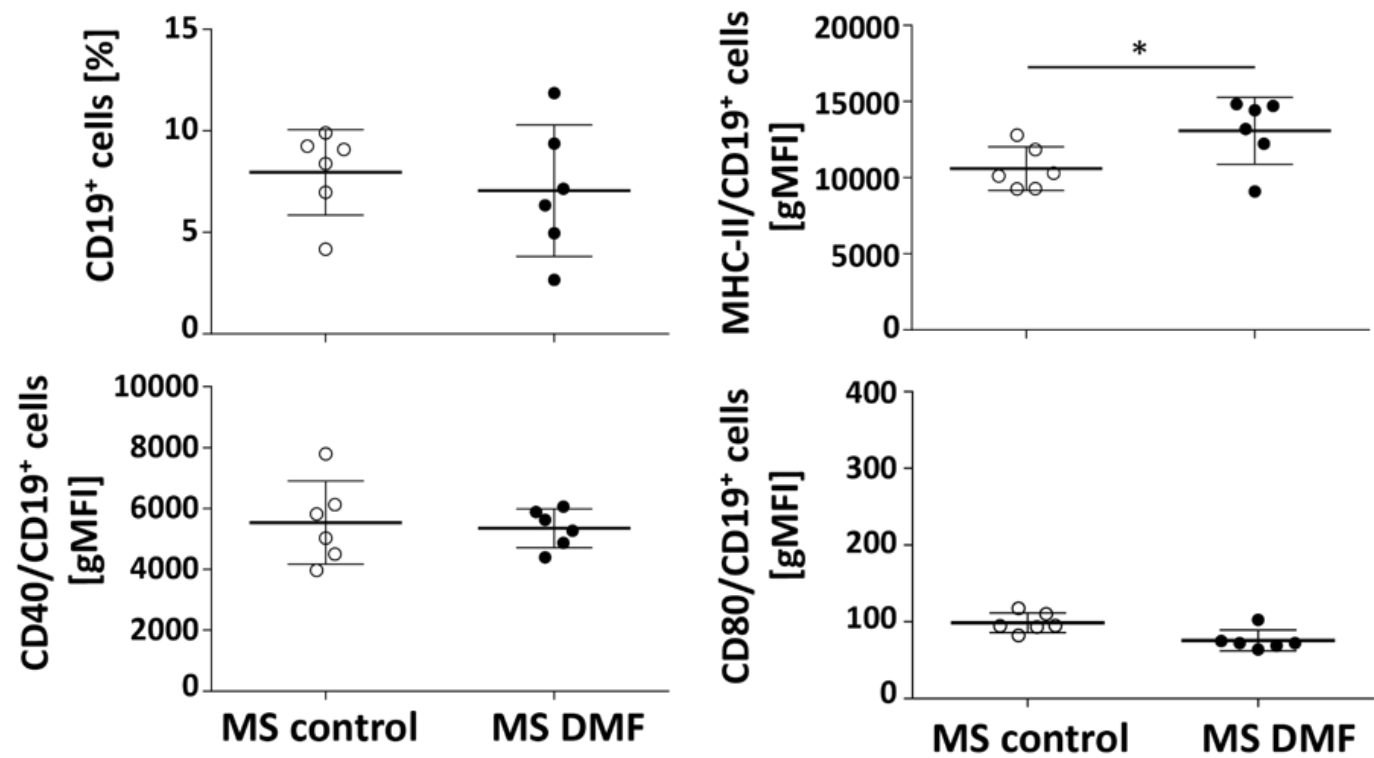

Figure 32: DMF effects on B cells of MS patients. PBMCs were isolated from non-treated (control) or DMF-treated MS patients. The frequency of B cells and expression of MHC-II and co-stimulatory molecules $\mathrm{CD} 80$ and $\mathrm{CD} 40$ on $\mathrm{B}$ cells $\left(\mathrm{CD} 19^{+}\right)$was analyzed by flow cytometry $(\mathrm{A})$. Data evaluation revealed that DMF significantly increases the expression of MHC-II on B cells of DMF-treated MS patients whereas the B cell frequency and expression of co-stimulatory molecules remain mostly unaltered (B). Data are represented as mean $\pm S D(* p<0.05$, unpaired t-test). 
In summary, DMF treatment in a B cell-mediated EAE model significantly ameliorated the disease course and reduced demyelination and inflammation of the spinal cord. Furthermore, Tcell activation, pro-inflammatory $\mathrm{T}$ cell differentiation and antigen-independent proliferation of $\mathrm{T}$ cells was significantly decreased under DMF treatment during the early phase of EAE. In contrast, DMF increased MHC-II expression, the frequency of follicular B cells and antigen-presenting properties of B cells. These results could also partly be observed in DMF-treated MS patients whose B cells also showed an increased expression of MHC-II. 


\section{Discussion}

The oral agent dimethyl fumarate (DMF) has been approved for the therapy of RRMS. Besides its beneficial effects on relapse rate and MRI lesion formation, DMF and its metabolite MMF have been shown to exert several immunomodulatory functions on cells of the adaptive immune system (Moharregh-Khiabani et al., 2009). This includes the ability to induce apoptosis of activated $\mathrm{T}$ cells and the downregulation of the transcription factor NF-KB in T cells, DCs and endothelial cells which results in a reduced production of inflammatory cytokines, chemokines and adhesion molecules (de Jong et al., 1996; Stoof et al., 2001; Treumer et al., 2003). In EAE and cell culture, DMF was described to have neuroprotective functions mediated by the activation of the transcription factor Nrf2 which lead to an increased protection of cells against reactive oxygen species (ROS) (Linker et al., 2011; Scannevin et al., 2012c). Nevertheless, it is still unknown if DMF treatment has any direct effects on the CNS which are not mediated via the modulation of peripheral immune cells.

The present study aimed to analyze if DMF has CNS intrinsic effects independent of the peripheral immune system. Therefore, the cuprizone mouse model was used to study the effects of DMF on CNS cells, demyelination and remyelination as well as axonal damage. Histological evaluation revealed that DMF showed neuroprotective and possibly neuroregenerative effects within the CNS.

In the second part of this study DMF effects were investigated in a B cell-mediated EAE model. So far, DMF was only analyzed in mainly T cell-mediated EAE models and direct effects of DMF on $B$ cells have not been reported. Clinical, histological and immunological analyses were performed to study the DMF effects in this animal model and revealed B cell altering properties of DMF.

\subsection{DMF shows neuroprotective and potentially regenerative effects in the cuprizone mouse model}

MS is an inflammatory and demyelinating disease of the CNS with focal lesions in which myelin, myelin-forming cells (oligodendrocytes) and axons are damaged (Trapp and Nave, 2008). The histopathology of MS is heterogeneous, with lesion patterns characterized by immune-mediated demyelination but also patterns which suggest a primary oligodendrogliopathy (Lucchinetti et al., 2000; Rone et al., 2016). The oral agent DMF has been shown to exert beneficial effects in the therapy of RRMS. So far, it is assumed that the successful treatment is mainly mediated via DMF 
effects on the peripheral immune system (e.g. reduction of pro-inflammatory T cells and DCs) whereas direct effects of DMF on the central nervous system are still controversially discussed (Ghoreschi et al., 2011; Litjens et al., 2006; Moharregh-Khiabani et al., 2009; Scannevin et al., 2012c). We investigated the DMF effects on the CNS in the cuprizone model in which the BBB remains intact and an influence of peripheral immune cells can be majorly excluded (Bakker and Ludwin, 1987; McMahon et al., 2002). Different time points were examined to analyze the treatment effects on oligodendrocyte apoptosis, axonal damage as well as demyelination and remyelination.

\subsubsection{DMF exerts neuroprotective effects during short-term cuprizone treatment}

One feature of MS lesions is the loss of myelin-producing oligodendrocytes. Oligodendrocytes may show signs of apoptotic cell death, e.g. the upregulation of apoptosis-related proteins such as FAS, (Dowling et al., 1996; Lucchinetti et al., 2000). Thus, we aimed to analyze if DMF could influence the apoptosis of oligodendrocytes induced by cuprizone intoxication. Loss of oligodendrocytes is an early event during cuprizone treatment and therefore DMF effects on apoptosis were analyzed after one week of cuprizone diet (Figure 2) (Matsushima and Morell, 2001b). The number of apoptotic cells was significantly reduced by DMF treatment, which suggested that DMF may have a cytoprotective effect on oligodendrocytes (Figure 2). The exact mechanism of cuprizone-induced oligodendrocyte apoptosis is still unknown, but several studies suggest that cuprizone provokes mitochondrial dysfunction, such as the formation of giant mitochondria, and disturbances of the oligodendroglial metabolism which could contribute to the apoptosis of oligodendrocytes (Acs et al., 2013; Goldberg et al., 2013; Matsushima and Morell, 2001b). The formation of these megamitochondria mainly takes place in hepatic cells but could also be observed in oligodendrocytes (Acs et al., 2013; Biancotti et al., 2008). It is considered to be a protective mechanism of cells against oxidative stress, since it was demonstrated that mitochondria enlarge when exposed to elevated levels of ROS in vitro (Wakabayashi, 2002). These data may suggest that the cuprizone-mediated loss of oligodendrocytes could be caused by increased oxidative damage. It could already be demonstrated that oligodendrocytes show a high vulnerability to oxidative stress (Praet et al., 2014). One factor which contributes to this high vulnerability is the intrinsically low amount of glutathione (GSH) in oligodendrocytes, a molecule which is required as an electron donor for the glutathione peroxidase (GPx) (Juurlink et al., 1998; Witherick et al., 2010). 
This enzyme reduces free hydrogen peroxide $\left(\mathrm{H}_{2} \mathrm{O}_{2}\right)$ in order to protect cells from oxidative damage. Furthermore, cuprizone intoxication was shown to decrease the GSH content of hepatic cells as well as oligodendrocytes and could thereby increase susceptibility of oligodendrocytes to oxidative stress (Biancotti et al., 2008). Several in vitro and in vivo studies revealed that DMF can protect cells against oxidative damage via an increased activation of $\mathrm{Nrf2}$ and increased production and recycling of GSH. Nrf2 elevates gene expression of several detoxification enzymes (e.g. GSH-dependent enzymes) and is normally located in the cytoplasm where it is sequestered to kelch-like erythroid cell-derived protein 1 (Keap1), a functional inhibitor of Nrf2 (Nguyen et al., 2009). Fumaric acid esters (FAEs), including DMF, can bind Keap1 by covalent binding to thiol groups and therefore promote the translocation of Nrf2 into the nucleus (Linker et al., 2011; Nguyen et al., 2005). A study in 1990 could show that in vivo DMF treatment induces the activity of GSH-dependent detoxification enzymes (e.g. NADPH oxidoreductase) in various murine tissues (Spencer et al., 1990). In vitro, DMF and its metabolite MMF elevated GSH levels in murine and human astrocytes and increased the viability of astrocytes and rat cortical neurons after oxidative challenge with $\mathrm{H}_{2} \mathrm{O}_{2}$ (Albrecht et al., 2012; Scannevin et al., 2012c). The DMF effect on cell viability after oxidative stress challenge was suggested to be Nrf2-dependent, since the effect was lost in cells lacking Nrf2. Additionally, in vitro treatment with MMF increased cellular ATP content and more importantly, enhanced mitochondrial membrane polarization which can antagonize mitochondrial dysfunction (Scannevin et al., 2012c). A recent study showed that in vitro DMF treatment increases the levels of antioxidant molecules including carnitine, ascorbic acid and GSH in human oligodendrocytes (Huang et al., 2015). Correspondingly, DMF could also protect oligodendrocytes against $\mathrm{H}_{2} \mathrm{O}_{2}$-mediated oxidative damage. Oxidative stress and mitochondrial injury are also assumed to contribute to oligodendrocyte loss in MS pathology (Bradl and Lassmann, 2010; Haider et al., 2011). A continuative study confirmed that mitochondrial injury occurs in active MS lesions and may contribute to the production of ROS (Fischer et al., 2012). Thus, the antioxidant impact of DMF may also exert beneficial effects leading to reduced oligodendrocyte loss in MS patients.

Besides the apoptosis of oligodendrocytes, it was also investigated if DMF influences the number of oligodendrocytes including oligodendrocyte precursor cells (Olig2 ${ }^{+}$cells) and specifically mature oligodendrocytes (NogoA ${ }^{+}$cells) after 7 days of cuprizone exposure. 
This study revealed that DMF treatment preserved a higher number of Olig2 ${ }^{+}$cells whereas the number of NogoA $\mathrm{A}^{+}$cells was only slightly increased by DMF treatment at this time point (Figure 3). The lowest numbers of Olig2 ${ }^{+}$cells are observed after 10 days of cuprizone treatment whereas fewest numbers of $\mathrm{NogoA}^{+}$cells are observed on day 21 of cuprizone treatment (Hesse et al., 2010b). Interestingly, on day 21 numbers of Olig2 ${ }^{+}$cells start to increase again suggesting a recruitment of oligodendroglial progenitor cells (OPCS) even with ongoing cuprizone treatment (Matsushima and Morell, 2001b). This phenomenon was also observed in our experiments, where Olig2 ${ }^{+}$cells were decreased compared to $\mathrm{NogoA}^{+}$cells on day 7 of cuprizone treatment (Figure 3 ). Our data suggest that DMF might exert an early protective effect on oligodendrocytes which are majorly affected by cuprizone intoxication, specifically preserving Olig2 ${ }^{+}$cells.

Furthermore, DMF also significantly reduced the number of acutely damaged axons compared to control treatment, investigated 7 days after cuprizone treatment (Figure 4). Acute axonal damage was analyzed by staining for amyloid precursor protein (APP), which is observed at sites of axonal injury (Koo et al., 1990). Although cuprizone treatment leads to axonal damage in mice, it is assumed that cuprizone has no direct toxic effect on axons and axonal damage is rather a secondary event following previous oligodendroglial damage (Irvine and Blakemore, 2006; Mason et al., 2001; Stidworthy et al., 2003). In murine EAE, DMF treatment could significantly increase axonal density in early and chronic disease stages (Linker et al., 2011; Reick et al., 2014). In a model of experimental autoimmune neuritis (EAN), DMF reduced the acute axonal damage in rats which correlated with a significant increase of Nrf2 in axons at this time point (Pitarokoili et al., 2015). Consequently, DMF-mediated Nrf2 activation is thought to lead to a better protection of axons. In MS, acute axonal damage mainly occurs during the early stages of disease and correlates with the extent of inflammation (Kuhlmann et al., 2002). Taken together, these data suggest that DMF treatment may reduce the acute axonal damage in MS patients by direct CNS effects in addition to the known axon-protective effect ascribed to the immunomodulatory mode of action of fumarates.

Cuprizone treatment of mice leads to an increased activation of microglia/macrophages and increased number of reactive astrocytes, features which also can be observed in MS lesions (Groebe et al., 2009; Hibbits et al., 2012; Hiremath et al., 1998). In our study DMF treatment only slightly decreased the number of microglia/macrophages ( $\mathrm{Mac}^{+}$cells) and reactive astrocytes 
expressing GFAP (glial fibrillary acidic protein) after 7 days of cuprizone treatment (Figure 4). Although it was reported that DMF reduced microglial inflammation in vitro, only mild in vivo effects of DMF on the infiltration of macrophages were observed in several EAE or previous cuprizone experiments (Linker et al., 2011; Moharregh-Khiabani et al., 2009; Reick et al., 2014; Wilms et al., 2010). Therefore, DMF seems to have no major effect on the activation and accumulation of microglia/macrophages in these animal models. In contrast, DMF has been shown to reduce the number of activated astrocytes in the spinal cord of EAE mice (Linker et al., 2011). This observation could suggest that the DMF-induced decrease of astrogliosis is mainly mediated by peripheral immunomodulatory effects of DMF.

To analyze if the DMF effects on oligodendrocyte apoptosis could also be observed at a later time point after cuprizone exposure, the number of apoptotic cells and mature oligodendrocytes were analyzed after 2 weeks of cuprizone treatment. Since in later stages of cuprizone diet, oligodendroglial cell death is independent of caspase 3, apoptotic cells were analyzed by morphology (condensed and/or fragmented nuclei) (Hesse et al., 2010b). DMF treatment slightly reduced the number of apoptotic cells, but in contrast to day 7 this effect did not reach statistical significance (Figure 5). The number of oligodendrocytes (Olig2 ${ }^{+}$cells) and mature oligodendrocytes (NogoA ${ }^{+}$cells) was not altered by DMF at this time point (Figure 5). As described above, the number of $\mathrm{NogoA}^{+}$cells decreases with ongoing cuprizone diet, a circumstance which could also be observed in this study (Kuhlmann et al., 2002). A possible explanation for the obtained results could be the strong toxic impact of cuprizone on oligodendrocytes which might override the DMF effect. Nevertheless, a slight reduction of apoptotic oligodendrocytes was still visible after 2 weeks. Conversely, it is also possible that DMF mainly affects only specific apoptotic mechanisms (e.g. caspase 3-dependent cell death) which may mainly occur during the early phase of cuprizone treatment and later changes to other cell death mechanism which are unaffected by DMF treatment (Kuhlmann et al., 2002).

Since it is assumed that the cytoprotective effects of DMF could be mainly mediated via the activation of Nrf2, a pilot experiment was performed to examine if the DMF effects observed after 7 days of cuprizone are also Nrf2-dependent. Therefore, DMF effects on the number of apoptotic cells were investigated in Nrf2 knock-out (Nrf2 k.o.) mice. In line with other studies, no protective DMF effects on oligodendrocytes could be seen in Nrf2 k.o. in these preliminary experiments, 
suggesting that the observed effects after 7 days of cuprizone treatment may indeed be Nrf2dependent (Figure 13) (Linker et al., 2011; Scannevin et al., 2012c). The obtained results further support the hypothesis that the neuroprotective effects of DMF could be mainly mediated by activation and stabilization of Nrf2.

\subsubsection{DMF treatment increases differentiation and regeneration of oligodendrocytes after long-term cuprizone treatment}

To analyze DMF effects on demyelination, mice were fed with cuprizone for 6 weeks which induces significant demyelination of the CC (Gudi et al., 2009; Matsushima and Morell, 2001b). DMF treatment of mice could only slightly decrease the demyelination occurring in the CC, whereas the number of mature oligodendrocytes (NogoA ${ }^{+}$cells) was significantly increased by DMF (Figure 6, Figure 9). Cuprizone-induced demyelination of the CC peaks at 5 weeks and remyelinated axons can already be observed between week 5 and 6 even with ongoing cuprizone treatment (Mason et al., 2001). DMF effects on demyelination were also investigated after 5 weeks of cuprizone exposure, and results were similar to data received after 6 weeks (data not shown). The received results are in line with the results of a previous study, where no significant effects of DMF on the demyelination of the CC could be observed (Moharregh-Khiabani et al., 2010). In addition to apoptosis of oligodendrocytes mediated by oxidative stress, cuprizone treatment also leads to disturbances of myelin protein synthesis and myelin lipid metabolism (Praet et al., 2014). Cuprizone intoxication reduces plasma levels of several amino acids leading to the activation of the amino acid response pathway (AAR) which in turn strongly reduces protein synthesis (Goldberg et al., 2013). A huge part of the myelin lipid layers consists of phospholipids, mainly plasmalogens (Farooqui and Horrocks, 2001). Cuprizone increases the activity of plasmalogenase and phospholipase A2 (PLA2), two enzymes which degrade membrane-bound plasmalogens and thereby contribute to myelin sheath destruction (Carey and Freeman, 1983). DMF treatment was shown to increase phospholipid synthesis by oligodendrocytes in vitro, but this effect might not be equally potent in vivo, which could explain the minor DMF effects on demyelination (Huang et al., 2015). Nevertheless, higher numbers of mature oligodendrocytes were observed under DMF after long-term cuprizone diet. These data suggest that long-term DMF treatment could be protective against cuprizone-induced oxidative stress while it may not majorly alter the cuprizone-induced metabolic disturbances contributing to myelin destruction. In a previous study, no significant DMF effect was found on the number of oligodendrocytes after long- 
term cuprizone exposure but DMF effects after short-term cuprizone diet were not investigated at all (Moharregh-Khiabani et al., 2009). In our study, DMF treatment increased the number of mature oligodendrocytes after long term treatment. Most probably, the higher numbers of OPCs after short-term cuprizone exposure resulted in more OPCs that differentiated into mature oligodendrocytes. Thereby, it may be assumed that DMF promotes the regeneration and differentiation of oligodendrocytes. This DMF-mediated maintenance or increased differentiation of oligodendrocytes could potentially be important for MS treatment, since it was described that especially in chronic MS lesions OPCs largely fail to mature to oligodendrocytes (Kuhlmann et al., 2008b).

\subsubsection{Therapeutic DMF treatment shows neuroprotective effects on axons}

To investigate how DMF can influence remyelination, mice were fed with cuprizone for 5 weeks to induce profound demyelination of the CC. Then the cuprizone diet was stopped and mice were therapeutically treated with control or DMF for 3 days. No significant DMF effect on the extent of remyelinaton or the number of activated macrophages/microglia in the CC was found (Figure 10, Figure 11). Also, the overall number of oligodendrocytes and mature oligodendrocytes were not altered by DMF treatment (data not shown). As described above, remyelination already starts after 5 weeks, even with ongoing cuprizone exposure (Mason et al., 2001). After cuprizone withdrawal, almost complete remyelination can be observed after 4 weeks (Lindner et al., 2008b; Torkildsen et al., 2008). Remyelination is accompanied by migration and differentiation of OPCs as well as a reduction of activated microglia/macrophages in the CC (Matsushima and Morell, 2001b; Stangel and Hartung, 2002). Microglia/macrophage numbers peak in week 3-5 during cuprizone treatment (Mason et al., 2001). On the one hand, microglia and macrophages are considered as detrimental because of their pro-inflammatory cytokine production, contributing to an increased inflammation and damage within the CNS (Lampron et al., 2015). On the other hand, these phagocytic cells are important for the clearance of myelin debris. It could be demonstrated that decreased myelin removal by microglia/macrophages can prevent proper remyelination in the cuprizone model (Lampron et al., 2015; Skripuletz et al., 2013). DMF treatment could not alter the number of microglia/macrophages 3 days after cuprizone removal which could be a possible explanation why remyelination was not enhanced by DMF. Another fact which has to be taken into account is that the remyelination in mice is very effective and therapeutic effects may be 
overridden by this fast process. Thus, the experimental setup used may not be suitable to show beneficial treatment effects on remyelination.

Importantly, DMF treatment significantly reduced the acute axonal damage 3 days after cuprizone withdrawal (Figure 11), suggesting a neuroprotective effect of therapeutic DMF application. Studies in the cuprizone model demonstrated that axonal damage could still be observed in the CC of mice long after remyelination was already completed (Manrique-Hoyos et al., 2012). Furthermore, persistent axonal loss despite sufficient remyelination was found after chronic cuprizone-mediated demyelination (Lindner et al., 2009). Therefore, therapeutic DMF treatment, although not influencing remyelination, could be an important tool to prevent axonal degeneration. Axonal loss occurs independent of the course of MS and majorly contributes to the development of brain atrophy (Chard et al., 2002; Kalkers et al., 2002). Hence, it is assumed that axonal loss leads to the development of permanent neurological deficits and long-term disability in MS patients (Ferguson et al., 1997; Grigoriadis et al., 2004; Haines et al., 2011). It was reported that axonal degeneration is already present at early stages of the disease highlighting the need of a neuroprotective therapy in MS at an early stage (Kalkers et al., 2002). Two recent studies demonstrated that especially an early DMF treatment mediates a beneficial effect on brain atrophy in MS patients (Dupuy et al., 2016; Kappos et al., 2016). Although, it is still unknown how DMF exerts its function on brain atrophy, beneficial effects on axonal damage may contribute to therapeutic effects observed in these studies. It is suggested that DMF facilitates mitochondrial function which was shown to be disturbed in axons of MS patients (Huang et al., 2015; Su et al., 2009). Since this mitochondrial dysfunction could contribute to axonal degeneration, a beneficial effect of DMF on mitochondria may subsequently reduce axonal damage.

In conclusion, the CNS intrinsic effects of DMF observed in this study may play an important role for the therapy of MS. After one week of cuprizone exposure, mice treated with DMF showed higher body weights compared to controls. After six weeks of cuprizone treatment body weights between control- and DMF-treated animals were comparable. These results indicate that the effects described above are not mediated by a reduced cuprizone intake of DMF mice, perhaps due to gastrointestinal side effects, but rather by DMF or its metabolite MMF itself. The latter was shown to reach the brain even when the BBB remains intact (Figure 12). In the present study, DMF decreased the cuprizone-mediated apoptosis of oligodendrocytes. 
Initially, DMF treatment seems to mainly increase the number of OPCs and is potentially promoting their differentiation into mature oligodendrocytes, which were increased after longterm cuprizone treatment. Furthermore, DMF treatment concurrent to cuprizone intoxication as well as applied after cuprizone induced demyelination had occurred ("therapeutic DMF treatment") reduced the acute axonal damage significantly. These results suggest that DMF exerts neuroprotective and neuroregenerative effects independent of peripheral inflammation. Currently, therapy of MS mainly includes immunomodulatory and immunosuppressive drugs whereas neuroprotective or regenerative treatments are basically not available (Stangel, 2008). The sole application of immunomodulatory drugs cannot completely prevent CNS injury. Thus, the CNS intrinsic effects of DMF observed in this study could therefore be an important therapeutic tool for the treatment of MS.

\subsection{DMF treatment shows opposing effects on lymphocytes in B cell- mediated EAE}

After the investigation of DMF effects within the CNS, we further investigated the DMF effects on the peripheral immune system. EAE is a suitable animal model of MS in which immunomodulatory drugs, like DMF, can be initially tested for their potential therapeutic effectiveness in MS. The effects of DMF have been investigated in mainly T cell-mediated EAE models in which DMF could ameliorate the disease course and decreased the overall CNS damage (Linker et al., 2011; Reick et al., 2014; Schilling et al., 2006). Furthermore, several studies demonstrated that DMF induces the apoptosis of pro-inflammatory T cells, the development of anti-inflammatory dendritic cells and reduces the secretion of pro-inflammatory cytokines and chemokines (Ghoreschi et al., 2011; Gillard et al., 2015; Litjens et al., 2006; Treumer et al., 2003). The clinical efficacy of rituximab in MS patients elucidated that also B cells can majorly contribute to the pathogenesis of MS (Hauser et al., 2008b). Hence, a medication exerting immunomodulatory effects on B cells could be a promising medication for MS patients. So far, DMF effects on B cells have been poorly described and only two recent studies suggest that DMF also directly influences B cell activation and can change the distribution of subpopulations (Lundy et al., 2016; Schulze-Topphoff et al., 2016). We investigated the effect of DMF in an EAE model, in which $B$ cells contribute in a more pathogenic manner. Clinical, histological and immunological analyses were performed to study the DMF effect on B cell and T cell activation, subpopulations and functions. 


\subsubsection{DMF treatment improves clinic and pathology of EAE mice}

At first it was evaluated how DMF treatment affects clinical parameters like disease severity, serum antibody level as well as demyelination and inflammation of the spinal cord in EAE mice. In our EAE model, C57BL/6 mice were immunized with a recombinant mouse myelin oligodendrocyte glycoprotein ( $\mathrm{rMOG}_{1-117}$ ), which leads to the development of antigen-activated $B$ cells and production of antibodies (Ab) directed against MOG (Weber et al., 2010). In this EAE model, B cells contribute majorly to the pathogenesis of the disease and support the development of proinflammatory IFNY- and IL-17-producing T cells. Mice were treated preventively or therapeutically with $15 \mathrm{mg} / \mathrm{kg}$ bodyweight DMF or control twice a day for 60 or 50 days. Preventive and therapeutic DMF treatment could profoundly ameliorate the disease course of mice compared to control-treated animals (Figure 15). In the past, DMF was mainly investigated in MOG $35-55$ peptide induced EAE, which is a primarily T cell-mediated model. In contrast to these previous studies, in our EAE model therapeutic DMF treatment showed a pronounced effect on disease severity whereas previously only slight or no effects were seen in $\mathrm{MOG}_{35-55}$ peptide induced EAE (Kihara et al., 2015; Linker et al., 2011). These data suggest that this beneficial effect could be mediated by an immunomodulatory impact of DMF on B cells which, different from B cells in $\mathrm{MOG}_{35-55}$ peptide induced $E A E$, substantially promote the disease severity in $\mathrm{rMOG}_{1-117}$ induced $\mathrm{EAE}$. Moreover, these results also highlight the importance of appropriate medication dosage since therapeutically applied DMF showed no effect when administered twice a day at a concentration of $100 \mathrm{mg} / \mathrm{kg}$ bodyweight (Kihara et al., 2015). Nevertheless, the impact of preventive DMF treatment was still significantly more distinct when compared to therapeutic application of DMF. These results are comparable to findings in $\mathrm{MOG}_{35-55}$ peptide induced $E A E$ where preventive DMF treatment also considerably improved the EAE course (Kihara et al., 2015; Linker et al., 2011; Reick et al., 2014; Schilling et al., 2006).

Activated B cells can differentiate into plasmablasts and plasma cells which secrete antigenspecific antibodies (Nutt et al., 2015). Immunization of mice with $\mathrm{rMOG}_{1-117}$ leads to the development of anti-MOG antibodies which recently have been shown to play an important role in the initiation of CNS demyelinating disease (Kinzel et al., 2016). Therefore, it was interesting to analyze DMF effects on the production of antibodies. Serum anti-MOG Ab levels of mice preventively or therapeutically treated with control or DMF were determined weekly until day 42 
p.i. (Figure 16). Neither preventive nor therapeutic DMF treatment significantly decreased the serum level of anti-MOG Ab levels. Preventive application of DMF even slightly increased antiMOG Ab level when compared to controls. A recent study showed that the immunomodulatory agent IFN $\beta$ also enhanced serum anti-MOG IgG and IgM antibodies in EAE, but these increased antibodies did not correlate with EAE severity and occurred despite clinical benefit (Schubert et al., 2015). According to these data, preventive and therapeutic DMF treatment improved EAE severity, although auto-antibody levels were not majorly altered. These data suggest that injury of the CNS may not be primarily mediated by auto-antibodies in EAE (Schubert et al., 2015).

Hence, preventive and therapeutic DMF treatment decreased EAE severity, these effects were further examined by histology. Demyelination and overall inflammation of the spinal cord was profoundly reduced by therapeutic DMF treatment and slightly decreased under preventive DMF treatment (Figure 17). In line with previous findings, DMF treatment did not majorly alter T cell (CD3 ${ }^{+}$cell) numbers in the spinal cord (Linker et al., 2011; Reick et al., 2014; Schilling et al., 2006). The DMF effects on the number of infiltrating B cells (B220 cells) were even less pronounced when compared to infiltrating $\mathrm{T}$ cell numbers. In contrast to preventive DMF treatment, therapeutic DMF application significantly decreased the number of infiltrating macrophages/microglia (Mac3 ${ }^{+}$cells). Several studies demonstrated that preventive DMF treatment has no effect on the infiltration of microglia/macrophages and also in this study, no significant effect could be observed under preventive DMF administration (Linker et al., 2011; Reick et al., 2014). These results are comparable to results received in the cuprizone model, where DMF did also not influence the accumulation of microglia/macrophages. However, this study is the first demonstrating that therapeutic DMF treatment reduced demyelination and inflammation of the spinal cord as well as the number of accumulating microglia/macrophages. Thus, it can be assumed that the time point of treatment start influences the immunomodulatory effects mediated by DMF. In MS, microglia and macrophages are supposed to contribute to CNS injury by the production of high amounts of pro-inflammatory cytokines and chemokines as well as ROS (Jack et al., 2005). These recent findings lead to the suggestion that DMF treatment of MS patients might reduce the CNS inflammation mediated by infiltrating immune cells. 


\subsubsection{DMF treatment has immunomodulatory effects on peripheral $B$ cells and $T$ cells}

The pathogenesis of MS is partly mediated by circulating $B$ and T cells and it was shown that the composition and functions of B cell and T cell subsets are altered in MS patients (Jones et al., 2016). Studies of DMF effects on the adaptive immune system revealed that DMF might mediate a shift in T cell subsets towards more anti-inflammatory $T$ cells and could induce the apoptosis of $B$ cells and T cells (Ghoreschi et al., 2011; Mrowietz and Asadullah, 2005; Treumer et al., 2003). To analyze how DMF influences the adaptive immune system and thereby improves clinical course of EAE and CNS injury, DMF effects on B cells and T cells were investigated in the initial phase of EAE. C57BL/6 mice were treated 2 or 7 days prior to immunization until day 12 p.i. It was investigated how DMF treatment affects activation, composition of subpopulations and functional properties of $B$ cells and T cells.

\subsubsection{DMF has anti-inflammatory effects on peripheral $T$ cells}

Several studies in animal models and the observation of inflammatory cells and their effector functions in MS lesions led to the majorly accepted hypothesis that the disease is mediated by autoreactive T cells which cross the BBB and induce inflammation and damage inside the CNS (Fletcher et al., 2010). The EAE model mirrors clinical and pathological features of MS and was mainly used to achieve a better understanding of the pathogenesis of MS. Due to the important role of T cells in MS and EAE, it was investigated if the beneficial clinical effects of DMF could be mediated by an alteration of T cell activation and differentiation. It was reported that DMF induces apoptosis of human T cells and could lead to lymphopenia in MS patients (Gold et al., 2012; Treumer et al., 2003). In a first experiment it was therefore analyzed if these effects could be observed in EAE mice treated with DMF. The frequencies of $\mathrm{CD} 4^{+} \mathrm{T}$ cells, $\mathrm{CD} 8^{+} \mathrm{T}$ cells, $\mathrm{CD} 19^{+}$cells (B cells) and CD11 b+ cells were examined in blood, lymph node and spleen of control- and DMFtreated mice. DMF treatment significantly reduced the frequency of CD4 ${ }^{+} \mathrm{T}$ cells in the blood whereas the frequencies of $\mathrm{CD} 8^{+} \mathrm{T}$ cells, CD19+ cells (B cells) and CD11 ${ }^{+}$cells were only slightly reduced (Figure 18). These results are comparable to data reported for human peripheral blood lymphocyte subsets, where short term DMF treatment led to a decrease of $C D 4^{+} \mathrm{T}$ cells (Spencer et al., 2015). Conversely, only a slight reduction of $C D 8^{+} \mathrm{T}$ cells and $\mathrm{CD} 19^{+}$cells could be observed in the blood of DMF-treated mice. 
These result may reflect a discrepancy between EAE and MS, since CD8 ${ }^{+}$T cells do not majorly contribute to the pathogenesis of EAE but are numerously found in lesions of MS patients ('t Hart et al., 2011). This might explain why circulating CD8+ T cells in EAE mice were not as strongly reduced by DMF as in humans. However, the most interesting result was that the frequency of $\mathrm{CD}^{+} \mathrm{T}$ cells in lymph node and the frequencies of $\mathrm{CD}^{+} \mathrm{T}^{\mathrm{T}}$ cells and $\mathrm{CD} 8^{+} \mathrm{T}$ cells in spleen were significantly increased under DMF treatment. These data would suggest that the decrease of T cells seen in the blood of MS patients and EAE mice could rather be mediated by reallocation of T cells than by DMF-mediated apoptosis. Initial studies of DMF, as a component of the anti-psoriatic drug Fumaderm ${ }^{\circledR}$, demonstrated a reduction of T cells in the majority of patients (Altmeyer et al., 1996). A subsequent in vitro study of DMF seemed to confirm the ability of DMF to mediate apoptosis in human T cells (Treumer et al., 2003). An important fact which has to be taken into account is that only in vitro treatment with DMF, not its metabolite MMF, induced T cell apoptosis and this additionally was solely observed under very high concentrations (Gill and Kolson, 2013). No apoptotic effect of DMF was shown under physiologic concentrations which can be accomplished by its metabolite MMF in vivo. These data support the hypothesis that DMF and its metabolite MMF rather mediate an accumulation of T cells in secondary lymphoid organs and not primarily induce the apoptosis of T cells.

The DMF-mediated accumulation of T cells in lymph node and spleen raised the question of how these $\mathrm{T}$ cells are activated and which $\mathrm{T}$ cell subsets contribute to the high $\mathrm{T}$ cell frequencies. To address this question a flow cytometric analysis was performed and the activation markers CD69 and $\mathrm{CD} 25$ were measured on $\mathrm{CD}^{+} \mathrm{T}$ cells and $\mathrm{CD} 8^{+} \mathrm{T}$ cells of control or DMF-treated mice. The expression of CD69 and CD25 was profoundly decreased on $\mathrm{CD}^{+}{ }^{+}$T cells and CD8 ${ }^{+} \mathrm{T}$ cells of DMFtreated mice (Figure 19). CD69 is one of the earliest activation markers and is upregulated on T cells after antigen-recognition (Groth et al., 2004). CD25 is the $\alpha$-chain of the IL-2 receptor. Upon T cell activation, CD25 expression is upregulated leading to the creation of a high affinity IL-2 receptor (Gaffen, 2001). IL-2 is a cytokine which majorly drives T cell differentiation and proliferation. Effector T cells show the highest expression of CD69 and CD25 whereas naïve and memory T cells only show low or no expression of CD69 and CD25 (Hataye et al., 2006). Considering these data, DMF-mediated downregulation of CD69 and CD25 reflects a decreased activation of T cells and could thereby subsequently reduce the population of effector T cells. 
The clinical benefit of DMF could thus be mediated by a suppressing effect on T cells, since especially autoreactive effector T cells exacerbate disease severity (Fletcher et al., 2010).

Additionally, it was studied if DMF alters the expression of the T cell activation marker CD44. $\mathrm{CD}^{+} \mathrm{T}$ cells and $\mathrm{CD} 8^{+} \mathrm{T}$ cells expressing high levels of CD44 (CD44 $\left.{ }^{\mathrm{hi}}\right)$ were significantly decreased in spleens of DMF-treated mice (Figure 20, Figure 21). This effect was also slightly visible in the lymph node of DMF-treated mice. CD44 is an adhesion receptor and enhanced levels of CD44 are found on memory cells (Baaten et al., 2010b; Groth et al., 2004). Therefore, CD44 is widely used as a " memory marker" to differentiate naïve from activated and memory T cells (Budd et al., 1987). In this study, DMF treatment led to a decrease of $\mathrm{CD}^{+}$and $\mathrm{CD} 8^{+}$memory $\mathrm{T}$ cells whereas the population of naïve $T$ cells remained unaltered. These results suggest that the increased population found in lymph node and spleen under DMF treatment is mainly composed of naïve $T$ cells rather than of activated/memory T cells (Figure 18). Furthermore, these findings support the results concerning the activation status of T cells (CD69/CD25) (Figure 19). Naïve CD4 ${ }^{+} \mathrm{T}$ cells show already an intermediate expression level of CD44, which explains why within the $C D 4^{+} \mathrm{T}$ cell population not only CD44 ${ }^{\text {low }}$ but also CD44 ${ }^{\text {int }} T$ cells are increased under DMF treatment (Figure 20) (Groth et al., 2004).

Activated $\mathrm{CD}^{+}$T cells can differentiate into different subpopulations, such as IFNY- (Th1), IL-17(Th17) or IL-4/IL-10- (Th2) producing T cells. IFNY- and IL-17-producing T cells (Th1, Th17 cells) are the commonly induced CD4 ${ }^{+}$T cells in EAE (Fletcher et al., 2010; Kurschus, 2015; O'Connor et al., 2008). A recent study demonstrated that in $M_{35-55}$ peptide induced $E A E, D M F$ treatment led to decreased frequencies of Th1 and Th17 cells (Schulze-Topphoff et al., 2016). Furthermore, it was shown that lymphocytes of DMF-treated MS patients produce higher amounts of the cytokines IL4 and IL-10, which are mainly produced by Th2 cells suggesting that DMF might mediate a "Th1 to Th2 shift" (Gill and Kolson, 2013). Thus, it was interesting to analyze if DMF also alters the differentiation of $\mathrm{T}$ cells in $\mathrm{rMOG}_{1-117}$ induced EAE model. The frequency of splenic and lymphatic Th1 cells was significantly reduced by DMF treatment and Th17 cell frequencies were slightly decreased (Figure 22). Importantly, this effect was not due to reduced frequencies of viable $\mathrm{CD}^{+} \mathrm{T}$ cells as shown in Figure 22. These results are comparable to previous studies in $\mathrm{MOG}_{35-55}$ peptide induced EAE where DMF treatment also decreased Th1 and Th17 cells (Schulze-Topphoff et al., 2016). A study of Baaten and colleagues could demonstrate that CD44 is crucial for the 
development and survival of Th1 cells whereas Th2 and Th17 differentiation seems to be independent of CD44 (Baaten et al., 2010b). Consequently, the prominent decrease of Th1 cells under DMF treatment could partly be mediated by the DMF-induced downregulation of CD44 (Figure 20). Conclusively, this would also explain why the DMF effect was more prominent on the Th1 population compared to the Th17 population. Th1 and Th17 cells contribute in a large part to the pathogenesis of EAE. Thus, a DMF-mediated downregulation of these two cell populations could majorly improve the disease course, as it was seen in this study.

Regulatory T cells (Tregs) play an important role in downregulating or suppressing excessive inflammatory responses. In MS patients, the frequency of Tregs is reduced during relapses and increases again during remission (Fletcher et al., 2010). A medication enhancing the frequency of Tregs could therefore bear a therapeutic benefit. In our EAE model, DMF treatment did not majorly alter the frequency of regulatory $T$ cells, although a slight increase could be observed in spleens from DMF-treated mice (Figure 23). These data suggest that the induction of Tregs is not profoundly altered by DMF treatment and that the clinical effects could be rather mediated by a downregulation of pro-inflammatory T cells.

\subsubsection{DMF alters $\mathrm{T}$ cell proliferation}

The previous ex-vivo experiments revealed that $\mathrm{T}$ cell activation and development of proinflammatory T cells (Th1 cells) is reduced in immunized EAE mice treated with DMF (Figures 1922). Conferring to these results, a further experiment determined how DMF influences the proliferation of $\mathrm{T}$ cells when these are stimulated in an antigen-independent manner. Purified T cells from naïve C57BL/6 mice, treated with either control- or DMF for 19 days, were stimulated with anti-CD3/CD28 in vitro to induce T cell proliferation. Treating $T$ cells with anti-CD3/CD28 simulates the activation by antigen-presenting cells (Trickett and Kwan, 2003). Ex vivo proliferation of $\mathrm{CD}^{+} \mathrm{T}$ cells and $\mathrm{CD} 8^{+} \mathrm{T}$ cells was significantly diminished when these were previously treated with DMF in vivo (Figure 24A-B). A detailed analysis of the proliferation revealed that $\mathrm{T}$ cells from DMF-treated animals showed lower proliferation rates compared to control-treated animals, illustrating that control-treated T cells divided themselves more often upon anti-CD3/CD28 stimulation. Considering these data, in vivo DMF treatment seems to have an anti-proliferative effect on naïve T cells when these are stimulated in vitro. These results are in line with the observations that DMF reduced the activation of $\mathrm{T}$ cells and decreases the frequency of 
activated/memory T cells. Additionally, it was investigated how in vivo DMF treatment of T cells influences their differentiation in vitro. Supernatants of this T cell cultures were collected and the amount of secreted IFN $\gamma$ and GM-CSF was measured by ELISA. Analysis revealed that DMF-treated T cells produced significantly less IFNY and GM-CSF compared to control-treated T cells (Figure 24C). Taken together, it could be assumed that DMF treatment decreases the differentiation of pro-inflammatory Th1 cells by downregulating $\mathrm{T}$ cell activation and proliferation. In the recent years it could be frequently shown that also GM-CSF producing $\mathrm{T}$ cells majorly contribute to pathogenesis of EAE and also occur in higher frequencies in MS patients (Codarri et al., 2011; Grifka-Walk et al., 2015; Rasouli et al., 2015). Thus, the DMF-mediated downregulation of GM-CSFproducing T cells could be another effect leading to an improvement of EAE severity.

In summary, DMF treatment reduced the activation and proliferation of T cells as well as inhibited their differentiation into pro-inflammatory effector cells. Fewer frequencies of $\mathrm{CD} 4^{+} \mathrm{T}$ cells and $\mathrm{CD}^{+} \mathrm{T}$ cells were found in the blood of DMF-treated mice, but showed an increased accumulation in secondary lymphoid organs. Since DMF decreased the generation of Th1 and Th17 cells, but did not increase the frequency of Tregs, it could be assumed that DMF induced the development of Th2 cells which could account for the higher frequency of $\mathrm{CD} 4^{+} \mathrm{T}$ cells. These results would be comparable to observations in DMF-treated patients where DMF mediates a "Th1 to Th2 cell shift" (Gill and Kolson, 2013). Furthermore, DMF treatment mediates a reduction of memory T cells and a relative expansion of naïve T cells, an effect which was also reported for MS patients treated with DMF (Gross et al., 2015; Longbrake et al., 2016). DMF treatment similarly decreased the activation of $\mathrm{CD}^{+} \mathrm{T}$ cells which can contribute to MS pathogenesis and are numerously found in brain lesions of MS patients (Friese and Fugger, 2009; 't Hart et al., 2011). This overall antiinflammatory effect of DMF on T cells could have majorly contributed to the disease improvement in $\mathrm{rMOG}_{1-117}$ induced EAE. In addition, the DMF effects observed in this study might be a hint on how DMF mediates the beneficial effects seen in MS therapy.

\subsubsection{DMF-treated B cells are more potent antigen-presenting cells}

Immunization with $\mathrm{MOG}_{35-55}$ peptide directly activates autoreactive $\mathrm{CD}^{+} \mathrm{T}$ cells via an interaction with the MHC-II complex-bound peptide on APCs without the need to of internal processing (Slavin et al., 2001; Weber et al., 2010). In contrast, in $\mathrm{rMOG}_{1-117}$ induced EAE the native MOG has to be internalized and processed by APCs to present the encephalitogenic peptide to autoreactive 
CD4 ${ }^{+} T$ cells (Slavin et al., 2001). This leads to the generation of pathogenic B cells, which recognize the MOG-protein via their B cell receptor and subsequently activate MHC-II restricted $\mathrm{CD} 4^{+} \mathrm{T}$ cells (Weber et al., 2010).

In this study, it was investigated how DMF treatment influences these pathogenic B cells and if the clinical benefits seen in this model could be mediated by an anti-inflammatory effect on pathogenic B cells. Similar to the analysis of T cells, first experiments examined DMF effects on the B cell activation at day 12 p.i. Data evaluation revealed that in contrast to T cells, DMF treatment rather increased the activation of $\mathrm{B}$ cells primarily by enhancing the MHC-II expression on lymphatic B cells (Figure 25). Although the co-stimulatory molecules CD80, CD86 and CD40 were not significantly altered their expression was slightly increased on lymphatic B cells of DMFtreated mice. The expression levels of the activation markers CD69, CD25 and Fas were not modified by DMF treatment (Figure 26). It could therefore be assumed that DMF primarily influences antigen-presenting and co-stimulatory functions of $B$ cells and not so much the expression of activation markers. Additionally, no significant DMF-mediated enhanced expression of MHC-II could be observed at day 60 after immunization (data not shown). This would suggest that either MHC-II expression on B cells is not further inducible at this time point or that DMF influences MHC-II especially during the early and acute phase of EAE, where immune cells become mainly activated in the periphery. MHC-II is important for the cognate interaction between B cells and T cells (Scholl and Geha, 1994). The peptide/MHC-II-complex is recognized by the T cell receptor (TCR) of $\mathrm{CD}^{+} \mathrm{T}$ cells and leads to the activation of antigen-specific T cells (Charles $A$ Janeway et al., 2001). These activated T cells increase the expression of co-stimulatory molecules and secret cytokines and chemokines which subsequently stimulate the proliferation and differentiation of B cells. Taken together, it could be assumed that the DMF-mediated increase of MHC-II expression on B cells promotes the activation and proliferation of B cells and T cells and conclusively this data suggests that DMF has opposing effects on B cells and T cells. Nevertheless, there was no enhanced expression of activation markers on B cells under DMF treatment leading to the suggestion that DMF-mediated dampening effects on $\mathrm{T}$ cells did not result in increased B cell activation. Naïve B cells require pronounced stimulating signals from $\mathrm{CD}^{+} \mathrm{T}$ cells or their respective antigen itself to proliferate and differentiate. Since DMF treatment decreased the frequency of activated $T$ cells, it can be assumed that B cells admittedly provided a first strong 
activation signal for $T$ cells but that these $T$ cells were not fully activated due to the immunomodulatory effects of DMF. Deductive, no effective T cell help was provided for antigenpresenting B cells which therefore did not become fully activated. Another hypothesis could be that DMF mediated a shift towards a more regulatory phenotype of B cells and following the initial activation of B cells, demonstrated by enhanced MHC-II expression, induced the development of anti-inflammatory B cells which can also be observed in individual DMF-treated MS patients (Li et al., 2017). This assumption would also explain why DMF treatment improved the course of EAE although it rather promotes activation of B cells by increasing their antigen-presenting properties.

The increased activation of $B$ cells raised the question how DMF influences individual subpopulations of B cells. B cell subsets can be defined by their expression of CD21 and CD23, which differs on specific B cell subtypes (Shen and Fillatreau, 2015). Both markers are highly expressed on transitional B cells whereas for example follicular B cells show a lower expression of CD21 (Meyer-Bahlburg et al., 2008). In this study $C D 21^{\text {hi }} C D 23^{+} B$ cells were referred to as transitional $\mathrm{B}$ cells and $\mathrm{CD} 21^{\text {int }} \mathrm{CD} 23^{+} \mathrm{B}$ cells were referred to as follicular $\mathrm{B}$ cells. In vivo DMF treatment induced a shift in B cell subsets towards fewer transitional and more follicular B cells in isolated splenic cells (Figure 27). The frequency of immature B cells (CD21- ${ }^{-}$2023) in the bone marrow was not altered suggesting that DMF-mediated changes only occur in the periphery (Figure 27). The observed results indicate that DMF treatment may promote the differentiation of $B$ cells towards a population which exerts a potent antigen-presenting function, the follicular $B$ cells. Inside secondary lymphoid organs like the spleen, naïve follicular B cells present antigens to $\mathrm{CD}^{+} \mathrm{T}$ cells which results in an immune response to the presented antigen (Allman and Pillai, 2008).

Furthermore, DMF effects were analyzed on the frequency of immature naïve $B$ cells, mature naïve B cells, memory B cells, regulatory B cells, germinal center B cells and antigen-activated $B$ cells (Figure 28). Although DMF did not significantly alter any of these B cell phenotypes, higher frequencies of antigen-activated $B$ cells and lower frequencies of immature naïve $B$ cells could be observed in DMF-treated, $\mathrm{rMOG}_{1-117}$ immunized animals. Antigen-activated B cells express CD69, CD80 and high levels of MHC-II, which supports the hypothesis that DMF contributes to the activation of B cells via an increased induction of MHC-II and co-stimulatory molecules such as CD80 (Figure 25). Furthermore, DMF seems to mediate a shift from immature naïve B cells to 
mature naïve B cells in the spleen, indicating that DMF treatment could moderately facilitate B cell maturation. On one side, these findings lead to the assumption that the beneficial clinical effects of DMF may not be Bcell-mediated since DMF rather promotes the generation of antigenactivated B cells which could contribute to the pathogenesis of the disease. On the other side, these activated $B$ cells could also exert a more anti-inflammatory and/or regulatory function which could mediate an improvement of the disease (Ray and Basu, 2014). The latter hypothesis can be supported by the slightly increased frequency of regulatory B cells which were observed in DMFtreated animals (Figure 28).

As a first functional analysis, it was investigated if DMF can influence the antigen-recognition and antigen-binding of B cells. Therefore, in vivo control- and DMF-treated B cells were isolated and ex vivo incubated with a fluorescent-labeled $\mathrm{rMOG}_{1-117}$ and the frequency $B$ cells which were able to recognize and bind rMOG $_{1-117}$ could be analyzed via flow cytometry. DMF treatment did not alter the frequency of rMOG-binding B cells compared to controls (Figure 29). This suggest that DMF did not influence the antigen-recognition and antigen-binding abilities of $B$ cells and that DMF therefore does not alter the antigen-affinity of the $B$ cell receptor.

Another functional analysis focused more on the antigen-presenting function of B cells. Thus, B cells purified from control- or DMF-treated immunized mice were co-cultured with naïve CFSElabeled 2D2 T cells, which have a transgenic T cell receptor specific for MOG, and were stimulated with rMOG $_{1-117}$ (Bettelli et al., 2003). Antigen-presenting function of these B cells was then analyzed via the extent of T cell proliferation. In this setting, T cell proliferation was significantly increased when these were co-cultured with DMF-treated B cells compared to control (Figure 30AB). A more detailed quantification revealed that the frequencies of T cells with low, intermediate and high proliferation rate were increased by DMF-treated B cells when compared to controls. Additionally, cultured DMF-treated B cells also showed a slightly higher expression of MHC-II compared to control-treated B cells (Figure 30C). These data support the hypothesis that DMF treatment can lead to the development of more potent antigen-presenting B cells which caused the increased proliferation of $T$ cells. These findings are also in line with the previous results illustrating an increased MHC-II expression and enhanced frequencies of follicular and antigenactivated B cells under DMF treatment. To receive a first hint if these DMF-treated B cells exert pro-inflammatory or anti-inflammatory functions, the frequency of IFN $\mathrm{p}$-producing $\mathrm{T}$ cells (Th1) 
was measured in a similar co-culture. When compared to control-treated B cells, DMF-treated B cells did not alter the frequency of IFNY-producing T cells (Figure 31). Thus, it could be assumed that the decrease of IFNy-producing T cells found ex vivo under DMF treatment might not be a $B$ cell-mediated effect. Furthermore, these data suggest that either DMF does not promote the development of a more anti-inflammatory and/or regulatory $B$ cell phenotype or that this effect is not strong enough to exert a B cell-mediated immunomodulatory effect on T cell differentiation in vitro.

In conclusion, the present study could show that DMF treatment significantly ameliorated the clinical course of $\mathrm{rMOG}_{1-117}$ induced EAE and that demyelination and inflammation in the spinal cord were profoundly decreased. Furthermore, DMF decreased T cell activation and the frequency of pro-inflammatory Th1 cells which majorly contribute to the disease pathogenesis. This antiinflammatory effect did not seem to be profoundly mediated by B cells since DMF-treated B cells did not influence Th1 cell differentiation in vitro. It could therefore be assumed that DMF either directly affects $T$ cell differentiation or that this effect is mediated by other immune cells. A study of Litjens et al. could demonstrate that the DMF-metabolite MMF alters the maturation and polarization of dendritic cells (DCs) resulting in a decreased generation of Th1 cells (Litjens et al., 2004b, 2006). This effect may have contributed to the amelioration of $\mathrm{rMOG}_{1-117}$ induced $E A E$, since DCs are the most potent APCs which promote the antigen-specific activation of encephalitogenic T cells (Ganguly et al., 2013). Surprisingly, DMF treatment increased MHC-II expression on B cells and increased their ability to present antigen. In contrast to results in B cellmediated EAE, DMF treatment decreased MHC-II expression on B cells in $\mathrm{MOG}_{35-55}$ peptide induced EAE suggesting that DMF may exerts opposing immunomodulatory effects on $B$ cells with (rMOG EAE) or without (MOG-peptide EAE) major pathogenic functions (Schulze-Topphoff et al., 2016). The increased ability of these B cells to present antigen via MHC-Il furthermore promoted the proliferation of T cells. It is still unclear if and how these potent antigen-presenting B cells could influence the $\mathrm{T}$ cell differentiation. Although, Th1 cell differentiation was not reduced by DMF-treated B cells, B cells may induce differentiation of Th2 cells, which can exert antiinflammatory functions. This would explain the increased population of $\mathrm{CD}^{+} \mathrm{T}$ cells found in lymph node and spleen of DMF-treated mice which was neither composed of Th1, Th17 cells nor of Tregs, leaving only Th2 cells. Although in this study no significant increase of regulatory B cells 
could be found under DMF treatment, it could be shown that B cells with regulatory function are found in DMF-treated MS patients (Lundy et al., 2016). Conclusively, the B cell-activating functions mediated by DMF could thereby contribute to an improvement of the disease.

\subsection{DMF altered B cell properties in MS patients}

DMF treatment of $\mathrm{rMOG}_{1-117}$ immunized mice ameliorated the disease course but seemed to simultaneously increase the activation of B cells, demonstrated by an increased expression of MHC-II and partly also co-stimulatory molecules. To analyze if this increased MHC-II expression could be found on human B cells, PBMCs from non-treated and DMF-treated MS patients (treatment duration $\geq 6$ months) were analyzed by flow cytometry. Evaluation of data revealed that human B cells isolated from DMF-treated MS patients showed an increased MHC-II expression when compared to controls (Figure 32). These data support the results found in our EAE model (Figure 25). Furthermore, similar findings could be demonstrated in a study which showed that B cells isolated from DMF-treated MS patients showed an enhanced MHC-II expression (StaunRam et al., Poster 185 ISNI 2016). Recent studies reported that DMF treatment could induce an anti-inflammatory B cell phenotype which contributes to the regulation of the peripheral immune system (Li et al., 2017; Lundy et al., 2016). Although DMF treatment increases the MHC-II expression on $B$ cells and increases their ability to present antigens, these $B$ cells might still be able to possess anti-inflammatory and/or regulatory properties and thereby exert beneficial functions. Nevertheless, DMF seems to have an activating function on B cells which should be taken into account when choosing proper medication for individual MS patients. For example, it could recently be demonstrated in $\mathrm{rMOG}_{1-117}$ induced $\mathrm{EAE}, \mathrm{B}$ cells which reoccur after anti-CD20 treatment show enhanced pro-inflammatory properties (Linda Feldmann, group internal communication, data not published). It could therefore be assumed that DMF may not be the appropriate follow up treatment for B cell-depleting agents due to its "B cell-activating" effects. 


\section{Outlook}

The present study provides evidence that DMF exerts axon- and cytoprotective effects and promotes regeneration of mature oligodendrocytes independent of the peripheral immune system. These DMF effects were potentially mediated by an increased activation of the transcription factor Nrf2 which leads to an enhanced protection of cells against oxidative stress. No significant effects were observed on demyelination and remyelination, but may also be due to limitations of this animal model. It could be interesting to analyze the DMF effects in a modified cuprizone model where the phase of extensive demyelination is prolonged and the process of remyelination is delayed (Bai et al., 2016).

In the second part of this study it could be show that DMF treatment improved clinical and pathological parameters of an EAE model with involvement of pathogenic B cells. Although DMF could profoundly decrease the activation and differentiation of pro-inflammatory $\mathrm{T}$ cells, it enhanced the antigen-presenting function of B cells. This study could not completely elucidate which B cell phenotype is promoted by DMF treatment and subsequently which T cell phenotype is induced by these B cells. Further analysis could focus on phenotyping these DMF-treated B cells and elucidate if they promote a pro- or anti-inflammatory milieu. One experimental approach to study the DMF-mediated B cell phenotype could be a B cell transfer experiment. Therefore, control- or DMF-treated CD20k.o. B cells could be transferred into immunized, B cell-depleted WT animals and clinical parameters such as EAE onset, severity and incidence could indicate if these B cells rather exert pro- or anti-inflammatory functions. 


\section{Bibliography}

Acs, P., Selak, M.A., Komoly, S., and Kalman, B. (2013). Distribution of oligodendrocyte loss and mitochondrial toxicity in the cuprizone-induced experimental demyelination model. J. Neuroimmunol. 262, 128-131.

Albrecht, P., Bouchachia, I., Goebels, N., Henke, N., Hofstetter, H.H., Issberner, A., Kovacs, Z., Lewerenz, J., Lisak, D., Maher, P., et al. (2012). Effects of dimethyl fumarate on neuroprotection and immunomodulation. J. Neuroinflammation 9, 163.

Allman, D., and Pillai, S. (2008). Peripheral B cell subsets. Curr. Opin. Immunol. 20, 149-157.

Altmeyer, P., Hartwig, R., and Matthes, U. (1996). [Efficacy and safety profile of fumaric acid esters in oral long-term therapy with severe treatment refractory psoriasis vulgaris. A study of 83 patients]. Hautarzt Z. Dermatol. Venerol. Verwandte Geb. 47, 190-196.

Altmeyer, P.J., Mattlies, U., Pawlak, F., Hoffmann, K., Frosch, P.J., Ruppert, P., Wassilew, S.W., Horn, T., Kreysel, H.W., Lutz, G., et al. (1994). Antipsoriatic effect of fumaric acid derivatives. J. Am. Acad. Dermatol. 30, 977-981.

Amor, S., Groome, N., Linington, C., Morris, M.M., Dornmair, K., Gardinier, M.V., Matthieu, J.M., and Baker, D. (1994). Identification of epitopes of myelin oligodendrocyte glycoprotein for the induction of experimental allergic encephalomyelitis in SJL and Biozzi AB/H mice. J. Immunol. Baltim. Md 1950 153, 4349-4356.

Ando, D.G., Clayton, J., Kono, D., Urban, J.L., and Sercarz, E.E. (1989). Encephalitogenic T cells in the B10.PL model of experimental allergic encephalomyelitis (EAE) are of the Th-1 lymphokine subtype. Cell. Immunol. 124, 132-143.

Baaten, B.J., Li, C.-R., and Bradley, L.M. (2010a). Multifaceted regulation of T cells by CD44. Commun. Integr. Biol. 3, 508-512.

Baaten, B.J.G., Li, C.-R., Deiro, M.F., Lin, M.M., Linton, P.J., and Bradley, L.M. (2010b). CD44 regulates survival and memory development in Th1 cells. Immunity 32, 104-115.

Bai, C.B., Sun, S., Roholt, A., Benson, E., Edberg, D., Medicetty, S., Dutta, R., Kidd, G., Macklin, W.B., and Trapp, B. (2016). A mouse model for testing remyelinating therapies. Exp. Neurol. 283, Part A, 330-340.

Bakker, D.A., and Ludwin, S.K. (1987). Blood-brain barrier permeability during Cuprizone-induced demyelination: Implications for the pathogenesis of immune-mediated demyelinating diseases. J. Neurol. Sci. 78, 125-137.

Barkhof, F., Bruck, W., De Groot, C.J.A., Bergers, E., Hulshof, S., Geurts, J., Polman, C.H., and van der Valk, P. (2003). Remyelinated lesions in multiple sclerosis: magnetic resonance image appearance. Arch. Neurol. 60, 1073-1081. 
Barnett, M.H., and Prineas, J.W. (2004). Relapsing and remitting multiple sclerosis: pathology of the newly forming lesion. Ann. Neurol. 55, 458-468.

Barnett, M.H., Parratt, J.D.E., Cho, E.-S., and Prineas, J.W. (2009). Immunoglobulins and complement in postmortem multiple sclerosis tissue. Ann. Neurol. 65, 32-46.

Barr, T.A., Shen, P., Brown, S., Lampropoulou, V., Roch, T., Lawrie, S., Fan, B., O'Connor, R.A., Anderton, S.M., Bar-Or, A., et al. (2012). B cell depletion therapy ameliorates autoimmune disease through ablation of IL-6-producing B cells. J. Exp. Med. 209, 1001-1010.

Bartholomäus, I., Kawakami, N., Odoardi, F., Schläger, C., Miljkovic, D., Ellwart, J.W., Klinkert, W.E.F., Flügel-Koch, C., Issekutz, T.B., Wekerle, H., et al. (2009). Effector T cell interactions with meningeal vascular structures in nascent autoimmune CNS lesions. Nature 462, 94-98.

Bénardais, K., Kotsiari, A., Skuljec, J., Koutsoudaki, P.N., Gudi, V., Singh, V., Vulinović, F., Skripuletz, T., and Stangel, M. (2013). Cuprizone [bis(cyclohexylidenehydrazide)] is selectively toxic for mature oligodendrocytes. Neurotox. Res. 24, 244-250.

Bettelli, E., Pagany, M., Weiner, H.L., Linington, C., Sobel, R.A., and Kuchroo, V.K. (2003). Myelin oligodendrocyte glycoprotein-specific $\mathrm{T}$ cell receptor transgenic mice develop spontaneous autoimmune optic neuritis. J. Exp. Med. 197, 1073-1081.

Biancotti, J.C., Kumar, S., and Vellis, J. de (2008). Activation of Inflammatory Response by a Combination of Growth Factors in Cuprizone-Induced Demyelinated Brain Leads to Myelin Repair. Neurochem. Res. 33, 2615-2628.

Bradl, M., and Lassmann, H. (2010). Oligodendrocytes: biology and pathology. Acta Neuropathol. (Berl.) 119, 37-53.

Brück, W., and Stadelmann, C. (2003). Inflammation and degeneration in multiple sclerosis. Neurol. Sci. 24, s265-s267.

Brück, W., Porada, P., Poser, S., Rieckmann, P., Hanefeld, F., Kretzschmarch, H.A., and Lassmann, H. (1995). Monocyte/macrophage differentiation in early multiple sclerosis lesions. Ann. Neurol. 38, 788-796.

Budd, R.C., Cerottini, J.C., Horvath, C., Bron, C., Pedrazzini, T., Howe, R.C., and MacDonald, H.R. (1987). Distinction of virgin and memory T lymphocytes. Stable acquisition of the Pgp-1 glycoprotein concomitant with antigenic stimulation. J. Immunol. Baltim. Md 1950 138, 31203129.

Carey, E.M., and Freeman, N.M. (1983). Biochemical changes in cuprizone-induced spongiform encephalopathy. Neurochem. Res. 8, 1029-1044.

Chan, K., Lu, R., Chang, J.C., and Kan, Y.W. (1996). NRF2, a member of the NFE2 family of transcription factors, is not essential for murine erythropoiesis, growth, and development. Proc. Natl. Acad. Sci. U. S. A. 93, 13943-13948. 
Chard, D.T., Griffin, C.M., Parker, G.J.M., Kapoor, R., Thompson, A.J., and Miller, D.H. (2002). Brain atrophy in clinically early relapsing-remitting multiple sclerosis. Brain J. Neurol. 125, 327-337.

Charles A Janeway, J., Travers, P., Walport, M., and Shlomchik, M.J. (2001). B-cell activation by armed helper T cells.

Chen, L., and Flies, D.B. (2013). Molecular mechanisms of T cell co-stimulation and co-inhibition. Nat. Rev. Immunol. 13, 227-242.

Chen, H., Assmann, J.C., Krenz, A., Rahman, M., Grimm, M., Karsten, C.M., Köhl, J., Offermanns, S., Wettschureck, N., and Schwaninger, M. (2014). Hydroxycarboxylic acid receptor 2 mediates dimethyl fumarate's protective effect in EAE. J. Clin. Invest. 124, 2188-2192.

Claussen, M.C., and Korn, T. (2012). Immune mechanisms of new therapeutic strategies in MS: teriflunomide. Clin. Immunol. Orlando Fla 142, 49-56.

Codarri, L., Gyülvészi, G., Tosevski, V., Hesske, L., Fontana, A., Magnenat, L., Suter, T., and Becher, B. (2011). ROR[gamma]t drives production of the cytokine GM-CSF in helper T cells, which is essential for the effector phase of autoimmune neuroinflammation. Nat. Immunol. 12, 560-567.

Cohen, J.A., Barkhof, F., Comi, G., Hartung, H.-P., Khatri, B.O., Montalban, X., Pelletier, J., Capra, R., Gallo, P., Izquierdo, G., et al. (2010). Oral Fingolimod or Intramuscular Interferon for Relapsing Multiple Sclerosis. N. Engl. J. Med. 362, 402-415.

Coles, A.J., Twyman, C.L., Arnold, D.L., Cohen, J.A., Confavreux, C., Fox, E.J., Hartung, H.-P., Havrdova, E., Selmaj, K.W., Weiner, H.L., et al. (2012). Alemtuzumab for patients with relapsing multiple sclerosis after disease-modifying therapy: a randomised controlled phase 3 trial. Lancet Lond. Engl. 380, 1829-1839.

Constant, S., Sant'Angelo, D., Pasqualini, T., Taylor, T., Levin, D., Flavell, R., and Bottomly, K. (1995). Peptide and protein antigens require distinct antigen-presenting cell subsets for the priming of CD4+ T cells. J. Immunol. Baltim. Md 1950 154, 4915-4923.

Cross, S.A., Cook, D.R., Chi, A.W.S., Vance, P.J., Kolson, L.L., Wong, B.J., Jordan-Sciutto, K.L., and Kolson, D.L. (2011). Dimethyl fumarate, an immune modulator and inducer of the antioxidant response, suppresses HIV replication and macrophage-mediated neurotoxicity; a novel candidate for HIV-neuroprotection. J. Immunol. Baltim. Md 1950 187, 5015-5025.

Dowling, P., Shang, G., Raval, S., Menonna, J., Cook, S., and Husar, W. (1996). Involvement of the CD95 (APO-1/Fas) receptor/ligand system in multiple sclerosis brain. J. Exp. Med. 184, 1513-1518.

Dupuy, S.L., Tauhid, S., Hurwitz, S., Chu, R., Yousuf, F., and Bakshi, R. (2016). The Effect of Dimethyl Fumarate on Cerebral Gray Matter Atrophy in Multiple Sclerosis. Neurol. Ther. 5, 215-229.

Evangelou, N., Konz, D., Esiri, M.M., Smith, S., Palace, J., and Matthews, P.M. (2000). Regional axonal loss in the corpus callosum correlates with cerebral white matter lesion volume and distribution in multiple sclerosis. Brain J. Neurol. 123 ( Pt 9), 1845-1849. 
Farooqui, A.A., and Horrocks, L.A. (2001). Plasmalogens: workhorse lipids of membranes in normal and injured neurons and glia. Neurosci. Rev. J. Bringing Neurobiol. Neurol. Psychiatry 7, 232-245.

Ferguson, B., Matyszak, M.K., Esiri, M.M., and Perry, V.H. (1997). Axonal damage in acute multiple sclerosis lesions. Brain J. Neurol. 120 ( Pt 3), 393-399.

Filippi, M., Rocca, M.A., Ciccarelli, O., De Stefano, N., Evangelou, N., Kappos, L., Rovira, A., SastreGarriga, J., Tintorè, M., Frederiksen, J.L., et al. (2016). MRI criteria for the diagnosis of multiple sclerosis: MAGNIMS consensus guidelines. Lancet Neurol. 15, 292-303.

Fillatreau, S., Sweenie, C.H., McGeachy, M.J., Gray, D., and Anderton, S.M. (2002). B cells regulate autoimmunity by provision of IL-10. Nat. Immunol. 3, 944-950.

Fischer, M.T., Sharma, R., Lim, J.L., Haider, L., Frischer, J.M., Drexhage, J., Mahad, D., Bradl, M., van Horssen, J., and Lassmann, H. (2012). NADPH oxidase expression in active multiple sclerosis lesions in relation to oxidative tissue damage and mitochondrial injury. Brain 135, 886-899.

Fletcher, J.M., Lalor, S.J., Sweeney, C.M., Tubridy, N., and Mills, K.H.G. (2010). T cells in multiple sclerosis and experimental autoimmune encephalomyelitis. Clin. Exp. Immunol. 162, 1-11.

Fox, R.J., Miller, D.H., Phillips, J.T., Hutchinson, M., Havrdova, E., Kita, M., Yang, M., Raghupathi, K., Novas, M., Sweetser, M.T., et al. (2012). Placebo-controlled phase 3 study of oral BG-12 or glatiramer in multiple sclerosis. N. Engl. J. Med. 367, 1087-1097.

Franciotta, D., Salvetti, M., Lolli, F., Serafini, B., and Aloisi, F. (2008). B cells and multiple sclerosis. Lancet Neurol. 7, 852-858.

Fraussen, J., Claes, N., de Bock, L., and Somers, V. (2014). Targets of the humoral autoimmune response in multiple sclerosis. Autoimmun. Rev. 13, 1126-1137.

Friese, M.A., and Fugger, L. (2009). Pathogenic CD8+ T cells in multiple sclerosis. Ann. Neurol. 66, 132-141.

Frischer, J.M., Weigand, S.D., Guo, Y., Kale, N., Parisi, J.E., Pirko, I., Mandrekar, J., Bramow, S., Metz, I., Brück, W., et al. (2015). Clinical and Pathological Insights into the Dynamic Nature of the White Matter Multiple Sclerosis Plaque. Ann. Neurol. 78, 710-721.

Furtado, G.C., Marcondes, M.C.G., Latkowski, J.-A., Tsai, J., Wensky, A., and Lafaille, J.J. (2008). Swift Entry of Myelin-Specific T Lymphocytes into the Central Nervous System in Spontaneous Autoimmune Encephalomyelitis. J. Immunol. Baltim. Md 1950 181, 4648-4655.

Gaffen, S.L. (2001). Signaling domains of the interleukin 2 receptor. Cytokine 14, 63-77.

Ganguly, D., Haak, S., Sisirak, V., and Reizis, B. (2013). The role of dendritic cells in autoimmunity. Nat. Rev. Immunol. 13, 566-577. 
Ghoreschi, K., Brück, J., Kellerer, C., Deng, C., Peng, H., Rothfuss, O., Hussain, R.Z., Gocke, A.R., Respa, A., Glocova, I., et al. (2011). Fumarates improve psoriasis and multiple sclerosis by inducing type II dendritic cells. J. Exp. Med. 208, 2291-2303.

Gill, A.J., and Kolson, D.L. (2013). Dimethyl fumarate modulation of immune and antioxidant responses: application to HIV therapy. Crit. Rev. Immunol. 33, 307-359.

Gillard, G.O., Collette, B., Anderson, J., Chao, J., Scannevin, R.H., Huss, D.J., and Fontenot, J.D. (2015). DMF, but not other fumarates, inhibits NF-KB activity in vitro in an Nrf2-independent manner. J. Neuroimmunol. 283, 74-85.

Gold, R., Linington, C., and Lassmann, H. (2006). Understanding pathogenesis and therapy of multiple sclerosis via animal models: 70 years of merits and culprits in experimental autoimmune encephalomyelitis research. Brain J. Neurol. 129, 1953-1971.

Gold, R., Kappos, L., Arnold, D.L., Bar-Or, A., Giovannoni, G., Selmaj, K., Tornatore, C., Sweetser, M.T., Yang, M., Sheikh, S.I., et al. (2012). Placebo-controlled phase 3 study of oral BG-12 for relapsing multiple sclerosis. N. Engl. J. Med. 367, 1098-1107.

Gold, R., Giovannoni, G., Selmaj, K., Havrdova, E., Montalban, X., Radue, E.-W., Stefoski, D., Robinson, R., Riester, K., Rana, J., et al. (2013). Daclizumab high-yield process in relapsingremitting multiple sclerosis (SELECT): a randomised, double-blind, placebo-controlled trial. The Lancet 381, 2167-2175.

Goldberg, J., Daniel, M., Heuvel, Y. van, Victor, M., Beyer, C., Clarner, T., and Kipp, M. (2013). Short-Term Cuprizone Feeding Induces Selective Amino Acid Deprivation with Concomitant Activation of an Integrated Stress Response in Oligodendrocytes. Cell. Mol. Neurobiol. 33, 10871098.

Goldschmidt, T., Antel, J., König, F.B., Brück, W., and Kuhlmann, T. (2009). Remyelination capacity of the MS brain decreases with disease chronicity. Neurology 72, 1914-1921.

Grifka-Walk, H.M., Giles, D.A., and Segal, B.M. (2015). IL-12-polarized Th1 cells produce GM-CSF and induce EAE independent of IL-23. Eur. J. Immunol. 45, 2780-2786.

Grigoriadis, N., Ben-Hur, T., Karussis, D., and Milonas, I. (2004). Axonal damage in multiple sclerosis: a complex issue in a complex disease. Clin. Neurol. Neurosurg. 106, 211-217.

Groebe, A., Clarner, T., Baumgartner, W., Dang, J., Beyer, C., and Kipp, M. (2009). Cuprizone treatment induces distinct demyelination, astrocytosis, and microglia cell invasion or proliferation in the mouse cerebellum. Cerebellum Lond. Engl. 8, 163-174.

Gross, C.C., Schulte-Mecklenbeck, A., Klinsing, S., Posevitz-Fejfár, A., Wiendl, H., and Klotz, L. (2015). Dimethyl fumarate treatment alters circulating $T$ helper cell subsets in multiple sclerosis. Neurol. Neuroimmunol. Neuroinflammation 3.

Groth, B.F.D.S., Smith, A.L., and Higgins, C.A. (2004). T cell activation: in vivo veritas. Immunol. Cell Biol. 82, 260-268. 
Gudi, V., Moharregh-Khiabani, D., Skripuletz, T., Koutsoudaki, P.N., Kotsiari, A., Skuljec, J., Trebst, C., and Stangel, M. (2009). Regional differences between grey and white matter in cuprizone induced demyelination. Brain Res. 1283, 127-138.

Haider, L., Fischer, M.T., Frischer, J.M., Bauer, J., Höftberger, R., Botond, G., Esterbauer, H., Binder, C.J., Witztum, J.L., and Lassmann, H. (2011). Oxidative damage in multiple sclerosis lesions. Brain 134, 1914-1924.

Haines, J.D., Inglese, M., and Casaccia, P. (2011). Axonal Damage in Multiple Sclerosis. Mt. Sinai J. Med. N. Y. 78, 231-243.

Harp, C.T., Ireland, S., Davis, L.S., Remington, G., Cassidy, B., Cravens, P.D., Stuve, O., Lovett-Racke, A.E., Eagar, T.N., Greenberg, B.M., et al. (2010). Memory B cells from a subset of treatment-naïve relapsing-remitting multiple sclerosis patients elicit $\mathrm{CD} 4(+)$ T-cell proliferation and IFN- $\gamma$ production in response to myelin basic protein and myelin oligodendrocyte glycoprotein. Eur. J. Immunol. 40, 2942-2956.

't Hart, B.A., Gran, B., and Weissert, R. (2011). EAE: imperfect but useful models of multiple sclerosis. Trends Mol. Med. 17, 119-125.

Hataye, J., Moon, J.J., Khoruts, A., Reilly, C., and Jenkins, M.K. (2006). Naive and memory CD4+ T cell survival controlled by clonal abundance. Science 312, 114-116.

Hauser, S.L., Waubant, E., Arnold, D.L., Vollmer, T., Antel, J., Fox, R.J., Bar-Or, A., Panzara, M., Sarkar, N., Agarwal, S., et al. (2008a). B-cell depletion with rituximab in relapsing-remitting multiple sclerosis. N. Engl. J. Med. 358, 676-688.

Hauser, S.L., Waubant, E., Arnold, D.L., Vollmer, T., Antel, J., Fox, R.J., Bar-Or, A., Panzara, M., Sarkar, N., Agarwal, S., et al. (2008b). B-Cell Depletion with Rituximab in Relapsing-Remitting Multiple Sclerosis. N. Engl. J. Med. 358, 676-688.

Hauser, S.L., Bar-Or, A., Comi, G., Giovannoni, G., Hartung, H.-P., Hemmer, B., Lublin, F., Montalban, X., Rammohan, K.W., Selmaj, K., et al. (2017). Ocrelizumab versus Interferon Beta-1a in Relapsing Multiple Sclerosis. N. Engl. J. Med. 376, 221-234.

healthline.com/health/multiple-sclerosis/facts-statistics-infographic Multiple Sclerosis by the Numbers: Facts, Statistics, and You.

Heigl, F., Hettich, R., Arendt, R., Durner, J., Koehler, J., and Mauch, E. (2013). Immunoadsorption in steroid-refractory multiple sclerosis: clinical experience in 60 patients. Atheroscler. Suppl. 14, 167173.

Hemmer, B., Kerschensteiner, M., and Korn, T. (2015). Role of the innate and adaptive immune responses in the course of multiple sclerosis. Lancet Neurol. 14, 406-419.

Henderson, A.P.D., Barnett, M.H., Parratt, J.D.E., and Prineas, J.W. (2009). Multiple sclerosis: distribution of inflammatory cells in newly forming lesions. Ann. Neurol. 66, 739-753. 
Hesse, A., Wagner, M., Held, J., Brück, W., Salinas-Riester, G., Hao, Z., Waisman, A., and Kuhlmann, T. (2010a). In toxic demyelination oligodendroglial cell death occurs early and is FAS independent. Neurobiol. Dis. 37, 362-369.

Hesse, A., Wagner, M., Held, J., Brück, W., Salinas-Riester, G., Hao, Z., Waisman, A., and Kuhlmann, T. (2010b). In toxic demyelination oligodendroglial cell death occurs early and is FAS independent. Neurobiol. Dis. 37, 362-369.

Hibbits, N., Yoshino, J., Le, T.Q., and Armstrong, R.C. (2012). Astrogliosis During Acute and Chronic Cuprizone Demyelination and Implications for Remyelination. ASN Neuro 4, AN20120062.

Hiremath, M.M., Saito, Y., Knapp, G.W., Ting, J.P.-Y., Suzuki, K., and Matsushima, G.K. (1998). Microglial/macrophage accumulation during cuprizone-induced demyelination in C57BL/6 mice. J. Neuroimmunol. 92, 38-49.

Hoffmann, K., Lindner, M., Gröticke, I., Stangel, M., and Löscher, W. (2008). Epileptic seizures and hippocampal damage after cuprizone-induced demyelination in C57BL/6 mice. Exp. Neurol. 210, 308-321.

Hori, S., Nomura, T., and Sakaguchi, S. (2003). Control of regulatory T cell development by the transcription factor Foxp3. Science 299, 1057-1061.

Huang, H., Taraboletti, A., and Shriver, L.P. (2015). Dimethyl fumarate modulates antioxidant and lipid metabolism in oligodendrocytes. Redox Biol. 5, 169-175.

Irvine, K.-A., and Blakemore, W.F. (2006). Age increases axon loss associated with primary demyelination in cuprizone-induced demyelination in C57BL/6 mice. J. Neuroimmunol. 175, 6976.

Jack, C., Ruffini, F., Bar-Or, A., and Antel, J.P. (2005). Microglia and multiple sclerosis. J. Neurosci. Res. 81, 363-373.

Jones, A.P., Kermode, A.G., Lucas, R.M., Carroll, W.M., Nolan, D., and Hart, P.H. (2016). Circulating immune cells in multiple sclerosis. Clin. Exp. Immunol. n/a-n/a.

de Jong, R., Bezemer, A.C., Zomerdijk, T.P., van de Pouw-Kraan, T., Ottenhoff, T.H., and Nibbering, P.H. (1996). Selective stimulation of $T$ helper 2 cytokine responses by the anti-psoriasis agent monomethylfumarate. Eur. J. Immunol. 26, 2067-2074.

Juurlink, B.H.J., Thorburne, S.K., and Hertz, L. (1998). Peroxide-scavenging deficit underlies oligodendrocyte susceptibility to oxidative stress. Glia 22, 371-378.

Kalkers, N.F., Ameziane, N., Bot, J.C.J., Minneboo, A., Polman, C.H., and Barkhof, F. (2002). Longitudinal brain volume measurement in multiple sclerosis: rate of brain atrophy is independent of the disease subtype. Arch. Neurol. 59, 1572-1576.

Kappos, L., Freedman, M.S., Polman, C.H., Edan, G., Hartung, H.-P., Miller, D.H., Montalbán, X., Barkhof, F., Radü, E.-W., Bauer, L., et al. (2007). Effect of early versus delayed interferon beta-1b 
treatment on disability after a first clinical event suggestive of multiple sclerosis: a 3-year followup analysis of the BENEFIT study. Lancet Lond. Engl. 370, 389-397.

Kappos, L., Gold, R., Miller, D.H., Macmanus, D.G., Havrdova, E., Limmroth, V., Polman, C.H., Schmierer, K., Yousry, T.A., Yang, M., et al. (2008). Efficacy and safety of oral fumarate in patients with relapsing-remitting multiple sclerosis: a multicentre, randomised, double-blind, placebocontrolled phase IIb study. Lancet Lond. Engl. 372, 1463-1472.

Kappos, L., Li, D., Calabresi, P.A., O’Connor, P., Bar-Or, A., Barkhof, F., Yin, M., Leppert, D., Glanzman, R., Tinbergen, J., et al. (2011). Ocrelizumab in relapsing-remitting multiple sclerosis: a phase 2, randomised, placebo-controlled, multicentre trial. The Lancet 378, 1779-1787.

Kappos, L., Yousry, T., Fox, R., Gold, R., Arnold, D., Potts, J., and Marantz, J. (2016). Rate of Brain Volume Loss with Long-Term Delayed-Release Dimethyl Fumarate Treatment in Patients with Relapsing-Remitting Multiple Sclerosis: 6-Year Results from ENDORSE (P3.061). Neurology 86, P3.061.

Karcher, D., Van Sande, M., and Lowenthal, A. (1959). Micro-electrophoresis in agar gel of proteins of the cerebrospinal fluid and central nervous system. J. Neurochem. 4, 135-140.

Kihara, Y., Groves, A., Rivera, R.R., and Chun, J. (2015). Dimethyl fumarate inhibits integrin $\alpha 4$ expression in multiple sclerosis models. Ann. Clin. Transl. Neurol. 2, 978-983.

Kinzel, S., Lehmann-Horn, K., Torke, S., Häusler, D., Winkler, A., Stadelmann, C., Payne, N., Feldmann, L., Saiz, A., Reindl, M., et al. (2016). Myelin-reactive antibodies initiate T cell-mediated CNS autoimmune disease by opsonization of endogenous antigen. Acta Neuropathol. (Berl.) 132, 43-58.

Knippenberg, S., Peelen, E., Smolders, J., Thewissen, M., Menheere, P., Cohen Tervaert, J.W., Hupperts, R., and Damoiseaux, J. (2011). Reduction in IL-10 producing B cells (Breg) in multiple sclerosis is accompanied by a reduced naïve/memory Breg ratio during a relapse but not in remission. J. Neuroimmunol. 239, 80-86.

Koo, E.H., Sisodia, S.S., Archer, D.R., Martin, L.J., Weidemann, A., Beyreuther, K., Fischer, P., Masters, C.L., and Price, D.L. (1990). Precursor of amyloid protein in Alzheimer disease undergoes fast anterograde axonal transport. Proc. Natl. Acad. Sci. U. S. A. 87, 1561-1565.

Koutsoudaki, P.N., Skripuletz, T., Gudi, V., Moharregh-Khiabani, D., Hildebrandt, H., Trebst, C., and Stangel, M. (2009). Demyelination of the hippocampus is prominent in the cuprizone model. Neurosci. Lett. 451, 83-88.

Krishnamoorthy, G., Lassmann, H., Wekerle, H., and Holz, A. (2006). Spontaneous opticospinal encephalomyelitis in a double-transgenic mouse model of autoimmune T cell/B cell cooperation. J. Clin. Invest. 116, 2385-2392.

Krumbholz, M., and Meinl, E. (2014). B cells in MS and NMO: pathogenesis and therapy. Semin. Immunopathol. 36, 339-350. 
Krumbholz, M., Theil, D., Derfuss, T., Rosenwald, A., Schrader, F., Monoranu, C.-M., Kalled, S.L., Hess, D.M., Serafini, B., Aloisi, F., et al. (2005). BAFF is produced by astrocytes and up-regulated in multiple sclerosis lesions and primary central nervous system lymphoma. J. Exp. Med. 201, 195200.

Kuhlmann, T., Lingfeld, G., Bitsch, A., Schuchardt, J., and Brück, W. (2002). Acute axonal damage in multiple sclerosis is most extensive in early disease stages and decreases over time. Brain 125, 2202-2212.

Kuhlmann, T., Lassmann, H., and Brück, W. (2008a). Diagnosis of inflammatory demyelination in biopsy specimens: a practical approach. Acta Neuropathol. (Berl.) 115, 275-287.

Kuhlmann, T., Miron, V., Cuo, Q., Wegner, C., Antel, J., and Brück, W. (2008b). Differentiation block of oligodendroglial progenitor cells as a cause for remyelination failure in chronic multiple sclerosis. Brain 131, 1749-1758.

Kurschus, F.C. (2015). T cell mediated pathogenesis in EAE: Molecular mechanisms. Biomed. J. 38, 183-193.

Kutzelnigg, A., Lucchinetti, C.F., Stadelmann, C., Brück, W., Rauschka, H., Bergmann, M., Schmidbauer, M., Parisi, J.E., and Lassmann, H. (2005). Cortical demyelination and diffuse white matter injury in multiple sclerosis. Brain 128, 2705-2712.

Lampron, A., Larochelle, A., Laflamme, N., Préfontaine, P., Plante, M.-M., Sánchez, M.G., Yong, V.W., Stys, P.K., Tremblay, M.-È., and Rivest, S. (2015). Inefficient clearance of myelin debris by microglia impairs remyelinating processes. J. Exp. Med. 212, 481-495.

Langer-Gould, A., and Steinman, L. (2006). Progressive multifocal leukoencephalopathy and multiple sclerosis: lessons from natalizumab. Curr. Neurol. Neurosci. Rep. 6, 253-258.

Larochelle, C., Alvarez, J.I., and Prat, A. (2011). How do immune cells overcome the blood-brain barrier in multiple sclerosis? FEBS Lett. 585, 3770-3780.

Lassmann, H., Brück, W., and Lucchinetti, C.F. (2007). The Immunopathology of Multiple Sclerosis: An Overview. Brain Pathol. 17, 210-218.

Lesley, R., Xu, Y., Kalled, S.L., Hess, D.M., Schwab, S.R., Shu, H.-B., and Cyster, J.G. (2004). Reduced competitiveness of autoantigen-engaged $B$ cells due to increased dependence on BAFF. Immunity 20, 441-453.

Li, R., Rezk, A., Ghadiri, M., Luessi, F., Zipp, F., Li, H., Giacomini, P.S., Antel, J., and Bar-Or, A. (2017). Dimethyl Fumarate Treatment Mediates an Anti-Inflammatory Shift in B Cell Subsets of Patients with Multiple Sclerosis. J. Immunol. 198, 691-698.

Lindner, M., Heine, S., Haastert, K., Garde, N., Fokuhl, J., Linsmeier, F., Grothe, C., Baumgärtner, W., and Stangel, M. (2008a). Sequential myelin protein expression during remyelination reveals fast and efficient repair after central nervous system demyelination. Neuropathol. Appl. Neurobiol. 34, 105-114. 
Lindner, M., Heine, S., Haastert, K., Garde, N., Fokuhl, J., Linsmeier, F., Grothe, C., Baumgärtner, W., and Stangel, M. (2008b). Sequential myelin protein expression during remyelination reveals fast and efficient repair after central nervous system demyelination. Neuropathol. Appl. Neurobiol. 34, 105-114.

Lindner, M., Fokuhl, J., Linsmeier, F., Trebst, C., and Stangel, M. (2009). Chronic toxic demyelination in the central nervous system leads to axonal damage despite remyelination. Neurosci. Lett. 453, 120-125.

Linker, R.A., Lee, D.-H., Ryan, S., van Dam, A.M., Conrad, R., Bista, P., Zeng, W., Hronowsky, X., Buko, A., Chollate, S., et al. (2011). Fumaric acid esters exert neuroprotective effects in neuroinflammation via activation of the Nrf2 antioxidant pathway. Brain J. Neurol. 134, 678-692.

Litjens, N.H.R., Rademaker, M., Ravensbergen, B., Rea, D., van der Plas, M.J.A., Thio, B., Walding, A., van Dissel, J.T., and Nibbering, P.H. (2004a). Monomethylfumarate affects polarization of monocyte-derived dendritic cells resulting in down-regulated Th1 lymphocyte responses. Eur. J. Immunol. 34, 565-575.

Litjens, N.H.R., Rademaker, M., Ravensbergen, B., Rea, D., van der Plas, M.J.A., Thio, B., Walding, A., van Dissel, J.T., and Nibbering, P.H. (2004b). Monomethylfumarate affects polarization of monocyte-derived dendritic cells resulting in down-regulated Th1 lymphocyte responses. Eur. J. Immunol. 34, 565-575.

Litjens, N.H.R., Rademaker, M., Ravensbergen, B., Thio, H.B., van Dissel, J.T., and Nibbering, P.H. (2006). Effects of monomethylfumarate on dendritic cell differentiation. Br. J. Dermatol. 154, 211217.

Litzenburger, T., Fässler, R., Bauer, J., Lassmann, H., Linington, C., Wekerle, H., and Iglesias, A. (1998). B Lymphocytes Producing Demyelinating Autoantibodies: Development and Function in Gene-targeted Transgenic Mice. J. Exp. Med. 188, 169-180.

Loewe, R., Pillinger, M., de Martin, R., Mrowietz, U., Gröger, M., Holnthoner, W., Wolff, K., Wiegrebe, W., Jirovsky, D., and Petzelbauer, P. (2001). Dimethylfumarate inhibits tumor-necrosisfactor-induced CD62E expression in an NF-kappa B-dependent manner. J. Invest. Dermatol. 117, 1363-1368.

Longbrake, E.E., Naismith, R.T., Parks, B.J., Wu, G.F., and Cross, A.H. (2015). Dimethyl fumarateassociated lymphopenia: Risk factors and clinical significance. Mult. Scler. J. - Exp. Transl. Clin. 1.

Longbrake, E.E., Ramsbottom, M.J., Cantoni, C., Ghezzi, L., Cross, A.H., and Piccio, L. (2016). Dimethyl fumarate selectively reduces memory $T$ cells in multiple sclerosis patients. Mult. Scler. Houndmills Basingstoke Engl. 22, 1061-1070.

Lowenthal, A., Vansande, M., and Karcher, D. (1960). The differential diagnosis of neurological diseases by fractionating electrophoretically the CSF gamma-globulins. J. Neurochem. 6, 51-56. 
Lublin, F.D., and Reingold, S.C. (1996). Defining the clinical course of multiple sclerosis: results of an international survey. National Multiple Sclerosis Society (USA) Advisory Committee on Clinical Trials of New Agents in Multiple Sclerosis. Neurology 46, 907-911.

Lublin, F.D., Reingold, S.C., Cohen, J.A., Cutter, G.R., Sørensen, P.S., Thompson, A.J., Wolinsky, J.S., Balcer, L.J., Banwell, B., Barkhof, F., et al. (2014). Defining the clinical course of multiple sclerosis. Neurology 83, 278-286.

Lucchinetti, C., Brück, W., Parisi, J., Scheithauer, B., Rodriguez, M., and Lassmann, H. (2000). Heterogeneity of multiple sclerosis lesions: implications for the pathogenesis of demyelination. Ann. Neurol. 47, 707-717.

Lukasova, M., Hanson, J., Tunaru, S., and Offermanns, S. (2011). Nicotinic acid (niacin): new lipidindependent mechanisms of action and therapeutic potentials. Trends Pharmacol. Sci. 32, 700707.

Lundy, S.K., Wu, Q., Wang, Q., Dowling, C.A., Taitano, S.H., Mao, G., and Mao-Draayer, Y. (2016). Dimethyl fumarate treatment of relapsing-remitting multiple sclerosis influences B-cell subsets. Neurol. Neuroimmunol. Neuroinflammation 3.

Manrique-Hoyos, N., Jürgens, T., Grønborg, M., Kreutzfeldt, M., Schedensack, M., Kuhlmann, T., Schrick, C., Brück, W., Urlaub, H., Simons, M., et al. (2012). Late motor decline after accomplished remyelination: impact for progressive multiple sclerosis. Ann. Neurol. 71, 227-244.

Marta, C.B., Oliver, A.R., Sweet, R.A., Pfeiffer, S.E., and Ruddle, N.H. (2005). Pathogenic myelin oligodendrocyte glycoprotein antibodies recognize glycosylated epitopes and perturb oligodendrocyte physiology. Proc. Natl. Acad. Sci. U. S. A. 102, 13992-13997.

Mason, J.L., Langaman, C., Morell, P., Suzuki, K., and Matsushima, G.K. (2001). Episodic demyelination and subsequent remyelination within the murine central nervous system: changes in axonal calibre. Neuropathol. Appl. Neurobiol. 27, 50-58.

Matsushima, G.K., and Morell, P. (2001a). The neurotoxicant, cuprizone, as a model to study demyelination and remyelination in the central nervous system. Brain Pathol. Zurich Switz. 11, 107-116.

Matsushima, G.K., and Morell, P. (2001b). The Neurotoxicant, Cuprizone, as a Model to Study Demyelination and Remyelination in the Central Nervous System. Brain Pathol. 11, 107-116.

McCormack, P.L., and Scott, L.J. (2004). Interferon-beta-1b: a review of its use in relapsingremitting and secondary progressive multiple sclerosis. CNS Drugs 18, 521-546.

McDonald, W.I., Compston, A., Edan, G., Goodkin, D., Hartung, H.-P., Lublin, F.D., McFarland, H.F., Paty, D.W., Polman, C.H., Reingold, S.C., et al. (2001). Recommended diagnostic criteria for multiple sclerosis: Guidelines from the international panel on the diagnosis of multiple sclerosis. Ann. Neurol. 50, 121-127. 
McMahon, E.J., Suzuki, K., and Matsushima, G.K. (2002). Peripheral macrophage recruitment in cuprizone-induced CNS demyelination despite an intact blood-brain barrier. J. Neuroimmunol. 130, 32-45.

Meinl, E., Krumbholz, M., and Hohlfeld, R. (2006). B lineage cells in the inflammatory central nervous system environment: migration, maintenance, local antibody production, and therapeutic modulation. Ann. Neurol. 59, 880-892.

Mendel, I., Kerlero de Rosbo, N., and Ben-Nun, A. (1995). A myelin oligodendrocyte glycoprotein peptide induces typical chronic experimental autoimmune encephalomyelitis in $\mathrm{H}-2 \mathrm{~b}$ mice: fine specificity and $T$ cell receptor $V$ beta expression of encephalitogenic $T$ cells. Eur. J. Immunol. 25, 1951-1959.

Meyer-Bahlburg, A., Andrews, S.F., Yu, K.O.A., Porcelli, S.A., and Rawlings, D.J. (2008). Characterization of a late transitional $B$ cell population highly sensitive to BAFF-mediated homeostatic proliferation. J. Exp. Med. 205, 155-168.

Mikol, D.D., Barkhof, F., Chang, P., Coyle, P.K., Jeffery, D.R., Schwid, S.R., Stubinski, B., Uitdehaag, B.M.J., and REGARD study group (2008). Comparison of subcutaneous interferon beta-1a with glatiramer acetate in patients with relapsing multiple sclerosis (the REbif vs Glatiramer Acetate in Relapsing MS Disease [REGARD] study): a multicentre, randomised, parallel, open-label trial. Lancet Neurol. 7, 903-914.

Miller, D.H., and Leary, S.M. (2007). Primary-progressive multiple sclerosis. Lancet Neurol. 6, 903912.

Moharregh-Khiabani, D., Linker, R.., Gold, R., and Stangel, M. (2009). Fumaric Acid and its Esters: An Emerging Treatment for Multiple Sclerosis. Curr. Neuropharmacol. 7, 60-64.

Moharregh-Khiabani, D., Blank, A., Skripuletz, T., Miller, E., Kotsiari, A., Gudi, V., and Stangel, M. (2010). Effects of Fumaric Acids on Cuprizone Induced Central Nervous System De- and Remyelination in the Mouse. PLoS ONE 5.

Mrowietz, U., and Asadullah, K. (2005). Dimethylfumarate for psoriasis: more than a dietary curiosity. Trends Mol. Med. 11, 43-48.

Mrowietz, Christophers, Altmeyer, and The Participants in the German Multicentre Study (1998). Treatment of psoriasis with fumaric acid esters: results of a prospective multicentre study. Br. J. Dermatol. 138, 456-460.

Nguyen, T., Sherratt, P.J., Nioi, P., Yang, C.S., and Pickett, C.B. (2005). Nrf2 controls constitutive and inducible expression of ARE-driven genes through a dynamic pathway involving nucleocytoplasmic shuttling by Keap1. J. Biol. Chem. 280, 32485-32492.

Nguyen, T., Nioi, P., and Pickett, C.B. (2009). The Nrf2-Antioxidant Response Element Signaling Pathway and Its Activation by Oxidative Stress. J. Biol. Chem. 284, 13291-13295. 
Nibbering, P.H., Thio, B., Zomerdijk, T.P.L., Bezemer, A.C., Beijersbergen, R.L., and Furth, R. van (1993). Effects of monomethylfumarate on human granulocytes. J. Invest. Dermatol. 101, 37-42.

Nieboer, C., de Hoop, D., Langendijk, P.N.J., van Loenen, A.C., and Gubbels, J. (1990). Fumaric Acid Therapy in Psoriasis: A Double-Blind Comparison between Fumaric Acid Compound Therapy and Monotherapy with Dimethylfumaric Acid Ester. Dermatology 181, 33-37.

Norkute, A., Hieble, A., Braun, A., Johann, S., Clarner, T., Baumgartner, W., Beyer, C., and Kipp, M. (2009). Cuprizone treatment induces demyelination and astrocytosis in the mouse hippocampus. J. Neurosci. Res. 87, 1343-1355.

Noseworthy, J.H., Lucchinetti, C., Rodriguez, M., and Weinshenker, B.G. (2000). Multiple sclerosis. N. Engl. J. Med. 343, 938-952.

Nutt, S.L., Hodgkin, P.D., Tarlinton, D.M., and Corcoran, L.M. (2015). The generation of antibodysecreting plasma cells. Nat. Rev. Immunol. 15, 160-171.

Obermeier, B., Lovato, L., Mentele, R., Brück, W., Forne, I., Imhof, A., Lottspeich, F., Turk, K.W., Willis, S.N., Wekerle, H., et al. (2011). Related B cell clones that populate the CSF and CNS of patients with multiple sclerosis produce CSF immunoglobulin. J. Neuroimmunol. 233, 245-248.

Ockenfels, H.M., Schultewolter, T., Ockenfels, G., Funk, R., and Goos, M. (1998). The antipsoriatic agent dimethylfumarate immunomodulates T-cell cytokine secretion and inhibits cytokines of the psoriatic cytokine network. Br. J. Dermatol. 139, 390-395.

O'Connor, R.A., Prendergast, C.T., Sabatos, C.A., Lau, C.W.Z., Leech, M.D., Wraith, D.C., and Anderton, S.M. (2008). Cutting Edge: Th1 Cells Facilitate the Entry of Th17 Cells to the Central Nervous System during Experimental Autoimmune Encephalomyelitis. J. Immunol. Baltim. Md 1950 181, 3750-3754.

Ontaneda, D., and Fox, R.J. (2015). Progressive multiple sclerosis. Curr. Opin. Neurol. 28, 237-243.

Ontaneda, D., Thompson, A.J., Fox, R.J., and Cohen, J.A. (2016). Progressive multiple sclerosis: prospects for disease therapy, repair, and restoration of function. The Lancet.

Owens, G.P., Ritchie, A.M., Burgoon, M.P., Williamson, R.A., Corboy, J.R., and Gilden, D.H. (2003). Single-cell repertoire analysis demonstrates that clonal expansion is a prominent feature of the $B$ cell response in multiple sclerosis cerebrospinal fluid. J. Immunol. Baltim. Md 1950 171, 27252733.

Parish, C.R. (1999). Fluorescent dyes for lymphocyte migration and proliferation studies. Immunol. Cell Biol. 77, 499-508.

Patrikios, P., Stadelmann, C., Kutzelnigg, A., Rauschka, H., Schmidbauer, M., Laursen, H., Sorensen, P.S., Brück, W., Lucchinetti, C., and Lassmann, H. (2006). Remyelination is extensive in a subset of multiple sclerosis patients. Brain J. Neurol. 129, 3165-3172. 
Paty, D.W., and Li, D.K. (1993). Interferon beta-1b is effective in relapsing-remitting multiple sclerosis. II. MRI analysis results of a multicenter, randomized, double-blind, placebo-controlled trial. UBC MS/MRI Study Group and the IFNB Multiple Sclerosis Study Group. Neurology 43, 662667.

Pitarokoili, K., Ambrosius, B., Meyer, D., Schrewe, L., and Gold, R. (2015). Dimethyl Fumarate Ameliorates Lewis Rat Experimental Autoimmune Neuritis and Mediates Axonal Protection. PLoS ONE 10.

Plavina, T., Subramanyam, M., Bloomgren, G., Richman, S., Pace, A., Lee, S., Schlain, B., Campagnolo, D., Belachew, S., and Ticho, B. (2014). Anti-JC virus antibody levels in serum or plasma further define risk of natalizumab-associated progressive multifocal leukoencephalopathy. Ann. Neurol. 76, 802-812.

Pöllinger, B., Krishnamoorthy, G., Berer, K., Lassmann, H., Bösl, M.R., Dunn, R., Domingues, H.S., Holz, A., Kurschus, F.C., and Wekerle, H. (2009). Spontaneous relapsing-remitting EAE in the SJL/J mouse: MOG-reactive transgenic T cells recruit endogenous MOG-specific B cells. J. Exp. Med. 206, 1303-1316.

Polman, C.H., Reingold, S.C., Edan, G., Filippi, M., Hartung, H.-P., Kappos, L., Lublin, F.D., Metz, L.M., McFarland, H.F., O'Connor, P.W., et al. (2005). Diagnostic criteria for multiple sclerosis: 2005 revisions to the "McDonald Criteria." Ann. Neurol. 58, 840-846.

Polman, C.H., O'Connor, P.W., Havrdova, E., Hutchinson, M., Kappos, L., Miller, D.H., Phillips, J.T., Lublin, F.D., Giovannoni, G., Wajgt, A., et al. (2006). A Randomized, Placebo-Controlled Trial of Natalizumab for Relapsing Multiple Sclerosis. N. Engl. J. Med. 354, 899-910.

Polman, C.H., Reingold, S.C., Banwell, B., Clanet, M., Cohen, J.A., Filippi, M., Fujihara, K., Havrdova, E., Hutchinson, M., Kappos, L., et al. (2011). Diagnostic criteria for multiple sclerosis: 2010 Revisions to the McDonald criteria. Ann. Neurol. 69, 292-302.

Praet, J., Guglielmetti, C., Berneman, Z., Van der Linden, A., and Ponsaerts, P. (2014). Cellular and molecular neuropathology of the cuprizone mouse model: Clinical relevance for multiple sclerosis. Neurosci. Biobehav. Rev. 47, 485-505.

Prineas, J.W. (1979). Multiple sclerosis: presence of lymphatic capillaries and lymphoid tissue in the brain and spinal cord. Science 203, 1123-1125.

Ransohoff, R.M. (2012). Animal models of multiple sclerosis: the good, the bad and the bottom line. Nat. Neurosci. 15, 1074-1077.

Rasouli, J., Ciric, B., Imitola, J., Gonnella, P., Hwang, D., Mahajan, K., Mari, E.R., Safavi, F., Leist, T.P., Zhang, G.-X., et al. (2015). Expression of GM-CSF in T Cells Is Increased in Multiple Sclerosis and Suppressed by IFN- $\beta$ Therapy. J. Immunol. Baltim. Md 1950 194, 5085-5093.

Ray, A., and Basu, S. (2014). Regulatory B cells in experimental autoimmune encephalomyelitis (EAE). Methods Mol. Biol. Clifton NJ 1190, 243-255. 
Reick, C., Ellrichmann, G., Thöne, J., Scannevin, R.H., Saft, C., Linker, R.A., and Gold, R. (2014). Neuroprotective dimethyl fumarate synergizes with immunomodulatory interferon beta to provide enhanced axon protection in autoimmune neuroinflammation. Exp. Neurol. 257, 50-56.

Rivers, T.M., Sprunt, D.H., and Berry, G.P. (1933). OBSERVATIONS ON ATTEMPTS TO PRODUCE ACUTE DISSEMINATED ENCEPHALOMYELITIS IN MONKEYS. J. Exp. Med. 58, 39-53.

Rone, M.B., Cui, Q.-L., Fang, J., Wang, L.-C., Zhang, J., Khan, D., Bedard, M., Almazan, G., Ludwin, S.K., Jones, R., et al. (2016). Oligodendrogliopathy in Multiple Sclerosis: Low Glycolytic Metabolic Rate Promotes Oligodendrocyte Survival. J. Neurosci. 36, 4698-4707.

Rosenkranz, T., Novas, M., and Terborg, C. (2015). PML in a patient with lymphocytopenia treated with dimethyl fumarate. N. Engl. J. Med. 372, 1476-1478.

de Sa, J.C.C., Airas, L., Bartholome, E., Grigoriadis, N., Mattle, H., Oreja-Guevara, C., O'Riordan, J., Sellebjerg, F., Stankoff, B., Vass, K., et al. (2011). Symptomatic therapy in multiple sclerosis: a review for a multimodal approach in clinical practice. Ther. Adv. Neurol. Disord. 4, 139-168.

Scannevin, R.H., Chollate, S., Jung, M., Shackett, M., Patel, H., Bista, P., Zeng, W., Ryan, S., Yamamoto, M., Lukashev, M., et al. (2012a). Fumarates promote cytoprotection of central nervous system cells against oxidative stress via the nuclear factor (erythroid-derived 2)-like 2 pathway. J. Pharmacol. Exp. Ther. 341, 274-284.

Scannevin, R.H., Bai, B., Huang, R., Trapp, B., and Rhodes, K.J. (2012b). BG-12 (Dimethyl Fumarate) is Neuroprotective in the Murine Cuprizone/Rapamycin Model of Demyelination and Neurodegeneration.

Scannevin, R.H., Chollate, S., Jung, M., Shackett, M., Patel, H., Bista, P., Zeng, W., Ryan, S., Yamamoto, M., Lukashev, M., et al. (2012c). Fumarates promote cytoprotection of central nervous system cells against oxidative stress via the nuclear factor (erythroid-derived 2)-like 2 pathway. J. Pharmacol. Exp. Ther. 341, 274-284.

Schilling, S., Goelz, S., Linker, R., Luehder, F., and Gold, R. (2006). Fumaric acid esters are effective in chronic experimental autoimmune encephalomyelitis and suppress macrophage infiltration. Clin. Exp. Immunol. 145, 101-107.

Schimrigk, S., Brune, N., Hellwig, K., Lukas, C., Bellenberg, B., Rieks, M., Hoffmann, V., Pöhlau, D., and Przuntek, H. (2006). Oral fumaric acid esters for the treatment of active multiple sclerosis: an open-label, baseline-controlled pilot study. Eur. J. Neurol. 13, 604-610.

Scholl, P.R., and Geha, R.S. (1994). MHC class II signaling in B-cell activation. Immunol. Today 15, 418-422.

Schubert, R.D., Hu, Y., Kumar, G., Szeto, S., Abraham, P., Winderl, J., Guthridge, J.M., Pardo, G., Dunn, J., Steinman, L., et al. (2015). IFN- $\beta$ treatment requires B cells for efficacy in neuroautoimmunity. J. Immunol. Baltim. Md 1950 194, 2110-2116. 
Schulze-Topphoff, U., Varrin-Doyer, M., Pekarek, K., Spencer, C.M., Shetty, A., Sagan, S.A., Cree, B.A.C., Sobel, R.A., Wipke, B.T., Steinman, L., et al. (2016). Dimethyl fumarate treatment induces adaptive and innate immune modulation independent of Nrf2. Proc. Natl. Acad. Sci. U. S. A. 113, 4777-4782.

Sellebjerg, F., Barnes, D., Filippini, G., Midgard, R., Montalban, X., Rieckmann, P., Selmaj, K., Visser, L.H., and Sørensen, P.S. (2005). EFNS guideline on treatment of multiple sclerosis relapses: report of an EFNS task force on treatment of multiple sclerosis relapses. Eur. J. Neurol. 12, 939-946.

Shen, P., and Fillatreau, S. (2015). Antibody-independent functions of B cells: a focus on cytokines. Nat. Rev. Immunol. 15, 441-451.

Shen, P., Roch, T., Lampropoulou, V., O'Connor, R.A., Stervbo, U., Hilgenberg, E., Ries, S., Dang, V.D., Jaimes, Y., Daridon, C., et al. (2014). IL-35-producing B cells are critical regulators of immunity during autoimmune and infectious diseases. Nature 507, 366-370.

Skripuletz, T., Bussmann, J.-H., Gudi, V., Koutsoudaki, P.N., Pul, R., Moharregh-Khiabani, D., Lindner, M., and Stangel, M. (2010). Cerebellar cortical demyelination in the murine cuprizone model. Brain Pathol. Zurich Switz. 20, 301-312.

Skripuletz, T., Hackstette, D., Bauer, K., Gudi, V., Pul, R., Voss, E., Berger, K., Kipp, M., Baumgärtner, W., and Stangel, M. (2013). Astrocytes regulate myelin clearance through recruitment of microglia during cuprizone-induced demyelination. Brain 136, 147-167.

Slavin, A.J., Soos, J.M., Stuve, O., Patarroyo, J.C., Weiner, H.L., Fontana, A., Bikoff, E.K., and Zamvil, S.S. (2001). Requirement for endocytic antigen processing and influence of invariant chain and $\mathrm{H}$ 2M deficiencies in CNS autoimmunity. J. Clin. Invest. 108, 1133-1139.

Smith, K.J., and McDonald, W.I. (1999). The pathophysiology of multiple sclerosis: the mechanisms underlying the production of symptoms and the natural history of the disease. Philos. Trans. R. Soc. Lond. B Biol. Sci. 354, 1649-1673.

Spencer, C.M., Crabtree-Hartman, E.C., Lehmann-Horn, K., Cree, B.A.C., and Zamvil, S.S. (2015). Reduction of CD8+ T lymphocytes in multiple sclerosis patients treated with dimethyl fumarate. Neurol. Neuroimmunol. Neuroinflammation 2.

Spencer, S.R., Wilczak, C.A., and Talalay, P. (1990). Induction of glutathione transferases and $\mathrm{NAD}(\mathrm{P}) \mathrm{H}$ :quinone reductase by fumaric acid derivatives in rodent cells and tissues. Cancer Res. 50, 7871-7875.

Stadelmann, C., Wegner, C., and Brück, W. (2011). Inflammation, demyelination, and degeneration - recent insights from MS pathology. Biochim. Biophys. Acta 1812, 275-282.

Stangel, M. (2008). Neuroprotection and neuroregeneration in multiple sclerosis. J. Neurol. 255 Suppl 6, 77-81.

Stangel, M., and Hartung, H.-P. (2002). Remyelinating strategies for the treatment of multiple sclerosis. Prog. Neurobiol. 68, 361-376. 
Steinman, L., and Zamvil, S.S. (2005). Virtues and pitfalls of EAE for the development of therapies for multiple sclerosis. Trends Immunol. 26, 565-571.

Stidworthy, M.F., Genoud, S., Suter, U., Mantei, N., and Franklin, R.J.M. (2003). Quantifying the Early Stages of Remyelination Following Cuprizone-induced Demyelination. Brain Pathol. 13, 329339.

Stoof, T.J., Flier, J., Sampat, S., Nieboer, C., Tensen, C.P., and Boorsma, D.M. (2001). The antipsoriatic drug dimethylfumarate strongly suppresses chemokine production in human keratinocytes and peripheral blood mononuclear cells. Br. J. Dermatol. 144, 1114-1120.

Stromnes, I.M., and Goverman, J.M. (2006a). Active induction of experimental allergic encephalomyelitis. Nat. Protoc. 1, 1810-1819.

Stromnes, I.M., and Goverman, J.M. (2006b). Passive induction of experimental allergic encephalomyelitis. Nat. Protoc. 1, 1952-1960.

Stüve, O., Kita, M., Pelletier, D., Fox, R.J., Stone, J., Goodkin, D.E., and Zamvil, S.S. (2004). Mitoxantrone as a potential therapy for primary progressive multiple sclerosis. Mult. Scler. Houndmills Basingstoke Engl. 10 Suppl 1, S58-61.

Su, K.G., Banker, G., Bourdette, D., and Forte, M. (2009). Axonal degeneration in multiple sclerosis: The mitochondrial hypothesis. Curr. Neurol. Neurosci. Rep. 9, 411-417.

Tallantyre, E.C., Bø, L., Al-Rawashdeh, O., Owens, T., Polman, C.H., Lowe, J., and Evangelou, N. (2009). Greater loss of axons in primary progressive multiple sclerosis plaques compared to secondary progressive disease. Brain 132, 1190-1199.

Thiessen, A., Schmidt, M.M., and Dringen, R. (2010). Fumaric acid dialkyl esters deprive cultured rat oligodendroglial cells of glutathione and upregulate the expression of heme oxygenase 1. Neurosci. Lett. 475, 56-60.

Thompson, A.J., Polman, C.H., Miller, D.H., McDonald, W.I., Brochet, B., Filippi M Montalban, X., and De Sá, J. (1997). Primary progressive multiple sclerosis. Brain J. Neurol. 120 ( Pt 6), 1085-1096.

Torkildsen, O., Brunborg, L.A., Myhr, K.-M., and Bø, L. (2008). The cuprizone model for demyelination. Acta Neurol. Scand. Suppl. 188, 72-76.

Trapp, B.D., and Nave, K.-A. (2008). Multiple sclerosis: an immune or neurodegenerative disorder? Annu. Rev. Neurosci. 31, 247-269.

Trebst, C., Reising, A., Kielstein, J.T., Hafer, C., and Stangel, M. (2009). Plasma exchange therapy in steroid-unresponsive relapses in patients with multiple sclerosis. Blood Purif. 28, 108-115.

Treumer, F., Zhu, K., Gläser, R., and Mrowietz, U. (2003). Dimethylfumarate is a potent inducer of apoptosis in human T cells. J. Invest. Dermatol. 121, 1383-1388. 
Trickett, A., and Kwan, Y.L. (2003). T cell stimulation and expansion using anti-CD3/CD28 beads. J. Immunol. Methods 275, 251-255.

Tuohy, V.K., Sobel, R.A., Lu, Z., Laursen, R.A., and Lees, M.B. (1992). Myelin proteolipid protein: minimum sequence requirements for active induction of autoimmune encephalomyelitis in SWR/J and SJL/J mice. J. Neuroimmunol. 39, 67-74.

Venturini, G. (1973). Enzymic activities and sodium, potassium and copper concentrations in mouse brain and liver after cuprizone treatment in vivo. J. Neurochem. 21, 1147-1151.

Vollmer, T., Stewart, T., and Baxter, N. (2010). Mitoxantrone and cytotoxic drugs' mechanisms of action. Neurology 74 Suppl 1, S41-46.

Wakabayashi, T. (2002). Megamitochondria formation - physiology and pathology. J. Cell. Mol. Med. 6, 497-538.

Wakabayashi, N., Slocum, S.L., Skoko, J.J., Shin, S., and Kensler, T.W. (2010). When NRF2 talks, who's listening? Antioxid. Redox Signal. 13, 1649-1663.

Wallbrecht, K., Drick, N., Hund, A.-C., and Schön, M.P. (2011). Downregulation of endothelial adhesion molecules by dimethylfumarate, but not monomethylfumarate, and impairment of dynamic lymphocyte-endothelial cell interactions. Exp. Dermatol. 20, 980-985.

Weber, M.S., Prod'homme, T., Patarroyo, J.C., Molnarfi, N., Karnezis, T., Lehmann-Horn, K., Danilenko, D.M., Eastham-Anderson, J., Slavin, A.J., Linington, C., et al. (2010). B cell activation influences T cell polarization and outcome of anti-CD20 B cell depletion in CNS autoimmunity. Ann. Neurol. 68, 369-383.

Weinshenker, B.G. (1998). The natural history of multiple sclerosis: update 1998. Semin. Neurol. 18, 301-307.

Williamson, E.M.L., and Berger, J.R. (2015). Central Nervous System Infections With Immunomodulatory Therapies. Contin. Minneap. Minn 21, 1577-1598.

Wilms, H., Sievers, J., Rickert, U., Rostami-Yazdi, M., Mrowietz, U., and Lucius, R. (2010). Dimethylfumarate inhibits microglial and astrocytic inflammation by suppressing the synthesis of nitric oxide, IL-1 $\beta$, TNF- $\alpha$ and IL- 6 in an in-vitro model of brain inflammation. J. Neuroinflammation $7,30$.

Witherick, J., Wilkins, A., Scolding, N., and Kemp, K. (2010). Mechanisms of oxidative damage in multiple sclerosis and a cell therapy approach to treatment. Autoimmune Dis. 2011, 164608.

Zhu, K., and Mrowietz, U. (2001). Inhibition of Dendritic Cell Differentiation by Fumaric Acid Esters. J. Invest. Dermatol. 116, 203-208. 


\section{CURRICUlum VITAE}

\begin{tabular}{|c|c|}
\hline Name: & Sarah Traffehn \\
\hline Date of birth: & 19.6.1988 \\
\hline Place of birth: & Hennigsdorf \\
\hline Citizenship: & German \\
\hline \multirow[t]{2}{*}{ Address: } & Hennebergstraße 8 \\
\hline & 37077 Göttingen \\
\hline \multicolumn{2}{|c|}{ Education and professional experience } \\
\hline \multirow[t]{3}{*}{$10 / 2013-04 / 2017$} & University Medical Center \\
\hline & Georg-August-University Göttingen \\
\hline & $\begin{array}{l}\text { PhD thesis: "Effects of dimethyl fumarate in two animal } \\
\text { models of MS" }\end{array}$ \\
\hline \multirow[t]{3}{*}{$10 / 2008-07 / 2013$} & Ernst-Moritz-Arndt-University Greifswald \\
\hline & Diploma studies in Biochemistry (Grade: 1.9) \\
\hline & $\begin{array}{l}\text { Diploma thesis: "Die T-Zellaktivierung bei einer murinen, } \\
\text { polymikrobiellen Sepsis" }\end{array}$ \\
\hline \multirow[t]{2}{*}{$07 / 2001-06 / 2008$} & Alexander S. Puschkin Gymnasium, Hennigsdorf \\
\hline & Abitur (Grade: 1.9) \\
\hline
\end{tabular}

